UNIVERSIDADE DE SÃO PAULO

FACULDADE DE FILOSOFIA, CIÊNCIAS E LETRAS DE RIBEIRÃO PRETO

DEPARTAMENTO DE FÍSICA E MATEMÁTICA

\author{
Luís Augusto Perles
}

\title{
Avaliação do algoritmo Macro Response Monte Carlo através dos espectros de elétrons
}

Ribeirão Preto - SP 
Luís Augusto Perles

\section{Avaliação do algoritmo Macro Response Monte Carlo através dos espectros de elétrons}

Tese apresentada à Faculdade de Filosofia, Ciências e Letras de Ribeirão Preto da USP para obtenção do título de Doutor em Ciências.

Área de Concentração: Física Aplicada à Medicina e Biologia. Orientadora: $\operatorname{Prof}^{\mathrm{a}}$. Dr ${ }^{\mathrm{a}}$. Adelaide de Almeida

Ribeirão Preto - SP 
AUTORIZO A REPRODUÇÃO E DIVULGAÇÃO TOTAL OU PARCIAL DESTE TRABALHO, POR QUALQUER MEIO CONVENCIONAL OU ELETRÔNICO, PARA FINS DE ESTUDO E PESQUISA, DESDE QUE CITADA A FONTE.

Ficha Catalográfica

Perles, Luís Augusto.

Avaliação do algoritmo Macro Response Monte Carlo através dos espectros de elétrons/ Luís Augusto Perles; orientadora Adelaide de Almeida.

- Ribeirão Preto, 2006.

119 f. :fig.

Tese (Doutorado - Programa de Pós Graduação da Faculdade de Filosofia, Ciências e Letras de Ribeirão Preto - Área de Concetração: Física Aplicada a Medicina e Biologia) - Faculdade de Filosofia, Ciências e Letras de Ribeirão Preto da Universidade de São Paulo.

1. Radioterapia. 2. Monte Carlo. 3. Transporte de elétrons 


\section{Agradecimentos}

À Prof ${ }^{\mathrm{a}}$. Dr ${ }^{\mathrm{a}}$. Adelaide de Almeida, pela orientação e paciência.

Ao prof. Dr. Antonio Carlos Roque da Silva Filho, por possibilitar o acesso ao cluster de micros.

Aos professores Dr. Alexandre Souto Martinez e Dr. Martin Eduardo Poletti pelas discussões e sugestões.

Ao físico médico Ms. José Renato Oliveira Rocha pelo incentivo, idéias e sugestões.

Ao prof. Dr. Alessandro Martins da Costa pela imensa ajuda com o $\mathrm{LTT}_{\mathrm{E}} \mathrm{X}$.

Ao CNPq pelo apoio financeiro em forma de bolsa e taxa de bancada.

Aos desenvolvedores dos programas/bibliotecas ROOT e Geant4, que, mesmo a distância, sempre que possível esclareciam as minhas dúvidas.

À todos os desenvolvedores de software livre, por terem feito ferramentas importantíssimas sem as quais este trabalho não seria feito legalmente.

À comunidade Linux, por terem feito um sistema operacional decente para rodar as simulações com desempenho, sem o fantasma da 'tela azul', vírus, cavalos de tróia, invasões, etc, etc.

Aos meus amigos e colegas do departamento, que tornaram suportável minha estada neste deserto cultural. 
"A new scientific truth does not triumph by convincing its opponents and making them to see the light, but rather because its opponents eventually die, and a new generation grows up that is familiar with it." 


\section{Sumário}

\section{Lista de Figuras}

\section{Lista de Tabelas}

\section{Resumo}

\section{Abstract}

1 Introdução $\quad$ p. 19

1.1 Técnicas de planejamento . . . . . . . . . . . . . . . . p. 19

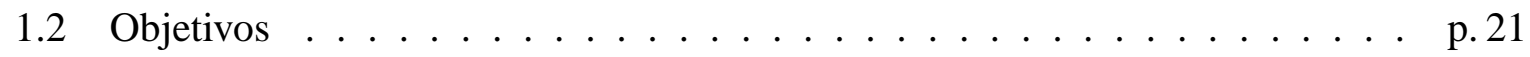

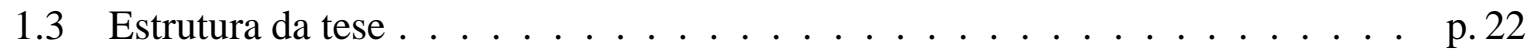

2 Noções teóricas $\quad$ p. 23

2.1 A simulação pelo método Monte Carlo . . . . . . . . . . . . . . . . p. 23

2.1.1 Aplicação ao transporte de partículas . . . . . . . . . . . . p. 24

2.2 As interações dos elétrons com o meio material . . . . . . . . . . p. 25

Espalhamento coulombiano . . . . . . . . . p. 26

Produção de raios delta . . . . . . . . . . . . . . p. 26

Emissão de radiação por bremsstrahlung . . . . . . . p. p. 26

Aniquilação de pares elétron-pósitron . . . . . . . . p. 26 
2.3 Os algoritmos de história condensada de elétrons $\ldots \ldots \ldots \ldots$. . . . . . 26

2.3.1 O modelo de Molière . . . . . . . . . . . . . . . . p. 28

2.3.2 O modelo de Goudsmit-Saunderson . . . . . . . . . . . p. 28

2.3 .3 O modelo de Lewis . . . . . . . . . . . . . . . . p. 28

2.4 Os métodos Local-to-Global Monte Carlo . . . . . . . . . . . . . . . . . p. 29

2.4.1 Phase-space evolution Monte Carlo . . . . . . . . . . . . . . . . . p. 29

2.4.2 Response History Monte Carlo . . . . . . . . . . . . . . . . . . . p.30

2.4.3 Macro Monte Carlo . . . . . . . . . . . . . . . p. 31

2.4.4 Macro Response Monte Carlo . . . . . . . . . . . . . . . p. 32

3 Geração da base de dados de kugels $\quad$ p. 34

3.1 A escala de energia e os raios dos kugels . . . . . . . . . . p. 34

$3.2 \mathrm{O}$ cálculo local $\ldots \ldots \ldots \ldots \ldots \ldots \ldots \ldots \ldots$

3.3 A estrutura do kugel . . . . . . . . . . . . . p. 36

3.3.1 As bandas do kugel . . . . . . . . . . . . . p. 36

3.3.2 O cosseno da posição de saída . . . . . . . . . . . . p. 38

3.3 .3 A energia de saída . . . . . . . . . . . . . p. 38

3.3.4 A direção de saída das partículas . . . . . . . . . . . . . p. 38

3.3.5 O número médio de elétrons secundários e fótons saindo do kugel . . p.41

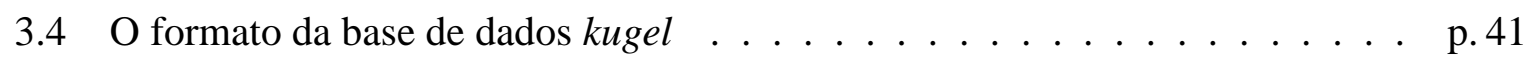

4 O Método de transporte MRMC p. 42

4.1 A implementação do sistema de transporte global . . . . . . . . . . . . p.43 
4.1.1 A escolha do kugel ................... p. . 46

4.1.2 Amostrando as saídas do kugel . . . . . . . . . . . . . p. 47

4.1.2.1 A banda de saída do elétron primário . . . . . . . . . p. 49

4.1.2.2 A posição de saída do elétron primário . . . . . . . . p. p. 49

4.1.2.3 A direção de saída do elétron primário . . . . . . . . . p. 50

4.1.2.4 A energia de saída do elétron primário . . . . . . . . p.50

4.1.2.5 As partículas secundárias . . . . . . . . . p. 51

$4.2 \mathrm{O}$ transporte eletrônico através de interfaces $\ldots \ldots \ldots \ldots \ldots \ldots$ p. . . . . . .

5 Metodologia dos testes do MRMC e da análise de seus resultados p.53

5.1 Os tipos de objetos simuladores testados $\ldots \ldots \ldots \ldots$ p. 53

5.1.1 O objeto simulador homogêneo . . . . . . . . . . p. 53

5.1.2 O objeto simulador heterogêneo . . . . . . . . . . p.54

5.2 Metodologia das simulações $\ldots \ldots \ldots \ldots \ldots \ldots$ p. . . . . . . . . . . . .

5.3 Metodologia da análise das simulações . . . . . . . . . . . . . . p. 59

6 Resultados e discussões $\quad$ p. 61

6.1 Objeto simulador homogêneo . . . . . . . . . . . . p. 61

6.1 .1 O espectro dos elétrons primários $\ldots \ldots \ldots$ p. 61

6.1.1.1 Discussão dos resultados dos espectros primários $\ldots \ldots$. . . 72

6.1.2 O espectro de elétrons primários e secundários $\ldots \ldots \ldots$. . . . . . . 77

6.1.2.1 Discussão dos resultados dos espectros primário e secundário p. 89

6.2 Objeto simulador heterogêneo . . . . . . . . . . . . . p.90 
6.3 Comparação entre os tempos de simulação do MRMC e Geant4 . . . . . . . p.93

7 Conclusões $\quad$ p. 96

$\begin{array}{lr}\text { Referências } & \text { p.97 }\end{array}$

Apêndice A - Exemplo de funções de distribuição de probabilidade de um kugel $\quad$ p. 100

Apêndice B - Terminologia usada pelo Geant4 r 111

B.1 Limites inferior de energia no transporte de partículas (Cutoffs) . . . . . . p. 111

B.2 Limiar de produção de secundários $($ RangeCut $) \ldots \ldots$. . . . . . . p. 111

B.2.1 A região sensível do detetor (SensitiveDetector) . . . . . . . . . . . p. 112

Apêndice C - Parâmetros das simulações dos kugels $\quad$ p. 113

Apêndice D - Diagramas de classes do código MRMC p 114

$\begin{array}{lr}\text { Anexo A - Dados dos Materiais e Tecidos } & \text { p. } 118\end{array}$ 


\section{Lista de Figuras}

1 Geração das funções distribuição de probabilidade, onde temos indicado o feixe de elétrons incidente e suas saídas. . . . . . . . . . . . . . . p.30

2 Método de simulação das funções distribuição de probabilidades em hemisférios, indicando o elétron incidente e suas saídas. . . . . . . . . . p. 31

3 Exemplo do método de transporte RHMC usando hemisférios. . . . . . . . . p. 31

4 Geração das funções distribuição de probabilidades em um kugel do MMC, indicando o elétron incidente e suas saídas. . . . . . . . . . . . p.32

5 Exemplo de transporte de um feixe incidente de elétrons por kugels pelo método MMC . . . . . . . . . . . . . . . . . p. 32

6 Geração das funções distribuição de probabilidades em um kugel do MRMC, indicando o elétron incidente e suas saídas. . . . . . . . . . . . p.33

7 Exemplo de transporte de um feixe incidente de elétrons por kugels pelo método MRMC . . . . . . . . . . . . . . . . . p.33

8 Energias adotadas para as simulações dos kugels. . . . . . . . . . . p. 35

9 Esquema ilustrativo da estrutura de bandas do kugel. . . . . . . . . . . p. 37

10 O vetor $\vec{R}_{1}$ de saída da partícula e os novos eixos de referência $(\vec{P}, \vec{N}, \vec{O})$. . p. 39

11 Diagrama do vetor $\vec{R}_{1}$ da direção de saída da partícula e sua decomposição em componentes $d c n, d c o$ e $d c p . \ldots \ldots \ldots$

12 O método de transporte global do MRMC . . . . . . . . . . . p. 43 
13 Diagrama UML de atividade do sistema de transporte MRMC . . . . . . . p. 45

14 Diagrama de atividade da determinação do estado final do kugel. . . . . . . . . p. 48

15 Vista lateral do objeto simulador A. . . . . . . . . . . . . p.55

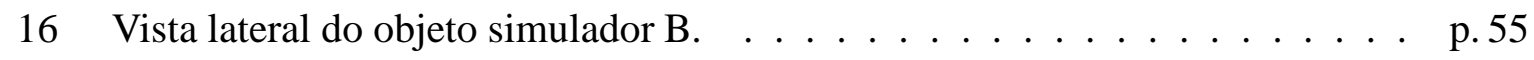

17 Vista lateral e detalhe do corte transversal do objeto simulador C . . . . . . p.56

18 Ilustração do objeto simulador homogêneo com o feixe incidente externo de elétrons e as regiões de saída. . . . . . . . . . . . . . . . p.57

19 Ilustração do objeto simulador homogêneo com o feixe incidente de elétrons posicionado dentro do mesmo. . . . . . . . . . . . . p.58

20 Gráfico das energias disponíveis na base dados kugel e as energias usadas nas simulações. . . . . . . . . . . . . . . . . . . . p. . . . . . . . . . . .

21 Espectro frontal de elétrons primários para feixe incidente de $25 \mathrm{MeV}$ no objeto simulador de água. . . . . . . . . . . . . . . . p.62

22 Espectro lateral de elétrons primários para feixe incidente de $25 \mathrm{MeV}$ no objeto simulador de água. . . . . . . . . . . . . . . . p. 62

23 Espectro frontal de elétrons primários para feixe incidente de $10 \mathrm{MeV}$ no objeto simulador de água. . . . . . . . . . . . . . . p. 63

24 Espectro lateral de elétrons primários para feixe incidente de $10 \mathrm{MeV}$ no objeto simulador de água. . . . . . . . . . . . . . . . . . p.63

25 Espectro frontal de elétrons primários para feixe incidente de $5 \mathrm{MeV}$ no objeto simulador de água. . . . . . . . . . . . . . . . . p.64

26 Espectro lateral de elétrons primários para feixe incidente de $5 \mathrm{MeV}$ no objeto simulador de água. $\ldots \ldots \ldots \ldots \ldots \ldots \ldots$. . . . . . . . . . . . . . . 64 
27 Espectro frontal de elétrons primários para feixe incidente de $1 \mathrm{MeV}$ no objeto simulador de água. . . . . . . . . . . . . . . . p. 65

28 Espectro lateral de elétrons primários para feixe incidente de $1 \mathrm{MeV}$ no objeto simulador de água. . . . . . . . . . . . . . . . p. 65

29 Espectro frontal de elétrons primários para feixe incidente de $25 \mathrm{MeV}$ no objeto simulador de osso compacto. . . . . . . . . . . . . . p.67

30 Espectro lateral de elétrons primários para feixe incidente de $25 \mathrm{MeV}$ no objeto simulador de osso compacto. . . . . . . . . . . . p. 68

31 Espectro frontal de elétrons primários para feixe incidente de $10 \mathrm{MeV}$ no objeto simulador de osso compacto. . . . . . . . . . . . . p.68

32 Espectro lateral de elétrons primários para feixe incidente de $10 \mathrm{MeV}$ no objeto simulador de osso compacto. . . . . . . . . . . . . p. 69

33 Espectro frontal de elétrons primários para feixe incidente de $5 \mathrm{MeV}$ no objeto simulador de osso compacto. . . . . . . . . . . . . . p. 69

34 Espectro lateral de elétrons primários para feixe incidente de $5 \mathrm{MeV}$ no objeto simulador de osso compacto. . . . . . . . . . . . . p. 70

35 Espectro frontal de elétrons primários para feixe incidente de $1 \mathrm{MeV}$ no objeto simulador de osso compacto. . . . . . . . . . . . p.70

36 Espectro lateral de elétrons primários para feixe incidente de $1 \mathrm{MeV}$ no objeto simulador de osso compacto. . . . . . . . . . . . . p.71

37 Comparação entre os desvios MRMC-Geant4 dos espectros frontais. . . . . . p.72

38 Comparação entre os desvios MRMC-Geant4 dos espectros laterais. . . . . . p.73

39 Cosseno de posição de saída para os elétrons primários da Banda 2 para o kugel de $17,78 \mathrm{MeV}$ e $1 \mathrm{~mm}$ de raio. . . . . . . . . . . . . . p. 74 
40 Comparação entre MRMC, Geant4 e uma versão do MRMC sem a correção para perda contínua de energia próximo às interfaces - feixe incidente de $10 \mathrm{MeV}$ e objeto simulador de água. . . . . . . . . . . . p. 75

41 Comparação entre MRMC, Geant4 e uma versão do MRMC sem a correção para perda contínua de energia próximo às interfaces - feixe incidente de $5 \mathrm{MeV}$ e objeto simulador de água. . . . . . . . . . . . . . . p.75

42 Comparação entre MRMC, Geant4 e uma versão do MRMC sem a correção para perda contínua de energia próximo às interfaces - feixe incidente de $1 \mathrm{MeV}$ e objeto simulador de água. . . . . . . . . . . . . p.76

43 Espectro frontal de elétrons para feixe incidente de $25 \mathrm{MeV}$ no objeto simulador de água. . . . . . . . . . . . . . . . . . . . . . . . p.78

44 Espectro lateral de elétrons para feixe incidente de $25 \mathrm{MeV}$ no objeto simulador de água. . . . . . . . . . . . . . . . . . . . p. 78

45 Espectro frontal de elétrons para feixe incidente de $10 \mathrm{MeV}$ no objeto simulador de água. . . . . . . . . . . . . . . . . . . . . p. 79

46 Espectro lateral de elétrons para feixe incidente de $10 \mathrm{MeV}$ no objeto simulador de água. . . . . . . . . . . . . . . . . . . . . . . . . p.79

47 Espectro frontal de elétrons para feixe incidente de $5 \mathrm{MeV}$ no objeto simula-

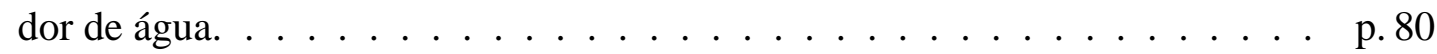

48 Espectro lateral de elétrons para feixe incidente de $5 \mathrm{MeV}$ no objeto simulador de água. . . . . . . . . . . . . . . . . . . . p. 80

49 Espectro frontal de elétrons para feixe incidente de $1 \mathrm{MeV}$ no objeto simulador de água. . . . . . . . . . . . . . . . . . p 81

50 Espectro lateral de elétrons para feixe incidente de $1 \mathrm{MeV}$ no objeto simulador de água. . . . . . . . . . . . . . . . . . . . p. 81 
51 Espectro frontal de elétrons para feixe incidente de $1 \mathrm{MeV}$ no objeto simulador de tecido mole. . . . . . . . . . . . . . . . . . p.82

52 Espectro lateral de elétrons para feixe incidente de $1 \mathrm{MeV}$ no objeto simulador de tecido mole. . . . . . . . . . . . . . . p. 83

53 Espectro frontal de elétrons para feixe incidente de $25 \mathrm{MeV}$ no objeto simulador de osso compacto. . . . . . . . . . . . . . . . . p. 84

54 Espectro lateral de elétrons para feixe incidente de $25 \mathrm{MeV}$ no objeto simulador de osso compacto. . . . . . . . . . . . . . . p. 85

55 Espectro frontal de elétrons para feixe incidente de $10 \mathrm{MeV}$ no objeto simulador de osso compacto. . . . . . . . . . . . . . . p. 85

56 Espectro lateral de elétrons para feixe incidente de $10 \mathrm{MeV}$ no objeto simulador de osso compacto. . . . . . . . . . . . . . . p. 86

57 Espectro frontal de elétrons para feixe incidente de $5 \mathrm{MeV}$ no objeto simulador de osso compacto. . . . . . . . . . . . . . . p. 86

58 Espectro lateral de elétrons para feixe incidente de $5 \mathrm{MeV}$ no objeto simulador de osso compacto. . . . . . . . . . . . . . . . p. 87

59 Espectro frontal de elétrons para feixe incidente de $1 \mathrm{MeV}$ no objeto simulador de osso compacto. . . . . . . . . . . . . . . p. 87

60 Espectro lateral de elétrons para feixe incidente de $1 \mathrm{MeV}$ no objeto simulador de osso compacto. . . . . . . . . . . . . . p. 88

61 Espectro de elétrons retroespalhado para feixe incidente de $5 \mathrm{MeV}$ no objeto simulador de osso compacto. . . . . . . . . . . . . . . p. 89

62 Espectro frontal de elétrons do objeto simulador A para feixe incidente de

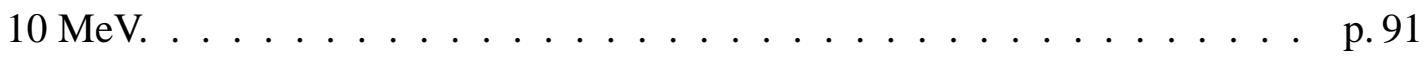


63 Espectro frontal de elétrons do objeto simulador B para feixe incidente de

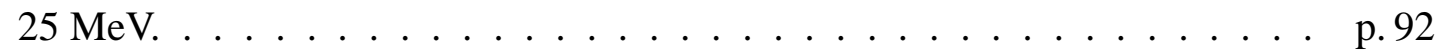

64 Espectro frontal de elétrons do objeto simulador C para feixe incidente de

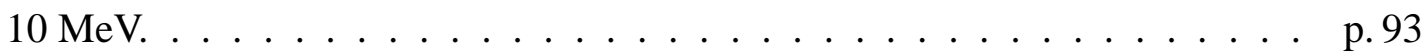

65 Comparação entre as razões dos tempos de simulação Geant4/MRMC . . p.94

66 Cosseno da posição de saída para os elétrons primários e secundários da Banda 1. . . . . . . . . . . . . . . . . . p. 101

67 Cosseno da posição de saída para os elétrons primários e secundários da Banda $2 \ldots \ldots \ldots \ldots \ldots \ldots \ldots \ldots \ldots$. . . . . . . . . . . . . . . . . . . .

68 Cosseno da posição de saída para os elétrons primários e secundários da Banda 3. . . . . . . . . . . . . . . . . . . p. 102

69 Cosseno da posição de saída para os elétrons primários e secundários da Banda 4. . . . . . . . . . . . . . . . . . p. 102

70 Energia de saída normalizada pela energia inicial dos elétrons primários e secundários da Banda $1 . \ldots \ldots \ldots$. . . . . . . . . . . . . 103

71 Energia de saída normalizada pela energia inicial dos elétrons primários e secundários da Banda $2 \ldots \ldots \ldots$. . . . . . . . . . . . . . . 103

72 Energia de saída normalizada pela energia inicial dos elétrons primários e secundários da Banda $3 . \quad \ldots \ldots \ldots$. . . . . . . . . . . . . . 104

73 Energia de saída normalizada pela energia inicial dos elétrons primários e

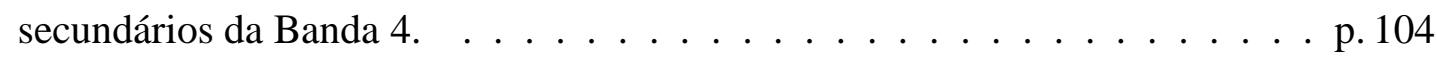

74 Trajetória de saída dep dos elétrons primários e secundários da Banda 1. . . . p. 105

75 Trajetória de saída dep dos elétrons primários e secundários da Banda 2. . . . p. 105

76 Trajetória de saída dep dos elétrons primários e secundários da Banda 3. . . . p. 106 
77 Trajetória de saída dcp dos elétrons primários e secundários da Banda 4. . . . p. 106

78 Trajetória de saída, $\cos (\mu)$, dos elétrons primários e secundários da Banda 1. p. 107

79 Trajetória de saída, $\cos (\mu)$, dos elétrons primários e secundários da Banda 2. p. 107

80 Trajetória de saída, $\cos (\mu)$, dos elétrons primários e secundários da Banda 3. p. 108

81 Trajetória de saída, $\cos (\mu)$, dos elétrons primários e secundários da Banda 4. p. 108

82 Número médio de elétrons secundários das Bandas 1 e $2 \ldots$. . . . . . . . . p. 109

83 Número médio de elétrons secundários das Bandas 3 e 4 . . . . . . . . . . . p. 109

84 Número médio de fótons das Bandas 1 e $2 \ldots \ldots \ldots \ldots$. . . . . . . 110

85 Número médio de fótons das Bandas 3 e $4 \ldots \ldots \ldots$. . . . . . . p. 110

86 Diagrama UML das classes relacionadas à geometria do MRMC . . . . . . . p. 115

87 Diagrama UML do código de transporte do MRMC. . . . . . . . . . . p. 116

88 Diagrama da classe de gerenciamento dos kugels e classes correlatas. . . . . . p. 117 


\section{Lista de Tabelas}

1 Dimensões dos objetos simuladores homogêneos para água e tecido mole

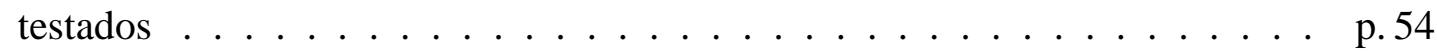

2 Dimensões dos objetos simuladores homogêneos para o osso compacto . . . p.54

3 Dimensões dos objetos simuladores A e B . . . . . . . . . . p.56

4 Dimensões do objeto simulador $\mathrm{C} \ldots \ldots \ldots \ldots$ p. . . . . . . . . . . .

5 Análise dos espectros primários referentes ao objeto simulador homogêneo

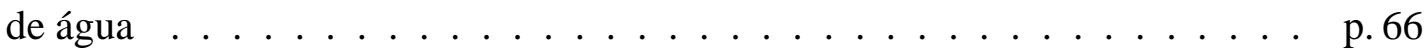

6 Análise dos espectros primários referentes ao objeto simulador homogêneo de tecido mole . . . . . . . . . . . . . . . . p. 66

7 Tabela de análise dos espectros primários referentes ao objeto simulador homogêneo de osso compacto . . . . . . . . . . . . . p.71

8 Tabela de análise dos espectros referentes ao objeto simulador homogêneo de

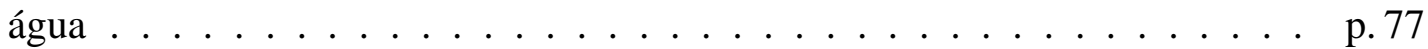

9 Tabela de análise dos espectros referentes ao objeto simulador homogêneo de tecido mole . . . . . . . . . . . . . . . . . p. 83

10 Tabela de análise dos espectros referentes ao objeto simulador homogêneo de osso compacto . . . . . . . . . . . . . . . . . . p 84

11 Análise dos espectros referentes ao objeto simulador A $\ldots \ldots \ldots$ p. . . . . 90

12 Análise dos espectros referentes ao objeto simulador B $\ldots \ldots$. . . . . p. 90 
13 Análise dos espectros referentes ao objeto simulador $\mathrm{C} \ldots \ldots$. . . . . p.90

14 Razão entre os tempos de simulação do Geant4 e MRMC . . . . . . . . . . . . p.94

15 Parâmetros das simulações . . . . . . . . . . . . . . . . . p. 113

16 Densidade e comprimento de radiação dos materiais/tecidos usados neste tra-

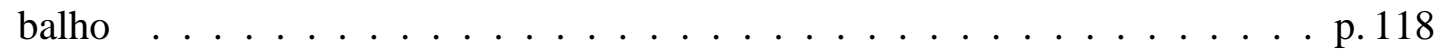

17 Composição atômica da água . . . . . . . . . . . . . . . . p. 118

18 Composição atômica do tecido mole . . . . . . . . . . . . . . . . p. 119

19 Composição atômica do osso compacto . . . . . . . . . . . . . . . . p. 119 


\section{Resumo}

Perles, L. A. Avaliação do algoritmo Macro Response Monte Carlo através dos espectros dos elétrons. 2006. Tese (Doutorado) - Faculdade de Filosofia, Ciências e Letras de Ribeirão Preto, Universidade de São Paulo, Ribeirão Preto, 2006.

O tempo de simulação computacional em planejamento de radioterapia ainda é muito alto. Diversas técnicas de redução de variância têm sido desenvolvidas para o transporte de elétrons a fim de reduzir o tempo de simulação. Destacamos algumas delas: Macro Monte Carlo (MMC), Response History Monte Carlo (RHMC) e Macro Response Monte Carlo (MRMC). Todas essas técnicas utilizam base de dados onde as histórias dos elétrons foram previamente simuladas. Tais algoritmos, até o presente momento, foram somente avaliados através da dose absorvida. Neste trabalho, fazemos uma comparação dos espectros dos elétrons utilizando uma implementação própria do MRMC. A base de dados do MRMC consiste de histórias pré-simuladas de elétrons em pequenas esferas de material homogêneo (chamadas de kugel) para diferentes tipos de energias e tamanhos de raios. O MRMC usa o kugel de maior raio para transportar o elétron, desde que o mesmo não cruze nenhuma interface entre materiais. Nesta implementação, o transporte do elétron através de uma interface é aproximado por uma linha reta e, ao final, corrige-se sua energia pela perda contínua de energia. A base de dados kugel foi gerada pelo Geant4 versão 8.0 para água, tecido mole e osso compacto, para a faixa de energia de $31,63 \mathrm{MeV}$ até $178 \mathrm{keV}$, com raios de $0,025 \mathrm{~cm}$ a $1,0 \mathrm{~cm}$. Os testes consistem na simulação de um feixe estreito de elétrons em objetos simuladores homogêneos e heterogêneos de forma cilíndrica. Foram obtidos os espectros frontais e laterais pelo MRMC e comparados aos respectivos espectros simulados pelo Geant4. Foram simulados $10^{6}$ histórias em ambos os sistemas, por este motivo não houve a necessidade de normalizar os histogramas. Os espectros avaliados mostram uma boa concordância para energias acima de $5 \mathrm{MeV}$. A diferença entre as energias dos picos foi menor que 1,7\%, para energias acima de $5 \mathrm{MeV}$ em objetos simuladores homogêneos. Para o osso compacto as diferenças entre os espectros frontais foram cerca de $5 \%$, e para os laterais menor que $2 \%$ para energias acima de $5 \mathrm{MeV}$. Os tempos de simulação com o MRMC foram de até 15 vezes menores para objetos simuladores homogêneos e cerca de 5 vezes menores para objetos simuladores heterogêneos.

Palavras chave: radioterapia, Monte Carlo, transporte de elétrons 


\section{Abstract}

Perles, L. A. Macro Response Monte Carlo algorithm evaluated through electron spectra. 2006. Thesis (Doctoral) - Faculdade de Filosofia, Ciências e Letras de Ribeirão Preto, Universidade de São Paulo, Ribeirão Preto, 2006.

In radiotherapy the computer simulation elapsed time for treatment planning is still a problem. Several techniques for electron transport variance reduction have been developed in order to speed up the calculations. Some of them are: Macro Monte Carlo (MMC), Response History Monte Carlo (RHMC) and Macro Response Monte Carlo (MRMC). All of them use a database where electrons histories were previously simulated. These algorithms have been evaluated only by absorbed dose. This work shows a comparison between electron spectra simulated by our implementation of MRMC. Such algorithm uses a database where electron histories were pre-simulated in small homogeneous spheres (called kugel) for several different initial energies and some different radii. The MRMC transportation code uses the largest kugel size for electron transportation, since it does not cross any material boundary. In this implementation the electron transport through a boundary is done in a straight line and the energy correction is made by continuous slowing down approximation. The kugel database has been generated using Geant 4 version 8.0 for water, soft tissue and compact bone, with energy range spanning from $31.63 \mathrm{MeV}$ down to $178 \mathrm{keV}$ and with radius range from 0.025 to $1.0 \mathrm{~cm}$. The MRMC benchmarks consist of an electron pencil beam simulation in homogeneous and heterogeneous cylindrical phantoms. The forward and lateral electron output spectra are computed and compared against Geant 4 simulations. We have simulated $10^{6}$ histories in both systems, so the histograms are compared without any normalization factors. The agreement between spectra shapes have been evaluated and show to be good above $5 \mathrm{MeV}$. The results show an agreement better than $1.7 \%$ in the peak energy for energies above $5 \mathrm{MeV}$, for water and soft tissue homogeneous phantoms. The agreement for compact bone homogeneous phantom between peaks of forward spectra were around 5\% and for side spectra were better than $2 \%$ for energies above $5 \mathrm{MeV}$. The benchmarks have shown that our implementation of MRMC are up to 15 times faster than Geant 4 for homogeneous phantoms and 5 times for heterogeneous ones.

Keywords: radiotherapy, Monte Carlo, electron transportation. 


\section{$1 \quad$ Introdução}

A aplicação da radiação ionizante na medicina compreende, basicamente, as áreas de diagnóstico e terapia. A primeira tem por objetivo principal obter imagens médicas por meio da radiação ionizante para fins diagnósticos, e a segunda tem por principal objetivo o uso terapêutico da radiação ionizante. A radioterapia pode utilizar diversos tipos de partículas ionizantes para irradiar o paciente, tais como fótons (raios-X e $\gamma$ ), elétrons, prótons, píons e nêutrons. As mais comuns são fótons e elétrons, tendo como fontes elementos radioativos como o Cobalto 60, tubos de raios-X ou aceleradores de elétrons.

A maioria dos casos clínicos na radioterapia é de tumores, e sua aplicação envolve várias etapas, desde o diagnóstico do paciente, planejamento da irradiação com a localização do tumor e dos tecidos sadios vizinhos, determinação do tipo de energia do feixe, posicionamento do paciente, simulação do tratamento e aplicação da irradiação.

Um dos objetivos do planejamento é aumentar a dose absorvida no tumor e minimizar a dose nos tecidos sadios circunvizinhos, através do posicionamento do campo de radiação, da determinação de sua forma e dos tempos de exposição para a dose absorvida prescrita.

\subsection{Técnicas de planejamento}

A dose absorvida definida pelo International Comission on Radiation Units and Measurements (ICRU) (1) é descrita pela seguinte equação: 


$$
D=\frac{d \bar{E}_{a b s}}{d m} \quad(\mathrm{~Gy})
$$

Onde $D$ é composta pela parcela da energia cinética das partículas carregadas, $d \bar{E}_{a b s}$, absorvida pelo meio material, de massa $\mathrm{dm}$.

Uma das técnicas de planejamento mais antigas envolve a determinação da dose no eixo central do campo de irradiação por meio de funções que dependem do material ou tipo de tecido envolvido e de parâmetros medidos experimentalmente. Outra técnica também antiga é a determinação das distribuições bidimensionais (2D) da dose de irradiação através da interpolação de curvas de isodose, medidas experimentalmente em objetos simuladores de água. Essas técnicas, embora antigas, ainda são utilizadas atualmente em procedimentos de planejamento.

Com o avanço dos computadores nas décadas de 80 e 90 , os procedimentos de planejamento passaram a serem feitos em computadores. Os programas de planejamento, inicialmente, faziam a interpolação das curvas de isodose medidas em objeto simulador de água, da mesma forma como eram feitas as interpolações das curvas manualmente. Posteriormente, os programas de planejamento passaram a adotar modelos numéricos mais sofisticados e a fazerem cálculos tridimensionais (3D), como os de convolução para a fótons (2-5) e os de Fermi-Eyges (6) para elétrons. No entanto, esses modelos, em geral, apresentam deficiências em aplicações onde é exigido o cálculo da distribuição da dose em meios heterogêneos.

Métodos de planejamento baseado em simulação por Monte Carlo têm sido explorados recentemente. Esta técnica consiste em simular o transporte e a interação das partículas em meios materiais para obter as distribuições 3D de dose absorvida. Tal método apresenta uma boa concordância com resultados experimentais. Alguns programas tradicionais de simulação por Monte Carlo são: Electron Gamma Shower version 4 (EGS4) (7), Monte Carlo N Particle (MCNP4) (8), PENetration and Energy LOss of Positrons and Electrons (PENELOPE) (9) e o Geometry and tracking (Geant4) (10). Recentemente, uma versão mais atualizada do EGS4 produzida com o apoio do National Research Council do Canadá, o EGSnrc (11), tem sido 
muito utilizada. Porém, todos esses algoritmos ainda são lentos para serem utilizados na rotina dos hospitais.

Ainda na década de 90, começaram os estudos com técnicas de redução de variância aplicada a programas de simulação do transporte de partículas. Para fótons temos o X Voxel Monte Carlo (XVMC) (12); para elétrons temos o Voxel Monte Carlo (VMC) (13), o Macro Monte Carlo (MMC) (14, 15), o Response History Monte Carlo (RHMC) (16) e o Macro Response Monte Carlo (MRMC) (17).

O VMC simplifica alguns passos no transporte dos elétrons, otimizando o transporte e a distribuição de energia através dos voxels. O XVMC alia a técnica do VMC às simplificações nas interações e transporte dos fótons.

O MMC, RHMC e o MRMC são baseados em histórias de elétrons previamente simuladas. O MMC usa histórias pré-simuladas pelo EGS4 em esferas, chamadas de kugel (esfera em alemão). O RHMC utiliza histórias pré-simuladas em hemisférios. O MRMC também faz uso de histórias pré-simuladas em kugels, contudo, a geração da base de dados de kugels é feita usando um código de simulação do transporte de elétrons mais preciso e detalhado que o EGS4. O sistema de transporte dos elétrons no MRMC também é diferente do MMC.

\subsection{Objetivos}

Por meio dos programas de simulação por Monte Carlo podemos extrair diversas informações, além da dose absorvida, mesmo sendo utilizadas técnicas de redução de variância. No entanto, a maioria dos códigos LGMC têm sido testados apenas no cálculo da dose. Outros ítens que influenciam na distribuição 3D da dose, tais como os espectros dos elétrons, não aparecem na literatura até o presente momento.

O objetivo deste trabalho é avaliar os espectros de elétrons produzidos pelas simulações com o algoritmo MRMC, cuja base de dados possui kugels de raios maiores e uma faixa de energia mais ampla que os já testados para a obtenção da dose. Também serão avaliados os 
tempos de simulação em objetos simuladores homogêneos e heterogêneos usando essa base de dados estendida.

\subsection{Estrutura da tese}

O código fonte da implementação do MRMC possui mais de 3000 linhas em sua versão final. O programa que simula o transporte de elétrons nos kugels possui mais de 3900 linhas de código. Se forem contabilizados também o programa para a obtenção dos espectros pelo Geant4, os scripts em C++ para análise da base de dados e apresentação de gráficos, no total, foram escritos mais de 10000 linhas de código final. O tempo de geração da base de dados de kugels completa para o tecido mole foi de aproximadamente uma semana em um cluster de micros rodando GNU/Linux otimizado, utilizando 13 processadores Intel Pentium4 de 2,66 GHz trabalhando em paralelo.

Devido a complexidade e a extensão deste trabalho, a tese ficou dividida em sete capítulos.

No capitulo 2 são apresentadas algumas noções teóricas sobre o problema do transporte de elétrons em meios materiais e as alternativas adotadas, a fim de aumentar a velocidade das simulações por Monte Carlo.

A metodologia da geração da base de dados, também conhecida por 'transporte local', é apresentada no capítulo 3. O exemplo das funções de distribuição de probabilidade de um kugel, pertencentes a essa base de dados encontra-se no apêndice A.

A implementação do código de MRMC, também conhecido por 'transporte global', é apresentado no capítulo 4.

A metodologia adotada para os testes que inclui a geometria e os parâmetros das simulações estão no capítulo 5, assim como a metodologia usada para a análise dos resultados.

No capítulo 6 estão os resultados e as discussões dos espectros de elétrons obtidos.

No capítulo 7 encontram-se as conclusões. Nos apêndices e no anexo temos informações complementares diversas. 


\section{Noções teóricas}

Neste capítulo são apresentadas algumas noções teóricas sobre a simulação pelo método Monte Carlo e algumas técnicas de simulação do transporte e interação dos elétrons.

\subsection{A simulação pelo método Monte Carlo}

A função distribuição de probabilidade associa uma probabilidade, $\operatorname{Pr}$, a cada intervalo numérico (18). A função distribuição de probabilidade de uma variável $X$ pode ser unicamente descrita por:

$$
F(x)=\operatorname{Pr}[X \leq x]
$$

Onde $F(x)$ é a função distribuição cumulativa de $X$. Se esta função não possui nenhuma discontinuidade, podemos descreve-la por meio de uma função densidade de probabilidade $f(t)$ assim:

$$
F(x)=\int_{-\infty}^{x} f(t) d t
$$

Onde a função densidade de probabilidade é sempre positiva em todo o seu domínio e normalizada, $\int_{-\infty}^{\infty} f(t) d t=1$.

Assim, a probabilidade de ocorrer um evento $x$ no intervalo $[a, b]$ é dada por: 


$$
\operatorname{Pr}[a \leq x \leq b]=\int_{a}^{b} f(t) d t
$$

\subsubsection{Aplicação ao transporte de partículas}

De uma maneira simplificada, a simulação do transporte e interação de partículas em meios materiais, compreende os seguintes passos:

1. Amostrar a posição da interação;

2. Amostrar o tipo de interação;

3. Amostrar o estado final da(s) partícula(s).

Na primeira etapa determinamos a posição onde ocorre a interação da partícula ao longo de sua trajetória. Em seguida determinamos a interação que irá ocorrer, que é dependente do tipo de partícula, sua energia cinética e do meio material. Por último, determinamos o estado final da partícula que, dependendo do tipo de interação, podem levar a criação ou aniquilação de de partículas.

A probabilidade $p(t) d t$ de interação de uma partícula ao longo do transporte é dada por:

$$
p(t) d t=\frac{1}{\lambda} \cdot e^{-\frac{t}{\lambda}} d t
$$

Onde $\lambda$ é o caminho livre médio da partícula no meio material. Por meio dessa probabilidade obtemos a seguinte função distribuição cumulativa:

$$
F(x)=\int_{0}^{x} \frac{1}{\lambda} \cdot e^{-\frac{t}{\lambda}} d t
$$

Observe que, a função densidade de probabilidade já está normalizada, $\int_{0}^{\infty} \frac{1}{\lambda} \cdot e^{-\frac{t}{\lambda}} d t=1$. 
A simulação do transporte da partícula pelo método Monte Carlo consiste, primeiramente, em saber em que posição, $x$, ela irá interagir. Para amostrar a posição de interação precisamos inverter a equação 2.5 , assim temos:

$$
x=-\lambda \ln (1-F(x))
$$

Observe agora que $F(x)$ está como variável independente contida no intervalo [0,1[. Esta é a base do chamado método direto (7), em que $F(x)=\xi$, sendo $\xi$ um número aleatório uniformemente distribuído no mesmo intervalo. Assim, a equação 2.6 pode ser reescrita como:

$$
x=-\lambda \ln (1-\xi)
$$

Se $\xi$ é um número aleatório uniformemente distribuído no intervalo $[0,1[, 1-\xi$ também é, mas no intervalo ]0,1]. Assim, podemos substituir $1-\xi$ por $\chi$, sendo que este último é um número aleatório uniformemente distribuído em ]0,1], e assim reescrevemos a equação 2.7 como:

$$
x=-\lambda \ln (\chi)
$$

A amostragem do tipo de interação leva em conta as probabilidades de cada processo em relação à probabilidade total de todos os processos. O estado final da partícula é amostrado de acordo com o tipo de interação ocorrido.

\subsection{As interações dos elétrons com o meio material}

Neste trabalho estamos interessados especialmente nas interações dos elétrons com o meio material. Os processos relevantes são: espalhamento coulombiano, produção de raios delta, emissão de radiação por bremsstrahlung e aniquilação de pares elétron-pósitron. 
Espalhamento coulombiano Quando um elétron atravessa a matéria ele sofre um grande número de colisões com os elétrons das camadas mais externas do átomo, onde as trocas de energia são pequenas. Neste processo também podem ocorrer excitação e ionização dos átomos. Existe outro tipo de espalhamento coulombiano, que ocorre quando o elétron interage com o núcleo do átomo. Na maioria destes casos o espalhamento é elástico e responde por mudanças bruscas na trajetória do elétron (19).

Produção de raios delta A interação do elétron com as camadas eletrônicas internas do átomo leva a extração de um elétron atômico, criando o chamado raio delta. Neste processo podem ocorrer grandes trocas de energia (19).

Emissão de radiação por bremsstrahlung Cerca de 2 a $3 \%$ das interações do elétron com o núcleo são inelásticas e produzem fótons chamados de bremsstrahlung. Neste processo também podem ocorrer grandes trocas de energia (19).

Aniquilação de pares elétron-pósitron Ocorre quando um pósitron é aniquilado no encontro com um elétron. Este processo não será abordado neste trabalho, porque, sendo o feixe incidente composto por elétrons, a probabilidade de aniquilação de pares dentro das esferas envolve a probabilidade de produção de fótons por bremsstrahlung, condicionada a probabilidade de produção de pares elétron-pósitron e sua conseqüente aniquilação, tudo isso dentro de esferas de raio menores que $1 \mathrm{~cm}$.

\subsection{Os algoritmos de história condensada de elétrons}

Simular cada um dos eventos para fótons, cujo caminho livre médio é da ordem de centímetros, é o método mais comum empregado atualmente. No entanto, para elétrons, cujo caminho livre médio é da ordem de micras, a simulação do transporte até que o mesmo tenha energia cinética nula podem ser necessários centenas de milhares de interações (19). Por este motivo, uma simulação que envolva o transporte de elétrons pode exigir várias horas de cálculo com- 
putacional. A fim de reduzir os tempos de simulação foram desenvolvidas técnicas alternativas para o transporte dos elétrons.

A história condensada de elétrons consiste em simular o transporte do elétron através de passos maiores que seu caminho livre médio. Após o elétron ser transportado por um determinado trecho, são feitas correções no caminho percorrido, deslocamento lateral, direção e perda de energia. Os múltiplos desvios sofridos pelo elétron, durante o transporte, são corrigidos pelo algoritmo de múltiplo espalhamento coulombiano (Multiple Scattering - MSC), e as perdas de energia computadas pela perda contínua de energia (19-21), $d E / d x$. Contudo, existem códigos de simulação que dispensam o uso dessas aproximações e implementam todos os detalhes do transporte de elétrons, tais programas são conhecidos por história detalhada ou Single Scattering.

Os programas de simulação que usam o algoritmo de história condensada foram agrupados em duas classes por Berger ((22) apud (21)).

Os de classe I transportam o elétron por meio de passos de comprimentos pré-determinados. Usualmente esse passo é ajustado para que a fração de energia transferida ao meio material seja constante. Após o transporte, procede-se às correções citadas anteriormente. A desvantagem deste método é que não são modelados os efeitos onde ocorrem grandes trocas de energias, tais como fótons por bremsstrahlung ou raios delta. As correções para o transporte dos elétrons limitam-se a desvios laterais e a correção da trajetória, assim como a perda de energia por $d E / d x$.

Os de classe II são conhecidos como algoritmos mistos porque, além de transportarem os elétrons da mesma maneira que os de classe I, também modelam eventos onde há grandes perdas de energias (bremsstrahlung e raios delta). A técnica de inclusão desses efeitos é análoga à apresentada na seção 2.1. Os tempos de simulação exigidos pelos programas de classe II são fortemente dependentes dos valores ajustados para o limiar de produção de secundários (fótons e elétrons), e tipicamente maiores que os de classe I.

A seguir veremos alguns dos modelos de história condensada e suas aplicações. 


\subsubsection{O modelo de Molière}

O modelo de Molière ((23) apud (24)) é uma aproximação que considera que, ao longo da trajetória do elétron, tenha ocorrido pelo menos 20 colisões elásticas e que o ângulo de espalhamento não tenha sido maior que 20 graus. Esta limitação decorre da aproximação $\operatorname{sen} \theta \approx \theta$. $\mathrm{O}$ EGS4 implementa uma versão do modelo de Molière modificado por Bethe $(7,24)$.

\subsubsection{O modelo de Goudsmit-Saunderson}

O modelo de Goudsmit-Saunderson não é uma aproximação para pequenos ângulos, mas uma expansão em séries de polinômios de Legendre. Por meio dele, podemos saber exatamente o ângulo de espalhamento independentemente do número de colisões elásticas que ocorreram durante o passo. A limitação deste modelo está justamente na expansão polinomial, que pode exigir muitos termos do polinômio de Legendre, quando o passo do elétron é bastante reduzido. Por exemplo, em situações onde o passo é da ordem de 20 caminhos livre médio, foram reportados que são necessários até 999 termos em materiais como o carbono e o ouro ((25) apud (17)). Este modelo é implementado no EGSnrc.

\subsubsection{O modelo de Lewis}

O modelo de Lewis é um outro tipo de aproximação para o transporte de elétrons através de meios materiais. Este modelo é capaz de prever, após o deslocamento da partícula, seu desvio lateral e sua distribuição angular (26). No Geant4 está implementado uma modificação deste modelo feita por Urbán $(10,27)$. Embora esta esteja baseada em um modelo mais completo que o de Molière, a mesma apresenta uma limitação a ser considerada: a espessura do material em que a partícula é transportada deve ser maior que um milésimo do comprimento de radiação, $X_{0}$, do mesmo (28). 


\subsection{Os métodos Local-to-Global Monte Carlo}

O método Local-to-Global Monte Carlo (LGMC) consiste em usar dados de funções distribuição de probabilidade que representam uma mudança no espaço de fase dos elétrons de saída de geometrias que possam ser consideradas um elemento de volume (17). O cálculo local consiste na simulação dessas funções distribuição de probabilidades em diversas energias iniciais e em vários tipos de materiais, compondo uma base de dados. O cálculo global compreende a simulação do transporte das mesmas partículas na geometria final, amostrando suas posições, direções e energias a partir das funções distribuição de probabilidade previamente simuladas e armazenadas em uma base de dados.

Este método foi originalmente proposto por Mackie e Battista ((29) apud (17)) em 1984, sob o nome de Macro Monte Carlo, onde as funções distribuição de probabilidade seriam obtidas da simulação dos elétrons em voxels cúbicos ${ }^{1}$.

A seguir são descritos, brevemente, os seguintes algoritmos LGMC encontrados na literatura: Phase-space evolution Monte Carlo (Evolution), Macro Monte Carlo (MMC), Response History Monte Carlo (RHMC) e o Macro Response Monte Carlo (MRMC).

\subsubsection{Phase-space evolution Monte Carlo}

Este algoritmo desenvolvido por Scora e Faddegon (30) implementa a idéia original de Mackie e Battista (29), usando voxels cúbicos de 0,5 cm de extensão, de onde obtém-se o espaço as funções distribuição de probabilidade do fase dos elétrons simulados pelo EGS4. Os autores reportaram diferenças nas doses absorvidas de até $4 \%$, porém o tempo computacional necessário para as simulações foi cerca de duas vezes maior que o EGS4. Outro ítem importante apontado pelos autores foi o tamanho da base de dados ocupado por apenas um tipo de material, cerca de 60 MB. A figura 1 mostra como é feito a simulação de um voxel para a obtenção do espaço de fase.

\footnotetext{
${ }^{1}$ Este Macro Monte Carlo não é o mesmo mencionado no capítulo anterior, conforme será explicado mais adiante nesta mesma seção.
} 


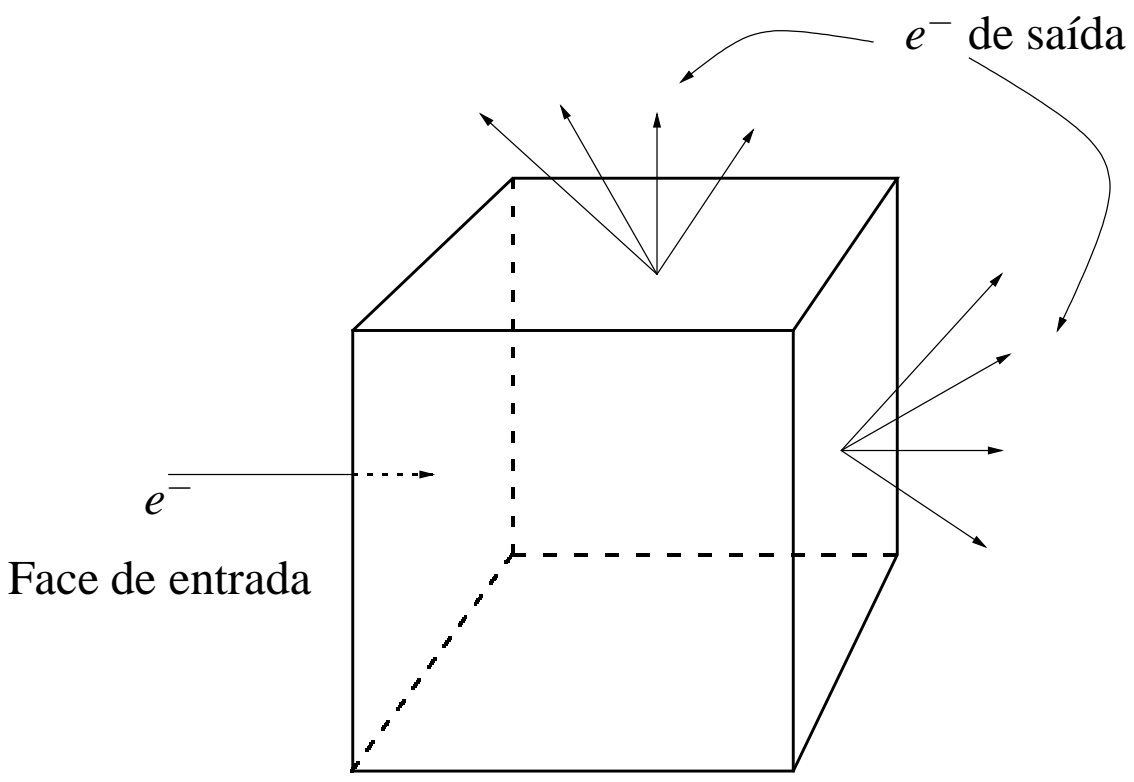

Figura 1: Geração das funções distribuição de probabilidade, onde temos indicado o feixe de elétrons incidente e suas saídas.

\subsubsection{Response History Monte Carlo}

Este algoritmo foi desenvolvido por Ballinger (16) e simula as funções distribuição de probabilidades dos elétrons em hemisférios por um código de história detalhada. $\mathrm{O}$ autor justifica a utilização dos hemisférios através de três pontos: não perde-se muito tempo de simulação local transportando os elétrons retroespalhados, é possível acoplar um hemisfério logo na entrada do elétron por uma interface, existe uma 'correlação' espacial entre os caminhos percorridos por todos os elétrons e a dose depositada no meio. Na figura 2 temos um esquema em que podemos ver como são obtidos as funções distribuição de probabilidades em hemisférios e na figura 3 um exemplo de como é feito o transporte neste sistema. 


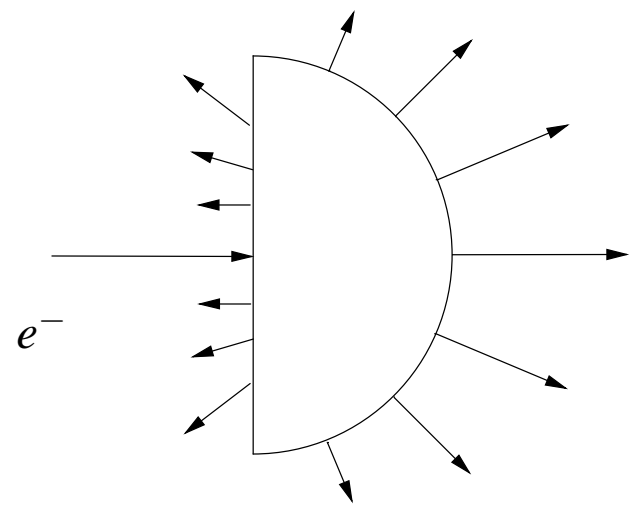

Figura 2: Método de simulação das funções distribuição de probabilidades em hemisférios, indicando o elétron incidente e suas saídas.

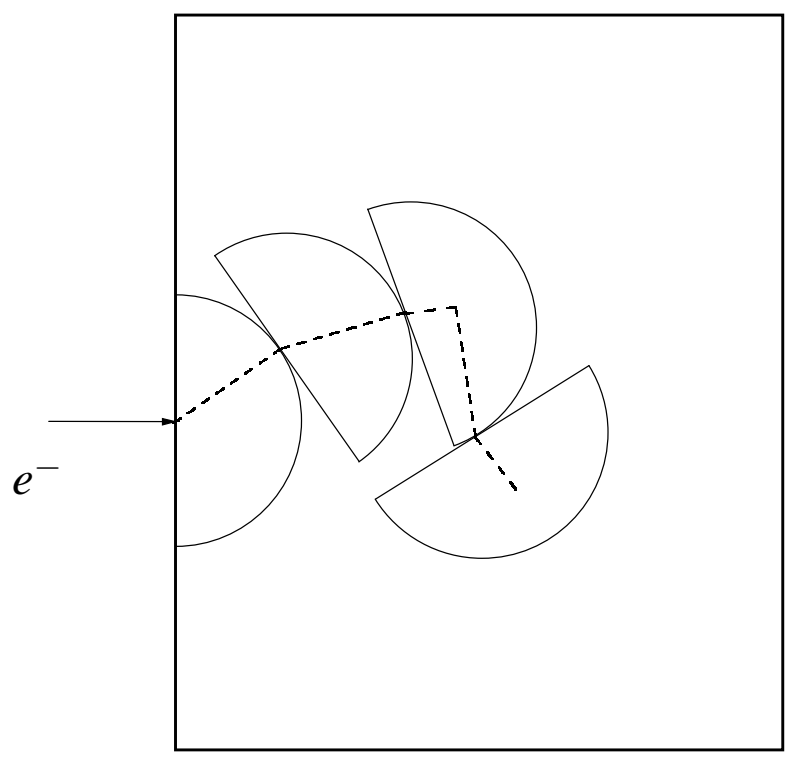

Figura 3: Exemplo do método de transporte RHMC usando hemisférios.

\subsubsection{Macro Monte Carlo}

O MMC foi desenvolvido por Neuenschwander e Born (14) usando esferas (kugels) para obter as funções distribuição de probabilidade dos elétrons transportados pelo EGS4. Na figura 4 temos um esquema de como são simuladas as funções distribuição de probabilidade, e na figura 5 um exemplo do transporte por este método, onde as setas indicam a direção de saída dos elétrons de cada kugel. Os tempos de simulação com o MMC foram de 10 a 18 vezes menores que os do EGS4 (15). 


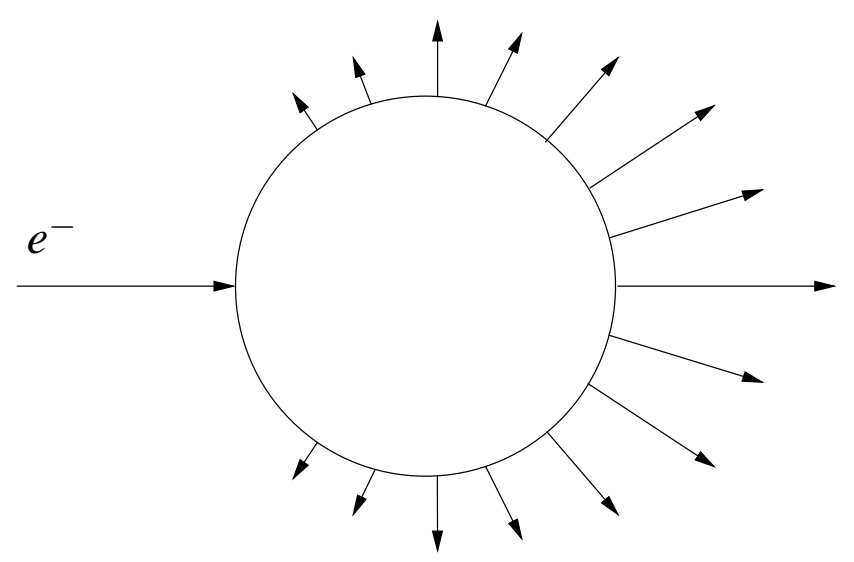

Figura 4: Geração das funções distribuição de probabilidades em um kugel do MMC, indicando o elétron incidente e suas saídas.

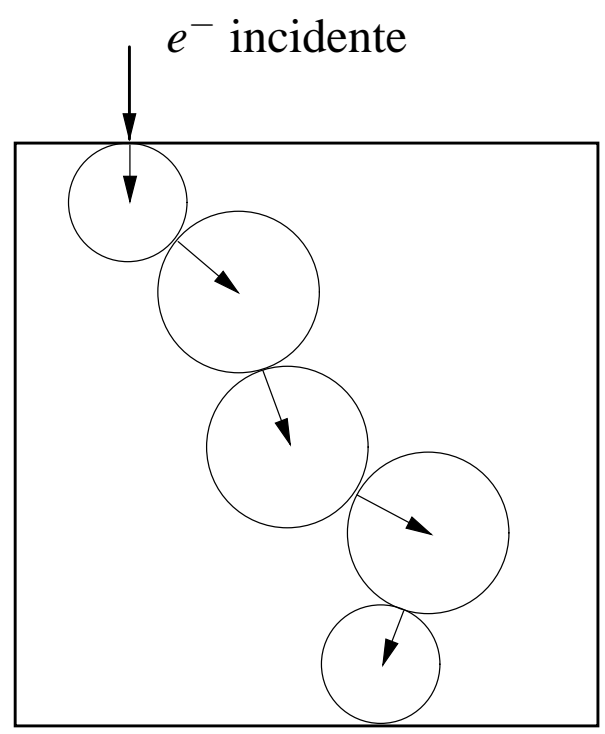

Figura 5: Exemplo de transporte de um feixe incidente de elétrons por kugels pelo método MMC.

\subsubsection{Macro Response Monte Carlo}

O MRMC foi implementado por Svatos (17) e também faz uso dos kugels para obter as funções distribuição de probabilidade dos espaços de fase. Neste caso, destacamos dois pontos que diferem do MMC: as simulações locais iniciam-se no centro do kugel, figura 6, e foi utilizado um algoritmo de simulação detalhada para o transporte dos elétrons. Na figura 7 temos um exemplo do transporte pelo método MRMC, onde as setas indicam a direção de saída dos elétrons de cada kugel. Os resultados para a dose absorvida, calculados por este modelo, 
quando comparados aos de um algoritmo de história detalhada, são bons. No entanto, os tempos de simulação são aproximadamente o dobro dos outros programas de simulação por história condensada de elétrons.

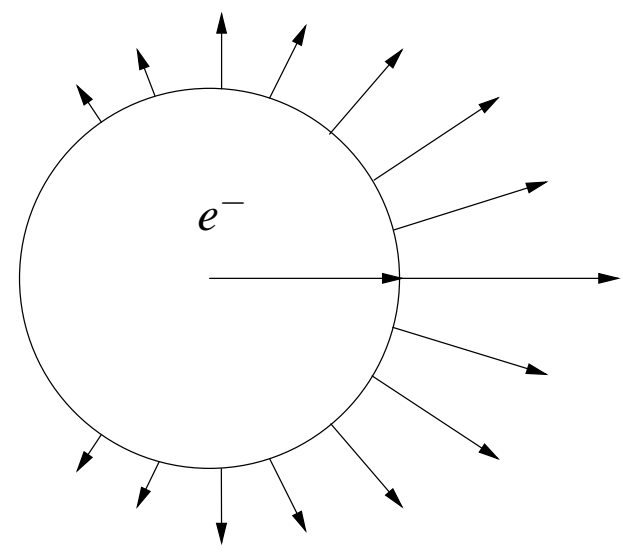

Figura 6: Geração das funções distribuição de probabilidades em um kugel do MRMC, indicando o elétron incidente e suas saídas.

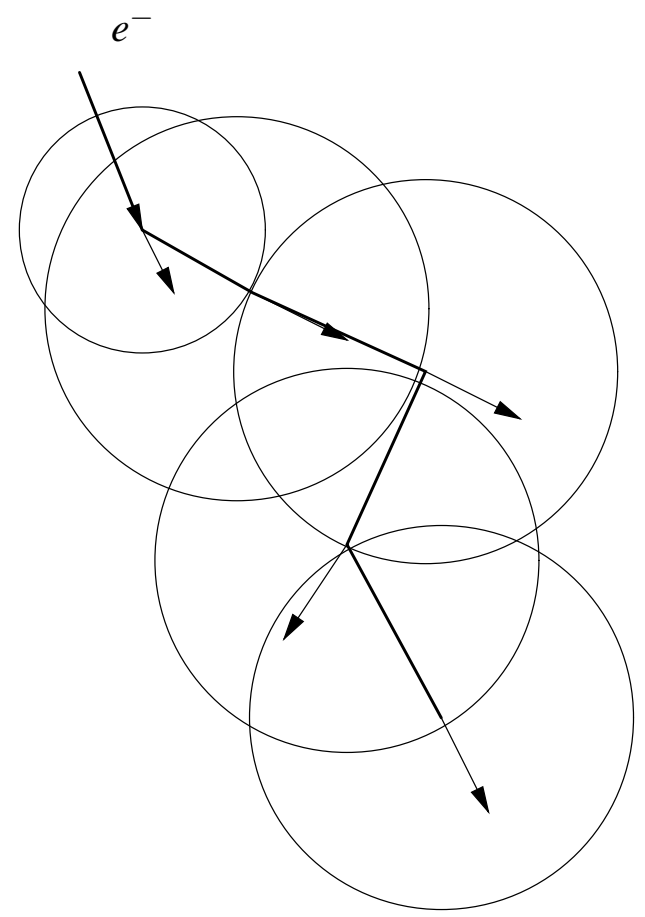

Figura 7: Exemplo de transporte de um feixe incidente de elétrons por kugels pelo método MRMC. 


\section{Geração da base de dados de kugels}

Neste trabalho geramos uma base de dados para cada tipo de tecido ou material testado. Os materiais usados foram: água, tecido mole e osso compacto, cujas composições atômicas estão no anexo A.

Cada base de dados é composta por um conjunto de kugels de vários diâmetros e diversas energias. Um kugel é definido em uma única energia e com um único raio, sendo composto por um conjunto de histogramas das funções distribuição de probabilidade para a posição, direção e a energia das partículas que deixam o kugel.

Todas as simulações da base de dados usam $5 \times 10^{5}$ histórias para cada kugel. No apêndice A temos as funções distribuição de probabilidade de um kugel de água com 0,25 mm de raio e $1,33 \mathrm{MeV}$ de energia incidente.

\subsection{A escala de energia e os raios dos kugels}

A escolha de um intervalo logarítmico entre as energias da base de dados permite um espaçamento maior nas energias altas enquanto mantém um espaçamento menor nas mais baixas. Adotamos a razão entre energias consecutivas sugerida por Svatos $(17),\left(E_{n}-E_{n-1}\right) / E_{n} \simeq 0.25$, no entanto os valores e a faixa de energia implementados neste trabalho são diferentes daquele implementado por Svatos. As energias aqui dotadas e sua posição na base de dados são mostradas no gráfico da figura 8, sendo o limite inferior de 178,00 keV e superior de 31,63 MeV. 
Escala de energia dos kugels e a energia inicial usada nos testes

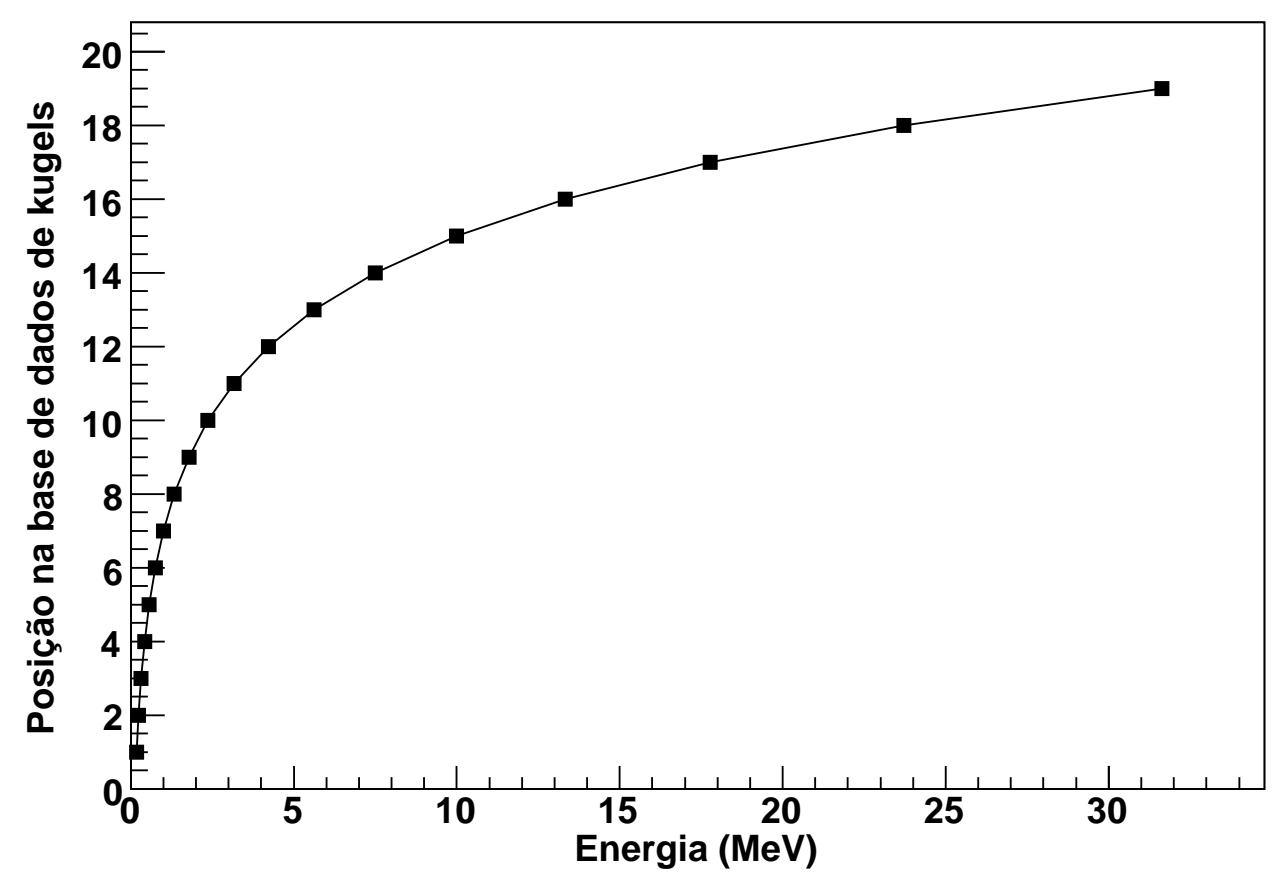

Figura 8: Energias adotadas para as simulações dos kugels.

Os raios escolhidos para compor a base de dados de kugels foram: 0,025;0,050;0,100; 0,$250 ; 0,500$ e $1,000 \mathrm{~cm}$.

\subsection{O cálculo local}

A base de dados obtida por Svatos (17) foi gerada pelo programa chamado CREEP (31). Este programa faz a simulação detalhada do transporte de elétrons, porém não faz o transporte e interação dos fótons. O trabalho desenvolvido por Neuenschwander e colaboradores $(14,15)$ mostra que é possível o uso de códigos de história condensada de elétrons para a geração dos kugels. Na falta de um programa de simulação detalhada de elétrons adotaremos o Geant4, que faz o transporte dos elétrons usando história condensada (10).

Quando utilizamos um código de história condensada de elétrons para a simulação de um kugel encontramos certas limitações a serem observadas, a principal delas é a menor dimensão geométrica que o código garante o resultado sem desvios sistemáticos. A limitação da espessura 
dos materiais no Geant4 está no algoritmo de MSC que, de acordo com Urbán (27, 32), é de um milésimo do comprimento de radiação do material. Para a água em sua densidade padrão, o limite de espessura dado pelo modelo MSC implementado no Geant4 é de aproximadamente $360 \mu \mathrm{m}$, e para o osso compacto de cerca de $165 \mu \mathrm{m}$, conforme dados disponíveis no anexo A. No entanto, com a finalidade de uniformizar a base de dados, utilizamos como menor raio $250 \mu \mathrm{m}$, tanto para a água quanto para o tecido mole e o osso compacto. Os parâmetros usados nas simulações dos kugels estão no apêndice C.

\subsection{A estrutura do kugel}

Todos os ítens descritos a seguir fazem parte dos histogramas de distribuição de probabilidade do kugel no cálculo local. Esses histogramas são normalizados pelo número de partículas incidentes, exceto quando indicado no texto.

\subsubsection{As bandas do kugel}

A região mais provável de saída dos elétrons é voltada para a direção inicial dos elétrons primários (região frontal). Este fato leva a uma distribuição com uma estatística melhor na região frontal em detrimento da região de retroespalhamento. Uma maneira de corrigir este problema é sub-dividir o kugel em bandas, onde cada banda deve possuir um conjunto completo de histogramas. Apenas os códigos RHMC e MRMC usam essa estrutura de bandas para agrupar as partículas de saída $(17,33)$. A estrutura de bandas usada neste trabalho segue a sugerida por Svatos (17), onde o kugel é sub-dividido em 4 bandas, figura 9, cuja projeção dessas bandas no eixo Z normalizada pelo raio do kugel $\left(z / R_{\text {kugel }}\right)$ corresponde a:

Banda 1: $1,00 \longrightarrow 0,98$;

Banda 2: $0,98 \longrightarrow 0,80$;

Banda 3: $0,80 \longrightarrow 0,40$;

Banda 4: $0,40 \longrightarrow-1,00$. 


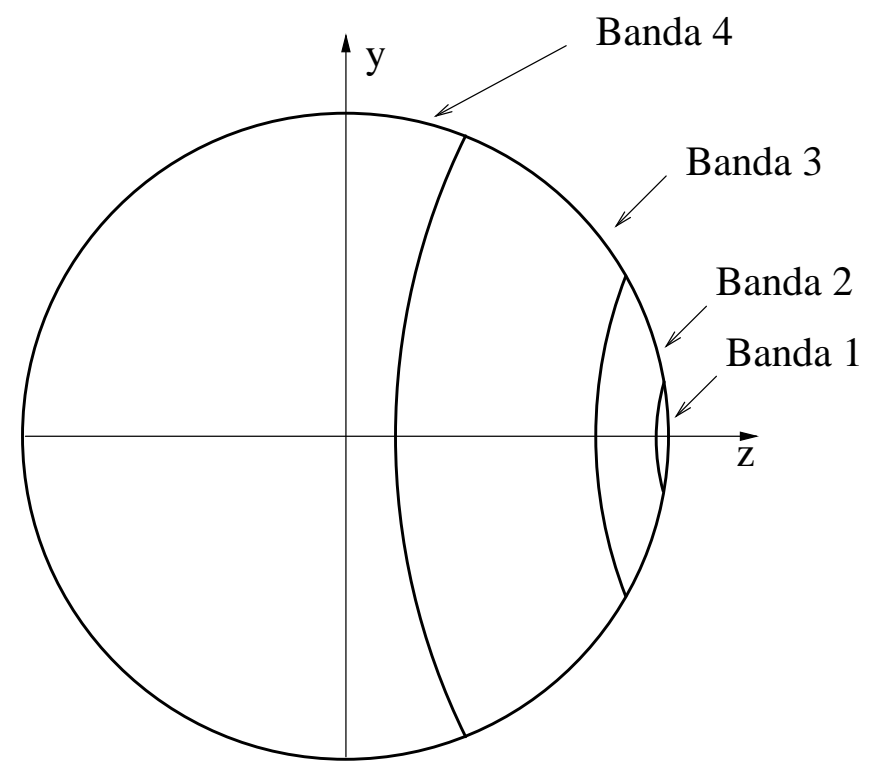

Figura 9: Esquema ilustrativo da estrutura de bandas do kugel.

Para os fótons usamos uma única banda com 100 canais que cobre todo o kugel, uma vez que a criação de fótons é relativamente pequena, a estatística dos histogramas será melhor quanto menor o número de canais usados.

A probabilidade de ocorrência de cada banda é dada pela integral dos histogramas do cosseno de posição, definida na seção 3.3.2. A fim de reduzir o tempo de computação do código global, essas probabilidades são armazenadas em um histograma apropriado. Para os elétrons primários, temos um histograma de probabilidades das bandas 0 a 4 , onde a banda 0 representa a probabilidade $P_{0}$ do elétron primário não sair do kugel, calculada a partir da equação 3.1, uma vez que esses elétrons, por uma questão de tempo computacional, não são registrados. Os elétrons secundários e os fótons não possuem a banda 0 , pois são contabilizados somente ao saírem do kugel.

$$
P_{0}=1-\sum_{i=1}^{4} P_{i}
$$

Os elétrons primários precisam de 5 histogramas por banda para serem corretamente descritos, são eles: um de posição, um de energia, dois de direção e um que descreve a probabilidade de ocorrência das bandas. Os elétrons secundários, além desses histogramas, necessitam de um 
outro histograma que indica o número médio de secundários saindo do kugel. Os fótons, que por serem descritos por uma única banda de saída, necessitam das mesmas informações que os elétrons secundários, exceto pelo histograma que descreve a probabilidade de ocorrência das bandas. Portanto, para a descrição completa de um kugel necessitamos de 5 ( $\times 4$ bandas) histogramas para os elétrons primários, $6(\times 4$ bandas $)$ para os elétrons secundários e $5(\times 1$ banda) para os fótons, totalizando 49 histogramas.

\subsubsection{O cosseno da posição de saída}

A posição de saída da partícula com referência ao eixo Z é normalizada pelo raio do kugel, $z / R_{\text {kugel }}$, e registrada em histogramas de 100 canais para cada banda. Portanto são 400 canais de registro de posição de saída em todo o kugel.

Não é necessário armazenar as outras variáveis de posição $x$ e $y$, devido a existência da simetria de rotação em torno do eixo Z, que será devidamente explorada pelo código de transporte global no capítulo 4.

\subsubsection{A energia de saída}

A energia de saída de cada partícula $E_{\text {saida }}$ é normalizada pela energia inicial do elétron primário e armazenada em histogramas de 100 canais para cada banda. Portanto estes histogramas são definidos no intervalo [0,1]. A única exceção a esta regra são os elétrons secundários, que, por definição, possuem até metade da energia do elétron primário, por isso usamos um histograma com apenas 50 canais para o intervalo $[0,0,5]$.

\subsubsection{A direção de saída das partículas}

A escolha de um sistema de referência para a descrição da direção de saída das partículas é de fundamental importância para a base de dados de kugels, porque uma escolha inadequada pode, por exemplo, exigir muita memória ou mesmo não descrever com precisão as direções de saída das partículas. O sistema de referência escolhido é o mesmo utilizado por Svatos (17). 


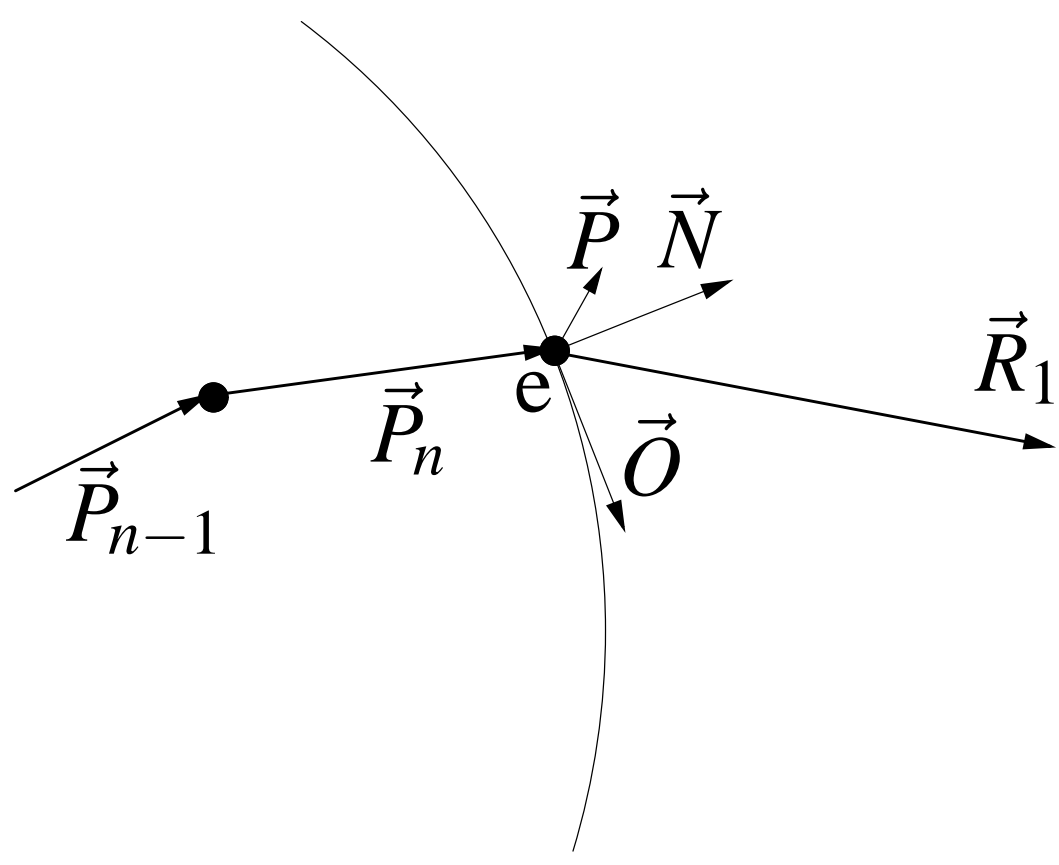

Figura 10: O vetor $\vec{R}_{1}$ de saída da partícula e os novos eixos de referência $(\vec{P}, \vec{N}, \vec{O})$.

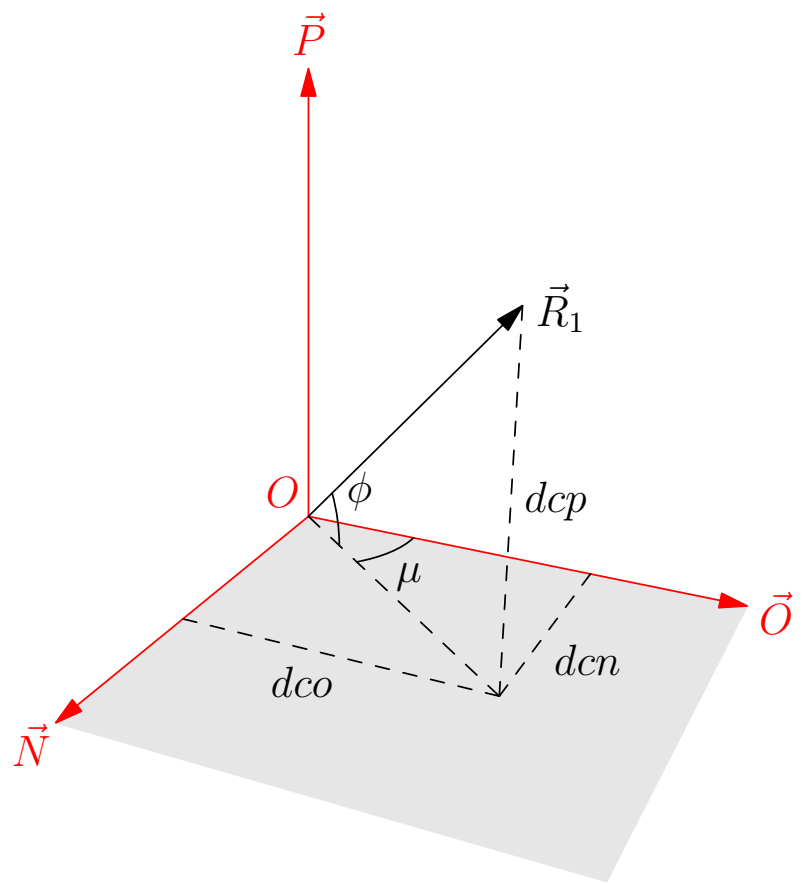

Figura 11: Diagrama do vetor $\vec{R}_{1}$ da direção de saída da partícula e sua decomposição em componentes $d c n, d c o$ e $d c p$.

Os eixos do novo sistema de referência são mostrados nas figuras 10 e 11 . O vetor $\vec{N}$ é unitário e normal à superfície da esfera na posição de saída da partícula, $\vec{O}$ é o vetor unitário 
perpendicular a $\vec{N}$ que intercepta o eixo Z, no referencial do kugel, em $z_{0}$; e $\vec{P}$ é dado pelo produto vetorial apresentado a seguir:

$$
\vec{P}=\vec{N} \times \vec{O}
$$

O vetor de direção $\vec{R}_{1}$ é então descrito nessa nova referência, com suas projeções dadas por:

$$
\begin{aligned}
d c n & =\vec{R}_{1} \cdot \vec{N} \\
d c o & =\vec{R}_{1} \cdot \vec{O} \\
d c p & =\vec{R}_{1} \cdot \vec{P}
\end{aligned}
$$

Sendo o vetor $\vec{R}_{1}$ unitário, $d c n^{2}+d c o^{2}+d c p^{2}=1$, apenas duas variáveis são independentes e precisam ser armazenadas para descrever o vetor $\vec{R}_{1}$ corretamente. No entanto, a amostragem do vetor de direção de saída pelo código global exigiria uma função de densidade de probabilidade condicional, isto é, temos uma probabilidade associada ao $d c n$ dada por $P[d c n]$ e uma probabilidade condicionada ao $d c o$ pelo resultado da amostragem de $d c n, P[d c o ; d c n]$. Tal fato leva a uma redução do desempenho do código de transporte global, bem como a um aumento considerável na memória utilizada, pois exigiria um histograma de probabilidade de $d c o$ para cada canal do histograma de $d c n$. A fim de evitar este problema recorremos às coordenadas esféricas, com as quais podemos descrever uma direção por meio dos ângulos azimutal $(\mu)$ e polar $(\phi)$, figura 11. Neste sistema de referências devemos apenas armazenar o cosseno da elevação do plano tangente ao kugel, $\cos \mu$, e um dos cossenos diretores que, no esquema mostrado pela figura 11, é dado por $\operatorname{sen} \phi=d c p$. A expressão para o $\cos \mu$ é dada por:

$$
\cos \mu=\frac{d c o}{\sqrt{d c o^{2}+d c n^{2}}}=\frac{d c o}{\sqrt{1-d c p^{2}}}
$$

Pela equação 3.6 temos a correlação entre $d c o$ e $d c p$ quando armazenamos o $\cos \mu$. 


\subsubsection{O número médio de elétrons secundários e fótons saindo do kugel}

Com o objetivo de saber o número de elétrons secundários e o número de fótons produzidos dentro do kugel, armazenamos o número médio dessas partículas em um histograma como função da energia de saída do elétron primário. Note que é importante saber essa quantidade mesmo quando o elétron primário não deixa o kugel (banda 0).

\subsection{O formato da base de dados kugel}

A base de dados kugel é armazenada no formato de arquivo ROOT com compactação nível 1, que representa a melhor relação desempenho/espaço em disco (34). Este formato permite que sejam armazenados objetos instanciados ${ }^{1}$ por classes pertencentes ao ROOT ou classes derivadas criadas pelo usuário. Este trabalho usa várias classes do ROOT, tanto no código de simulação local quanto no global. Por este motivo escolhemos o formato ROOT para o armazenamento da base de dados de kugel.

Em cada arquivo temos uma descrição completa de um determinado tipo de material ou tecido contendo os histogramas descritos neste capítulo, bem como as informações adicionais da escala de energia, dos raios dos kugels e tabelas de Stopping Power total.

O tamanho final dos arquivos da base de dados de cada material ocupa menos que $3 \mathrm{MB}$ em disco, e quando descompactado e carregado na menória, menos que $15 \mathrm{MB}$.

\footnotetext{
${ }^{1}$ Instanciar: Ato de criar objetos pertencentes a determinadas classes (orientação a objeto). Uma classe está para um tipo de dado assim como a variável está para a classe.
} 


\section{O Método de transporte MRMC}

O transporte MRMC consiste em utilizar o maior passo possível para os elétrons. O passo neste caso é o kugel, mais precisamente o passo seu raio. É através do kugel que o sistema amostra a posição, direção e energia de saída do elétron primário e das partículas secundárias, caso existam. Esta etapa é também chamada de transporte global, em complementação à simulação da base de dados chamada de transporte local.

A sequiência compreendida pelo método de transporte MRMC é a seguinte:

1. Encontrar o kugel mais adequado (energia e raio);

2. Amostrar a saída do elétron primário (posição e momento);

3. Amostrar o número e o tipo de partículas secundárias e seus respectivos estados de posição e momento.

Na figura 12 temos uma ilustração do transporte pelo método MRMC implementado neste trabalho. No topo desta figura observamos o elétron incidente que é transportado usando o maior kugel possível, desde que o mesmo não cruze nenhuma interface entre meios materiais. Quando o elétron encontra-se próximo a uma interface entre materiais diferentes e o sistema não encontra um kugel cujo raio não a ultrapasse, o elétron passa a ser transportado em linha reta, e a perda de energia é computada pelo Stopping Power total. Para este trabalho não foram implementadas as correções devido ao MSC.

A figura 12 também ilustra a produção de secundários. Os elétrons secundários são transportados da mesma forma que os primários. A simulação da interação de fótons com o meio 
material não foi implementada, por esse motivo os fótons são transportados em linha reta até saírem da geometria.

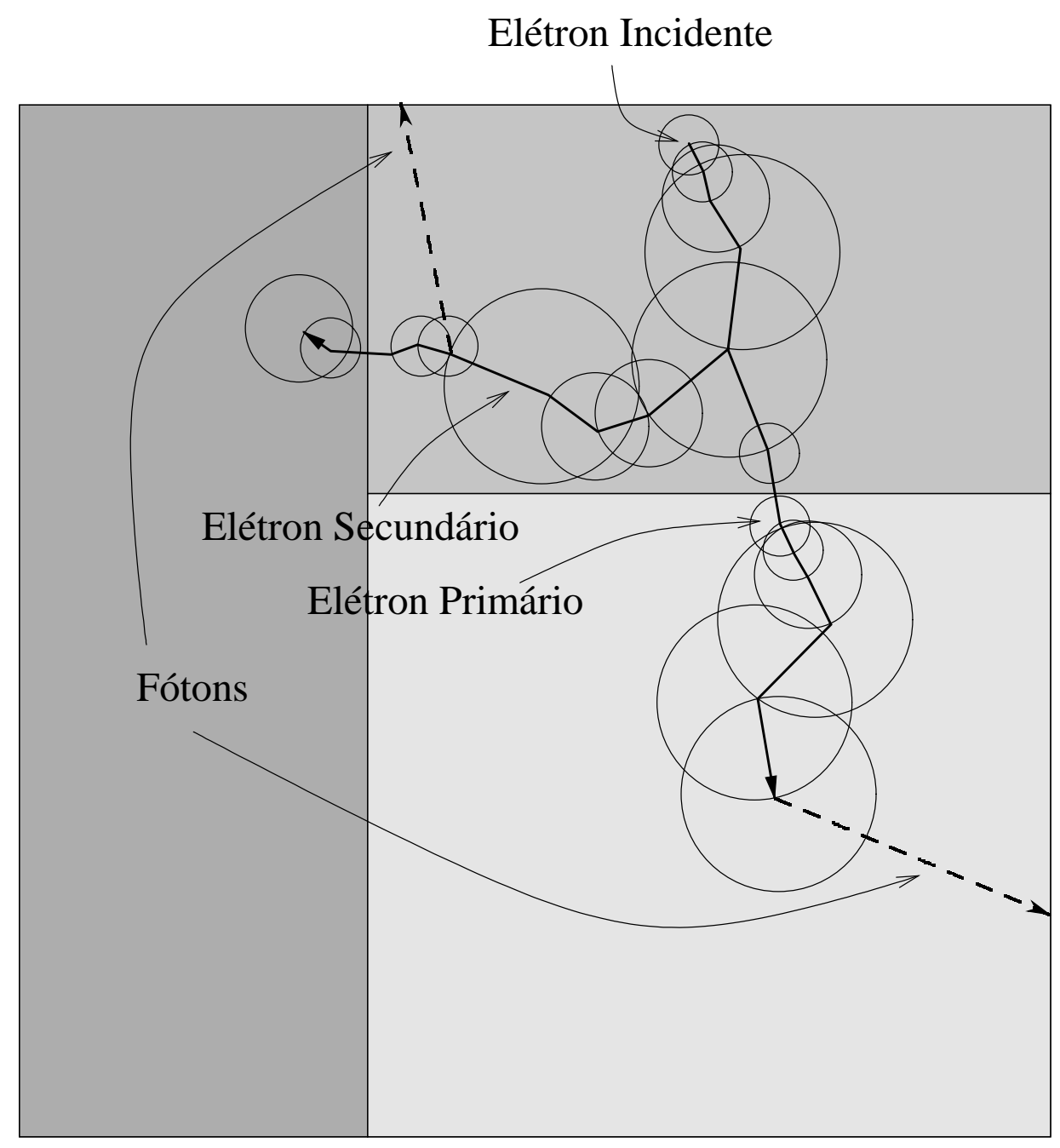

Figura 12: O método de transporte global do MRMC.

\subsection{A implementação do sistema de transporte global}

O método de transporte global MRMC compreende o transporte do elétron primário por meio de kugels, bem como a geração e transporte dos elétrons secundários.

Para mostrar como funciona o sistema implementado do transporte de partículas usamos a linguagem chamada Unified Modeling Language (UML). Nesta seção usamos o diagrama de atividade para mostrar a lógica de ações no transporte das partículas. No apêndice D temos os 
diagramas das principais classes do MRMC, mostrando as inter-relações das mesmas, também descritos em UML.

No diagrama de atividade mostrado na figura 13 temos a representação da seqüência lógica de um evento. O evento inicia-se com a inserção na pilha de partículas da partícula primária, que no caso do MRMC implementado é sempre um elétron. A seguir o sistema retira a partícula da pilha e atualiza a posição da mesma na geometria. Se esta partícula for um fóton, ela será transportada sem interação até sair da geometria. Caso seja um elétron, ela entrará no sistema de simulação MRMC. Se esta partícula possuir energia acima do cutoff de energia e estiver dentro da geometria, o sistema passa para a seção de transporte de elétrons. Caso exista algum kugel disponível o transporte será feito pelo método MRMC usando o kugel selecionado. Caso não exista nenhum kugel com raio menor ou igual a distância entre a partícula e a interface mais próxima, o transporte será feito em linha reta até a interface corrigindo a energia pela perda contínua de energia. A disponibilidade de kugels é determinada pela energia do elétron em questão, que deve estar entre as existentes na base de dados, e também pelos raios dos kugels, pois um kugel nunca deve transpor uma interface. Quando o transporte é feito usando os kugels, existe a possibilidade da geração de secundários, que tanto podem ser fótons ou elétrons. Se forem geradas partículas secundárias, estas serão imediatamente inseridas na pilha de partículas. Os elétrons são sempre transportados até saírem da geometria de interação, definida com o auxílio do pacote de geometria do ROOT, ou até sua energia ficar abaixo do limite inferior de energia (cutoff) definido na simulação, quando então tal partícula é rotulada como "MORTA".

Ao término do transporte do elétron primário, o sistema retira a próxima partícula da pilha e repete o ciclo apresentado no diagrama 13.

O gerador de números aleatórios escolhido foi o Mersenne Twister, que possui uma periodicidade de $2^{19937}-1$ e produz distribuições equiprováveis em até 623 dimensões (35). A implementação usada deste gerador neste trabalho é a que está na biblioteca ROOT (34). 


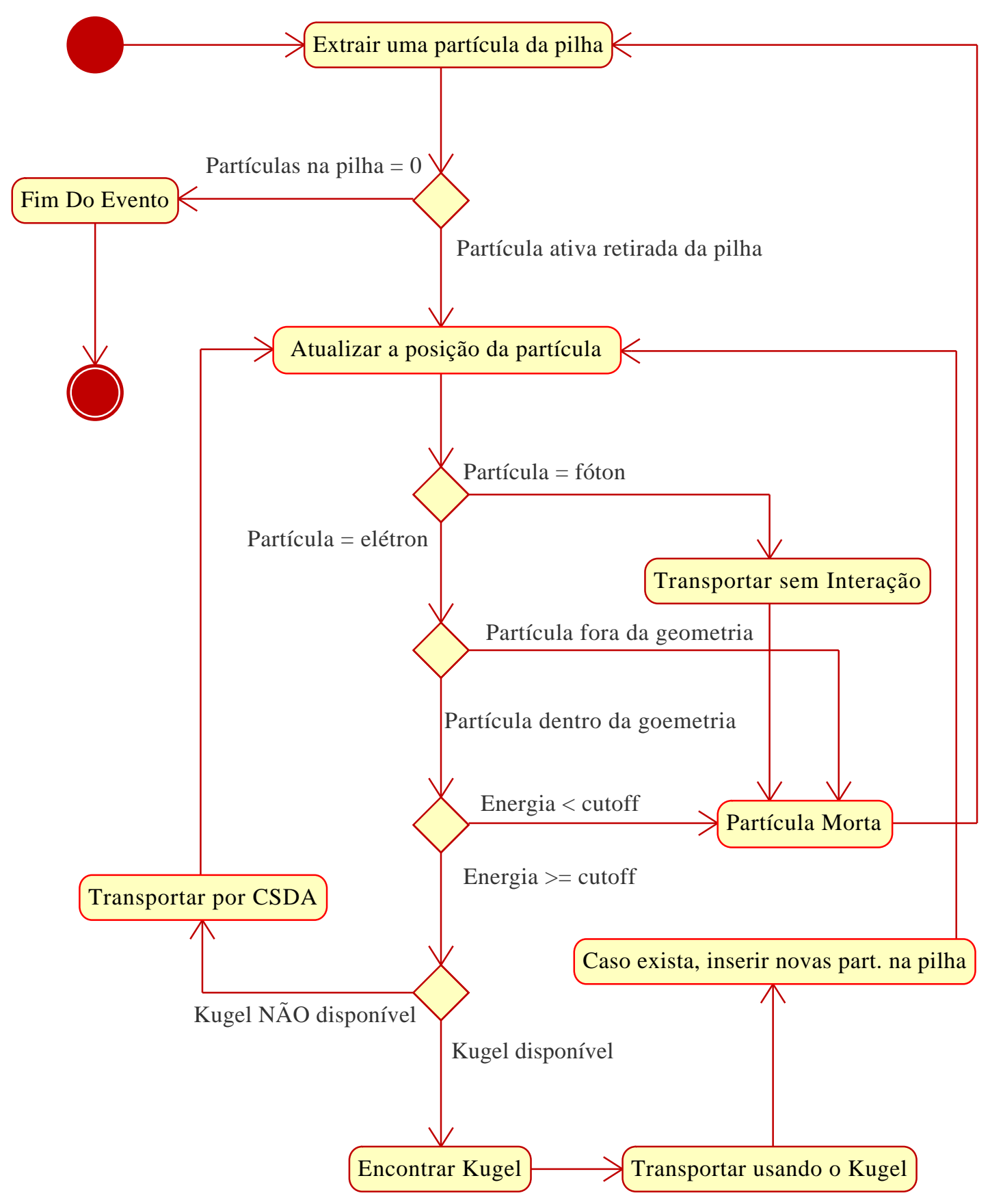

Figura 13: Diagrama UML de atividade do sistema de transporte MRMC. 
A descrição da geometria e o sistema de transporte foram implementados usando o pacote de geometria da biblioteca ROOT. Esta biblioteca possui classes base para a construção de programas de transporte de partículas.

Nas seções seguintes são descritas em detalhes as etapas do transporte global MRMC implementado.

\subsubsection{A escolha do kugel}

Para a determinação do kugel são necessários os seguintes passos:

1. determinação da energia a ser usada;

2. escolha do raio do kugel na energia selecionada.

Esta ordem se deve ao fato de que não encontramos todos os raios listados na seção $3.1 \mathrm{em}$ todas as energias de kugel. Em algumas combinações raio-energia a probabilidade de saída do elétron primário (o de maior energia) é muito pequena, elevando a incerteza estatística. Além disso, os tempos de simulação nos casos em que os primários têm pouca chance de saírem do kugel também são consideravelmente maiores. Por todos esses motivos, as energias mais baixas podem não ter, em sua base de dados, os raios maiores, porém sempre terão pelo menos o menor raio.

A escolha da energia segue uma interpolação linear-logarítmica estocástica dada pela equação 4.1, conforme apresentada por Svatos (17).

$$
\chi>\frac{\log E_{+}-\log E}{\log E_{+}-\log E_{-}}
$$

Sendo $E$ a energia do elétron a ser transportado, e $E_{+}$e $E_{-}$as energias existentes na base de dados kugel imediatamente superior e inferior a $E$, respectivamente. $\chi$ é um número aleatório contido no intervalo [0,1[. Caso o número aleatório escolhido satisfaça a expressão 4.1, a energia escolhida será $E_{+}$, caso contrário será $E_{-}$. Por este motivo, para que o transporte do 
elétron seja feito usando o método MRMC, deve sempre haver pelo menos um kugel de energia superior e outro de energia inferior à energia do elétron a ser transportado. As energias da base de dados são mostradas na figura 8 da seção 3.1. O caso especial em que a energia $E$ coincide exatamente com alguma energia da base de dados é tratada de forma trivial, embora a probabilidade de ocorrência seja muito pequena.

Após a escolha da energia o sistema encontra o raio do kugel, que é sempre o maior possível desde que não ultrapasse nenhuma interface entre materiais.

\subsubsection{Amostrando as saídas do kugel}

Esta é a parte mais importante do transporte MRMC, a amostragem do estado final do transporte do elétron e de seus secundários. A amostragem se dá através dos histogramas armazenados no kugel, e logo em seguida ocorre a mudança do referencial local para o global das partículas amostradas. Os histogramas de um kugel são descritos no capítulo 3 e um exemplo desses histogramas encontra-se no apêndice A. O procedimento para a amostragem do estado final do kugel é mostrado na figura 14.

A determinação do estado final do kugel começa com a amostragem da banda de saída do elétron primário, a seguir temos a amostragem da posição, direção e energia de saída do mesmo elétron primário. As posições de saída amostradas pelo kugel estão sempre no sistema de referência centrado no kugel (local), por isso todas as posições amostradas são transladadas para o referencial global usado pelo pacote que descreve a geometria do objeto simulador. Após amostrado o estado final do elétron primário o sistema passa para a determinação da quantidade de secundários. Primeiramente, é amostrado o número de elétrons secundários. A seqüência de amostragem do estado final dos elétrons secundários segue a mesma linha que para o primário: amostrar a banda de saída, em seguida a posição, direção e energia. Além disso, é necessário mais um passo, adicionar os secundários à pilha de partículas, para que eles sejam transportados posteriormente. A seqüência de amostragem do número de fótons e seu estado final segue a mesma seqüência apresentada para os elétrons secundários, exceto pelo fato de que não é 


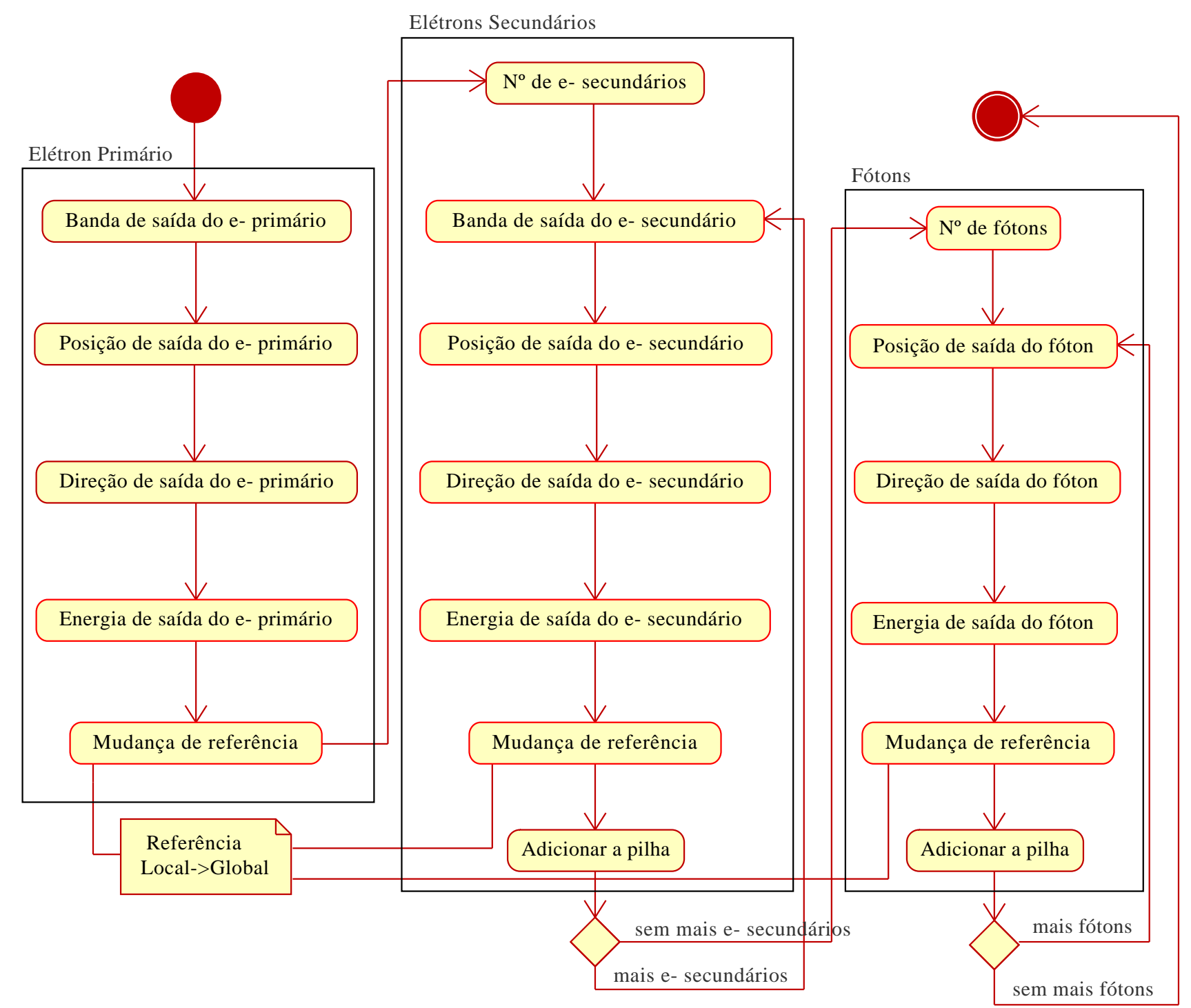

Figura 14: Diagrama de atividade da determinação do estado final do kugel. 
amostrada a banda de saída, pois os fótons são registrados em apenas uma única banda que cobre todo o kugel.

\subsubsection{A banda de saída do elétron primário}

A banda de saída é amostrada por meio de um histograma da probabilidades de saída do elétron primário pelas bandas 0 a 4 . A banda $i$ escolhida é dada pela expressão 4.2.

$$
\sum_{i=0}^{4} P_{i}>\chi
$$

Onde $P_{i}$ é a probabilidade cumulativa da banda $i$ e $\chi$ é um número aleatório contido no intervalo $[0,1[$.

\subsubsection{A posição de saída do elétron primário}

A componente $z$ da posição de saída é amostrada por meio dos histogramas mostrados nas figuras 66 a 69 do apêndice A, conforme a banda previamente selecionada. As componentes $x$ e $y$ são determinadas pelas equações 4.3 e 4.4 .

$$
\begin{aligned}
& x=\sqrt{R_{\text {kugel }}^{2}-z^{2}} \operatorname{sen} \theta \\
& y=\sqrt{R_{\text {kugel }}^{2}-z^{2}} \cos \theta
\end{aligned}
$$

Sendo o ângulo $\theta$ amostrado por meio de uma distribuição de probabilidade uniforme contida na intervalo $\left[0,2 \pi\left[, R_{\text {kugel }}\right.\right.$ é o raio do kugel e $z$ é o resultado da amostragem da posição de saída do elétron primário.

Após determinado o vetor de posição de saída do elétron primário, o sistema realiza a mudança de referencial do kugel (local) para o referencial da geometria (global). 


\subsubsection{A direção de saída do elétron primário}

A determinação da direção de saída é um procedimento mais complexo que a determinação da posição. Para obtermos a direção de saída, primeiro são amostrados os valores de $d c p$ e cos $\mu$ armazenados no kugel. As outras componentes são obtidas por meio das equações 4.5 e 4.6.

$$
\begin{aligned}
d c o & =\cos \mu \cdot \sqrt{1-d c p^{2}} \\
d c n & =|d c o| \cdot \sqrt{\left(1 / \cos ^{2} \mu\right)-1}
\end{aligned}
$$

Onde $d c n$ é a projeção do vetor de direção do elétron no eixo normal $\vec{N}$, figura 11 , e é sempre positiva pois o elétron está saindo do kugel.

Com as equações 4.5 e 4.6, $d c p$ e $\cos \mu$ amostrados, obtemos o vetor de direção $\vec{R}_{1}$ de saída do elétron no referencial normal à superfície do kugel, figura 3.2. No entanto, ainda não temos a orientação desta referência mas apenas o seu eixo normal $\vec{N}$. A determinação dos eixos da referência normal segue a mesma descrição apresentada na seção 3.3.4. Na seqüência, o vetor de direção passa a ser descrito no sistema de referência do kugel e, posteriormente, convertido para o sistema de referência da geometria.

\subsubsection{A energia de saída do elétron primário}

A energia de saída do elétron primário é determinada por uma amostragem do histograma de energia da banda selecionada previamente. A energia de saída $E_{\text {saida }}$ do elétron primário é dada pela equação 4.7 , onde $\varepsilon_{i}$ é a energia amostrada do histograma da banda $i$ e $E_{\text {inicial }}$ é a energia inicial do elétron que está sendo transportado na simulação global.

$$
E_{\text {saida }}=\varepsilon_{i} \cdot E_{\text {inicial }}
$$




\subsubsection{As partículas secundárias}

As partículas secundárias são amostradas por meio da distribuição de Poisson usando-se a média do número de elétrons secundários/fótons saindo do kugel. A distribuição de Poisson é utilizada por Svatos (17), que é uma boa aproximação se considerarmos que o número de partículas secundárias que emergem do kugel é um evento raro (18).

O número médio de partículas secundárias (fótons e elétrons) é armazenado em histogramas como função da energia e da banda de saída do elétron primário. Por este motivo, a amostragem das partículas secundárias depende do resultado da banda de saída do elétron primário e de sua respectiva energia. Nas figuras 82 e 83 do apêndice $A$, temos os histogramas referentes às bandas 1 a 4 do número médio dos elétrons secundários saindo do kugel, e nas figuras 84 e 85 do mesmo apêndice os histogramas do número médio de fótons saindo do kugel para as bandas 1 a 4.

Após amostrado o número de secundários saindo do kugel, o sistema amostra a banda da saída da partícula, equação 4.2 com o índice $i$ do somatório entre 1 e 4 . Para os fótons, que são descritos por uma única banda, esse passo não é executado. Após determinada a banda de saída, o sistema determina a posição da partícula na superfície do kugel, sua direção e respectiva energia de saída. Para cada uma dessas variáveis temos um histograma específico, pois estamos tratando de partículas secundárias, porém a metodologia de amostragem é exatamente a mesma apresentada para o elétron primário. Este ciclo é repetido para cada uma das partículas secundárias geradas.

\subsection{O transporte eletrônico através de interfaces}

Quando o sistema de busca de energias não encontra um kugel disponível, devido a distância entre a partícula atualmente transportada e a interface mais próxima ser menor que o menor raio existente na base de dados, ou porque a energia da partícula é menor que as energias 
simuladas para a base de dados, o transporte eletrônico deve ser feito por outros métodos mais convenientes.

Considerando que as distâncias não serão maiores que $250 \mu \mathrm{m}$, podemos aproximar o transporte para uma linha reta e corrigir a energia cinética da partícula por meio da perda contínua de energia, usando uma tabela de Stopping Power total. A tabela utilizada nesta implementação foi a disponibilizada na internet pelo National Institute of Standards and Technology (NIST) (36). Conforme mostrado no capítulo 6, esta pode ser considerada uma boa aproximação para energias acima de $5 \mathrm{MeV}$.

Ao atravessar uma interface, o elétron passa pelo processo descrito anteriormente duas vezes, uma quando se aproxima da interface pela lado interno, e outra logo após atravessar a interface, até que haja uma distância suficiente para que seja encontrado um kugel sem que o mesmo cruze uma interface. 


\section{$5 \quad$ Metodologia dos testes do MRMC e da análise de seus resultados}

Neste capítulo apresentamos os tipos de objetos simuladores utilizados nos testes de comparação entre o MRMC e o Geant4, bem como a metodologia das análises usada neste trabalho. Consideramos que o Geant4 já está validado para o transporte de elétrons $(37,38)$, por este motivo não serão feitas comparações do MRMC com dados experimentais.

\subsection{Os tipos de objetos simuladores testados}

Foram testados objetos simuladores homogêneos dos três tipos de materiais que compõe a base de dados, e três modelos de objetos simuladores heterogêneos.

Todas as geometrias utilizadas nos testes são cilíndricas. A geometria cilíndrica foi escolhida para facilitar a análise e discussão dos resultados. O pacote de geometria do ROOT, empregado para a descrição dos objetos simuladores e como ferramenta auxiliar no transporte das partículas, não é limitado apenas à cilindros ou outras geometrias simples (34), no entanto não é o objetivo deste trabalho promover um extenso estudo dos tipos de geometrias e das capacidades deste pacote.

\subsubsection{O objeto simulador homogêneo}

As dimensões dos objetos simuladores cilíndricos homogêneos de água e tecido mole, utilizados neste trabalho, estão na tabela 1. Para o osso compacto as dimensões estão na tabela 2. Essas dimensões foram escolhidas no intuito de promover uma quantidade razoável de intera- 
ções dos elétrons com o meio material e, concomitantemente, conseguir uma boa estatística de saída dos espectros frontais e laterais.

Tabela 1: Dimensões dos objetos simuladores homogêneos para água e tecido mole testados

\begin{tabular}{|c|c|c|}
\hline Energias (MeV) & Comprimento $(\mathrm{cm})$ & Raio $(\mathrm{cm})$ \\
\hline \hline 25 & 3,00 & 0,70 \\
\hline 10 & 2,00 & 0,50 \\
\hline 5 & 1,00 & 0,25 \\
\hline 1 & 0,30 & 0,10 \\
\hline
\end{tabular}

Tabela 2: Dimensões dos objetos simuladores homogêneos para o osso compacto

\begin{tabular}{|c|c|c|}
\hline Energias (MeV) & Comprimento $(\mathrm{cm})$ & Raio $(\mathrm{cm})$ \\
\hline \hline 25 & 3,00 & 0,70 \\
\hline 10 & 2,00 & 0,50 \\
\hline 5 & 1,00 & 0,25 \\
\hline 1 & 0,10 & 0,10 \\
\hline
\end{tabular}

\subsubsection{O objeto simulador heterogêneo}

A simulação da interação dos elétrons com um objeto simulador heterogêneo tem por objetivo avaliar o desempenho do MRMC em um sistema onde o algoritmo tem de lidar com interfaces entre materiais de diferentes densidades e seções de choque, além das interfaces de saída do objeto simulador.

Basicamente os objetos simuladores heterogêneos são constituídos por um cilindro externo cujo material equivalente é água, e outro interno cujo material equivalente é osso compacto. Os desenhos desses objetos simuladores encontram-se nas figuras 15 a 17, e suas dimensões encontram-se nas tabelas 3 e 4. 


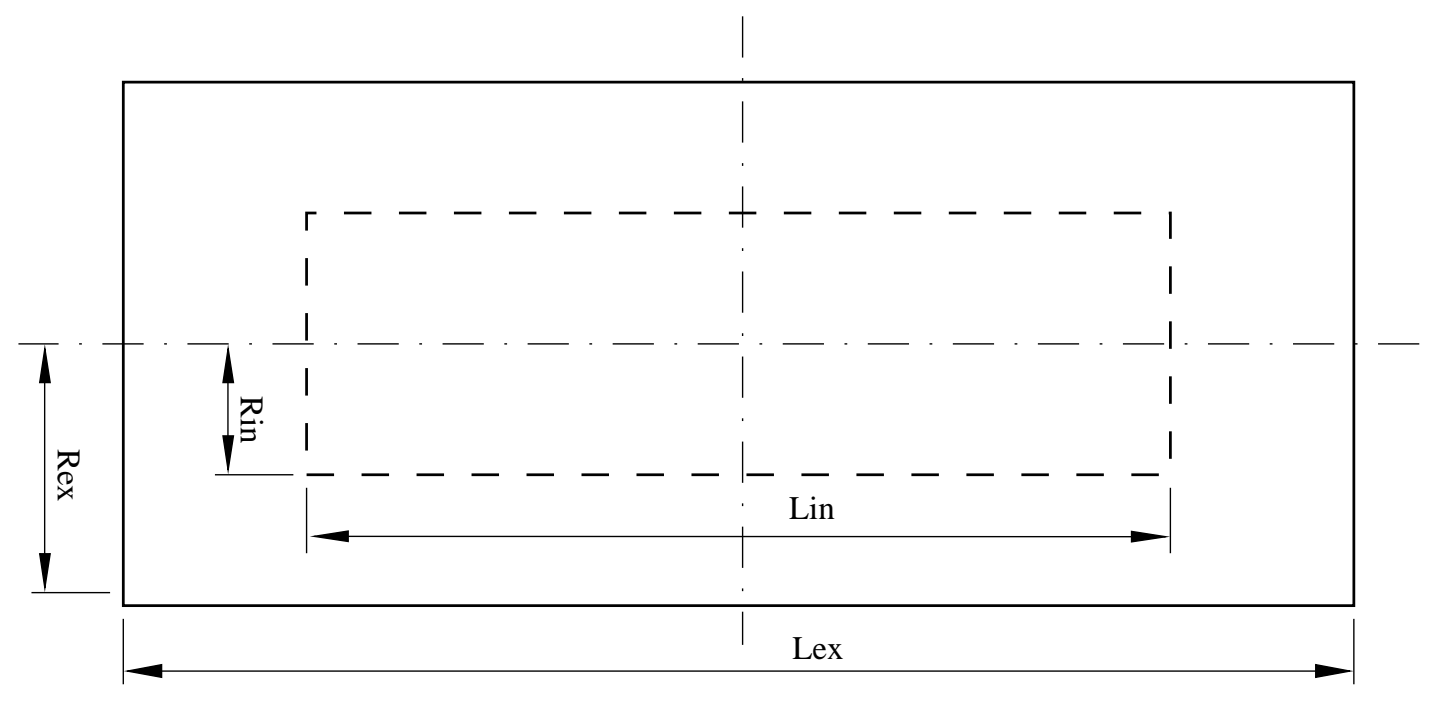

Figura 15: Vista lateral do objeto simulador A.

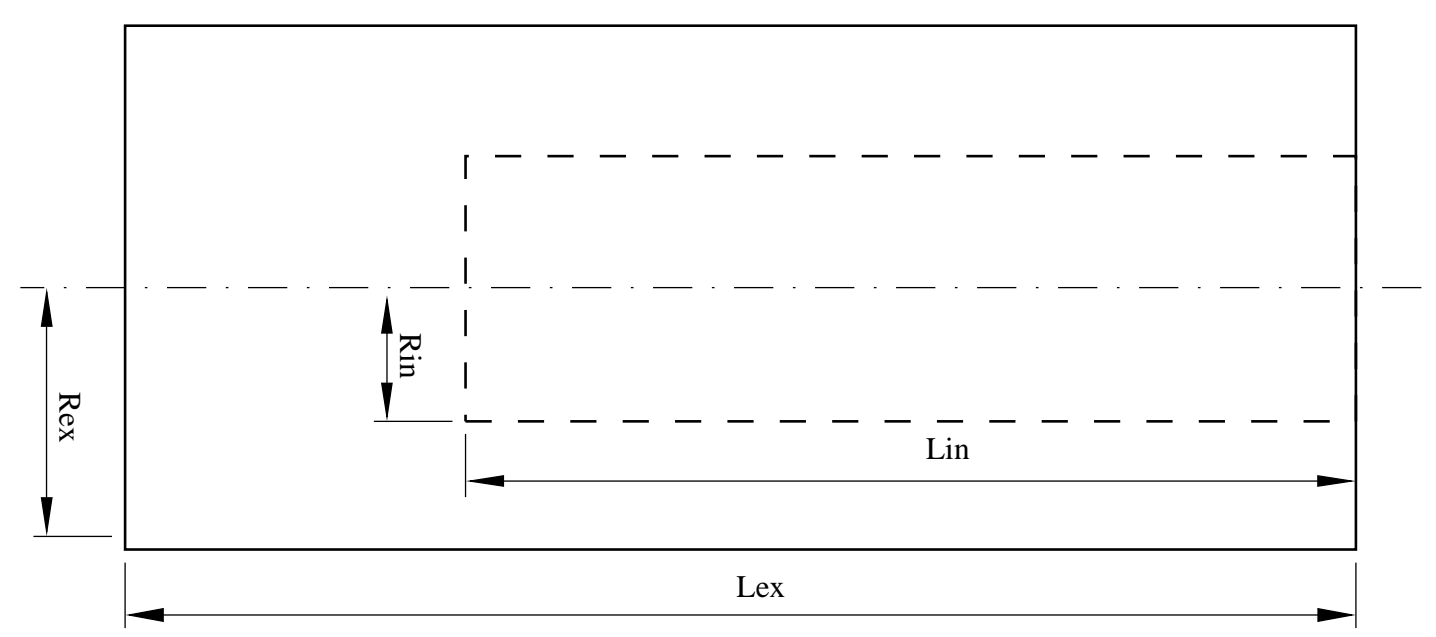

Figura 16: Vista lateral do objeto simulador B. 

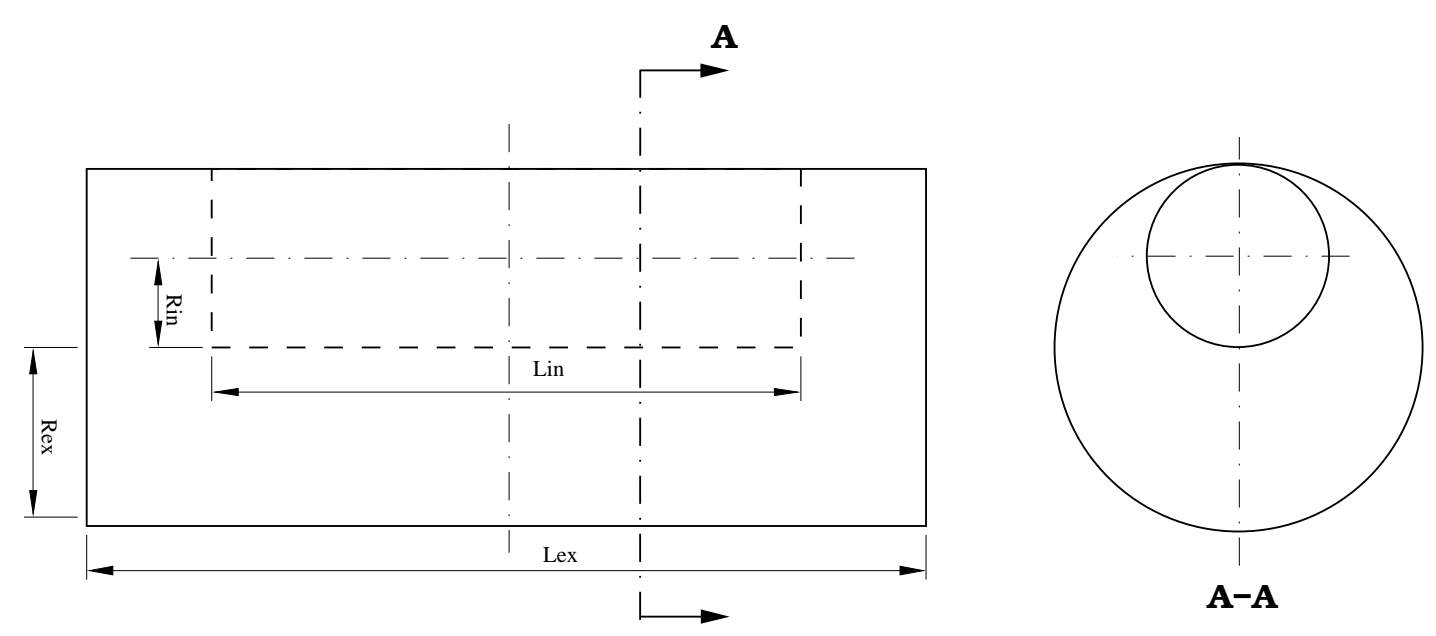

$\mathbf{A}$

$\mathbf{A}-\mathbf{A}$

Figura 17: Vista lateral e detalhe do corte transversal do objeto simulador C.

Tabela 3: Dimensões dos objetos simuladores A e B

\begin{tabular}{|c|c|c|c|c|}
\hline Energias $(\mathrm{MeV})$ & Lex $(\mathrm{cm})$ & Rex $(\mathrm{cm})$ & Lin $(\mathrm{cm})$ & Rin $(\mathrm{cm})$ \\
\hline \hline 25 & 3,0 & 0,7 & 1,8 & 0,49 \\
\hline 10 & 2,0 & 0,5 & 1,4 & 0,35 \\
\hline 5 & 1,0 & 0,25 & 0,6 & 0,175 \\
\hline 1 & 0,3 & 0,1 & 0,18 & 0,07 \\
\hline
\end{tabular}

Tabela 4: Dimensões do objeto simulador C

\begin{tabular}{|c|c|c|c|c|}
\hline Energias $(\mathrm{MeV})$ & Lex $(\mathrm{cm})$ & Rex $(\mathrm{cm})$ & Lin $(\mathrm{cm})$ & Rin $(\mathrm{cm})$ \\
\hline \hline 25 & 3,0 & 0,7 & 1,8 & 0,35 \\
\hline 10 & 2,0 & 0,5 & 1,4 & 0,25 \\
\hline 5 & 1,0 & 0,25 & 0,6 & 0,125 \\
\hline 1 & 0,3 & 0,1 & 0,18 & 0,05 \\
\hline
\end{tabular}

O objeto simulador A apresenta uma simetria em torno do eixo do cilindro externo e outra perpendicular, tendo por objetivo avaliar o comportamento do MRMC quando a heterogeneidade está inserida no centro do objeto simulador. O objeto simulador B possui apenas simetria no eixo do cilindro externo e seu o objetivo é testar o MRMC na situação em que as partículas podem deixar o objeto simulador tanto pela interface com o osso compacto quanto pela interface da água na região frontal. No objeto simulador C o eixo do cilindro de osso compacto 
fica fora do eixo do cilindro de água, porém preserva-se a simetria perpendicular ao eixo dos cilindros, e o objetivo desta configuração é testar o comportamento do MRMC no transporte de elétrons na presença de uma interface paralela ao sentido do transporte do feixe primário. Esta é uma geometria crítica para este tipo de implementação.

\subsection{Metodologia das simulações}

Os testes consistem em simular o transporte de um feixe estreito de elétrons através de um meio material. O posicionamento do feixe incidente é perpendicular a uma das faces do cilindro e coincidente com o eixo de simetria do cilindro externo, conforme mostra a figura 18.

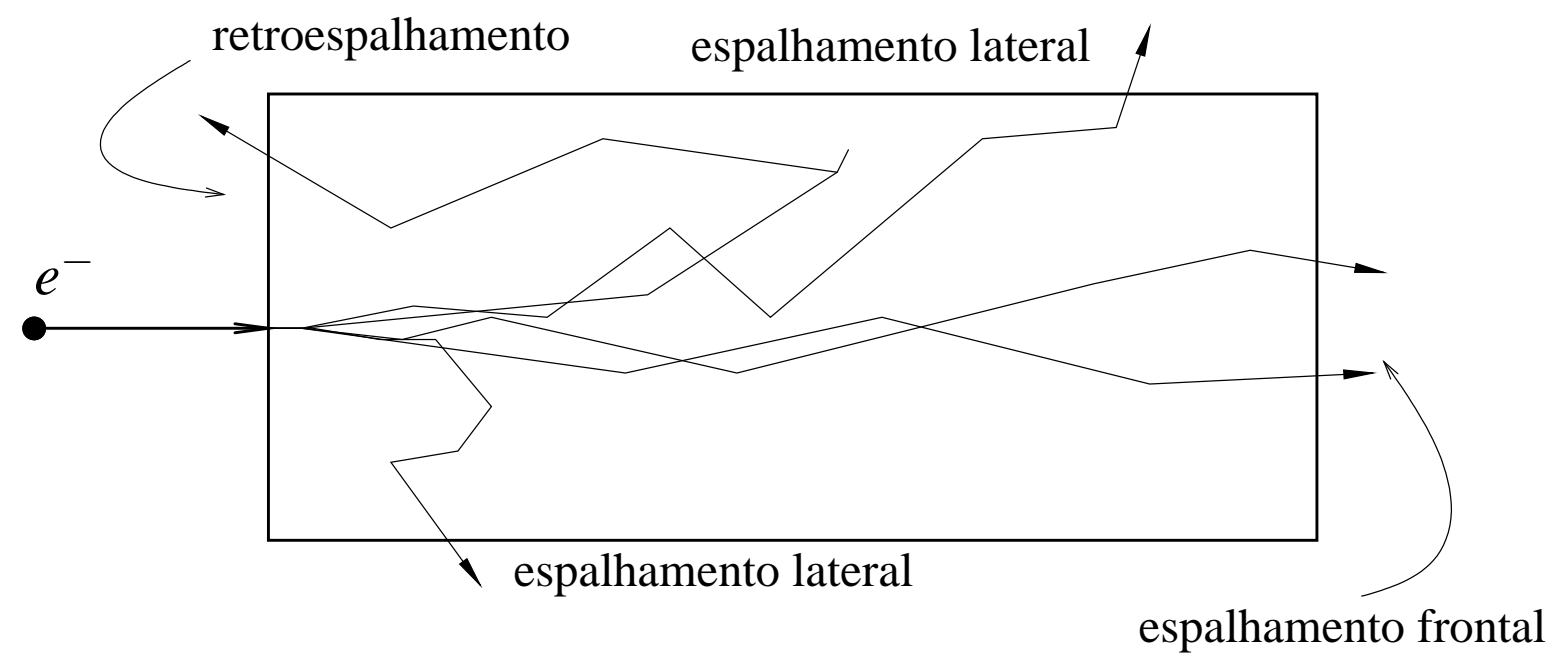

Figura 18: Ilustração do objeto simulador homogêneo com o feixe incidente externo de elétrons e as regiões de saída.

Embora o pacote de geometria do ROOT seja capaz de começar a transportar o elétron incidente a partir do meio exterior ao objeto simulador, os testes serão feitos com o elétron incidente posicionado a $250 \mu \mathrm{m}$ adentro do objeto simulador, a fim de eliminar o erro devido ao transporte do elétron incidente pela interface de entrada sem a correção para o MSC, figura 19. 


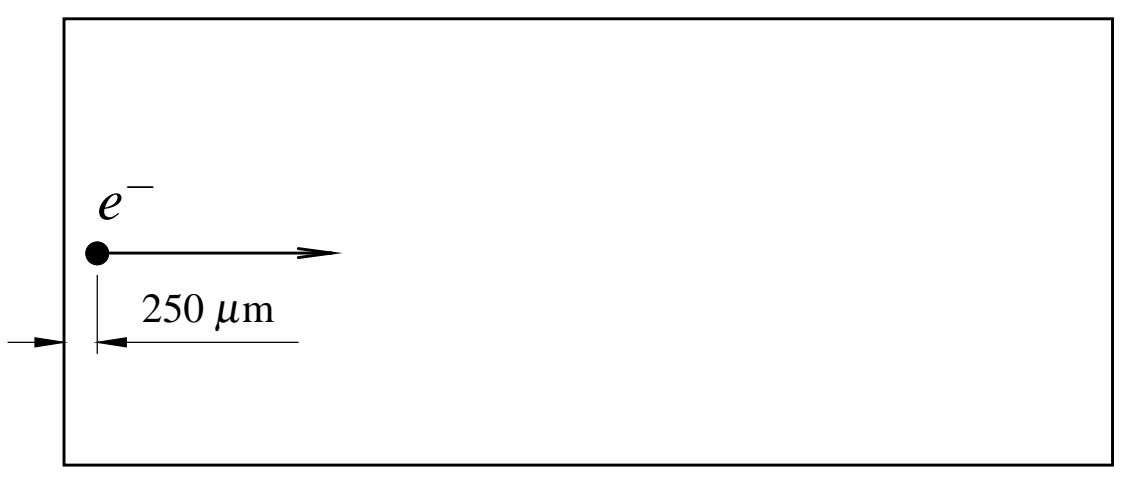

Figura 19: Ilustração do objeto simulador homogêneo com o feixe incidente de elétrons posicionado dentro do mesmo.

Todas as simulações foram feitas com $10^{6}$ histórias, tanto no MRMC quanto no Geant4, portanto não houve a necessidade de normalização dos histogramas. Os histogramas apresentados no capítulo 6 possuem 100 canais que se estendem de zero até a energia do elétron primário. Os dados das simulações são histogramados durante a simulação, por este motivo todos histogramas têm tamanho fixo.

As simulações foram feitas usando as energias 1, 5, 10 e $25 \mathrm{MeV}$ para o feixe incidente de elétrons. Essas energias foram escolhidas pois exigem, logo de início, duas características do sistema de busca de kugels: interpolação logaritmo-linear estocástica para as energias de 5 e $25 \mathrm{MeV}$, e para as energias de 1 e $10 \mathrm{MeV}$ busca direta, pois estas energias já estão disponíveis na base de dados. Na figura 20 vemos o gráfico das energias disponíveis na base de dados kugel e as energias escolhidas para o teste. 


\section{Escala de energia dos kugels e as energias iniciais escolhidas}

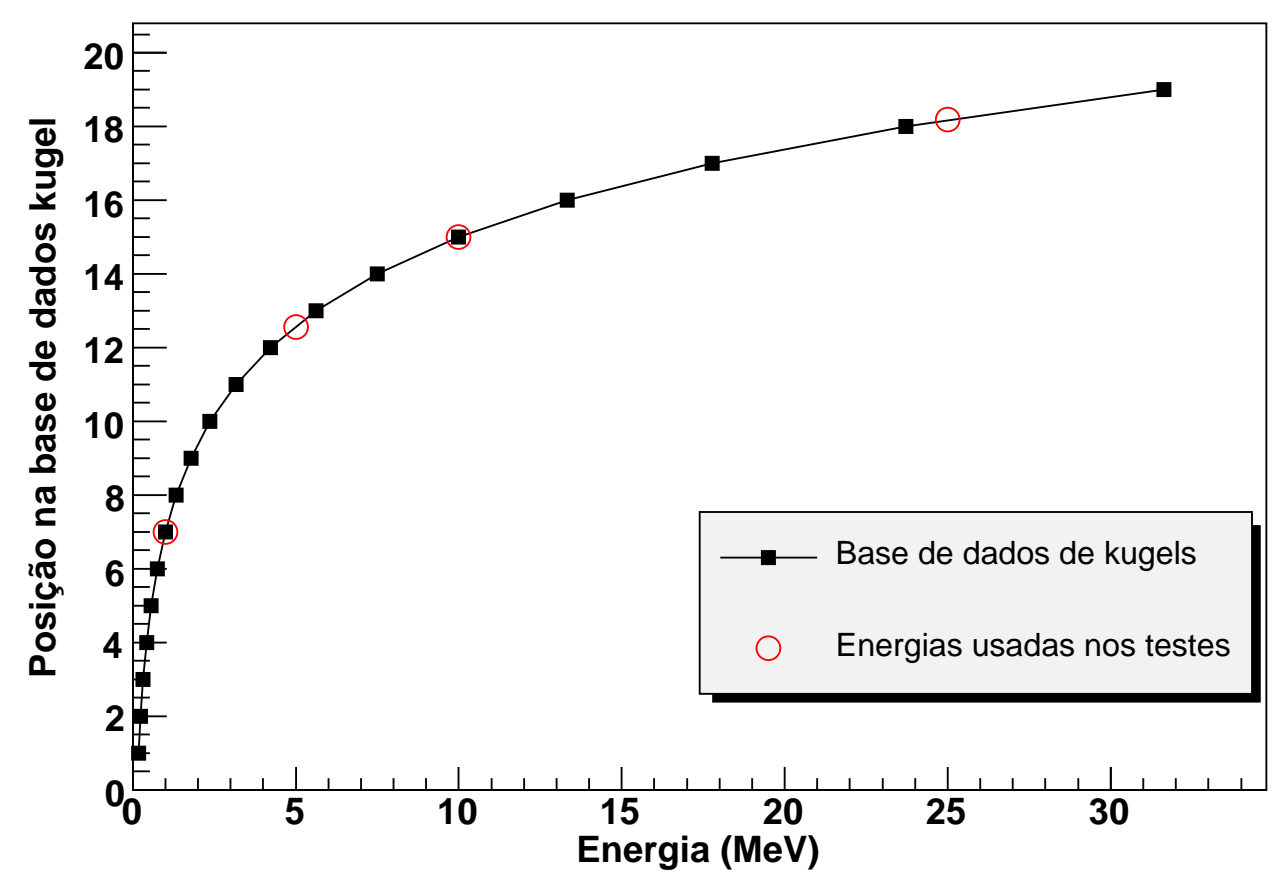

Figura 20: Gráfico das energias disponíveis na base dados kugel e as energias usadas nas simulações.

O limiar no transporte dos elétrons (cutoff) no MRMC foi ajustado para $5 \mathrm{keV}$, enquanto que no Geant4 foi de $1 \mathrm{keV}$. O limiar de produção de secundários no MRMC foi também ajustado para $5 \mathrm{keV}$. No Geant4, esse parâmetro é dado pelo RangeCut, que foi ajustado para $100 \mu \mathrm{m}$, o que equivale a aproximadamente $84 \mathrm{keV}$ para a água e tecido mole, e $116 \mathrm{keV}$ para o osso compacto. Embora os ajustes de limiar de produção sejam muito diferentes entre o MRMC e o Geant4, isto não deve representar problemas nas comparações, pois o Geant4 reduz esse limiar de produção de secundários próximo às interfaces (32).

\subsection{Metodologia da análise das simulações}

Nos testes realizados são comparados os espectros dos elétrons que saem pelas faces frontal, traseira (por onde entra o feixe incidente) e lateral do objeto simulador, conforme ilustrado na figura 18. Embora o transporte de fótons tenha sido implementado, não faremos uma análise dos 
espectros dos mesmos. Para cada simulação foram gerados 6 histogramas. Os erros mostrados nos histogramas são os erros estatísticos da simulação.

Os ítens analisados neste trabalho foram: diferença na energia dos picos $\left(\Delta E_{\text {pico }}\right)$ e na energia máxima $\left(\Delta E_{\max }\right)$ dos espectros, e a diferença no número (contagem) de partículas dos canais.

A determinação do posicionamento dos picos de energia nos espectros é feito pelo algoritmo de determinação de picos de Morhac e colaboradores (39) implementado no ROOT (34). $\mathrm{O} \Delta E_{\max }$ é obtido através da diferença entre as energias máximas obtidas pelas simulações, excluindo-se os canais onde a contagem de elétrons é menor que 100. A diferença nas energias $\Delta E_{\text {pico }}$ e $\Delta E_{\text {max }}$ é apresentada na forma percentual e relativa ao respectivo resultado obtido pelo Geant4.

Os desvios médios nas contagens, $\overline{\Delta N}$, são calculados por meio do ajuste de um polinômio de grau zero dos dados do gráfico de diferenças. Este gráfico de diferenças é computado através do módulo da diferença entre o conteúdo dos canais e normalizado pelo histograma gerado pela simulação feita pelo Geant4, equação 5.1.

$$
\Delta N=\sum_{i=1}^{100} \frac{\left|h_{i}-g 4_{i}\right|}{g 4_{i}} \times 100 \%
$$

Onde $h_{i}$ é o conteúdo do canal $i$ do histograma gerado pelo MRMC e $g 4_{i}$ é o conteúdo do canal $i$ do histograma correspondente do Geant 4 . 


\section{$6 \quad$ Resultados e discussões}

Neste capítulo são apresentados os espectros dos elétrons das regiões frontal, lateral e traseira. Nas seções 6.1 e 6.2 temos os resultados para os objetos simuladores homogêneos e heterogêneos, respectivamente. Os parâmetros utilizados para esses testes são descritos no capítulo 5 .

\subsection{Objeto simulador homogêneo}

Apresentamos nesta seção os resultados para o objeto simulador homogêneo, figura 18 . Primeiramente analisaremos os dados dos espectros dos elétrons primários, e na seção 6.1.2 os espectros completos, contendo os elétrons primárias e secundárias. Com essa separação poderemos compreender melhor como é composto os desvios nos resultados.

\subsubsection{O espectro dos elétrons primários}

Os espectros resultantes das simulações para as energias mencionadas na seção 5.2 são apresentados nas figuras 21 a 28 . 


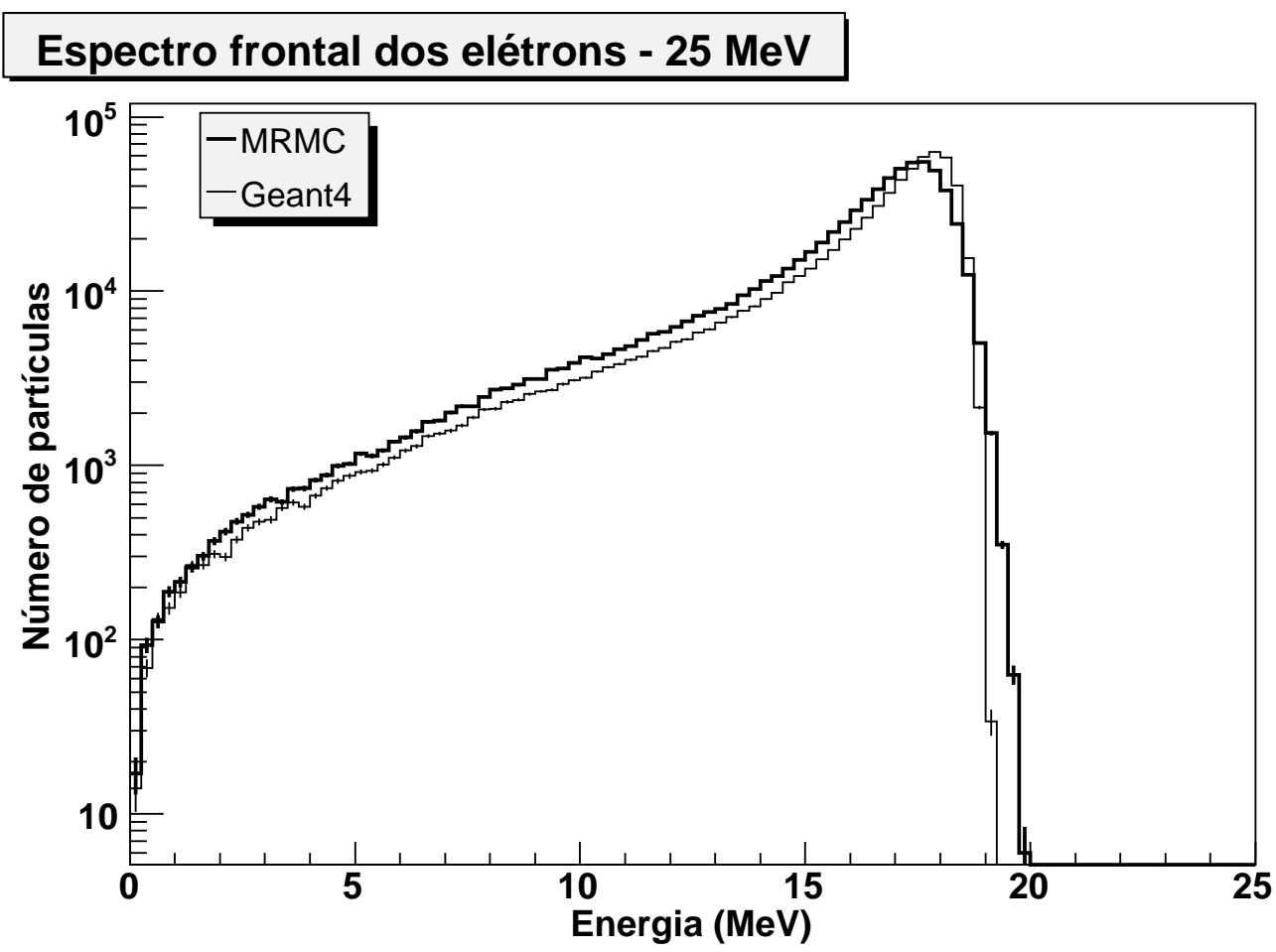

Figura 21: Espectro frontal de elétrons primários para feixe incidente de $25 \mathrm{MeV}$ no objeto simulador de água.

\section{Espectro lateral dos elétrons - $25 \mathrm{MeV}$}

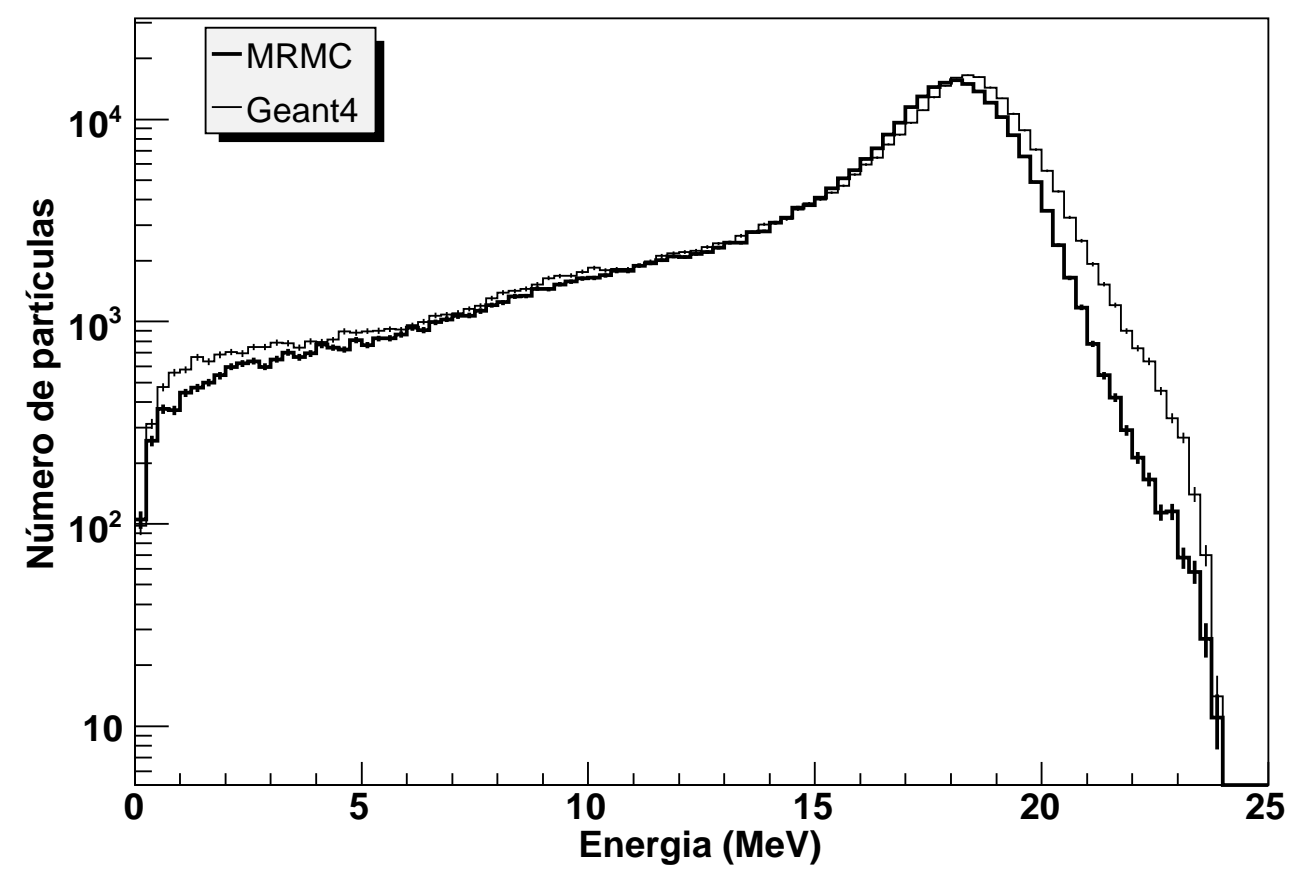

Figura 22: Espectro lateral de elétrons primários para feixe incidente de $25 \mathrm{MeV}$ no objeto simulador de água. 


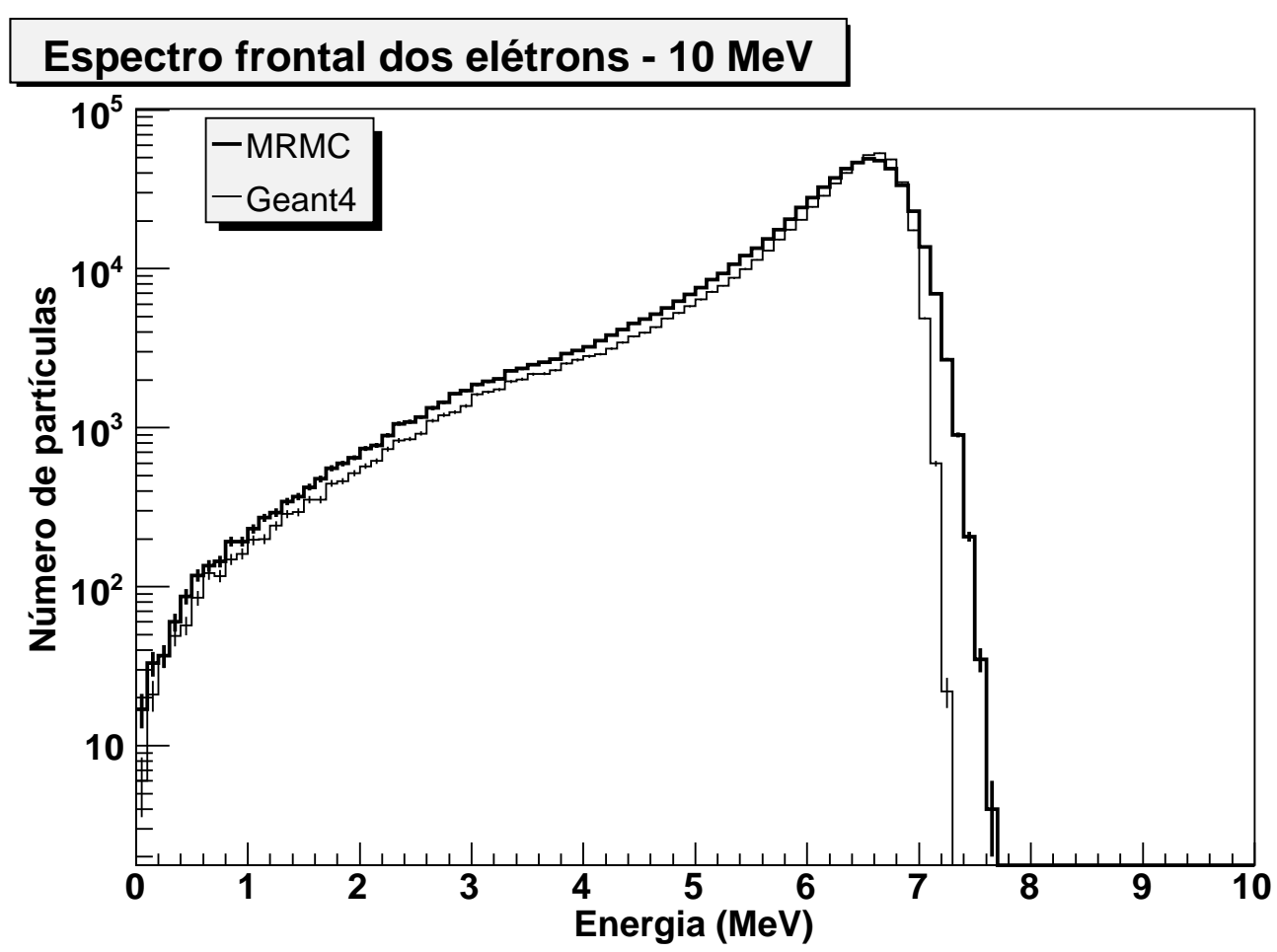

Figura 23: Espectro frontal de elétrons primários para feixe incidente de $10 \mathrm{MeV}$ no objeto simulador de água.

\section{Espectro lateral dos elétrons - $10 \mathrm{MeV}$}

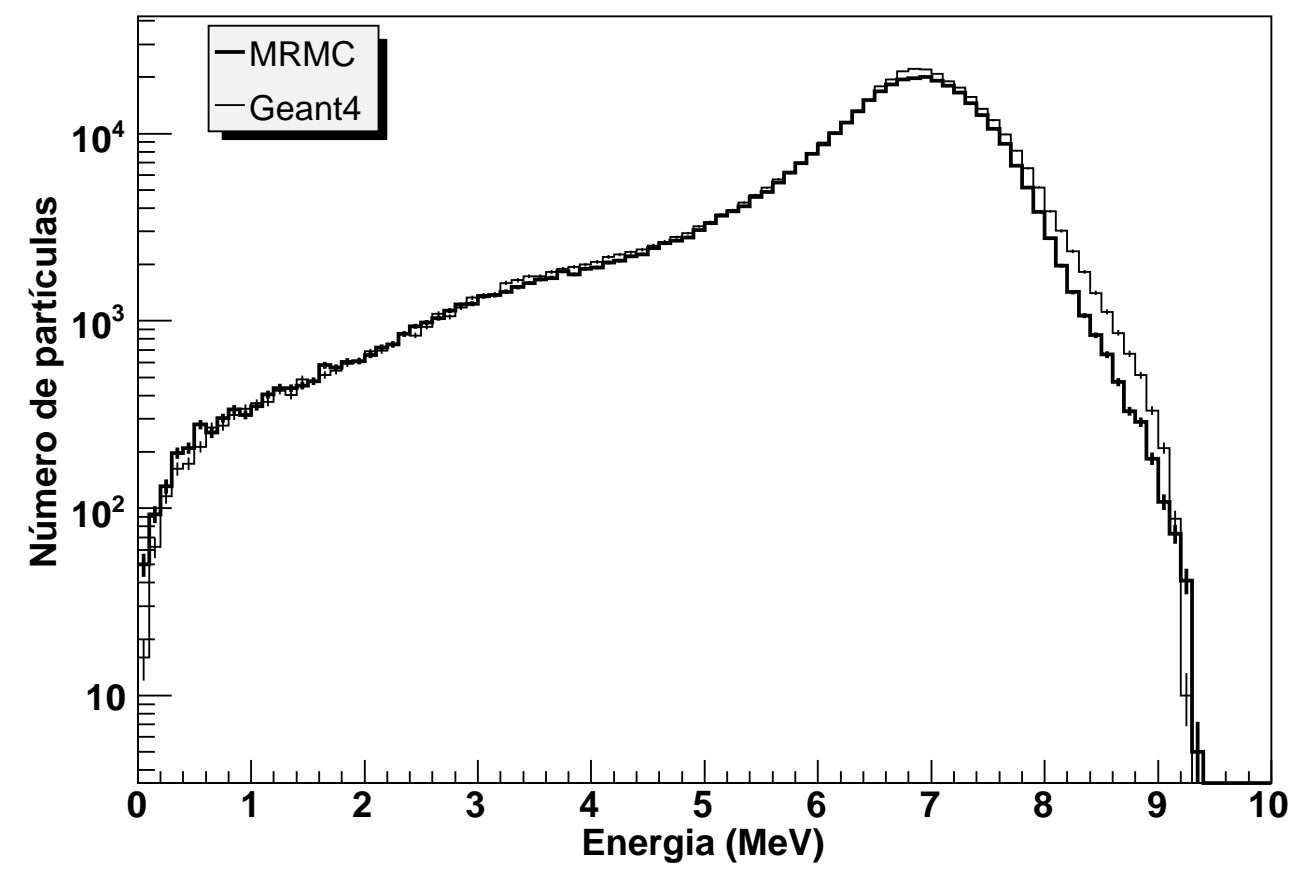

Figura 24: Espectro lateral de elétrons primários para feixe incidente de $10 \mathrm{MeV}$ no objeto simulador de água. 


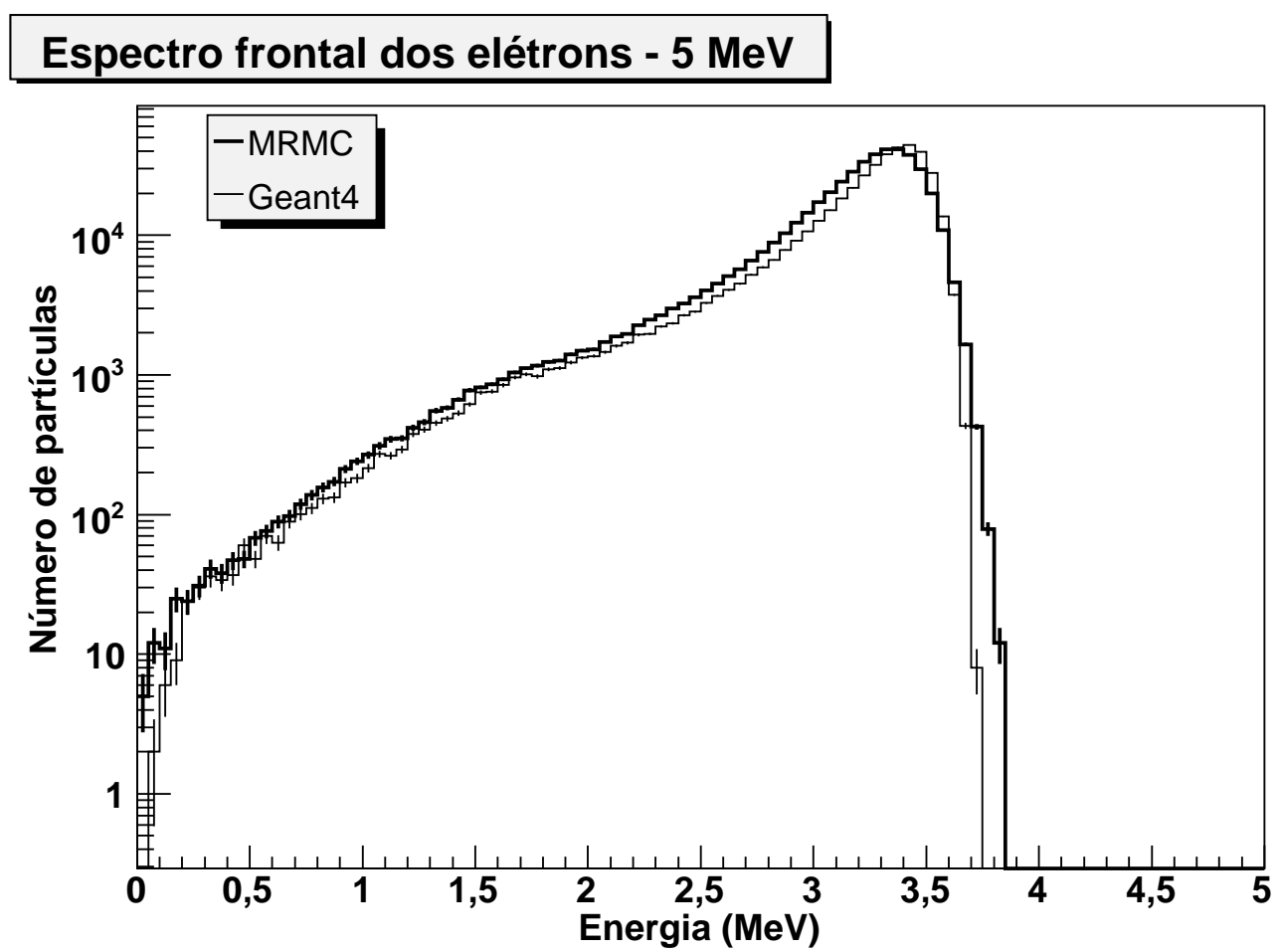

Figura 25: Espectro frontal de elétrons primários para feixe incidente de $5 \mathrm{MeV}$ no objeto simulador de água.

\section{Espectro lateral dos elétrons - $5 \mathrm{MeV}$}

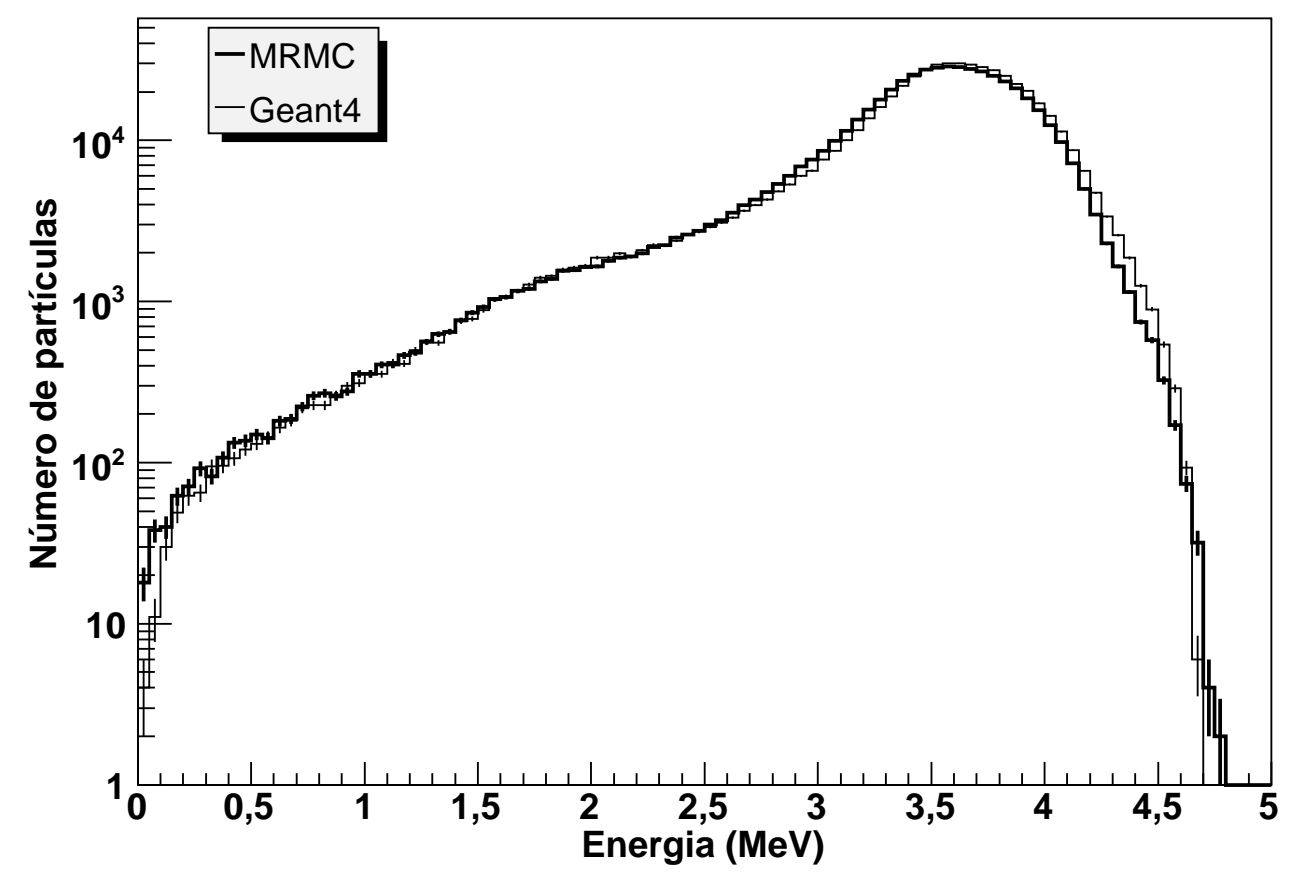

Figura 26: Espectro lateral de elétrons primários para feixe incidente de $5 \mathrm{MeV}$ no objeto simulador de água. 


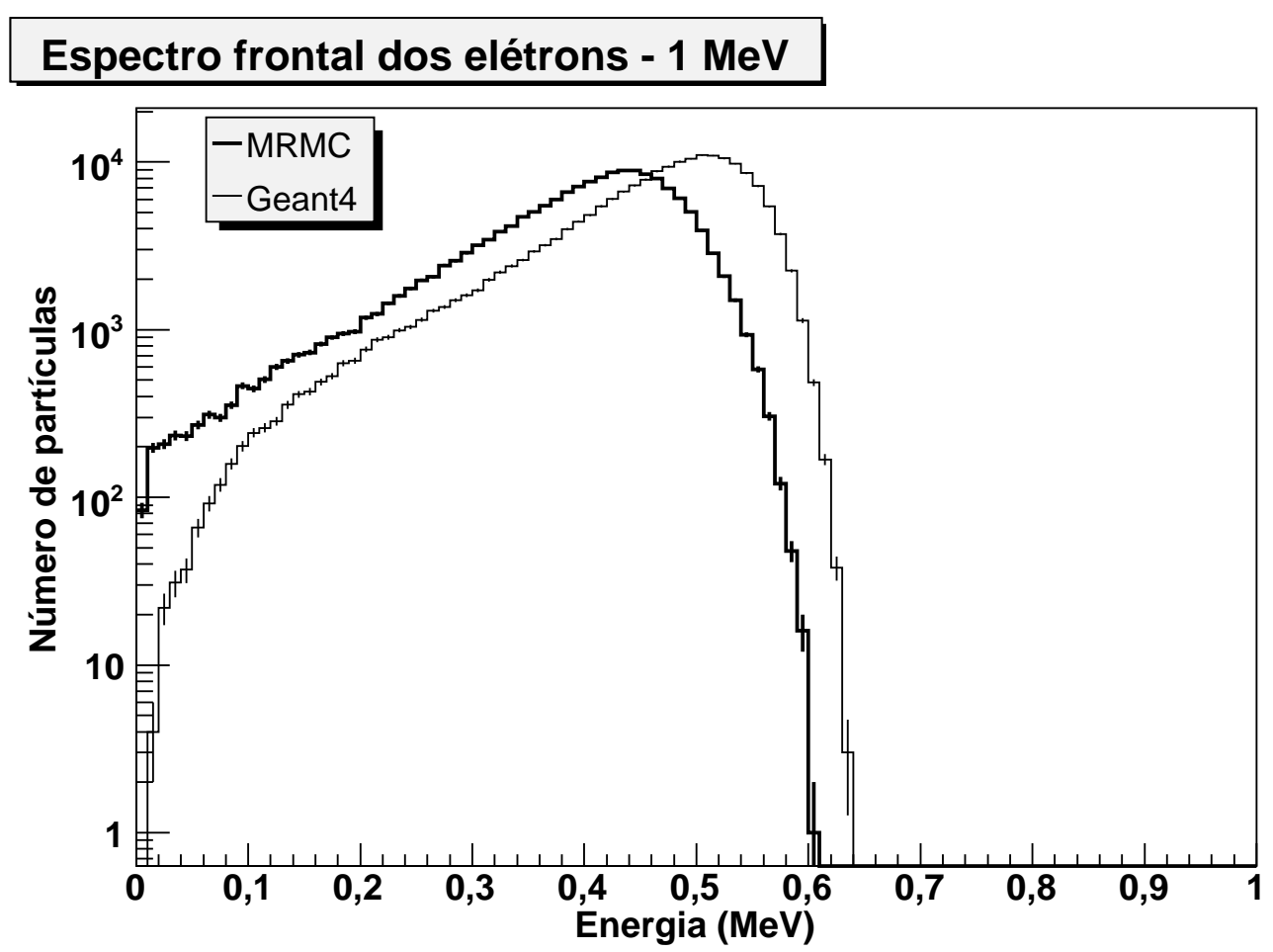

Figura 27: Espectro frontal de elétrons primários para feixe incidente de $1 \mathrm{MeV}$ no objeto simulador de água.

\section{Espectro lateral dos elétrons $-1 \mathrm{MeV}$}

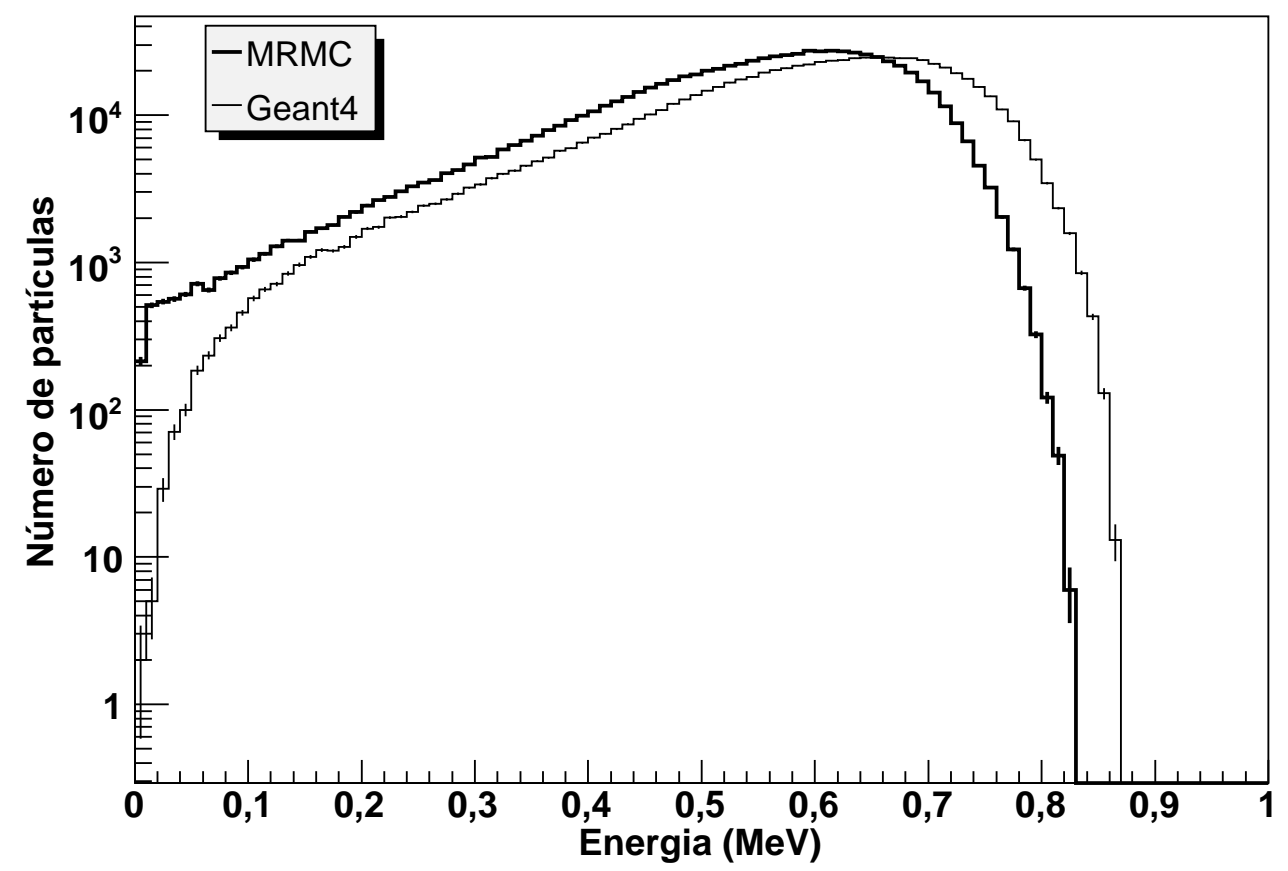

Figura 28: Espectro lateral de elétrons primários para feixe incidente de $1 \mathrm{MeV}$ no objeto simulador de água. 
Tabela 5: Análise dos espectros primários referentes ao objeto simulador homogêneo de água

\begin{tabular}{|c||c|c|c|c|}
\hline Ítem/Energia & $25 \mathrm{MeV}$ & $10 \mathrm{MeV}$ & $5 \mathrm{MeV}$ & $1 \mathrm{MeV}$ \\
\hline \hline$\Delta E_{\text {pico }}$ frontal & $1,5 \pm 0,7 \%$ & $1,5 \pm 0,7 \%$ & $1,5 \pm 0,7 \%$. & $11,9 \pm 1,0 \%$ \\
\hline$\Delta E_{\text {max }}$ frontal & $2,6 \pm 0,6 \%$ & $4,1 \pm 0,7 \%$ & $2,5 \pm 0,7 \%$ & $4,8 \pm 0,8 \%$ \\
\hline$\Delta E_{\text {pico }}$ lateral & $1,5 \pm 0,7 \%$ & $1,5 \pm 0,7 \%$ & $1,5 \pm 0,7 \%$ & $6,1 \pm 0,8 \%$ \\
\hline$\Delta E_{\text {max }}$ lateral & $0,0 \pm 0,5 \%$ & $0,0 \pm 0,5 \%$ & $1,2 \pm 0,5 \%$ & $4,6 \pm 0,6 \%$ \\
\hline$\overline{\Delta N}$ frontal & $22,0 \pm 0,1 \%$ & $21,6 \pm 0,1 \%$ & $25,7 \pm 0,1 \%$ & $57,3 \pm 0,1 \%$ \\
\hline$\overline{\Delta N}$ lateral & $17,5 \pm 0,1 \%$ & $11,7 \pm 0,1 \%$ & $11,2 \pm 0,1 \%$ & $61,8 \pm 0,1 \%$ \\
\hline
\end{tabular}

Conforme podemos observar, a qualidade dos resultados para a energia incidente de $1 \mathrm{MeV}$ é muito inferior às demais.

A quantidade relativa de partículas retroespalhadas em todas as simulações para a água foi inferior a $0,6 \%$ das partículas incidentes e a estatística obtida não permite fazer as análises do retroespalhamento.

Na tabela 5 temos a compilação das análises para o objeto simulador de água, onde podemos ver que esta implementação do MRMC mantém praticamente a mesma qualidade dos resultados de $25 \mathrm{MeV}$ até $5 \mathrm{MeV}$, no entanto, perde precisão quando a energia do feixe incidente chega a $1 \mathrm{MeV}$.

Tabela 6: Análise dos espectros primários referentes ao objeto simulador homogêneo de tecido mole

\begin{tabular}{|c||c|c|c|c|}
\hline Ítem/Energia & $25 \mathrm{MeV}$ & $10 \mathrm{MeV}$ & $5 \mathrm{MeV}$ & $1 \mathrm{MeV}$ \\
\hline \hline$\Delta E_{\text {pico }}$ frontal & $1,2 \pm 0,7 \%$ & $1,5 \pm 0,7 \%$ & $1,5 \pm 0,7 \%$. & $11,9 \pm 1,0 \%$ \\
\hline$\Delta E_{\text {max }}$ frontal & $3,9 \pm 0,6 \%$ & $4,1 \pm 0,7 \%$ & $2,7 \pm 0,7 \%$ & $3,2 \pm 0,8 \%$ \\
\hline$\Delta E_{\text {pico }}$ lateral & $1,2 \pm 0,7 \%$ & $1,5 \pm 0,7 \%$ & $0,0 \pm 0,7 \%$ & $5,9 \pm 0,8 \%$ \\
\hline$\Delta E_{\text {max }}$ lateral & $0,0 \pm 0,5 \%$ & $1,1 \pm 0,5 \%$ & $1,0 \pm 0,5 \%$ & $3,5 \pm 0,6 \%$ \\
\hline$\overline{\Delta N}$ frontal & $21,6 \pm 0,1 \%$ & $20,1 \pm 0,1 \%$ & $28,4 \pm 0,1 \%$ & $68,5 \pm 0,1 \%$ \\
\hline$\overline{\Delta N}$ lateral & $18,0 \pm 0,1 \%$ & $11,4 \pm 0,1 \%$ & $11,0 \pm 0,1 \%$ & $84,3 \pm 0,1 \%$ \\
\hline
\end{tabular}


O tecido mole possui seções de choque para elétrons muito semelhantes às da água, por este motivo, os espectros assemelham-se aos da água e não serão apresentados. Os resultados das análises para o objeto simulador homogêneo de tecido mole estão na tabela 6 , onde podemos ver que as análises para o objeto simulador de tecido mole são semelhantes aos do objeto simulador de água, mostrados na tabela 5.

Os histogramas dos espectros primários para o objeto simulador de osso compacto são mostrados nas figuras 29 a 36. Na tabela 7 estão os resultados das análises para este objeto simulador.

\section{Espectro frontal dos elétrons - $25 \mathrm{MeV}$}

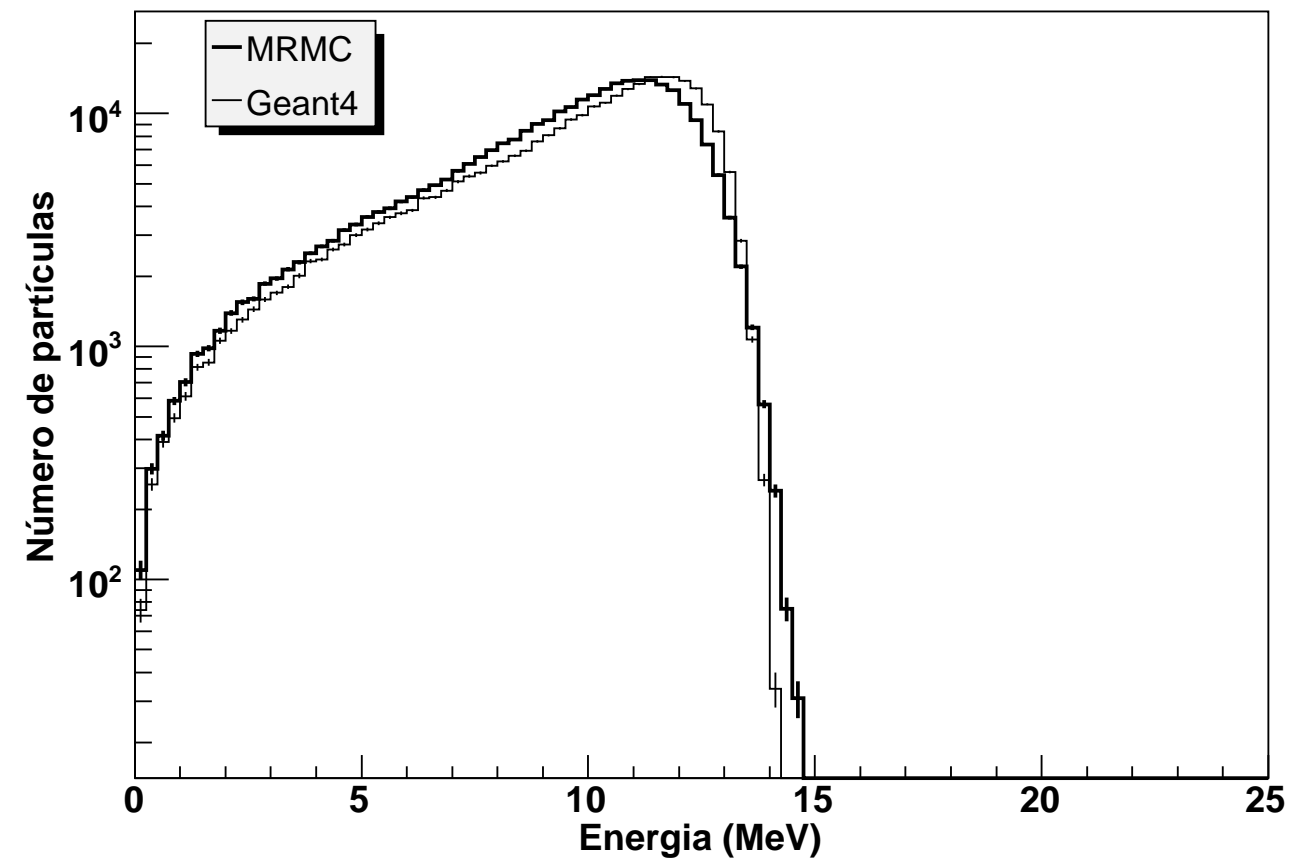

Figura 29: Espectro frontal de elétrons primários para feixe incidente de $25 \mathrm{MeV}$ no objeto simulador de osso compacto. 


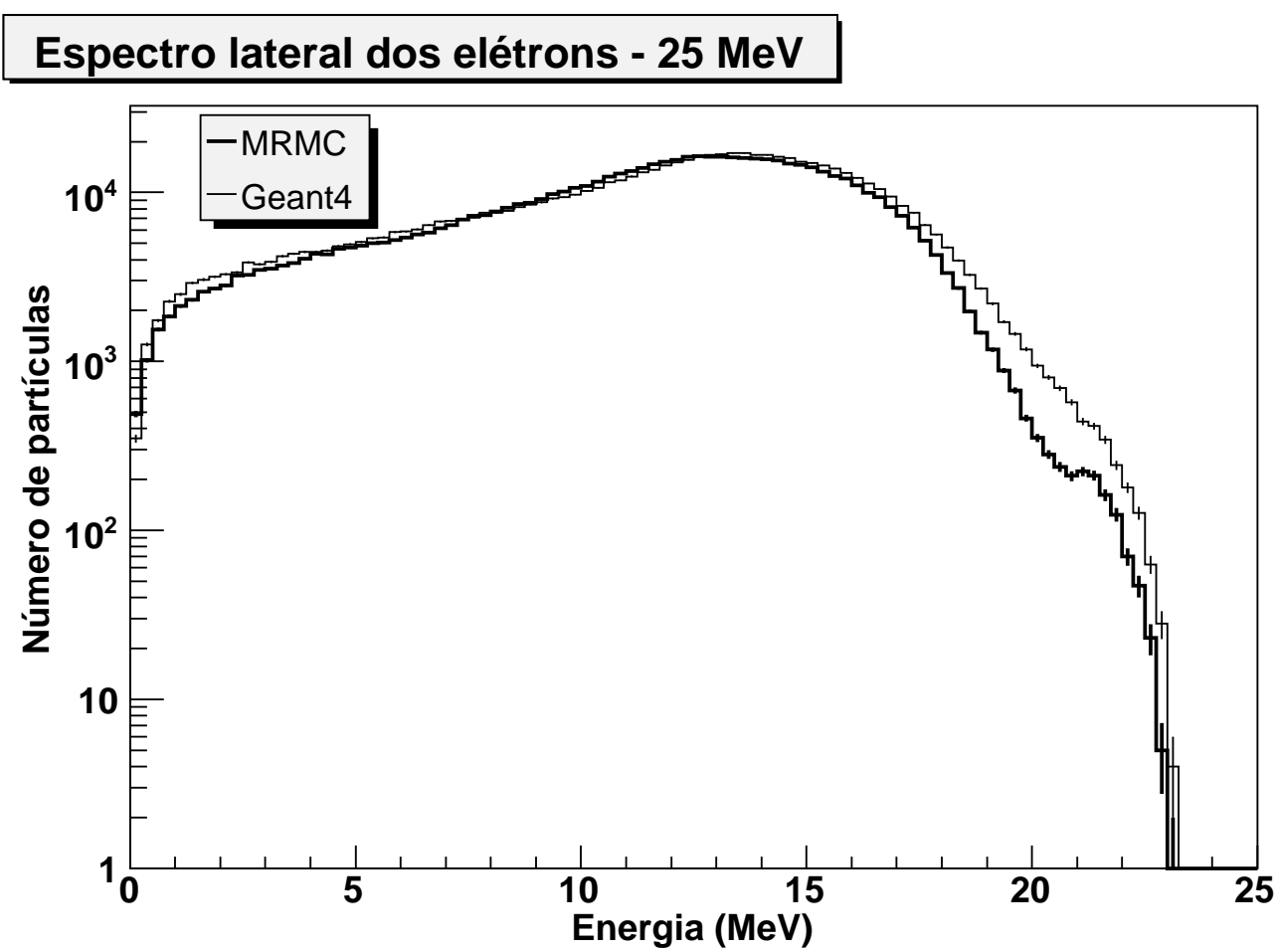

Figura 30: Espectro lateral de elétrons primários para feixe incidente de $25 \mathrm{MeV}$ no objeto simulador de osso compacto.

\section{Espectro frontal dos elétrons - $10 \mathrm{MeV}$}

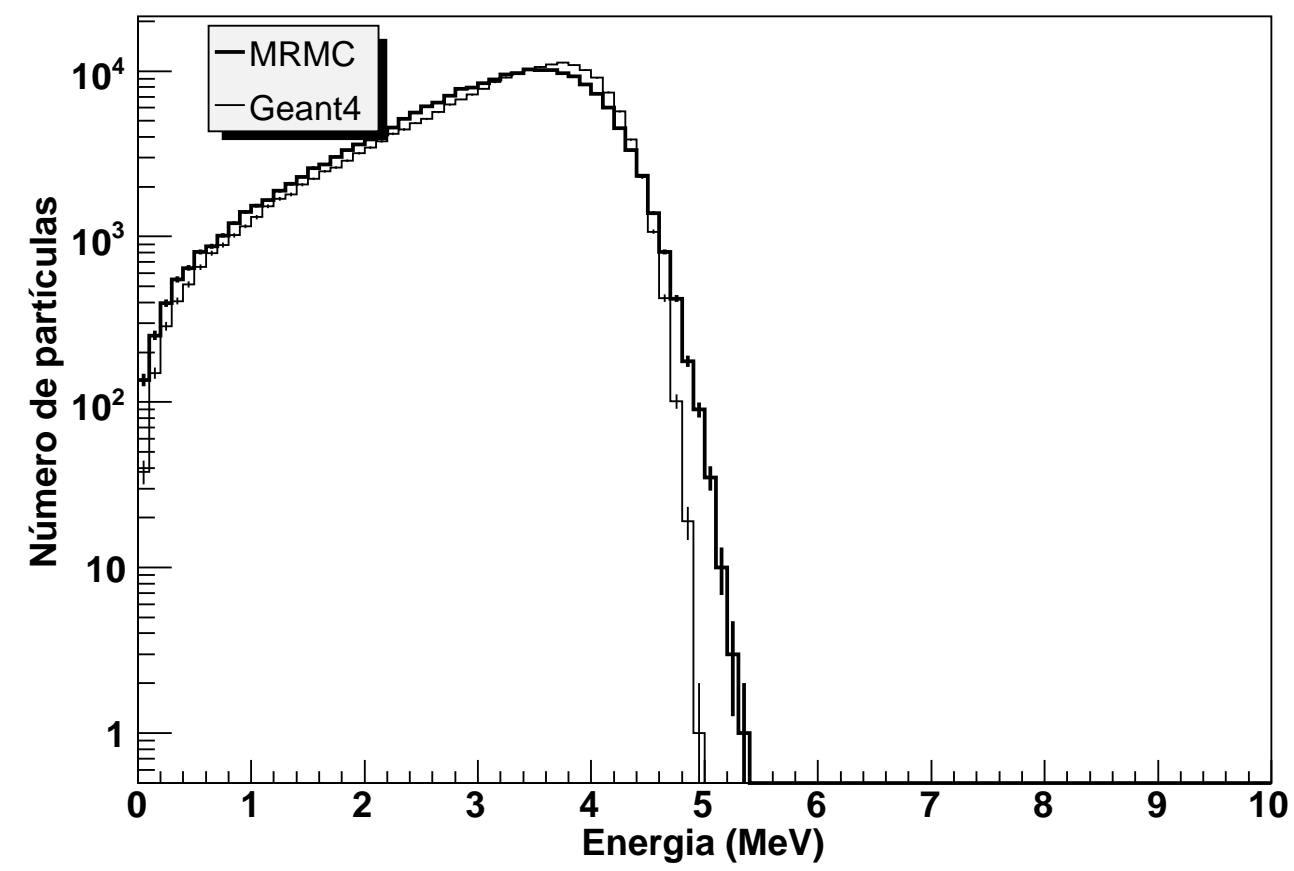

Figura 31: Espectro frontal de elétrons primários para feixe incidente de $10 \mathrm{MeV}$ no objeto simulador de osso compacto. 


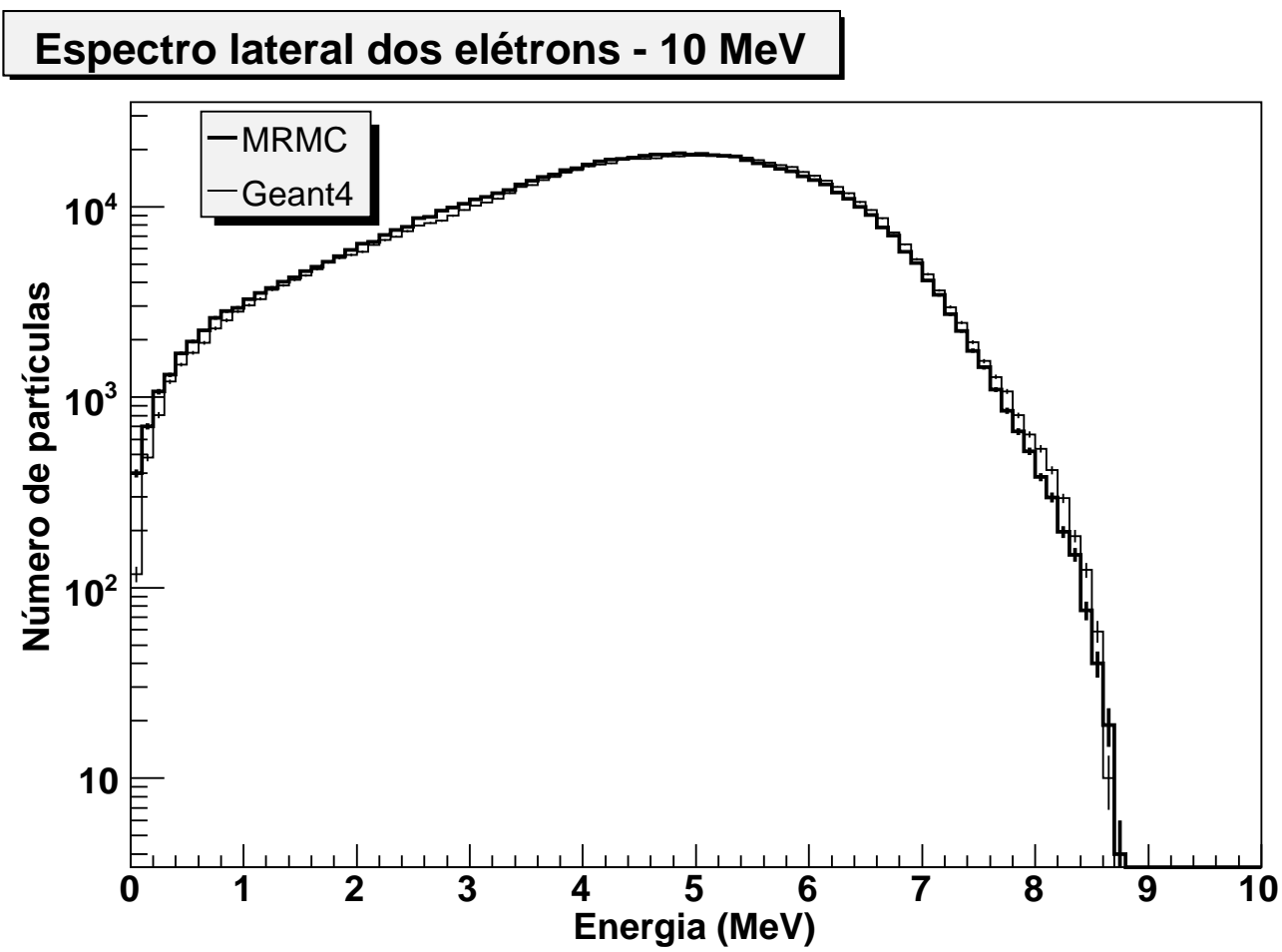

Figura 32: Espectro lateral de elétrons primários para feixe incidente de $10 \mathrm{MeV}$ no objeto simulador de osso compacto.

\section{Espectro frontal dos elétrons - $5 \mathrm{MeV}$}

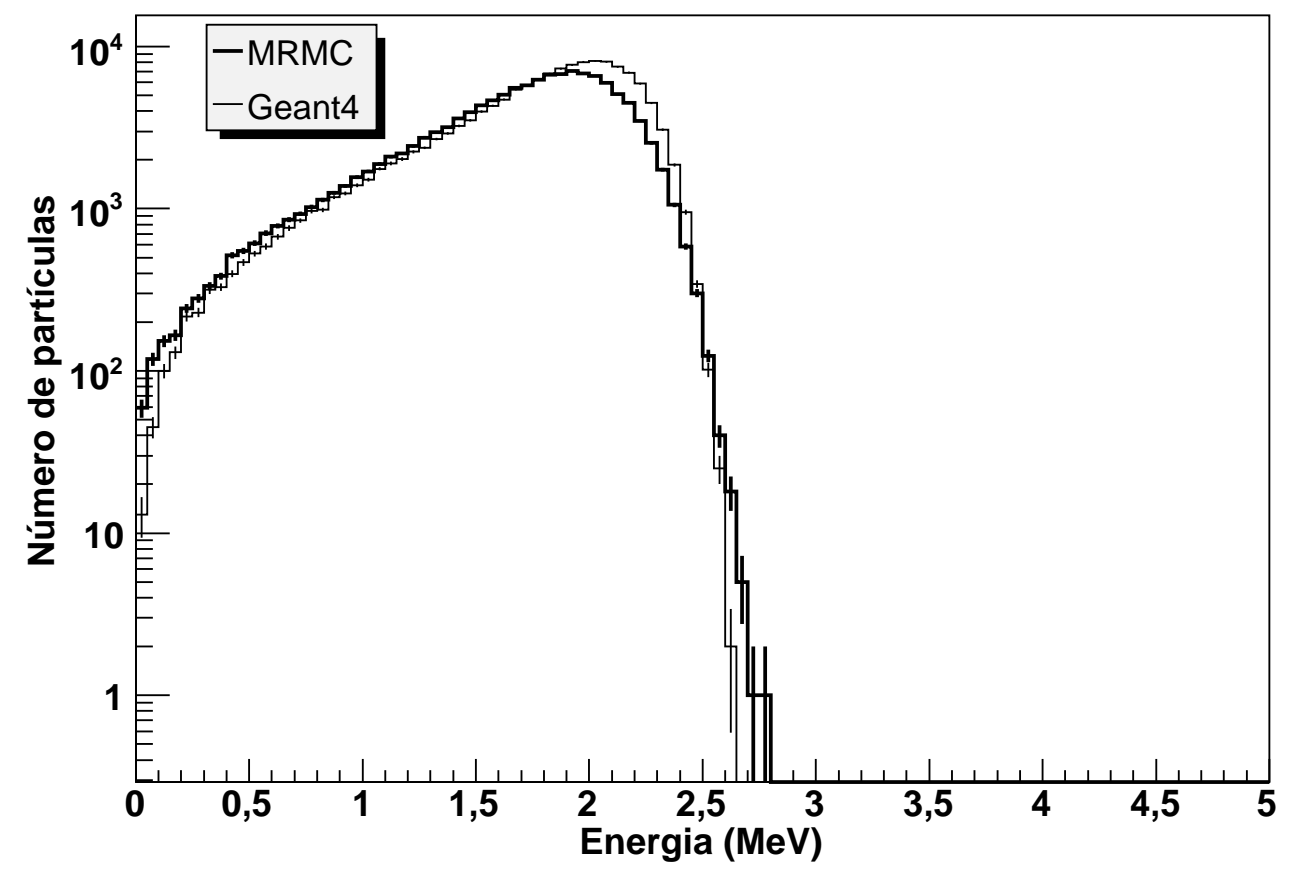

Figura 33: Espectro frontal de elétrons primários para feixe incidente de $5 \mathrm{MeV}$ no objeto simulador de osso compacto. 


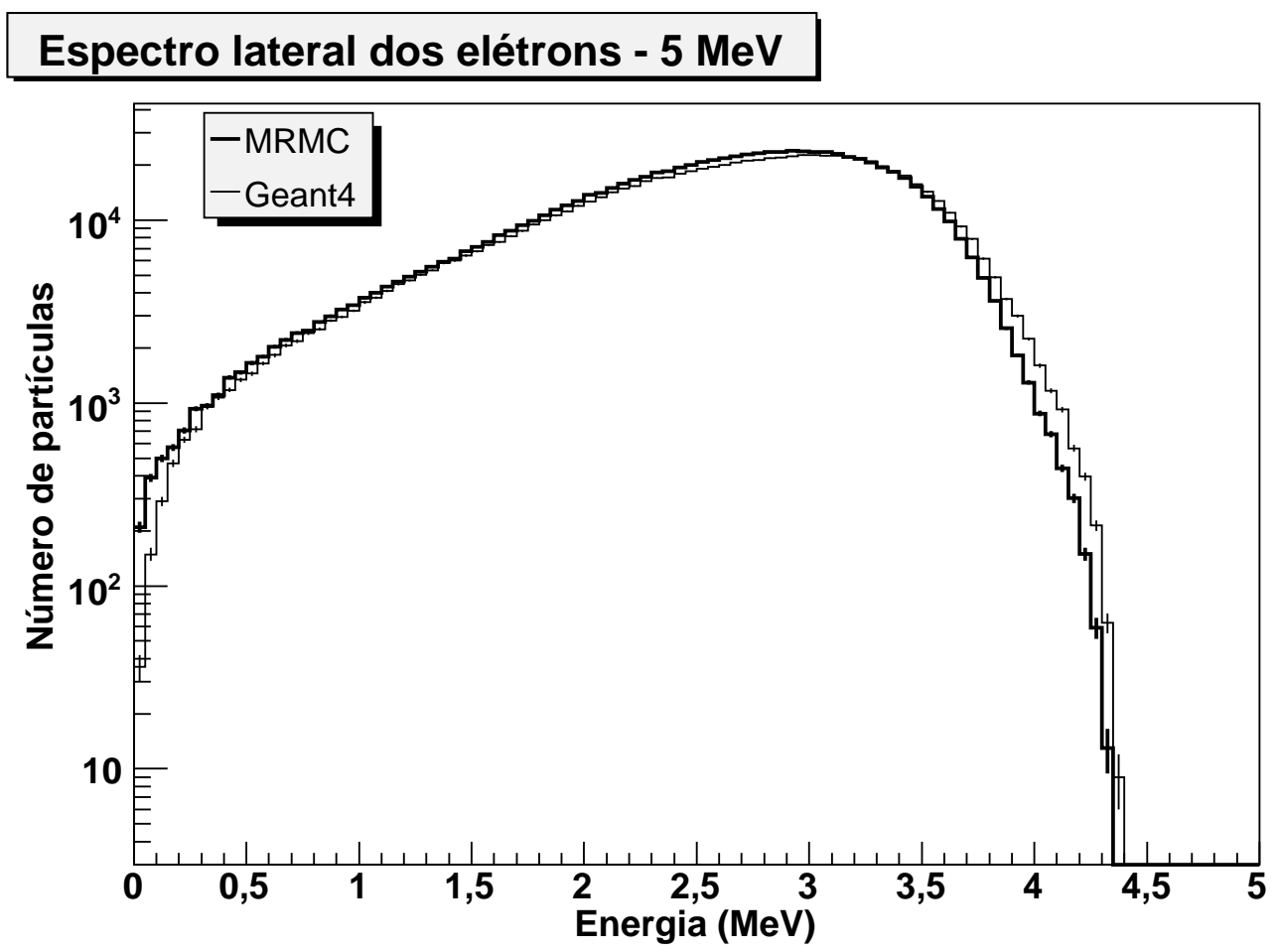

Figura 34: Espectro lateral de elétrons primários para feixe incidente de $5 \mathrm{MeV}$ no objeto simulador de osso compacto.

\section{Espectro frontal dos elétrons - $1 \mathrm{MeV}$}

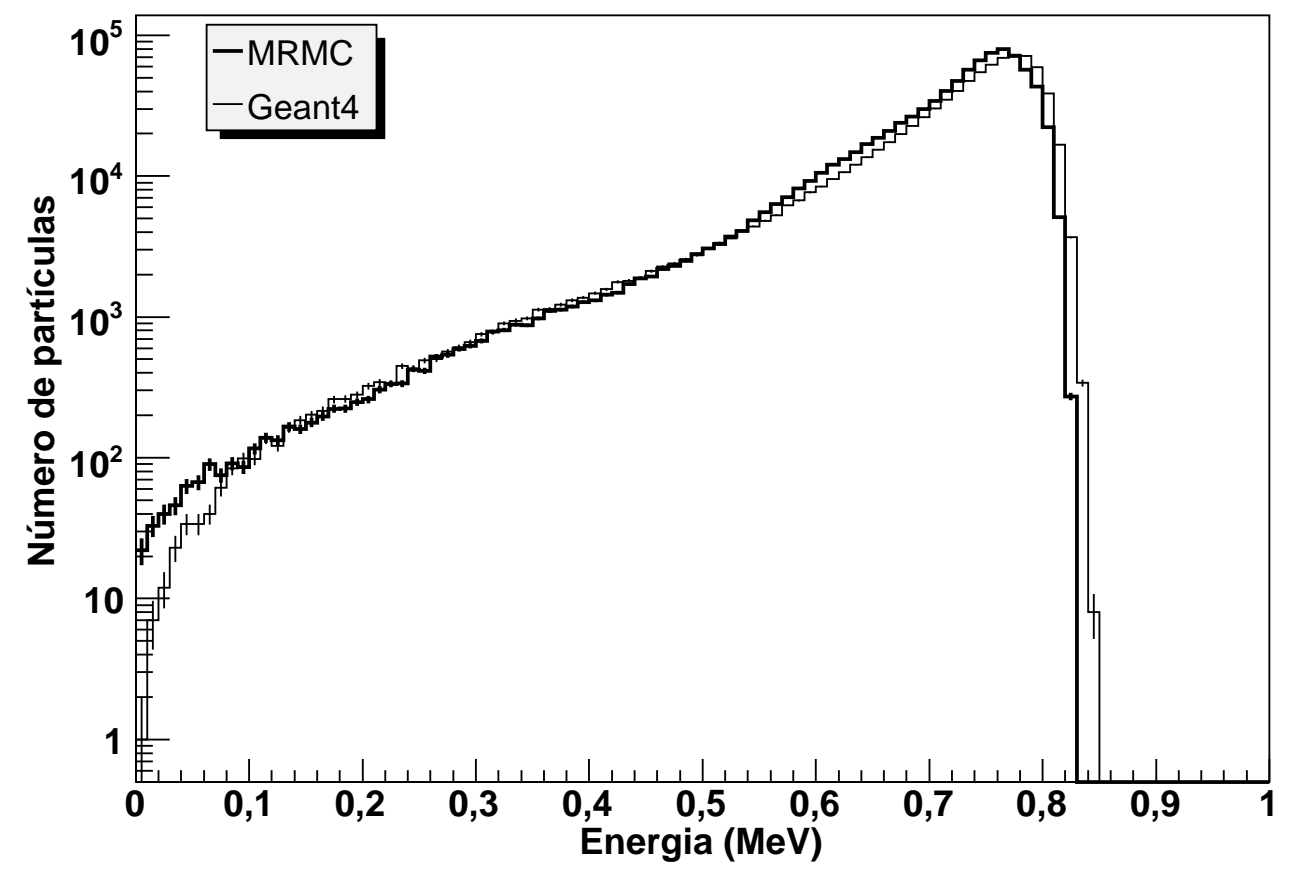

Figura 35: Espectro frontal de elétrons primários para feixe incidente de $1 \mathrm{MeV}$ no objeto simulador de osso compacto. 


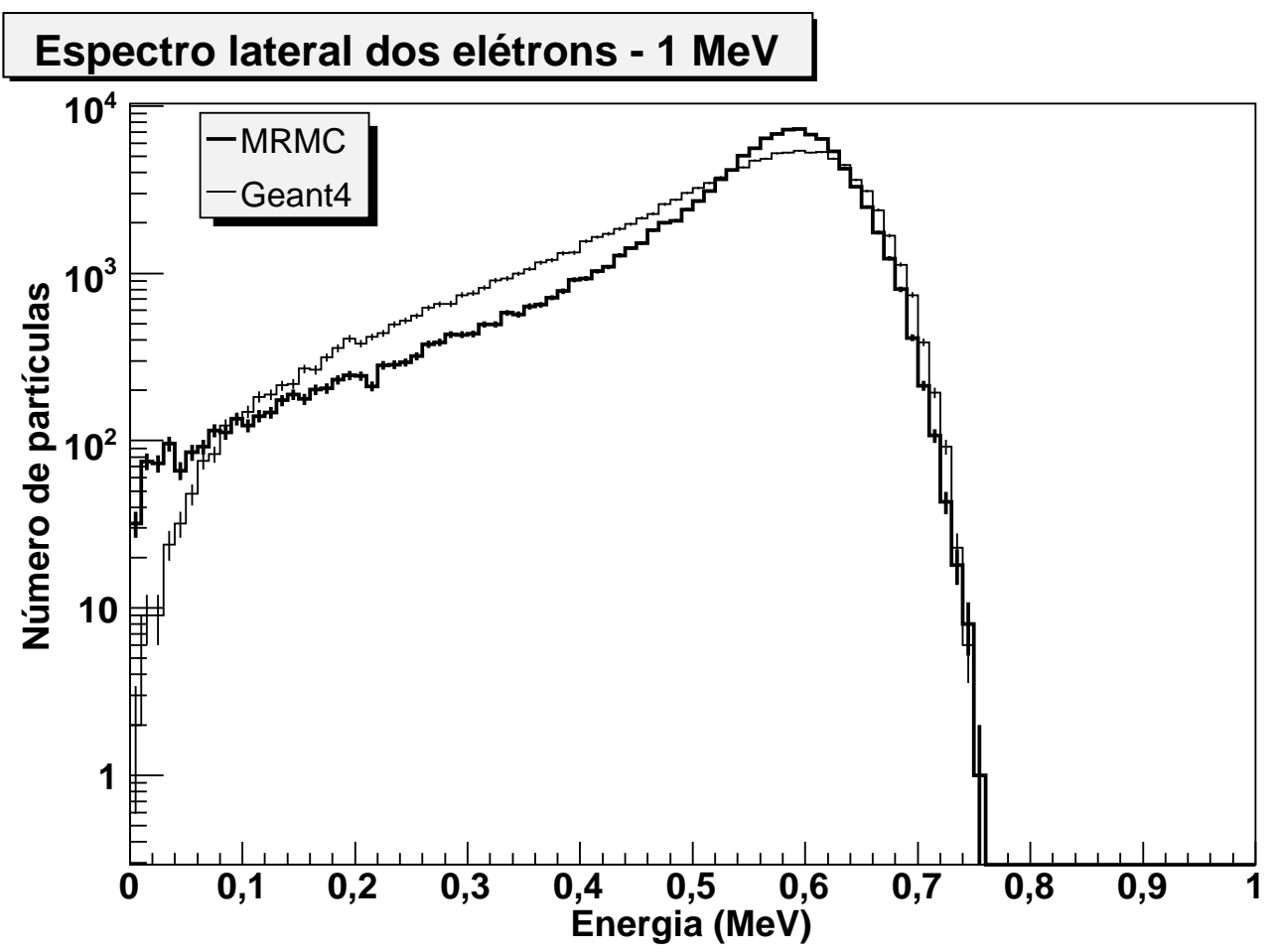

Figura 36: Espectro lateral de elétrons primários para feixe incidente de $1 \mathrm{MeV}$ no objeto simulador de osso compacto.

Tabela 7: Tabela de análise dos espectros primários referentes ao objeto simulador homogêneo de osso compacto

\begin{tabular}{|c||c|c|c|c|}
\hline Ítem/Energia & $25 \mathrm{MeV}$ & $10 \mathrm{MeV}$ & $5 \mathrm{MeV}$ & $1 \mathrm{MeV}$ \\
\hline \hline$\Delta E_{\text {pico }}$ frontal & $4,3 \pm 1,1 \%$ & $5,3 \pm 1,3 \%$ & $4,9 \pm 1,2 \%$ & $1,3 \pm 0,6 \%$ \\
\hline$\Delta E_{\text {max }}$ frontal & $1,8 \pm 0,9 \%$ & $6,2 \pm 1,0 \%$ & $1,9 \pm 0,9 \%$ & $1,2 \pm 0,6 \%$ \\
\hline$\Delta E_{\text {pico }}$ lateral & $3,7 \pm 0,9 \%$ & $1,9 \pm 0,9 \%$ & $3,2 \pm 0,8 \%$ & $1,7 \pm 0,8 \%$ \\
\hline$\Delta E_{\text {max }}$ lateral & $1,1 \pm 0,5 \%$ & $0,0 \pm 0,6 \%$ & $1,2 \pm 0,6 \%$ & $0,0 \pm 0,6 \%$ \\
\hline$\overline{\Delta N}$ frontal & $15,2 \pm 0,1 \%$ & $15,4 \pm 0,2 \%$ & $19,9 \pm 0,1 \%$ & $23,2 \pm 0,1 \%$ \\
\hline$\overline{\Delta N}$ lateral & $17,9 \pm 0,1 \%$ & $8,5 \pm 0,1 \%$ & $14,2 \pm 0,1 \%$ & $40,2 \pm 0,1 \%$ \\
\hline
\end{tabular}

Para o osso compacto temos, no máximo, 1,6\% das partículas incidentes retroespalhadas, o que ainda não permite uma análise dos espectros de retroespalhamento. Observamos também que para o osso compacto a concordância entre o espectros com feixe incidente de $1 \mathrm{MeV}$ é maior que no caso da água e do tecido mole. 


\subsubsection{Discussão dos resultados dos espectros primários}

Observando os espectros frontais e laterais para a água e o osso compacto, constatamos que as diferenças entre as energias de pico, $\Delta E_{\text {pico }}$, e as energias máximas, $\Delta E_{\max }$, não representam adequadamente a concordância dos resultados do MRMC quando comparados aos do Geant4. No entanto, os ajustes do polinômio de grau zero à diferença entre os espectros do MRMC e do Geant4, equação 5.1, são mais representativos da qualidade da simulação. Nas figuras 37 e 38 temos os gráficos dos desvios médios para a água, tecido mole e osso compacto apresentados nas tabelas 5 a 7.

\section{Comparação entre os desvios dos espectros frontais}

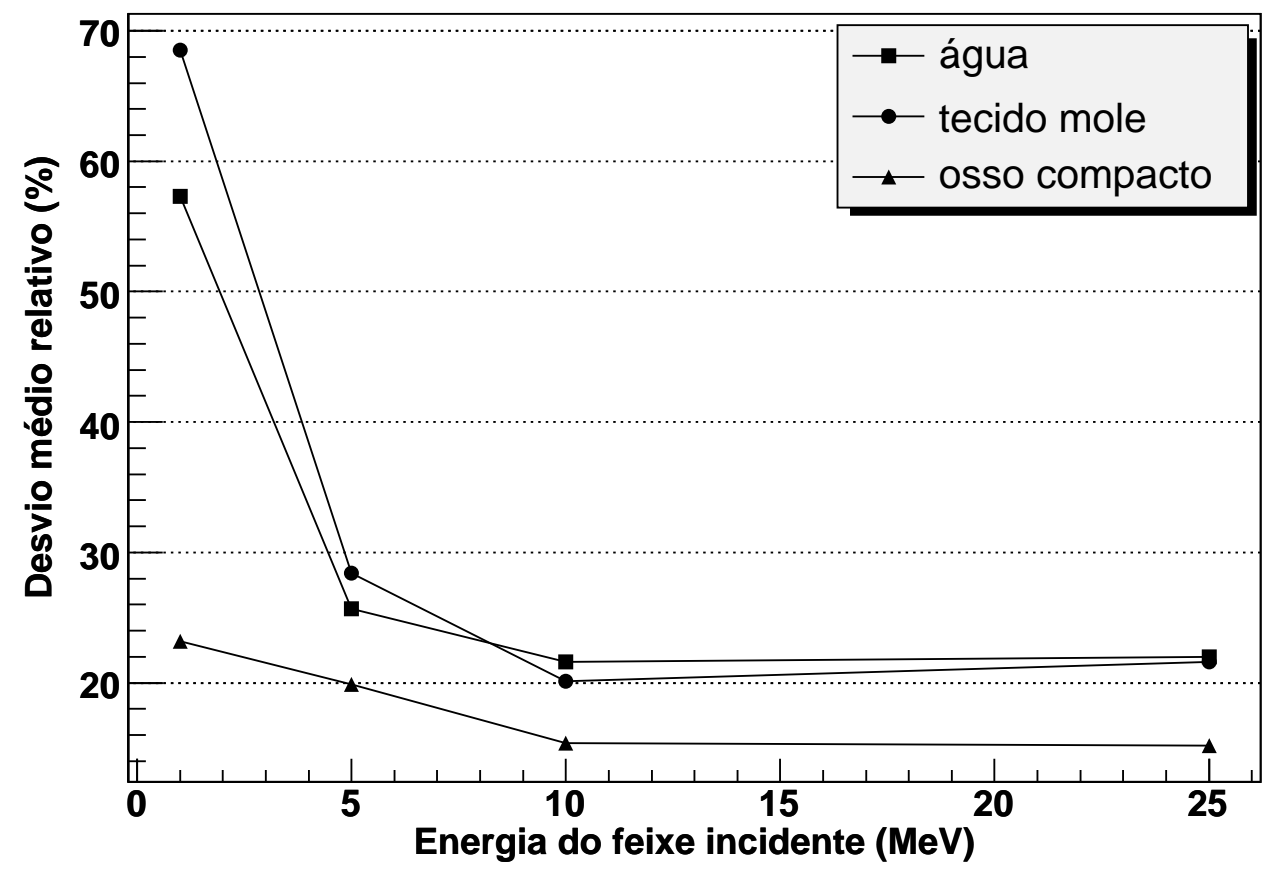

Figura 37: Comparação entre os desvios MRMC-Geant4 dos espectros frontais. 


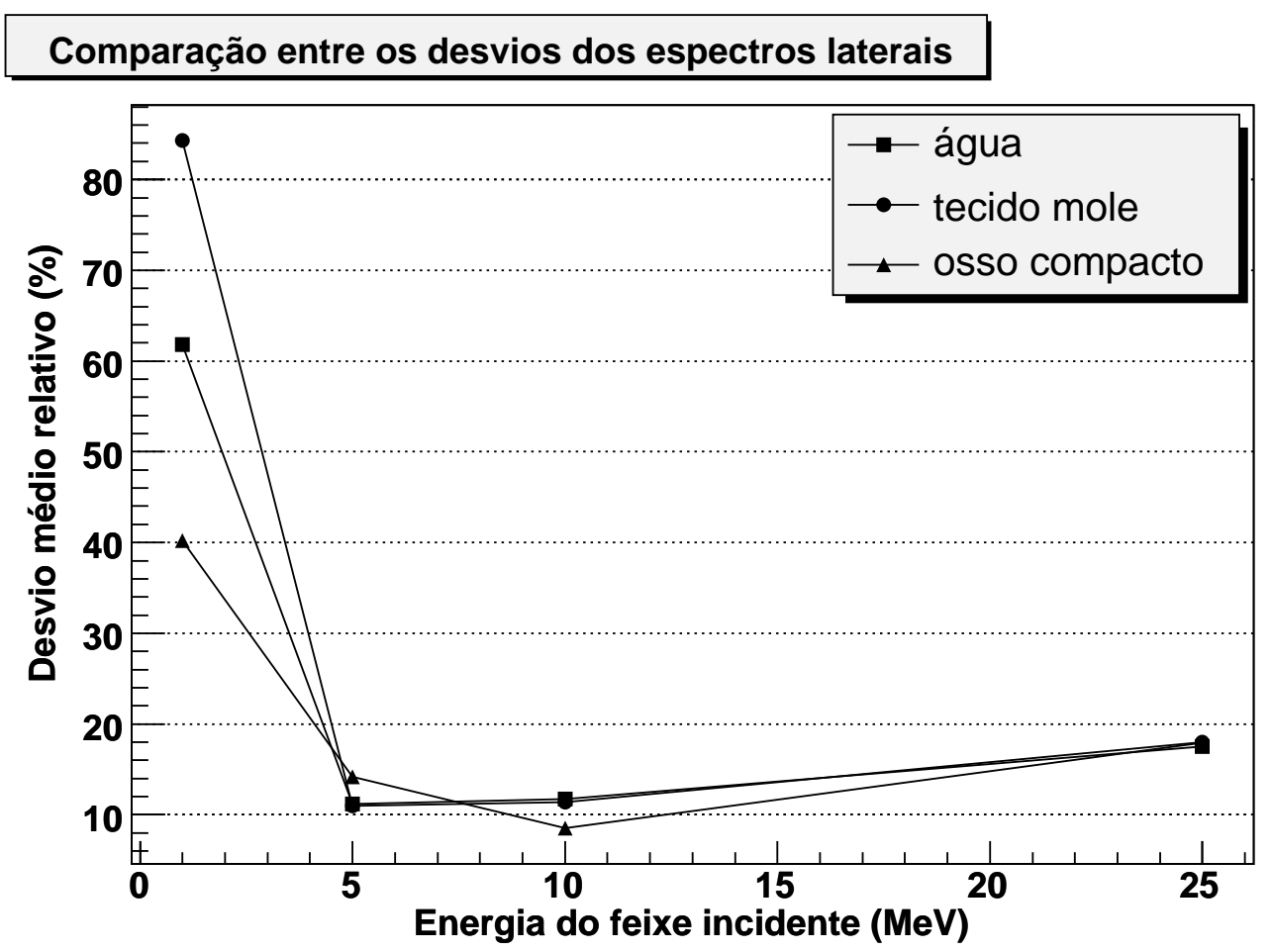

Figura 38: Comparação entre os desvios MRMC-Geant4 dos espectros laterais.

Por meio dos histogramas dos espectros e dos gráficos das figuras 37 e 38, podemos considerar que esta implementação do MRMC tem um desempenho satisfatório quando o desvio médio do número de partículas está abaixo dos 30\%. O que ocorre para as energias entre de 5 e $25 \mathrm{MeV}$ em todos os materiais para os espectros frontais e laterais.

Os espectros laterais para feixe incidente de $25 \mathrm{MeV}$ apresentam um desvio "anômalo" entre, aproximadamente, 20 e $23 \mathrm{MeV}$, tanto para o osso compacto quanto para a água e tecido mole. Por meio da expressão 4.1 obtemos que a probabilidade de escolha do kugel de 17,78 MeV é de 59\% para um elétron de $20 \mathrm{MeV}$, e de $77 \%$ para um elétron de $19 \mathrm{MeV}$, quando comparados ao kugel de 23,72 MeV. Observando os histogramas de probabilidade do kugel de $17,78 \mathrm{MeV}$ e raio $1 \mathrm{~mm}$, podemos constatar que apenas $0,56 \%$ dos elétrons primários saem pela banda 2 e $0,03 \%$ pela banda 3. Devido a estatística pobre das bandas 2 e 3, responsáveis pela maioria do espalhamento lateral, a resposta do MRMC para o espectro lateral fica comprometida . Para o kugel de 23,72 MeV, a banda 2 contabiliza apenas 0,3\% das partículas incidentes 
e a banda 3 menos de $0,02 \%$. Na figura 39 temos o histograma de posição de saída da banda 2 para o kugel de raio $1 \mathrm{~mm}$ e energia $17,78 \mathrm{MeV}$.

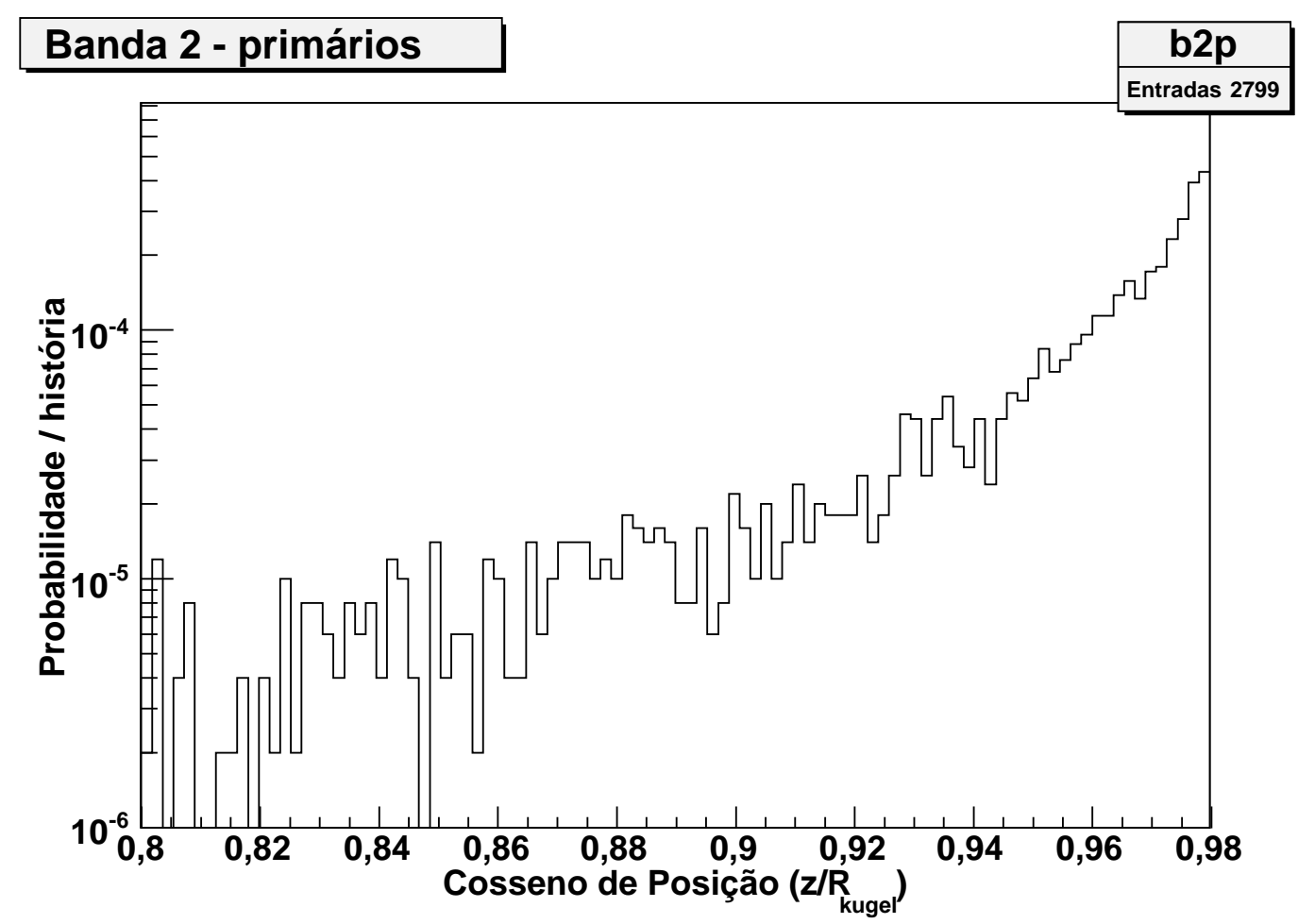

Figura 39: Cosseno de posição de saída para os elétrons primários da Banda 2 para o kugel de 17,78 MeV e $1 \mathrm{~mm}$ de raio.

Para o osso compacto temos um resultado de boa qualidade também para a energia inicial de $1 \mathrm{MeV}$ para o espectro frontal, porém o mesmo não ocorre para o espectro lateral. Uma possível explicação para esse resultado de qualidade inferior do espectro lateral seria a não correção do transporte do elétron primário pelo MSC próximo a interface lateral.

Os histogramas dos espectros frontais e laterais produzidos pelo MRMC apresentam o pico de energia primário sempre abaixo ou coincidente ao pico de energia calculado pelo Geant4. As máximas energias calculadas pelo MRMC são superiores ou iguais às calculadas pelo Geant4, exceção feita aos espectros de $1 \mathrm{MeV}$. Com a finalidade de avaliar a importância da implementação da correção pela perda contínua de energia no transporte eletrônico próximo às interfaces, foram feitas algumas simulações sem essa correção. Os espectros resultantes deste teste encontram-se nas figuras 40 a 42. 


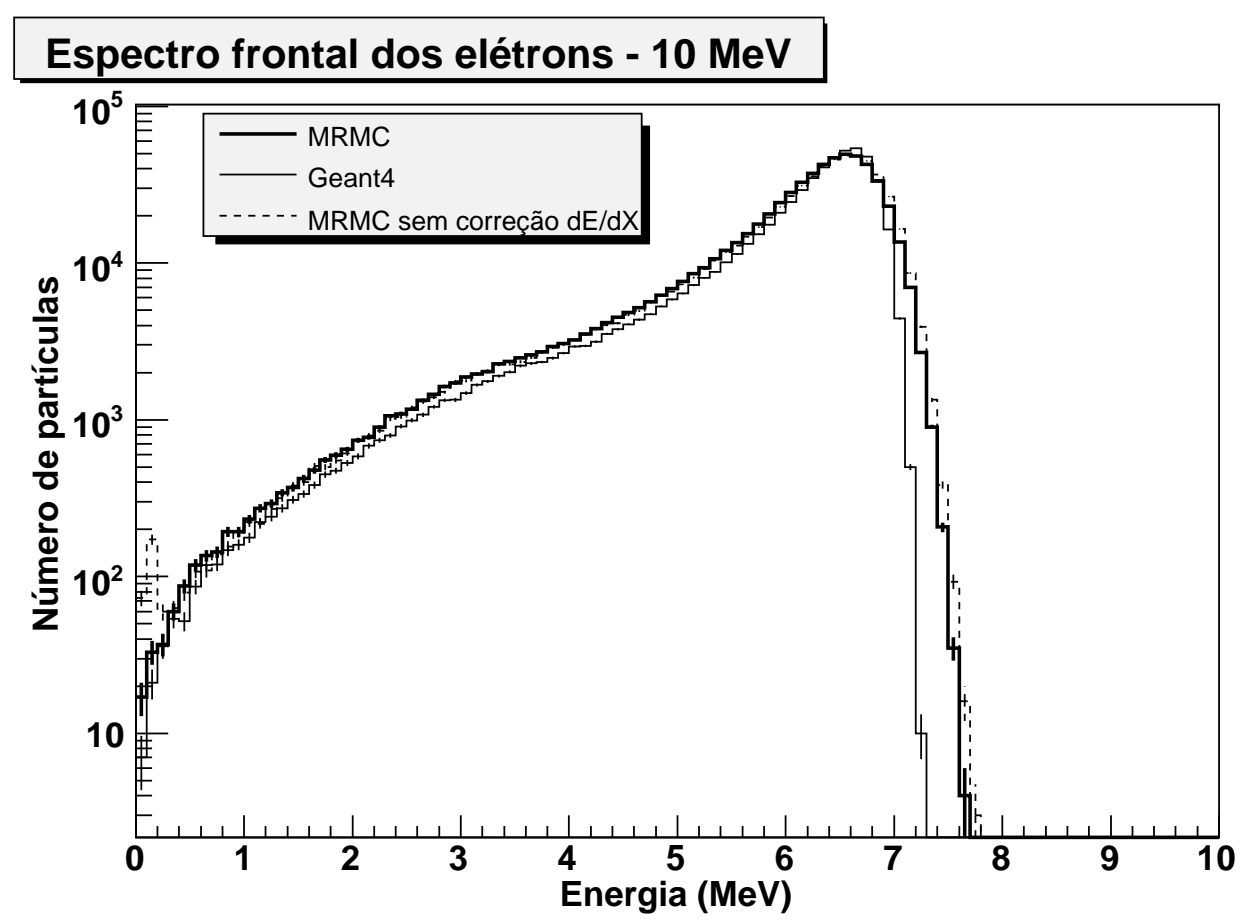

Figura 40: Comparação entre MRMC, Geant4 e uma versão do MRMC sem a correção para perda contínua de energia próximo às interfaces - feixe incidente de $10 \mathrm{MeV}$ e objeto simulador de água.

\section{Espectro frontal dos elétrons - $5 \mathrm{MeV}$}

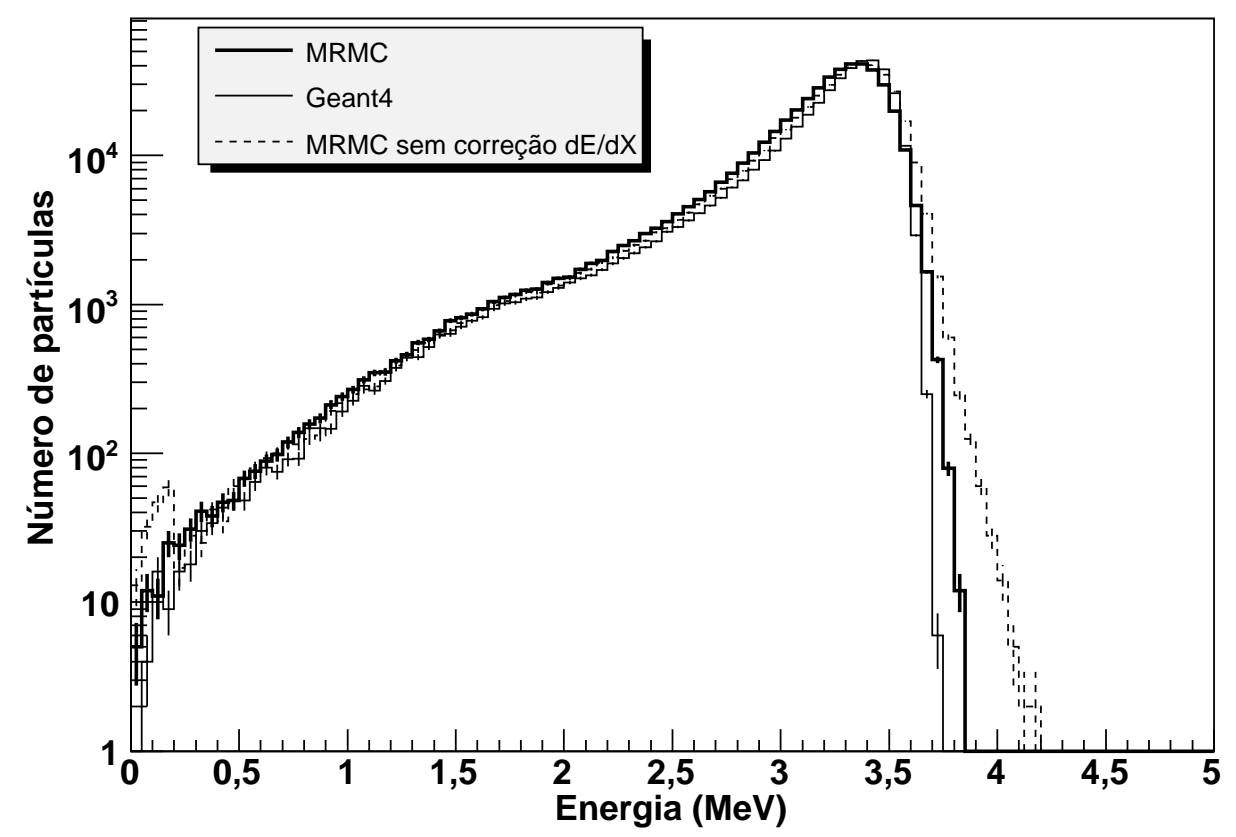

Figura 41: Comparação entre MRMC, Geant4 e uma versão do MRMC sem a correção para perda contínua de energia próximo às interfaces - feixe incidente de $5 \mathrm{MeV}$ e objeto simulador de água. 


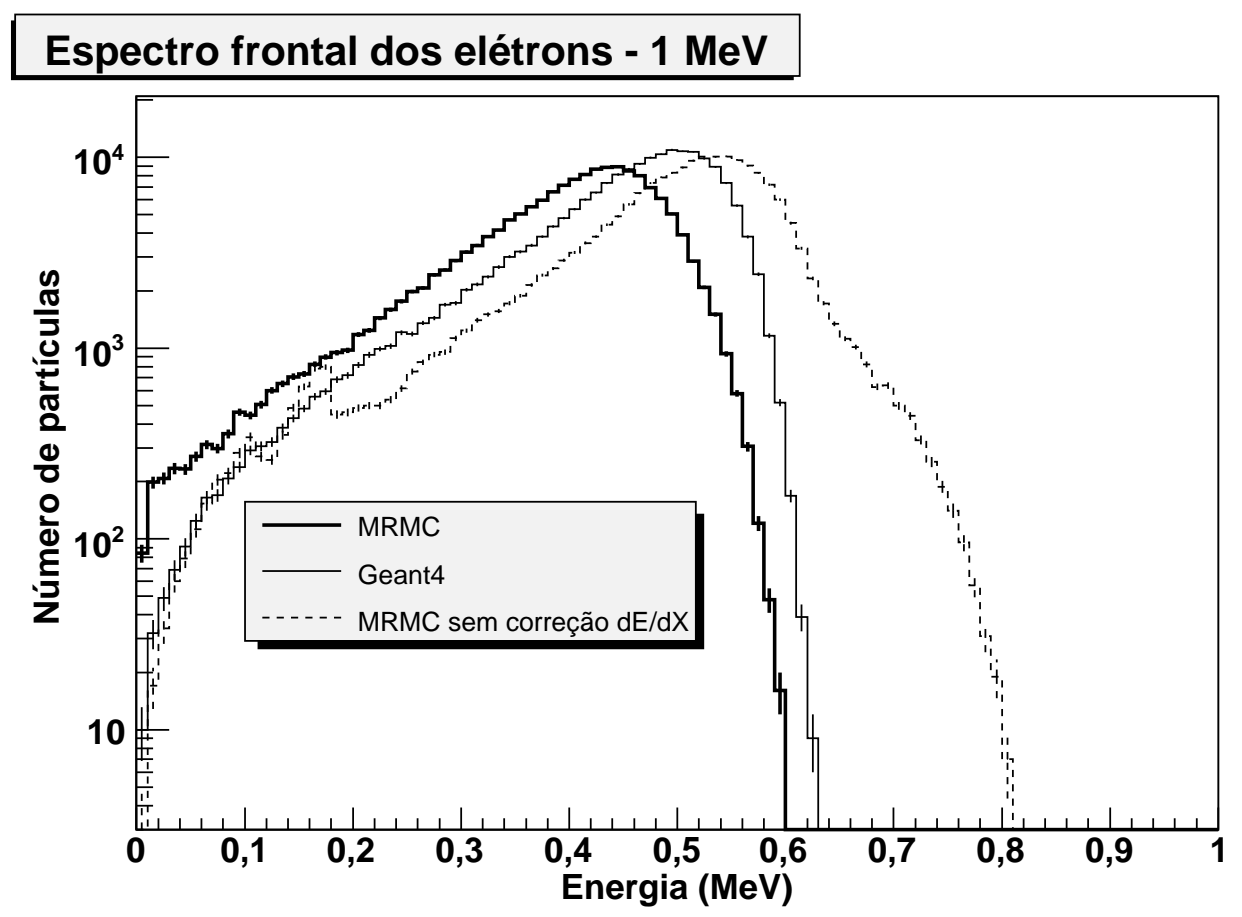

Figura 42: Comparação entre MRMC, Geant4 e uma versão do MRMC sem a correção para perda contínua de energia próximo às interfaces - feixe incidente de $1 \mathrm{MeV}$ e objeto simulador de água.

Conforme podemos observar, o desligamento dessa correção desloca para a direita o espectro frontal do feixe incidente de $1 \mathrm{MeV}$ no objeto simulador de água, além de gerar algumas anomalias no espectro. Essas anomalias tendem a desaparecer com o aumento da energia, uma vez que a perda contínua de energia passa a ser desprezível em elétrons com altas energias para distâncias de até $250 \mu \mathrm{m}$.

Observamos também que os espectros para feixe incidente de $1 \mathrm{MeV}$ no objeto simulador de osso compacto concordam melhor com os simulados pelo Geant4, quando comparados à mesma energia incidente no objeto simulador de água ou tecido mole. Uma possível causa desses desvios em materiais de $\bar{Z}$ baixo são os kugels de $250 \mu \mathrm{m}$ de raio que, conforme apresentado na seção 2.3.3, o algoritmo de MSC do Geant4 possui como limite inferior na espessura dos materiais de um milésimo do comprimento de radiação, que no caso da água é de $360 \mu \mathrm{m}$. Como as dimensões dos objetos simuladores de água e tecido mole utilizados nas simulações para feixe incidente de $1 \mathrm{MeV}$ possuem $0,3 \mathrm{~cm}$ de comprimento e $0,1 \mathrm{~cm}$ de raio, os kugels mais requisitados são os de raios $0,05 \mathrm{~cm}$ e $0,025 \mathrm{~cm}$. Por esse motivo, qualquer pequeno 
erro sistemático introduzido no transporte local (geração do kugel) pode resultar em desvios significativos no resultado final do transporte global.

Os desvios nas energias dos espectros mostrados nesta seção, podem ser atribuídos às tabelas de Stopping Power utilizadas para a correção pela perda contínua de energia nos trechos onde não há kugel disponível, conforme apresentado na seção 4.2. Tais tabelas são conhecidas por apresentarem incertezas da ordem de 1 a $2 \%$ para energias acima de $100 \mathrm{keV}$; para energias entre 100 e $10 \mathrm{keV}$ as incertezas podem chegar a 3\% para materiais de baixo Z, e até $10 \%$ para materiais de alto Z (40). Portanto, esta pode ser a causa para os desvios da ordem de 1,5\% nos picos dos espectros dos objetos simuladores de água e tecido mole.

\subsubsection{O espectro de elétrons primários e secundários}

Nesta seção e nas seguintes trataremos apenas das simulações completas, com os elétrons secundários sendo gerados e transportados normalmente, assim como os primários, conforme descrito no capítulo 4.

Os espectros resultantes para o objeto simulador de água estão nos gráficos das figuras 43 a 50, e as análises desses resultados são apresentadas na tabela 8 .

Tabela 8: Tabela de análise dos espectros referentes ao objeto simulador homogêneo de água

\begin{tabular}{|c||c|c|c|c|}
\hline Ítem/Energia & $25 \mathrm{MeV}$ & $10 \mathrm{MeV}$ & $5 \mathrm{MeV}$ & $1 \mathrm{MeV}$ \\
\hline \hline$\Delta E_{\text {pico }}$ frontal & $1,7 \pm 0,7 \%$ & $1,5 \pm 0,7 \%$ & $0,0 \pm 0,7 \%$. & $13,9 \pm 1,0 \%$ \\
\hline$\Delta E_{\text {max }}$ frontal & $3,9 \pm 0,6 \%$ & $4,1 \pm 0,7 \%$ & $2,7 \pm 0,7 \%$ & $4,8 \pm 0,8 \%$ \\
\hline$\Delta E_{\text {pico } \text { lateral }}$ & $1,4 \pm 0,7 \%$ & $0,0 \pm 0,7 \%$ & $0,0 \pm 0,7 \%$ & $4,6 \pm 0,8 \%$ \\
\hline$\Delta E_{\text {max }}$ lateral & $0,0 \pm 0,5 \%$ & $1,1 \pm 0,5 \%$ & $2,1 \pm 0,5 \%$ & $3,6 \pm 0,6 \%$ \\
\hline$\overline{\Delta N}$ frontal & $18,2 \pm 0,1 \%$ & $12,0 \pm 0,1 \%$ & $17,0 \pm 0,1 \%$ & $46,9 \pm 0,1 \%$ \\
\hline$\overline{\Delta N}$ lateral & $15,4 \pm 0,1 \%$ & $11,6 \pm 0,1 \%$ & $10,6 \pm 0,1 \%$ & $53,0 \pm 0,1 \%$ \\
\hline
\end{tabular}




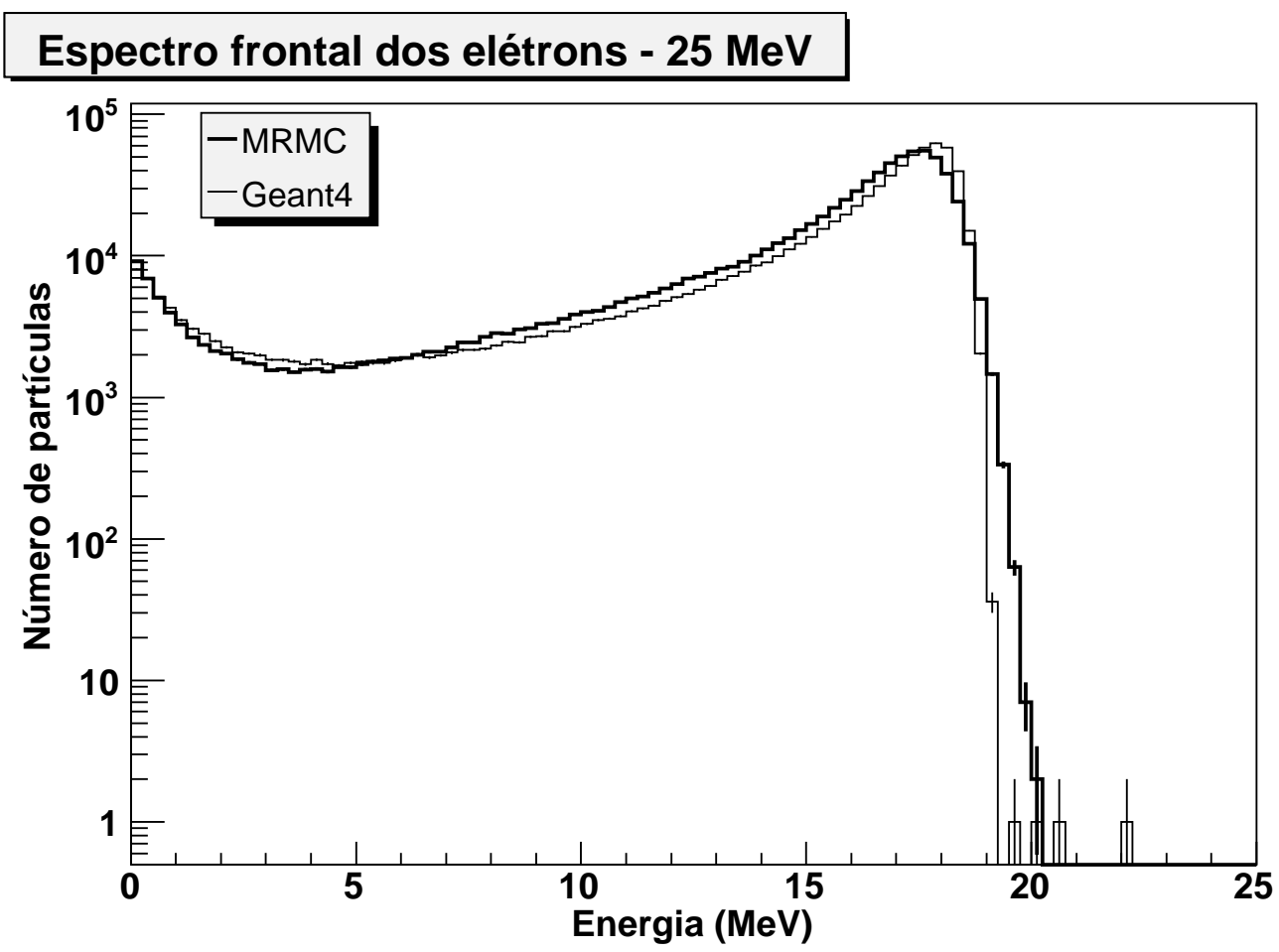

Figura 43: Espectro frontal de elétrons para feixe incidente de $25 \mathrm{MeV}$ no objeto simulador de água.

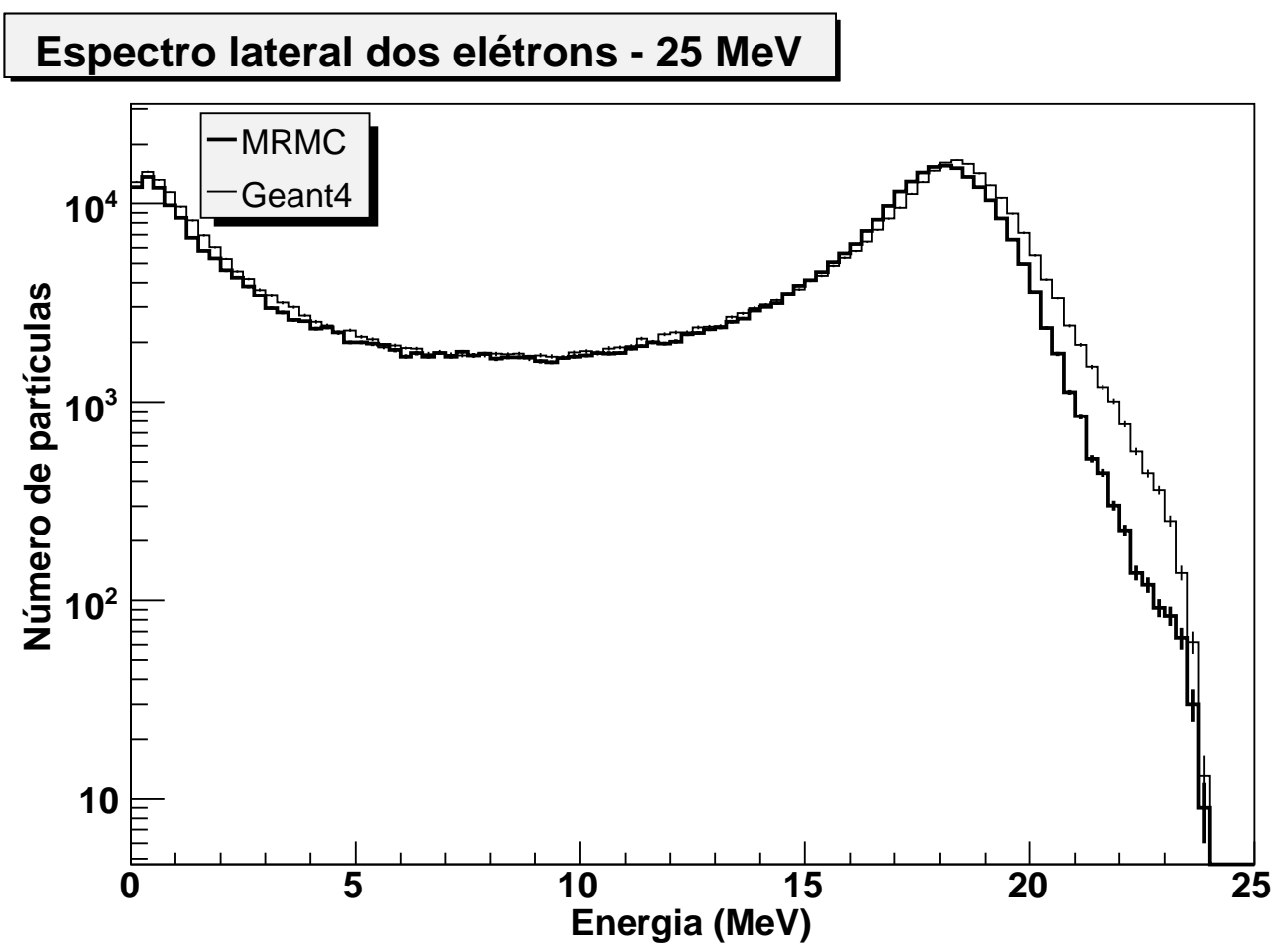

Figura 44: Espectro lateral de elétrons para feixe incidente de $25 \mathrm{MeV}$ no objeto simulador de água. 


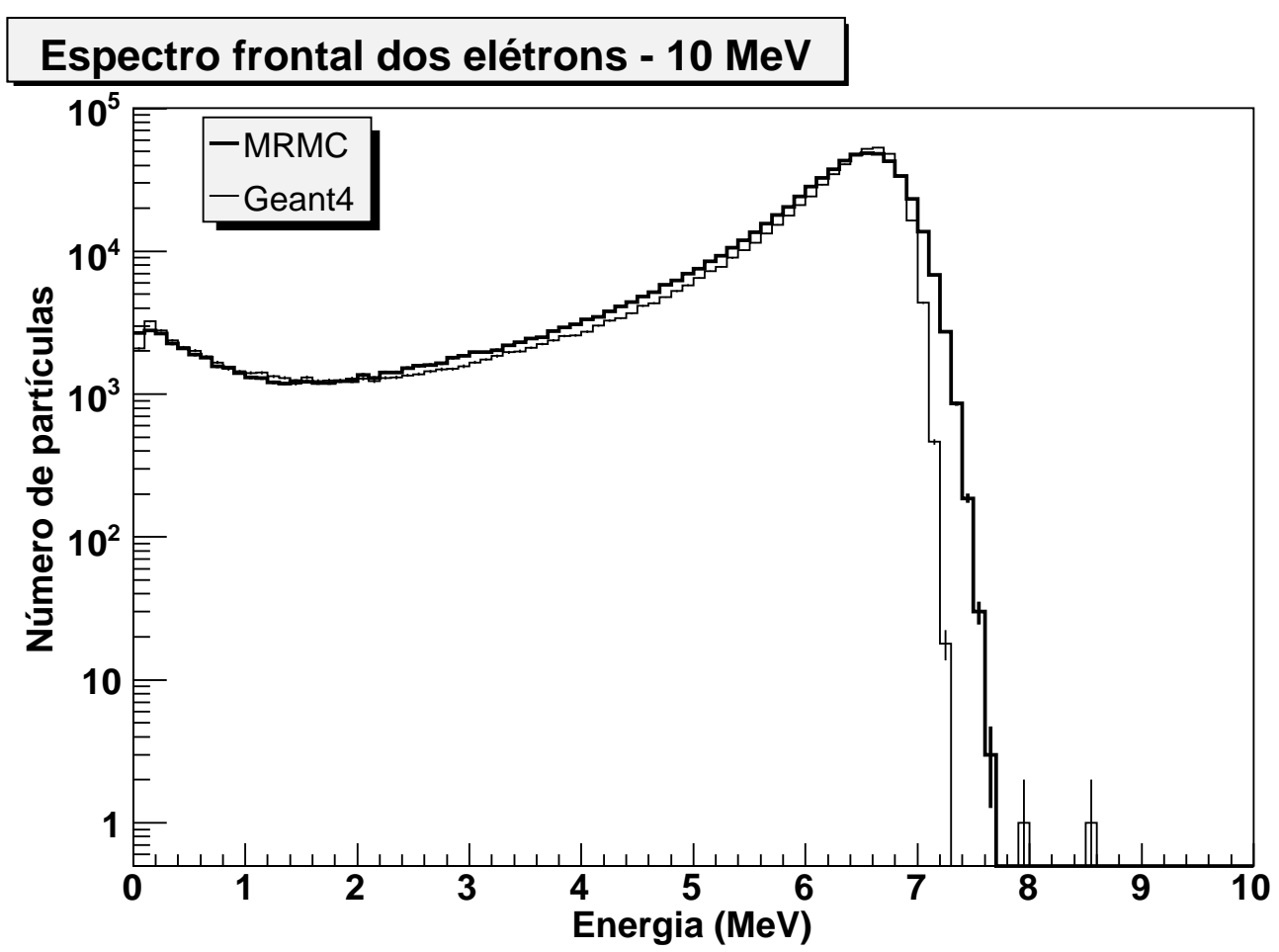

Figura 45: Espectro frontal de elétrons para feixe incidente de $10 \mathrm{MeV}$ no objeto simulador de água.

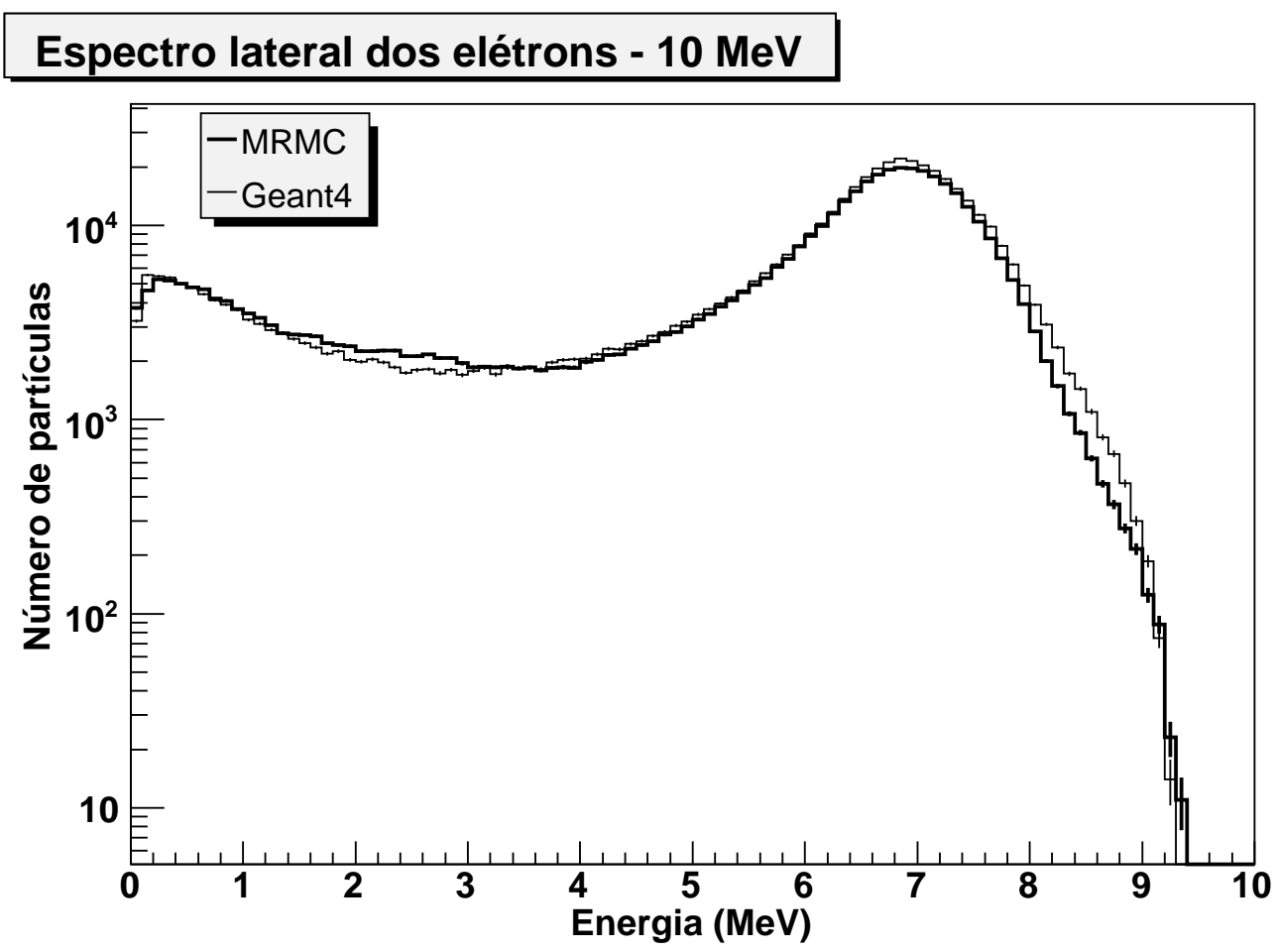

Figura 46: Espectro lateral de elétrons para feixe incidente de $10 \mathrm{MeV}$ no objeto simulador de água. 


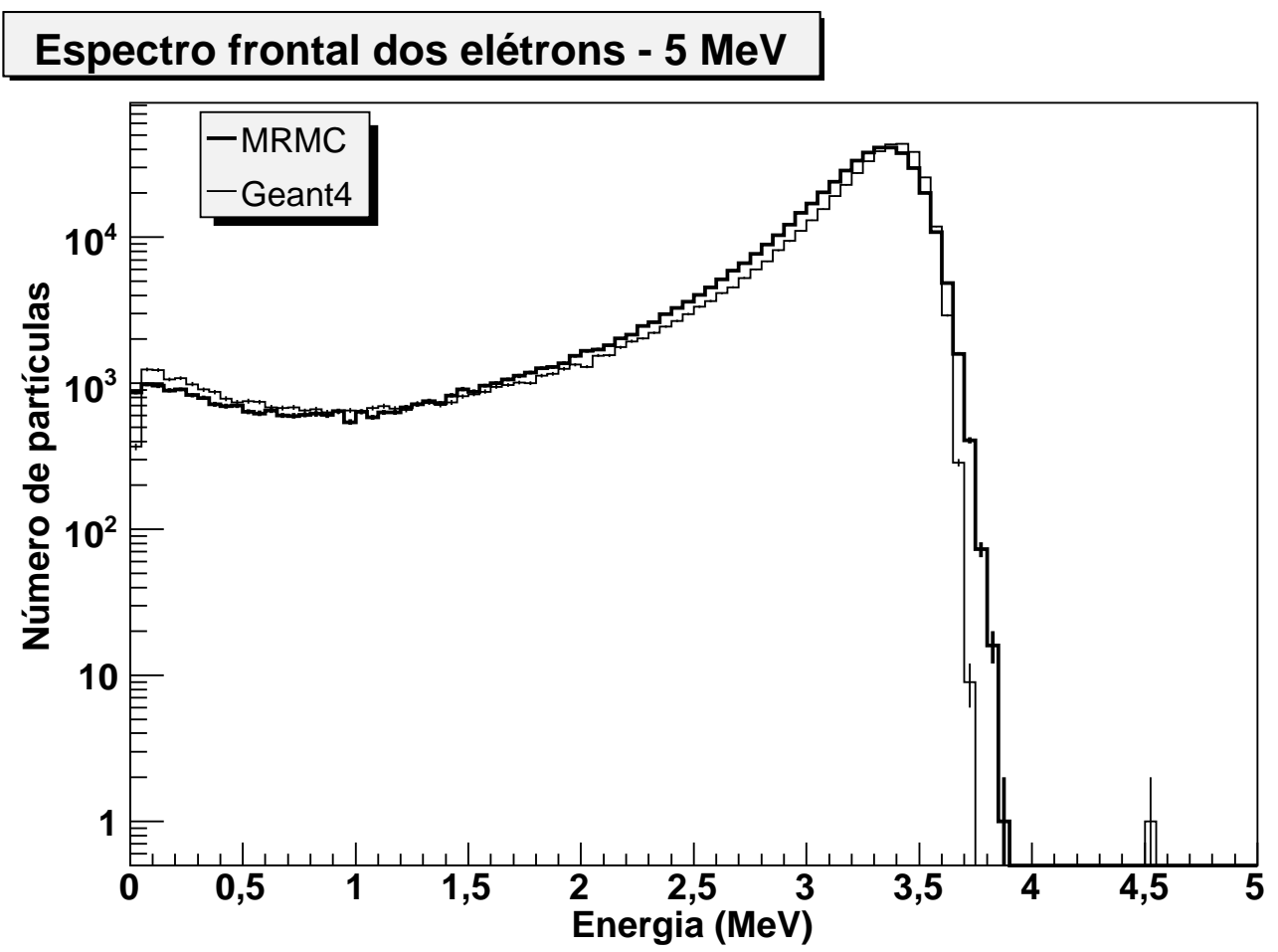

Figura 47: Espectro frontal de elétrons para feixe incidente de $5 \mathrm{MeV}$ no objeto simulador de água.

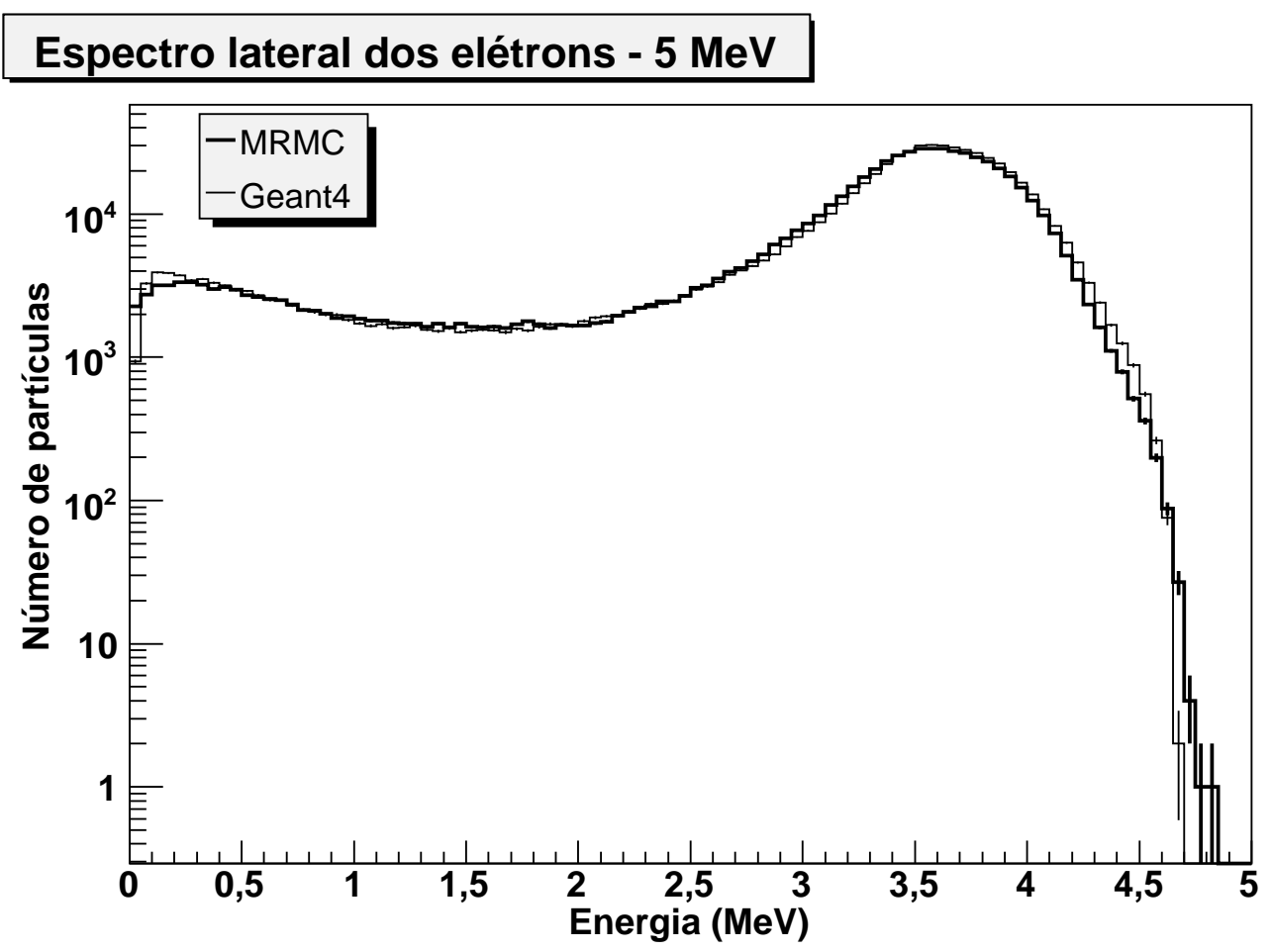

Figura 48: Espectro lateral de elétrons para feixe incidente de $5 \mathrm{MeV}$ no objeto simulador de água. 


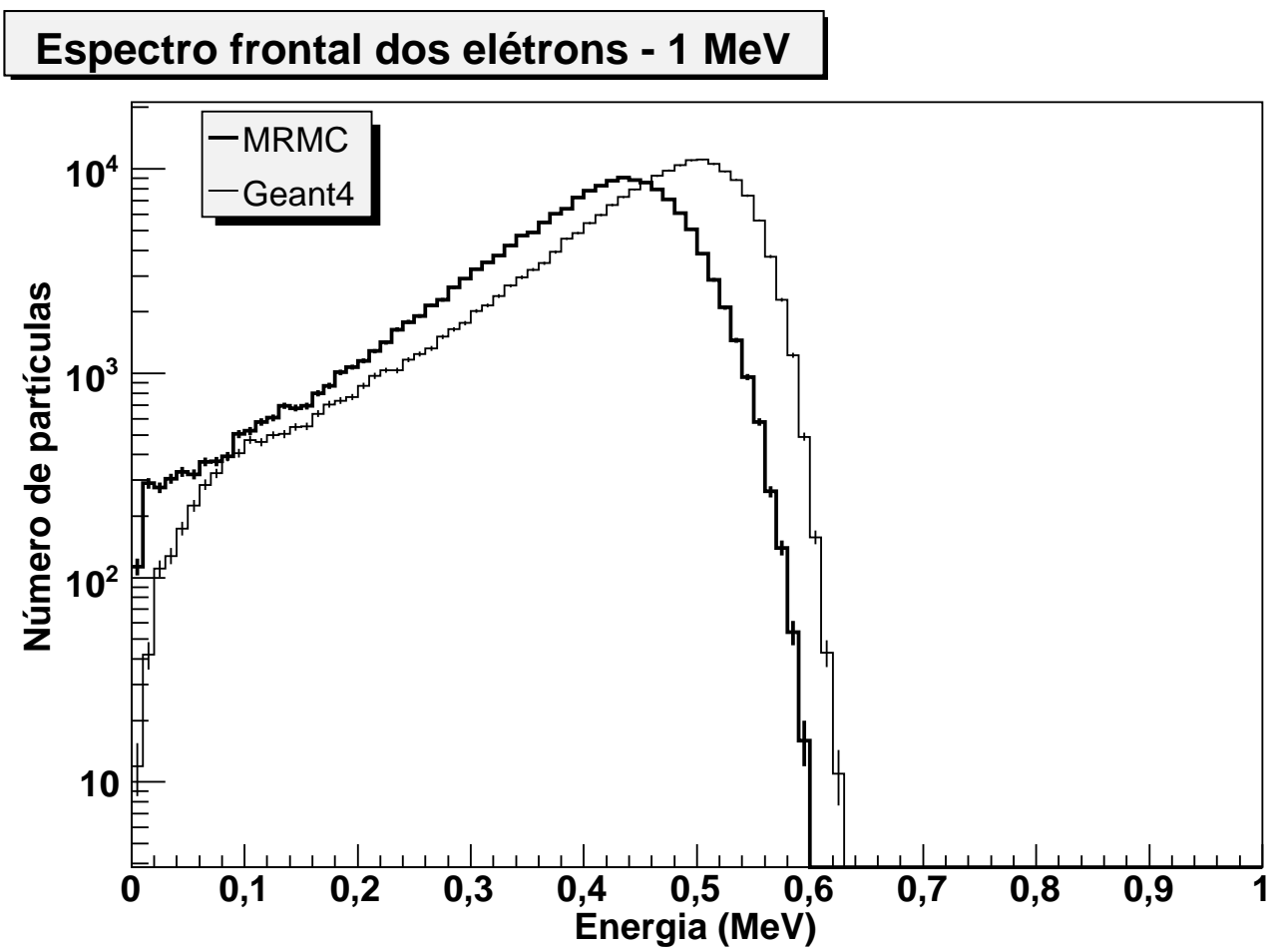

Figura 49: Espectro frontal de elétrons para feixe incidente de $1 \mathrm{MeV}$ no objeto simulador de água.

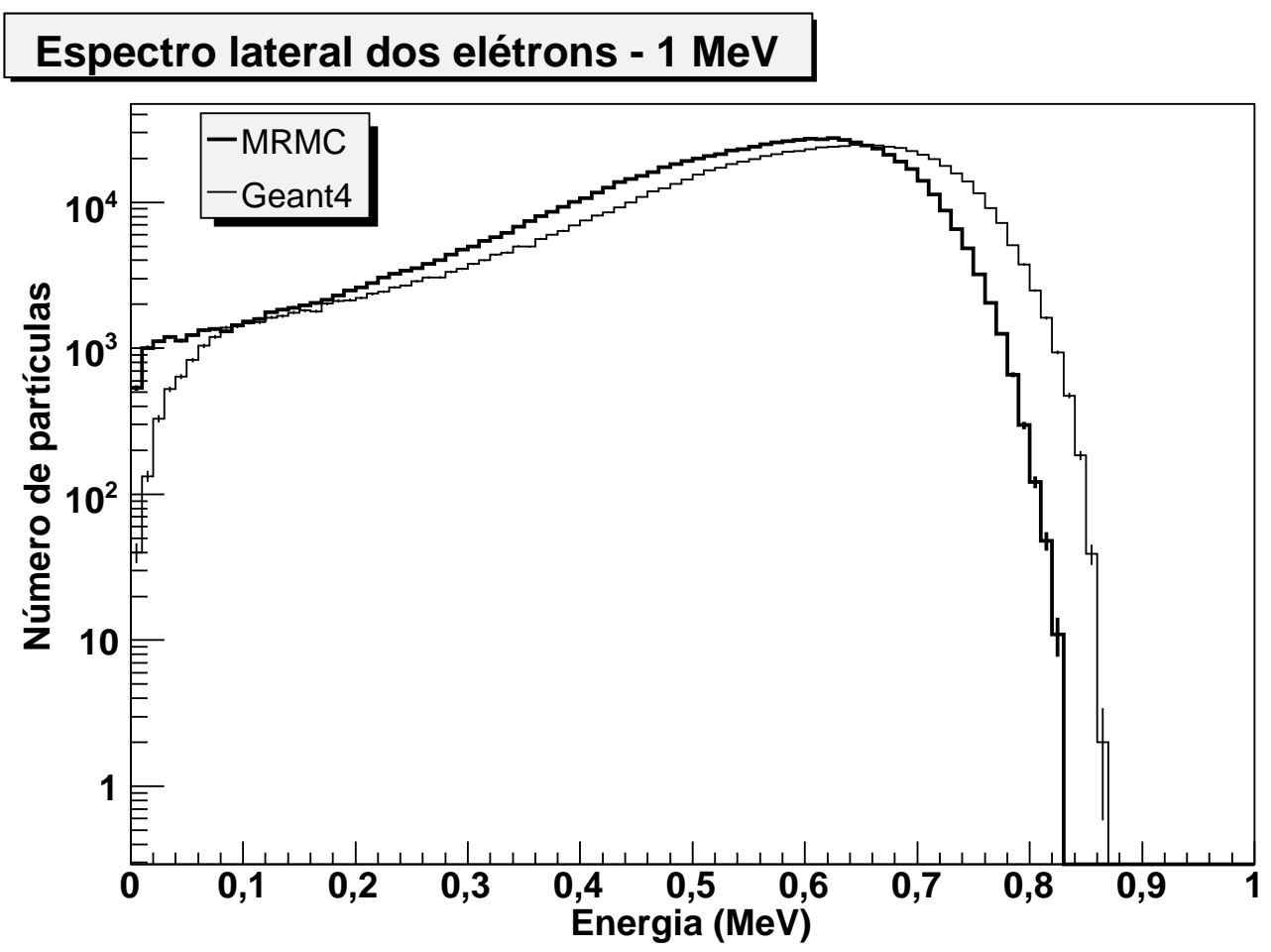

Figura 50: Espectro lateral de elétrons para feixe incidente de $1 \mathrm{MeV}$ no objeto simulador de água. 
Os espectros provenientes da simulação completa apresentam um pico secundário próximo a região de baixa energia. Esse pico não será considerado nas análises, porque a precisão nessa região é bastante inferior aos demais dados usados para as análises de concordância. No entanto, qualitativamente, há uma boa concordância entre esses picos secundários simulados pelo Geant4 e pelo MRMC, exceto no caso do feixe incidente de $1 \mathrm{MeV}$, que não possui esse pico secundário.

Conforme podemos observar, os resultados apresentados para o objeto simulador de água na simulação completa são significativamente melhores que os apresentados na tabela 5 para os espectros primários.

\section{Espectro frontal dos elétrons - $1 \mathrm{MeV}$}

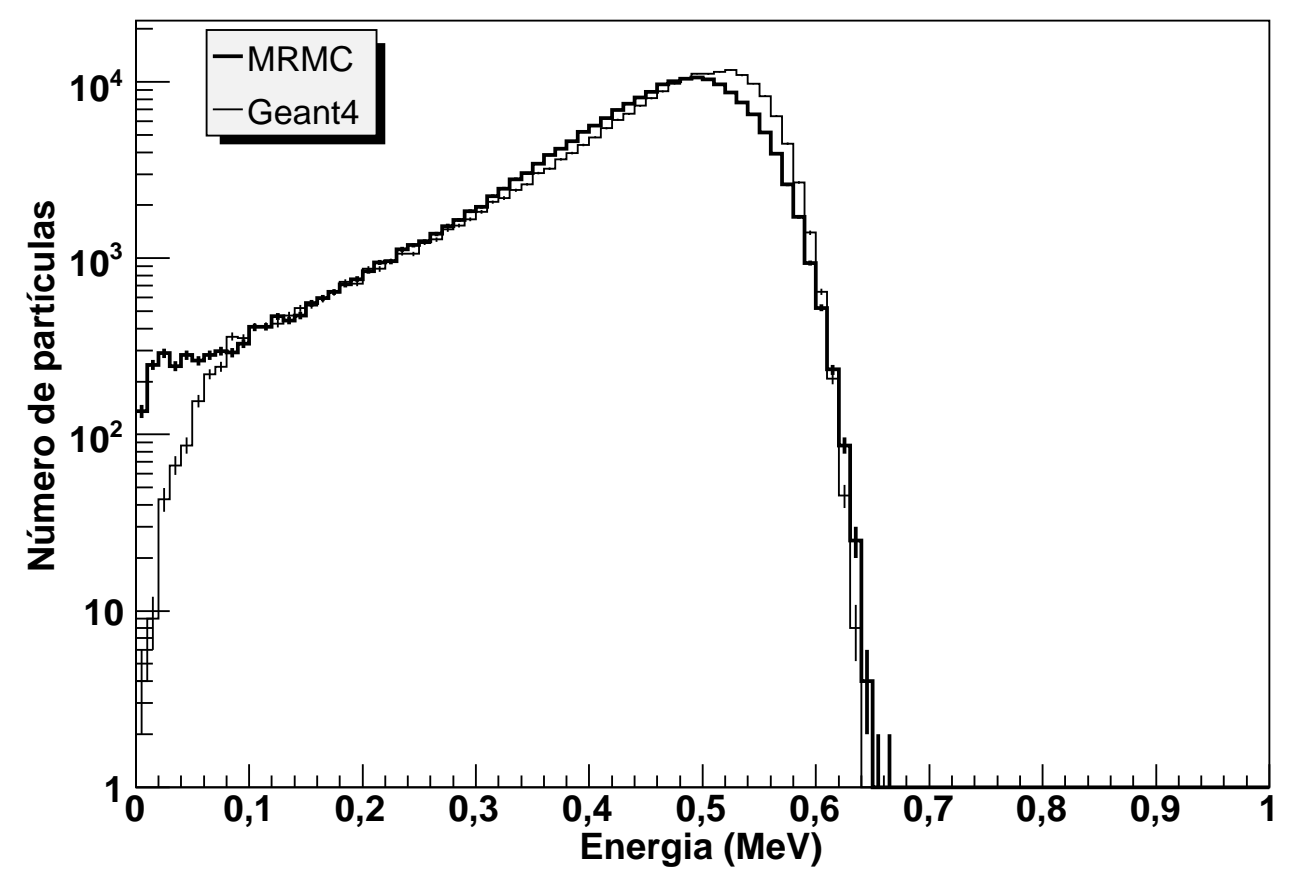

Figura 51: Espectro frontal de elétrons para feixe incidente de $1 \mathrm{MeV}$ no objeto simulador de tecido mole. 


\section{Espectro lateral dos elétrons $-1 \mathrm{MeV}$}

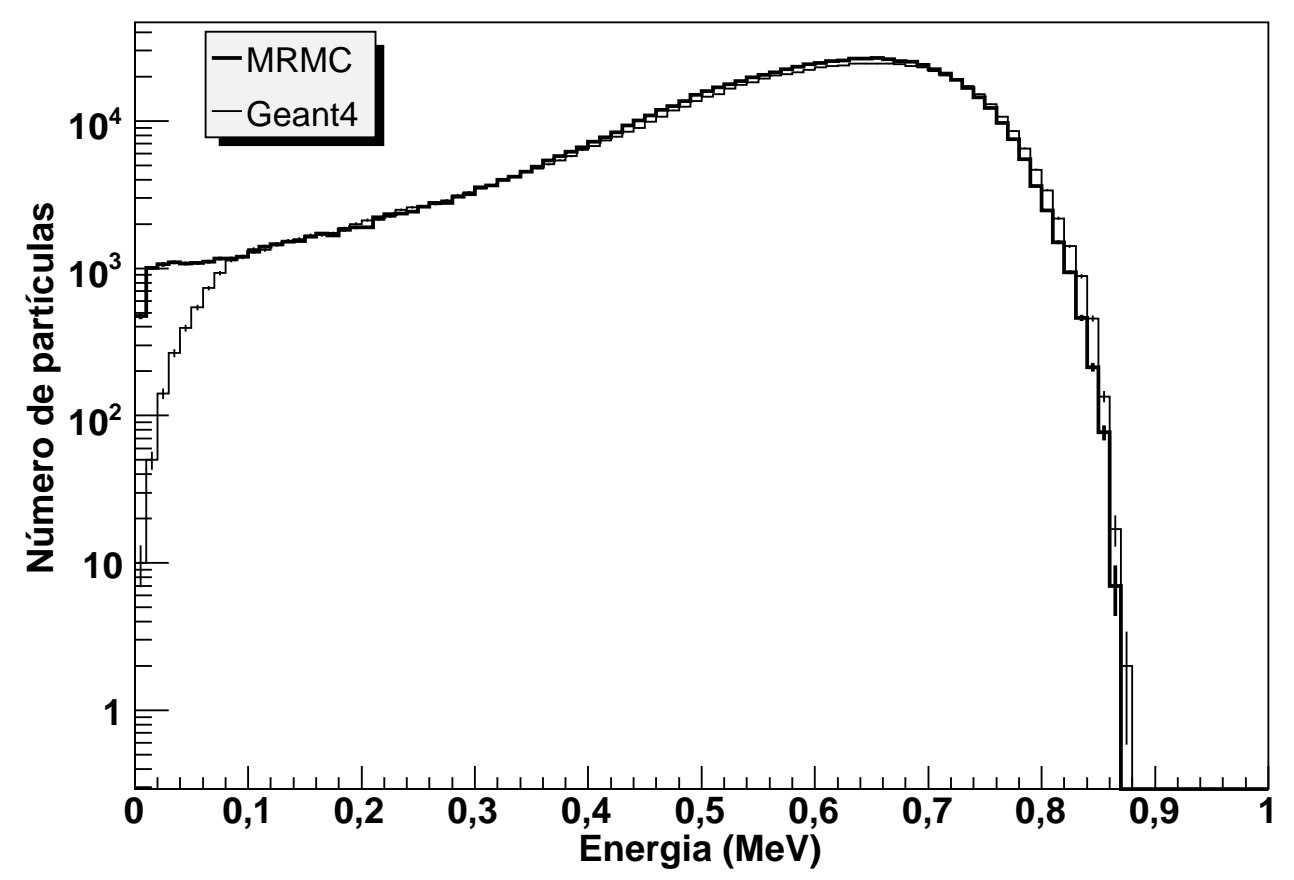

Figura 52: Espectro lateral de elétrons para feixe incidente de $1 \mathrm{MeV}$ no objeto simulador de tecido mole.

Tabela 9: Tabela de análise dos espectros referentes ao objeto simulador homogêneo de tecido mole

\begin{tabular}{|c||c|c|c|c|}
\hline Ítem/Energia & $25 \mathrm{MeV}$ & $10 \mathrm{MeV}$ & $5 \mathrm{MeV}$ & $1 \mathrm{MeV}$ \\
\hline \hline$\Delta E_{\text {pico }}$ frontal & $1,4 \pm 0,7 \%$ & $1,5 \pm 0,7 \%$ & $1,5 \pm 0,7 \%$ & $2,0 \pm 1,0 \%$ \\
\hline$\Delta E_{\text {max }}$ frontal & $2,5 \pm 0,6 \%$ & $4,1 \pm 0,7 \%$ & $2,7 \pm 0,7 \%$ & $3,2 \pm 0,8 \%$ \\
\hline$\Delta E_{\text {pico lateral }}$ & $1,4 \pm 0,7 \%$ & $1,5 \pm 0,7 \%$ & $0,0 \pm 0,7 \%$ & $0,0 \pm 0,8 \%$ \\
\hline$\Delta E_{\text {max }}$ lateral & $0,0 \pm 0,5 \%$ & $1,1 \pm 0,5 \%$ & $1,0 \pm 0,5 \%$ & $0,0 \pm 0,6 \%$ \\
\hline$\overline{\Delta N}$ frontal & $18,1 \pm 0,1 \%$ & $13,0 \pm 0,1 \%$ & $19,3 \pm 0,1 \%$ & $46,8 \pm 0,1 \%$ \\
\hline$\overline{\Delta N}$ lateral & $15,9 \pm 0,1 \%$ & $11,9 \pm 0,1 \%$ & $11,09 \pm 0,1 \%$ & $32,0 \pm 0,1 \%$ \\
\hline
\end{tabular}

As mesmas observações feitas para o objeto simulador de água também podem ser feitas para o objeto simulador de tecido mole, exceto pela surpreendente concordância dos espectros para feixe incidente de $1 \mathrm{MeV}$. Os gráficos para esses espectros são apresentados nas figuras 51 e 52, e na tabela 9 temos as análises desses resultados. Como os outros espectros para 
o objeto simulador de tecido mole são muito semelhantes aos da água, os mesmos não serão apresentados.

Tabela 10: Tabela de análise dos espectros referentes ao objeto simulador homogêneo de osso compacto

\begin{tabular}{|c||c|c|c|c|}
\hline Ítem/Energia & $25 \mathrm{MeV}$ & $10 \mathrm{MeV}$ & $5 \mathrm{MeV}$ & $1 \mathrm{MeV}$ \\
\hline \hline$\Delta E_{\text {pico }}$ frontal & $4,2 \pm 0,7 \%$ & $5,3 \pm 0,7 \%$ & $4,9 \pm 0,7 \%$ & $1,3 \pm 1,0 \%$ \\
\hline$\Delta E_{\text {max }}$ frontal & $3,6 \pm 0,6 \%$ & $6,1 \pm 0,7 \%$ & $1,9 \pm 0,7 \%$ & $1,2 \pm 0,8 \%$ \\
\hline$\Delta E_{\text {pico }}$ lateral & $1,8 \pm 0,7 \%$ & $1,9 \pm 0,7 \%$ & $1,7 \pm 0,7 \%$ & $1,7 \pm 0,8 \%$ \\
\hline$\Delta E_{\text {max }}$ lateral & $0,0 \pm 0,5 \%$ & $1,1 \pm 0,5 \%$ & $1,1 \pm 0,5 \%$ & $0,0 \pm 0,6 \%$ \\
\hline$\overline{\Delta N}$ frontal & $39,5 \pm 0,1 \%$ & $11,4 \pm 0,1 \%$ & $19,1 \pm 0,1 \%$ & $30,0 \pm 0,1 \%$ \\
\hline$\overline{\Delta N}$ lateral & $20,5 \pm 0,1 \%$ & $9,0 \pm 0,1 \%$ & $15,3 \pm 0,1 \%$ & $46,0 \pm 0,1 \%$ \\
\hline
\end{tabular}

\section{Espectro frontal dos elétrons - $25 \mathrm{MeV}$}

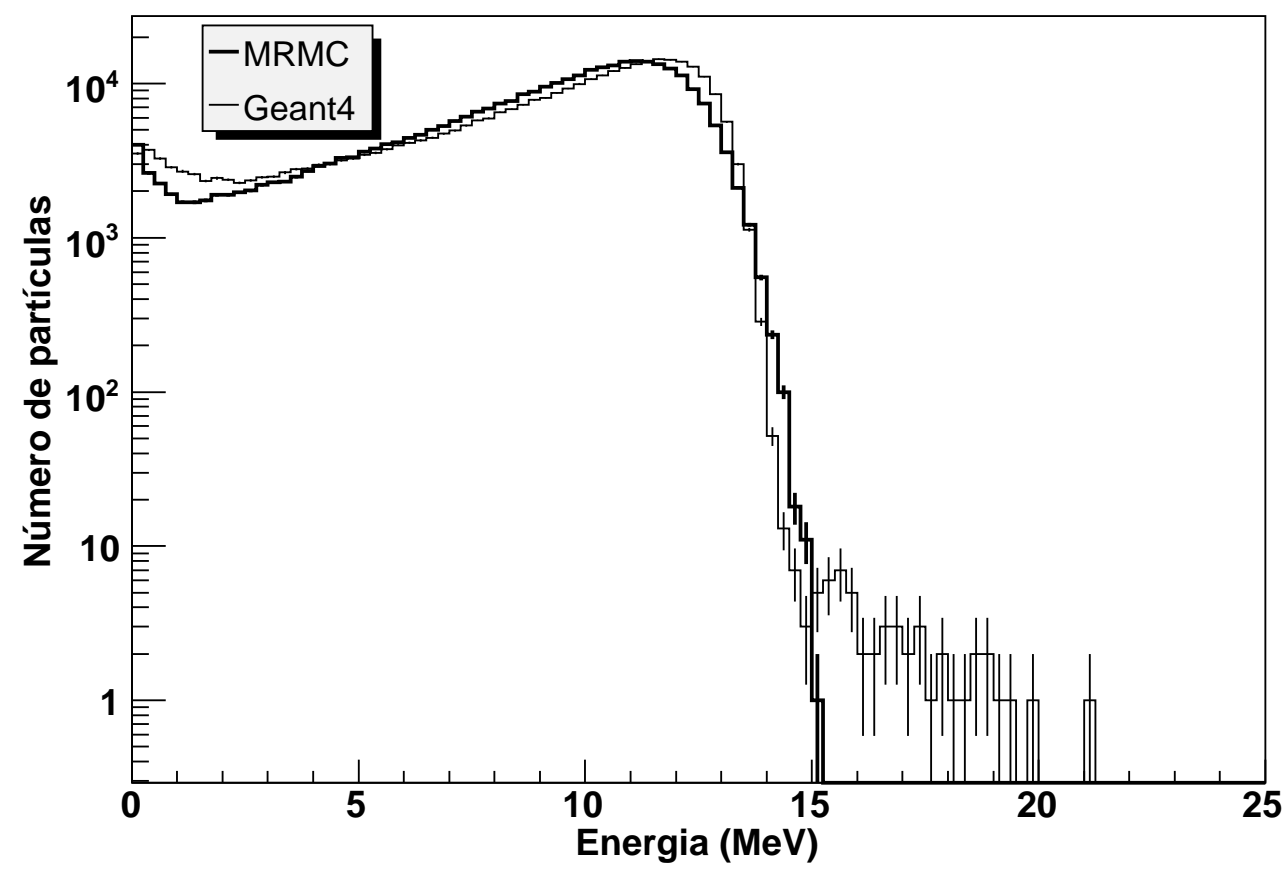

Figura 53: Espectro frontal de elétrons para feixe incidente de $25 \mathrm{MeV}$ no objeto simulador de osso compacto. 


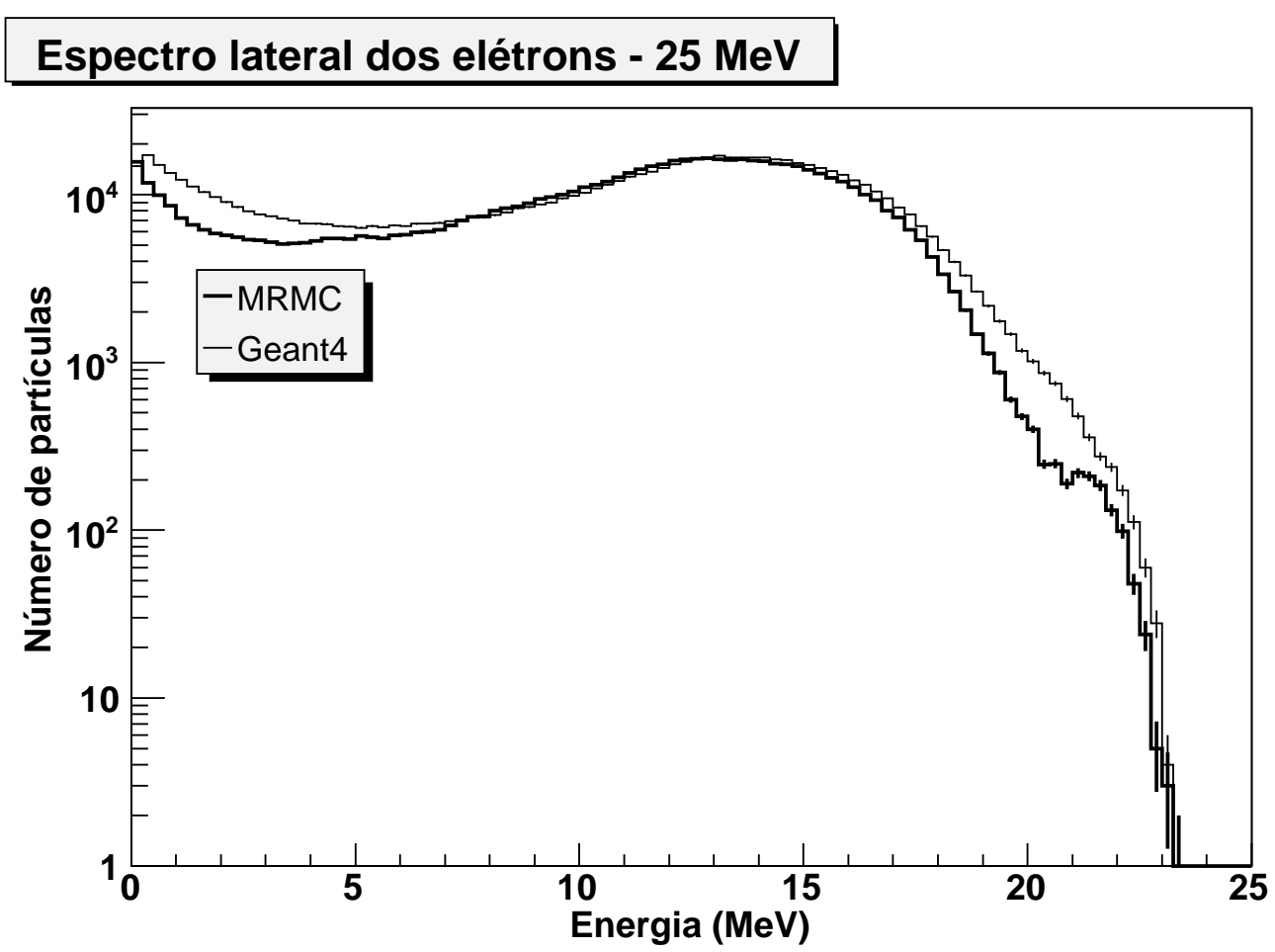

Figura 54: Espectro lateral de elétrons para feixe incidente de $25 \mathrm{MeV}$ no objeto simulador de osso compacto.

\section{Espectro frontal dos elétrons - $10 \mathrm{MeV}$}

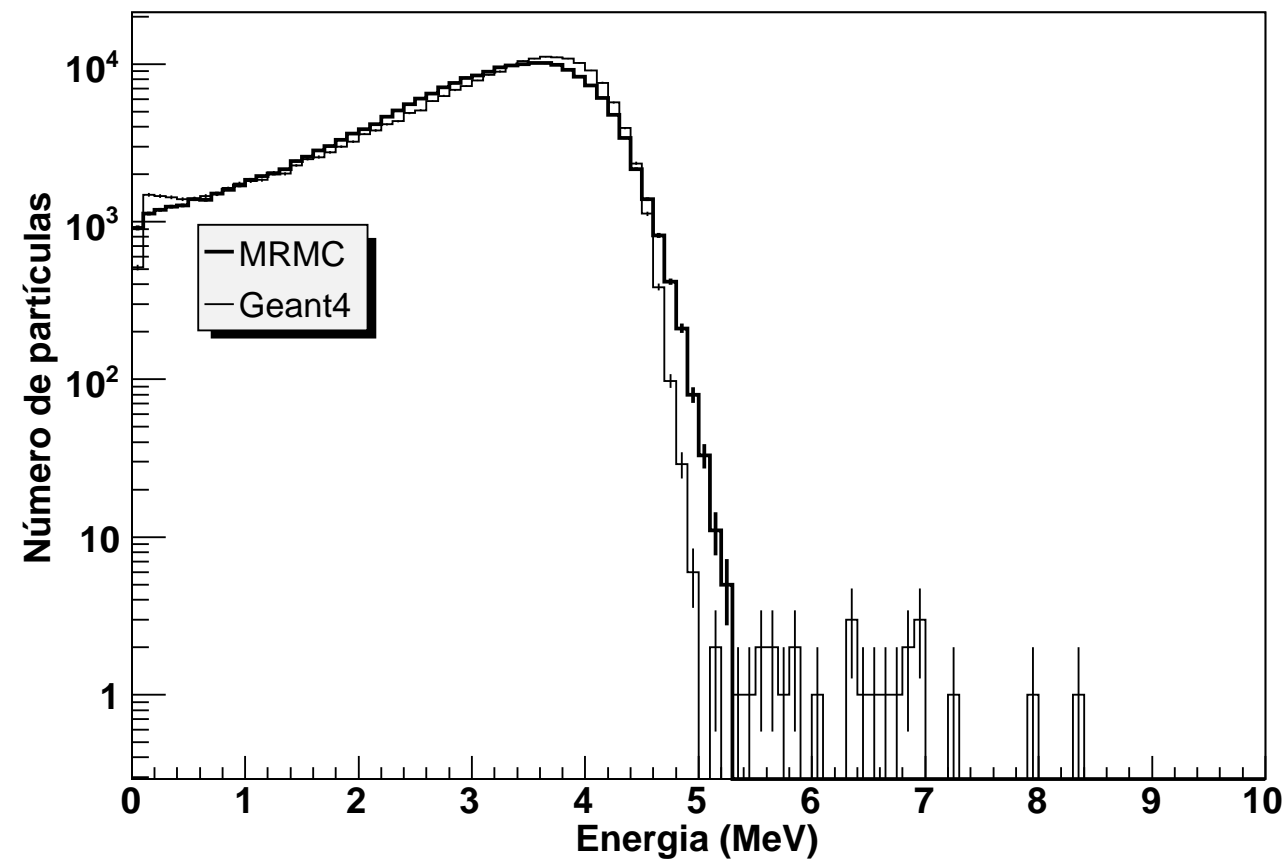

Figura 55: Espectro frontal de elétrons para feixe incidente de $10 \mathrm{MeV}$ no objeto simulador de osso compacto. 


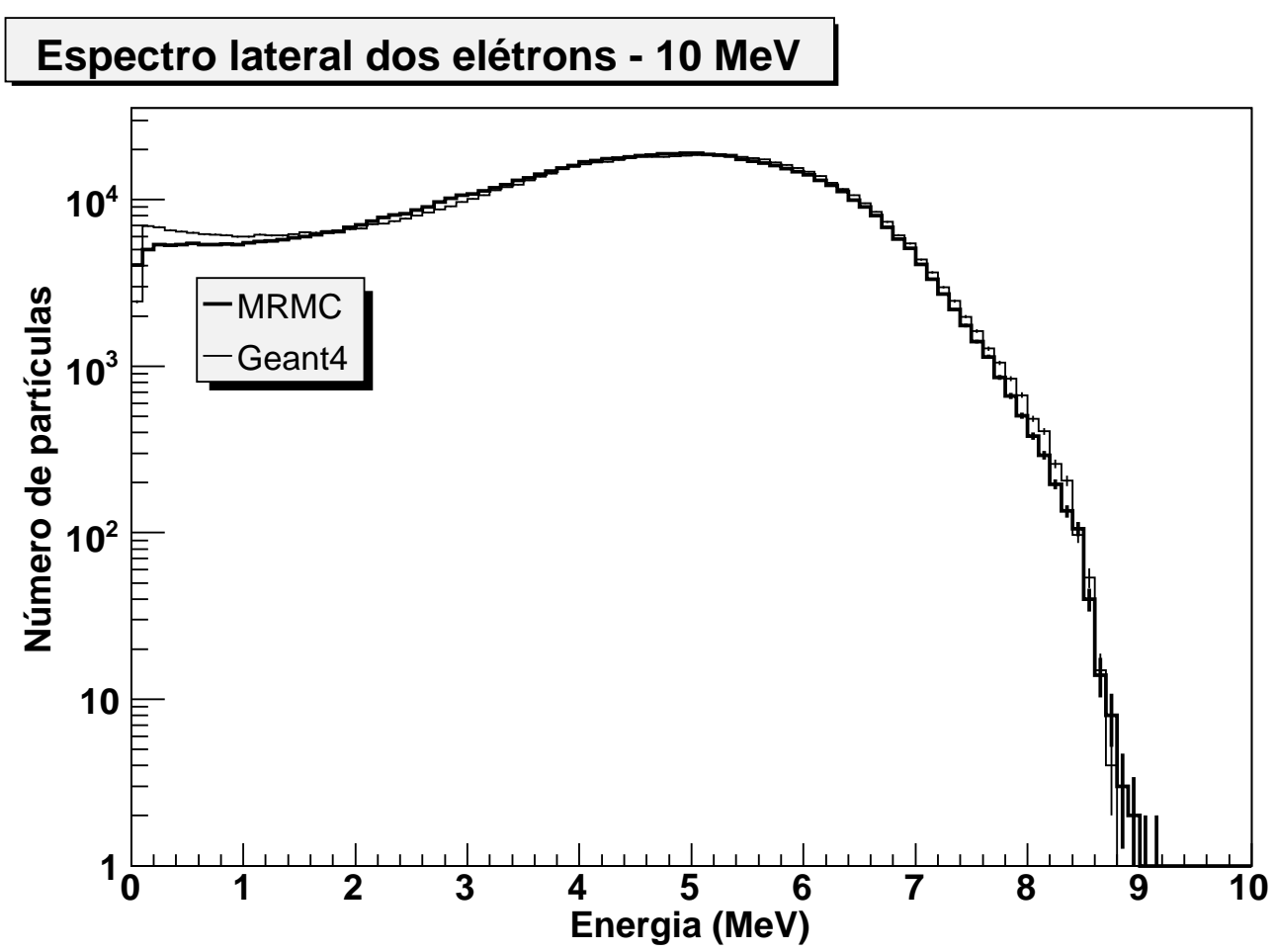

Figura 56: Espectro lateral de elétrons para feixe incidente de $10 \mathrm{MeV}$ no objeto simulador de osso compacto.

\section{Espectro frontal dos elétrons - $5 \mathrm{MeV}$}

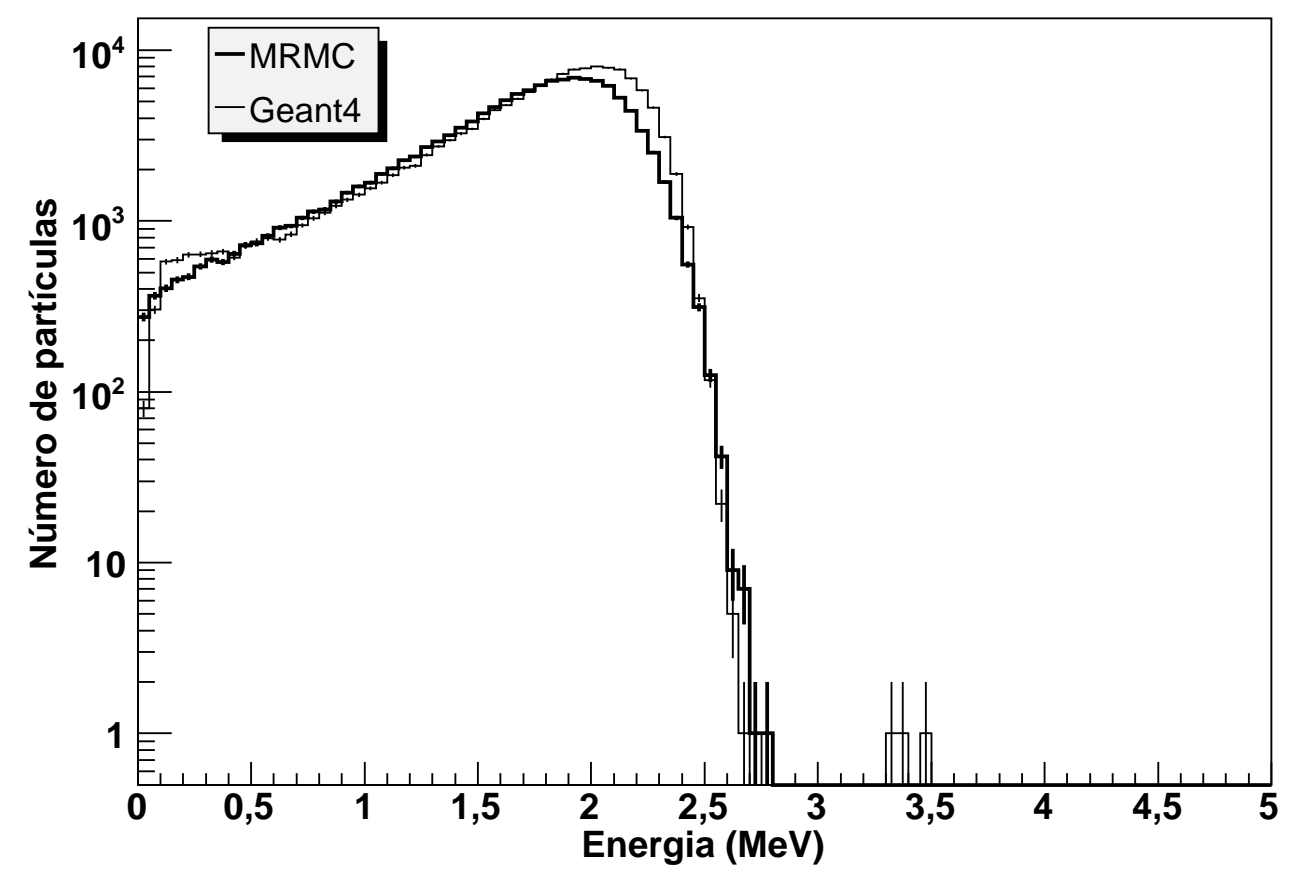

Figura 57: Espectro frontal de elétrons para feixe incidente de $5 \mathrm{MeV}$ no objeto simulador de osso compacto. 


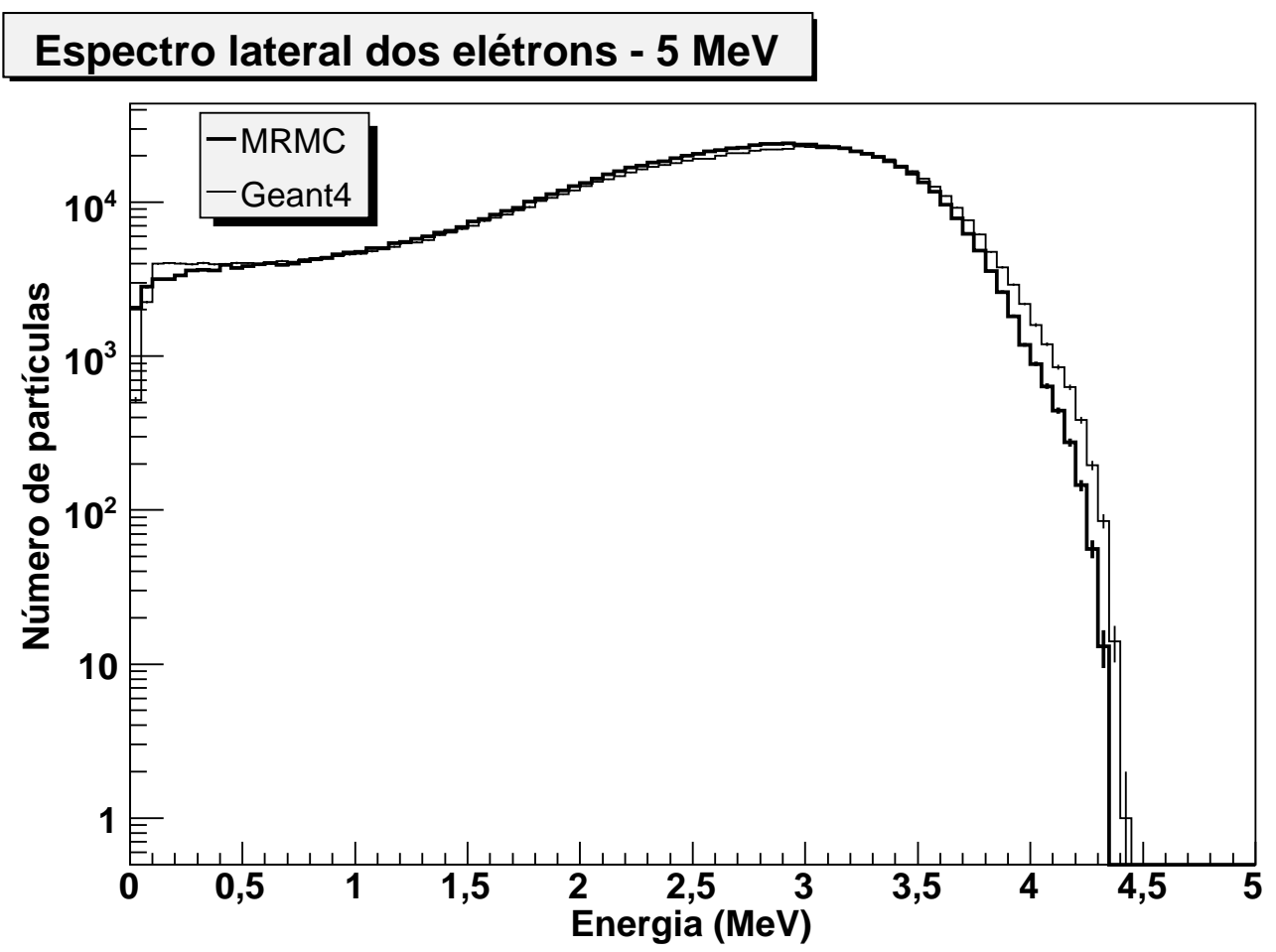

Figura 58: Espectro lateral de elétrons para feixe incidente de $5 \mathrm{MeV}$ no objeto simulador de osso compacto.

\section{Espectro frontal dos elétrons $-1 \mathrm{MeV}$}

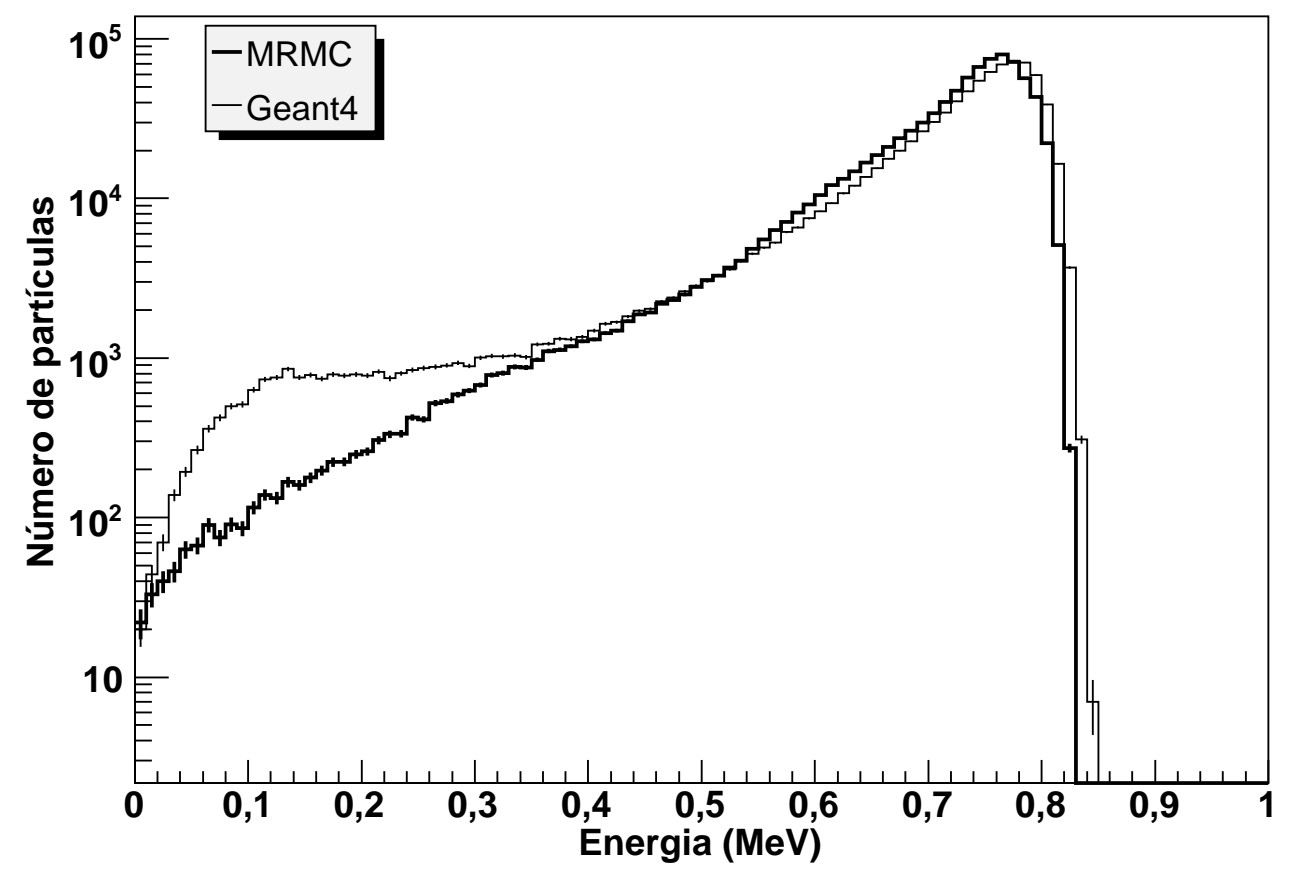

Figura 59: Espectro frontal de elétrons para feixe incidente de $1 \mathrm{MeV}$ no objeto simulador de osso compacto. 


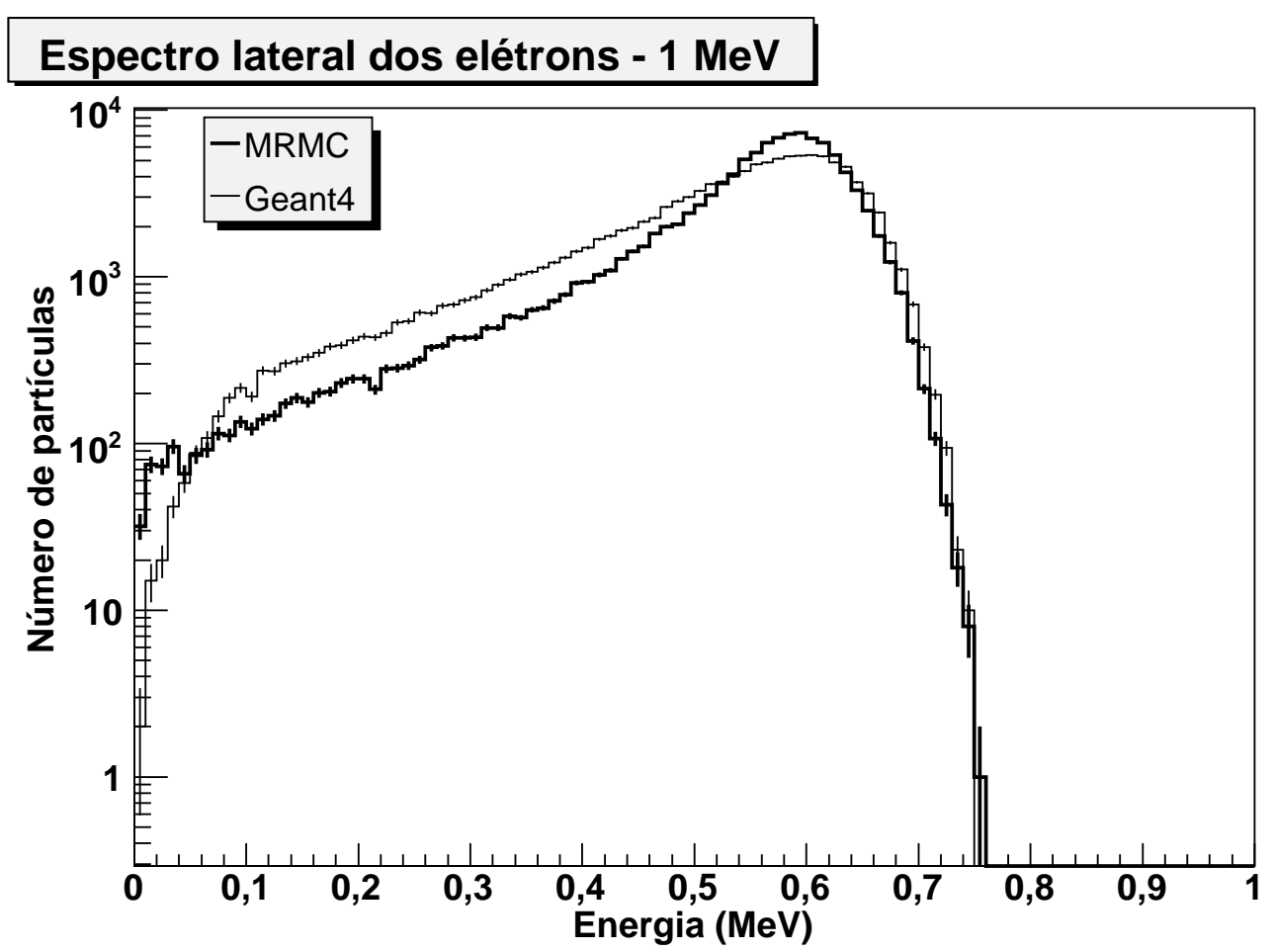

Figura 60: Espectro lateral de elétrons para feixe incidente de $1 \mathrm{MeV}$ no objeto simulador de osso compacto.

Os espectros para o objeto simulador de osso compacto são mostrados nas figuras 53 a 60 , e na tabela 10 são apresentadas as análises para esses espectros.

As simulações completas para o osso compacto apresentam alguns espectros de retroespalhamento que até permitem algum tipo de análise, conforme pode ser visto na figura 61 . Contudo, como não há como comparar com as análises dos espectros retroespalhados dos elétrons primários e nem com as análises dos espectros de retroespalhamento dos outros tipos de materiais, também não fizemos uma análise do mesmo. 


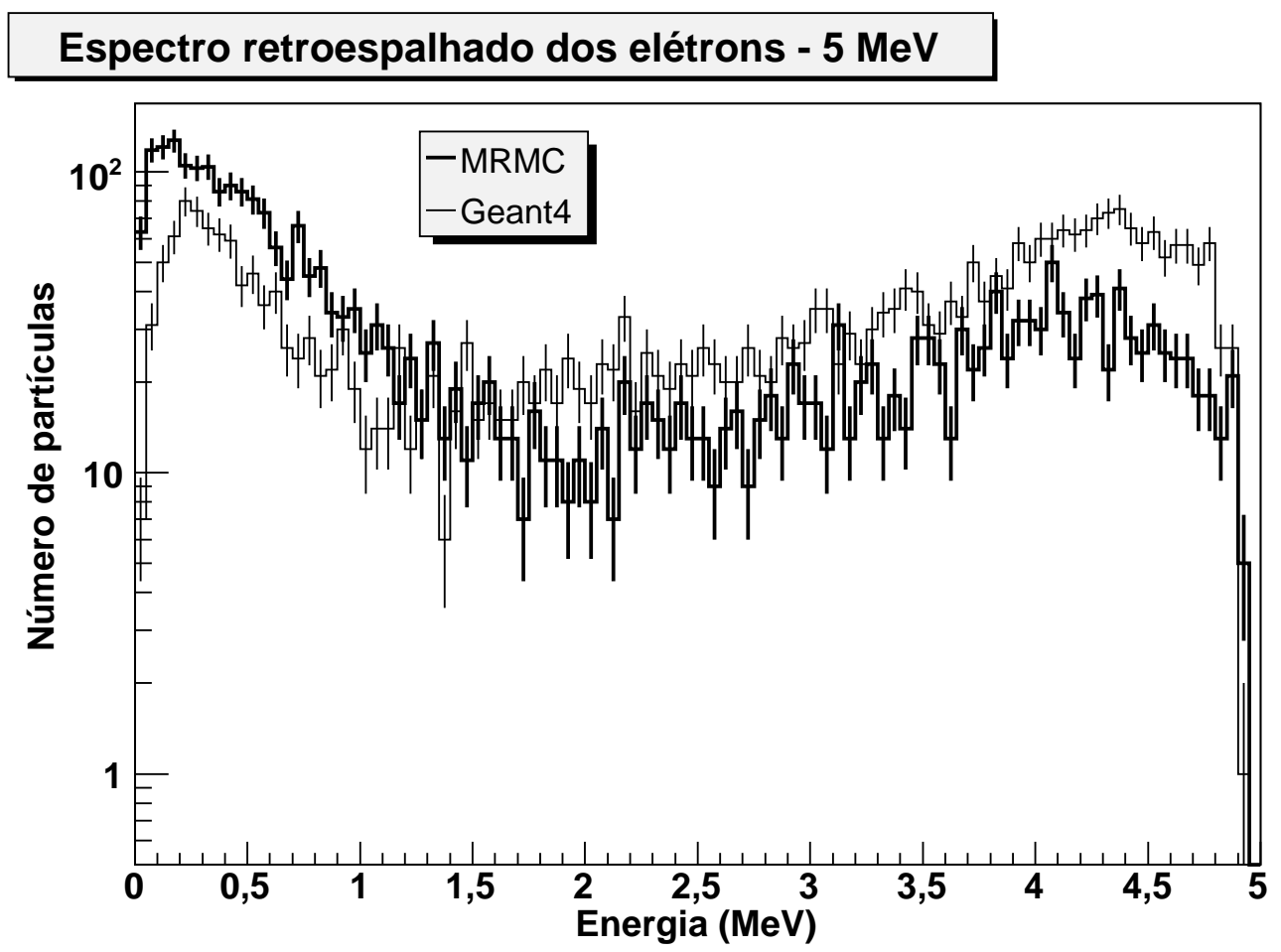

Figura 61: Espectro de elétrons retroespalhado para feixe incidente de $5 \mathrm{MeV}$ no objeto simulador de osso compacto.

\subsubsection{Discussão dos resultados dos espectros primário e secundário}

As análises dos espectros resultantes das simulações feitas pelo MRMC para objetos simuladores de água e tecido mole apresentaram uma sensível melhora nos resultados quando comparados com as mesmas análises feitas para os espectros primários.

As análises dos espectros completos para o osso compacto não apresentaram uma concordância maior quando comparadas às respectivas análises dos primários, provavelmente devido à menor produção de secundários. Essa produção menor de secundários pode estar relacionada à geração da base de dados que, por limitações técnicas, o RangeCut usado para o para o osso compacto foi duas vezes maior que para os outros materiais, conforme tabela 15 .

A exceção feita nos parágrafos acima, os mesmos comentários feitos na seção 6.1.1.1 para os espectros primários também se aplicam aos espectros completos. 
Apesar de não existirem na literatura comparações entre os espectros de algoritmos LGMC e algoritmos de história condensada, as comparações entre a dose absorvida mostram um desvio de até $4 \%$ em objetos simuladores homogêneos tanto na primeira versão do MMC (14) quanto no Evolution (30), e para o MRMC as diferenças chegam a 2,5\%.

\subsection{Objeto simulador heterogêneo}

A mesma metodologia usada na análise dos dados da seção anterior é aplicada para a análise dos espectros completos dos elétrons de saída frontal e lateral dos objetos simuladores heterogêneos. Os desenhos dos objetos simuladores heterogêneos e suas dimensões são mostrados na seção 5.1.2. Os resultados das análises encontram-se nas tabelas 11 a 13.

Tabela 11: Análise dos espectros referentes ao objeto simulador A

\begin{tabular}{|c|c|c|c|c|}
\hline Ítem/Energia & $25 \mathrm{MeV}$ & $10 \mathrm{MeV}$ & $5 \mathrm{MeV}$ & $1 \mathrm{MeV}$ \\
\hline \hline$\overline{\Delta N}$ frontal & $29,9 \pm 0,1 \%$ & $35,1 \pm 0,1 \%$ & $20,2 \pm 0,1 \%$ & $107,8 \pm 0,1 \%$ \\
\hline$\overline{\Delta N}$ lateral & $17,0 \pm 0,1 \%$ & $9,9 \pm 0,1 \%$ & $19,9 \pm 0,1 \%$ & $92,3 \pm 0,1 \%$ \\
\hline
\end{tabular}

Tabela 12: Análise dos espectros referentes ao objeto simulador B

\begin{tabular}{|c|c|c|c|c|}
\hline Ítem/Energia & $25 \mathrm{MeV}$ & $10 \mathrm{MeV}$ & $5 \mathrm{MeV}$ & $1 \mathrm{MeV}$ \\
\hline \hline$\overline{\Delta N}$ frontal & $25,8 \pm 0,1 \%$ & $34,4 \pm 0,1 \%$ & $19,7 \pm 0,1 \%$ & $269,4 \pm 0,1 \%$ \\
\hline$\overline{\Delta N}$ lateral & $21,9 \pm 0,1 \%$ & $11,7 \pm 0,1 \%$ & $16,5 \pm 0,1 \%$ & $48,8 \pm 0,1 \%$ \\
\hline
\end{tabular}

Tabela 13: Análise dos espectros referentes ao objeto simulador $\mathrm{C}$

\begin{tabular}{|c|c|c|c|c|}
\hline Ítem/Energia & $25 \mathrm{MeV}$ & $10 \mathrm{MeV}$ & $5 \mathrm{MeV}$ & $1 \mathrm{MeV}$ \\
\hline \hline$\overline{\Delta N}$ frontal & $46,5 \pm 0,1 \%$ & $29,6 \pm 0,1 \%$ & $62,0 \pm 0,1 \%$ & $73,1 \pm 0,1 \%$ \\
\hline$\overline{\Delta N}$ lateral & $37,1 \pm 0,1 \%$ & $33,4 \pm 0,1 \%$ & $39,3 \pm 0,1 \%$ & $56,1 \pm 0,1 \%$ \\
\hline
\end{tabular}


As análises dos espectros resultantes desses objetos simuladores heterogêneos apresentam desvios médios maiores que para os objetos simuladores homogêneos. Esse fato já era esperado, pois neste tipo de simulação o sistema de transporte de partículas precisa transpor mais interfaces, e por este motivo, os erros devido a aproximação no transporte através das interfaces acumulam-se, aumentando assim os desvios médios nos espectros de saída.

O objeto simulador A foi o que apresentou melhor concordância entre os espectros de saída, como podemos ver na figura 62.

\section{Espectro frontal dos elétrons $-10 \mathrm{MeV}$}

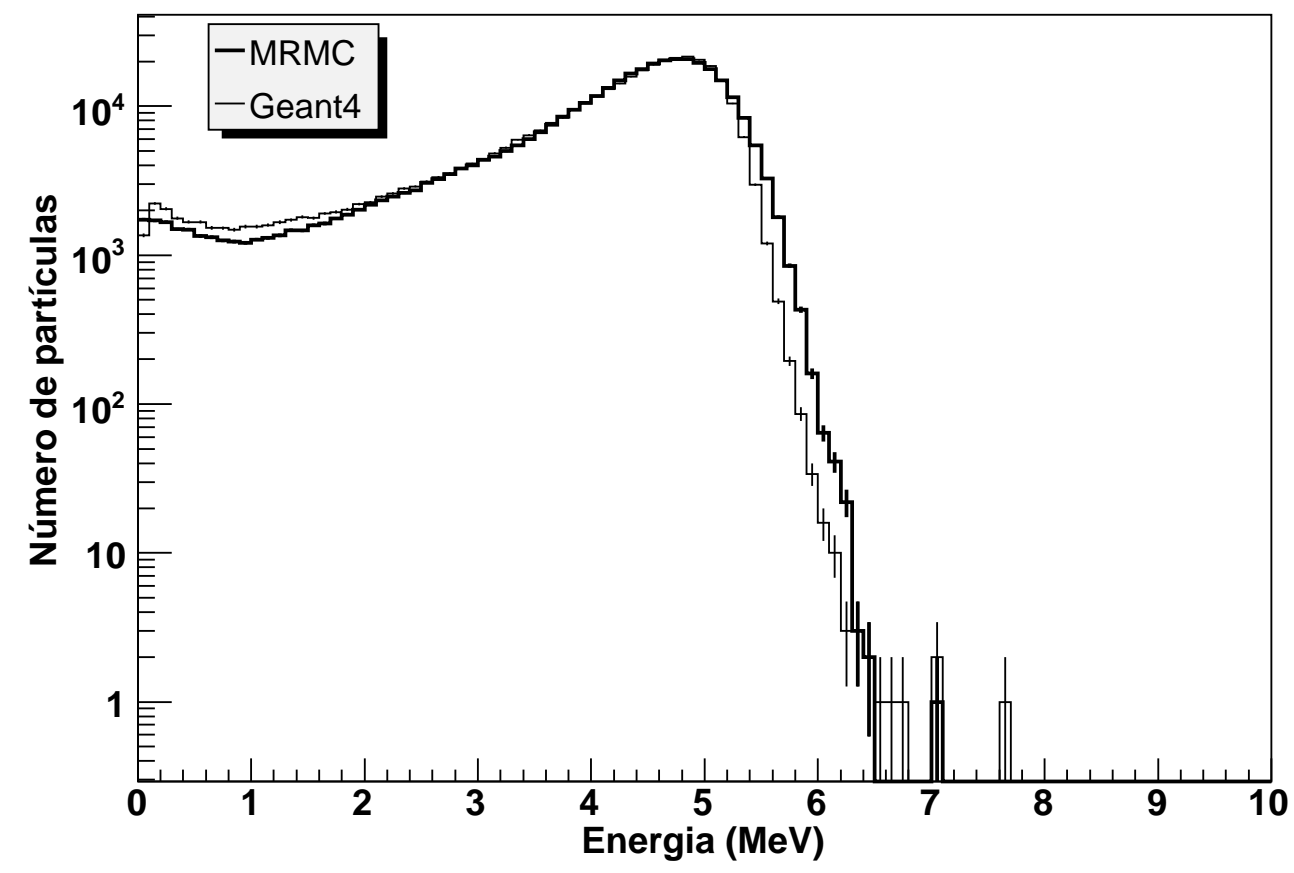

Figura 62: Espectro frontal de elétrons do objeto simulador A para feixe incidente de $10 \mathrm{MeV}$.

O objeto simulador B mostra uma falha enunciada anteriormente, a baixa produção de secundários no osso compacto, conforme pode ser visto na figura 63. 


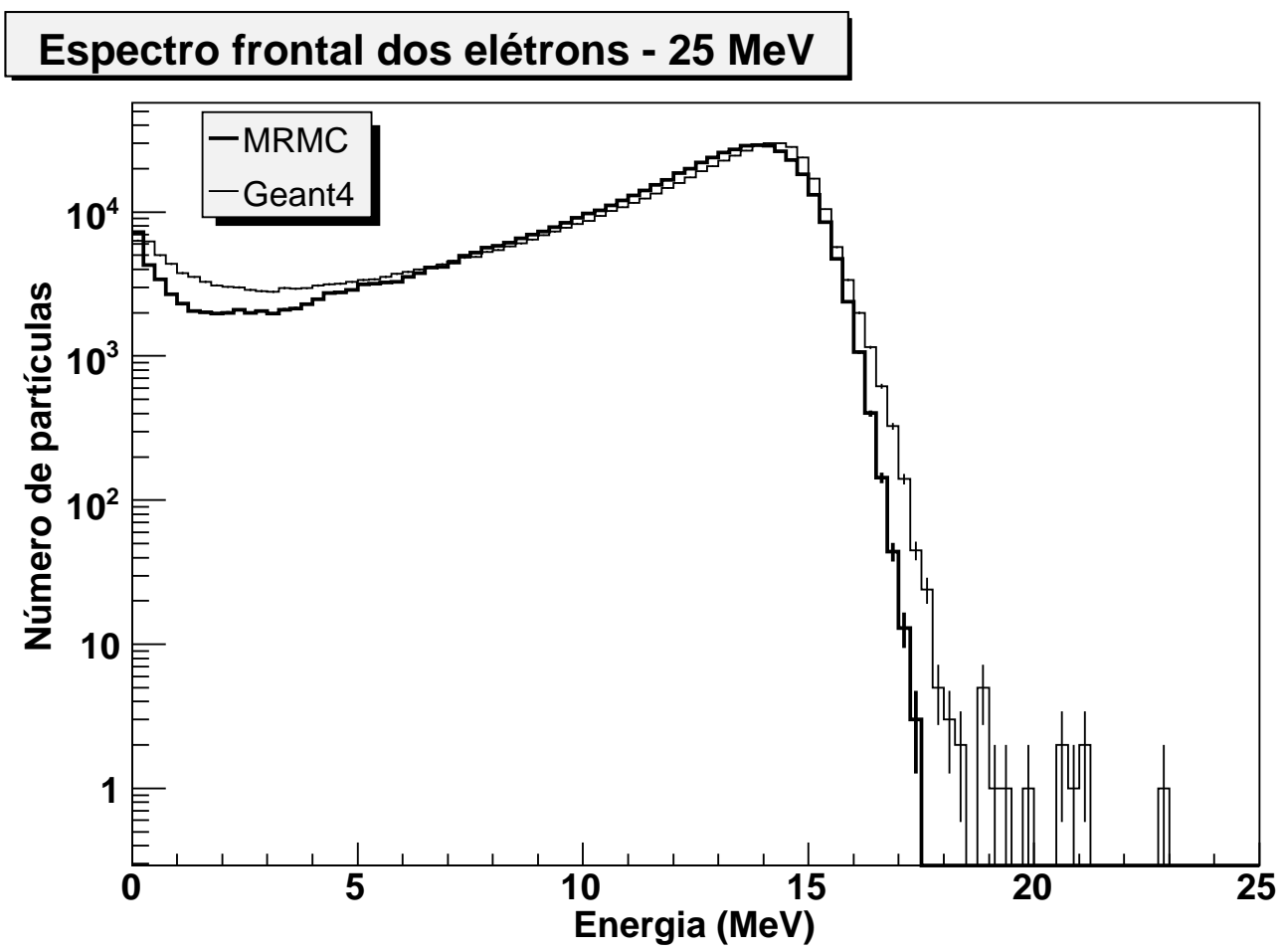

Figura 63: Espectro frontal de elétrons do objeto simulador B para feixe incidente de $25 \mathrm{MeV}$.

O objeto simulador C apresenta espectros que são bastante diferentes, figura 64. Essa simulação é a mais crítica, pois a trajetória inicial do elétron incidente tangencia o cilindro de osso compacto. Como não há algoritmo de MSC implementado, o elétron que tangenciar o cilindro interno a uma distância inferior que $250 \mu \mathrm{m}$, poderá caminhar muito em linha reta até se distanciar da interface. Esses resultados para esse tipo de geometria já eram esperados e representam uma limitação conhecida desta implementação. 


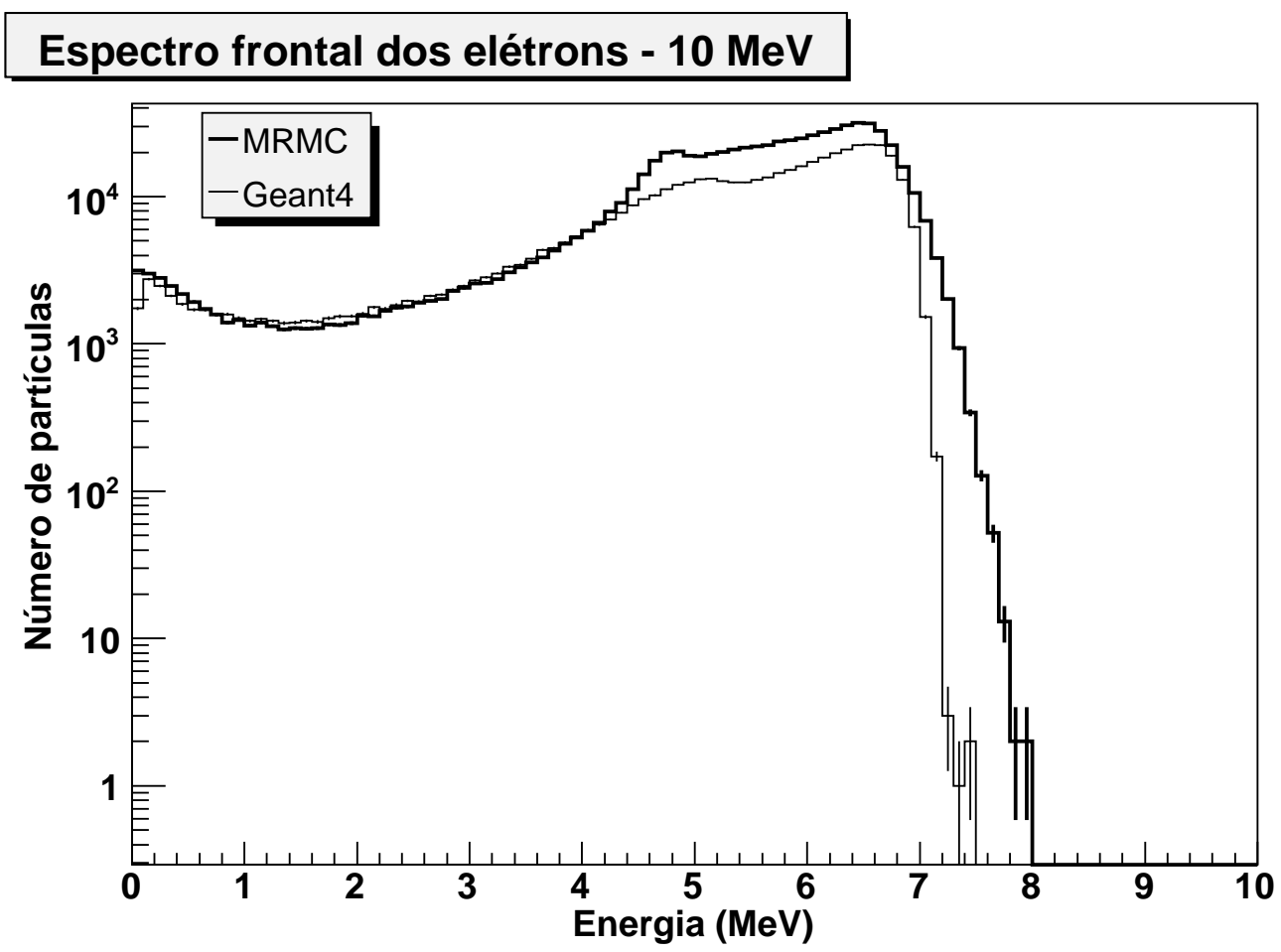

Figura 64: Espectro frontal de elétrons do objeto simulador $\mathrm{C}$ para feixe incidente de $10 \mathrm{MeV}$.

Na literatura são encontradas diferenças de até $5 \%$ na dose absorvida nas simulações realizadas em objetos simuladores heterogêneos para a segunda versão do MMC (15), e até 3,2\% para o MRMC (17).

\subsection{Comparação entre os tempos de simulação do MRMC e Geant4}

Apresentamos na tabela 14 a razão entre os tempos de simulação no Geant4 e os tempos de simulação no MRMC dos testes mostrados neste capítulo. Esses mesmos dados são apresentados em um gráfico na figura 65. 
Tabela 14: Razão entre os tempos de simulação do Geant4 e MRMC

\begin{tabular}{|c|c|c|c|c|}
\hline Tipo de objeto simulador & $25 \mathrm{MeV}$ & $10 \mathrm{MeV}$ & $5 \mathrm{MeV}$ & $1 \mathrm{MeV}$ \\
\hline \hline Água & 16,53 & 11,25 & 5,16 & 3,24 \\
\hline Tecido Mole & 18,86 & 11,75 & 5,36 & 3,05 \\
\hline Osso Compacto & 17,13 & 21,96 & 6,60 & 3,43 \\
\hline Objeto simulador A & 4,52 & 3.13 & 2,17 & 3,94 \\
\hline Objeto simulador B & 5,30 & 3,65 & 3,47 & 3,88 \\
\hline Objeto simulador C & 4,53 & 3,60 & 2,98 & 3,41 \\
\hline
\end{tabular}

\section{Razão entre os tempos de simulação}

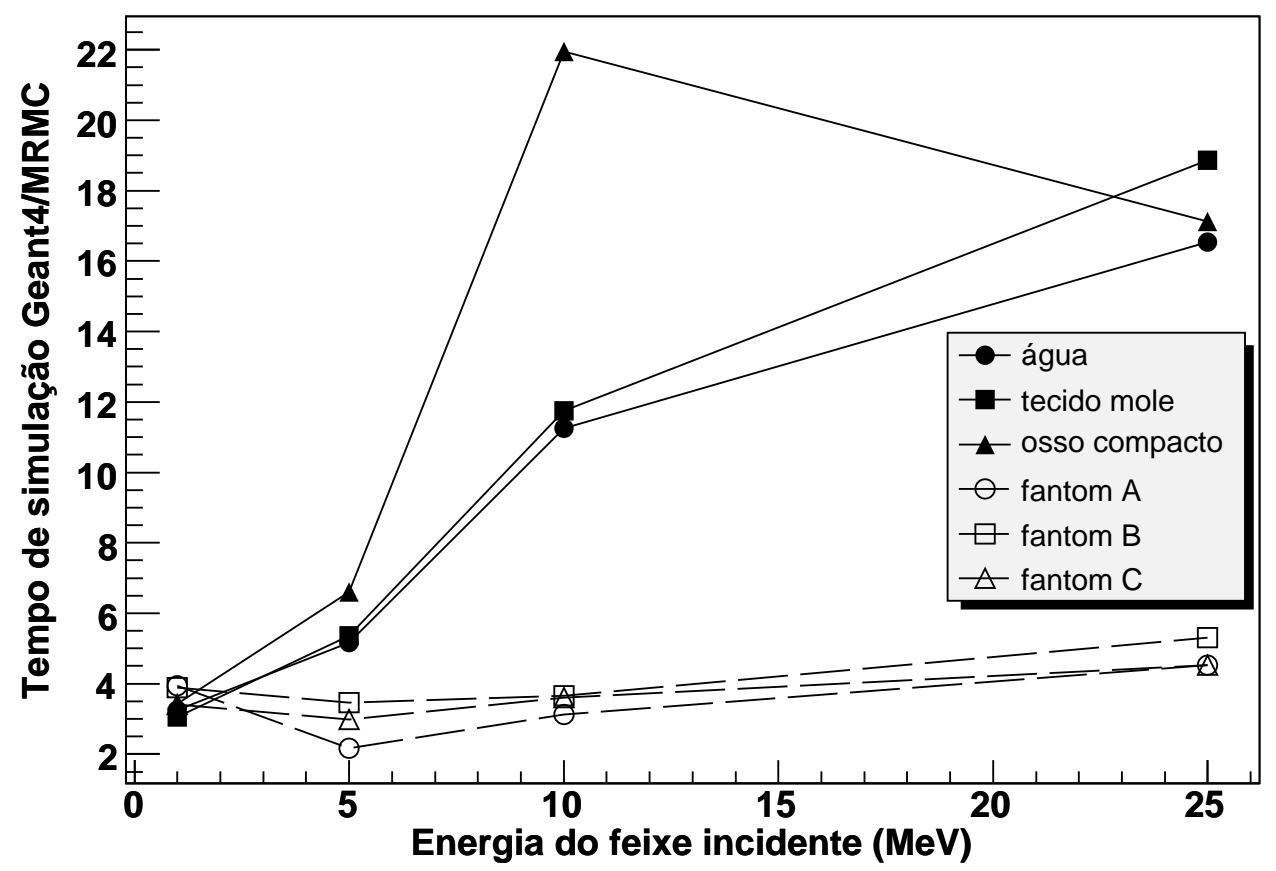

Figura 65: Comparação entre as razões dos tempos de simulação Geant4/MRMC.

Conforme podemos observar, a razão entre os tempos de simulação para objeto simulador homogêneo aumenta conforme aumenta a energia do feixe incidente, com o MRMC sendo aproximadamente 3 vezes mais rápido que o Geant 4 para objetos simuladores pequenos e energia incidente baixa, e até cerca de 15 vezes para a maior energia incidente testada neste trabalho. 
Para os objetos simuladores heterogêneos essa razão não oscilou muito, com o MRMC ficando entre 2 e quase 5 vezes mais rápido que o Geant4. Esse comportamento já era esperado, pois nesses tipos de objetos simuladores o sistema de transporte MRMC não consegue usar com muita frequiência os kugels de raios maiores, comprometendo assim o desempenho do MRMC.

Na implementação do MRMC por Svatos (17), a razão entre o MRMC e o programa Peregrine (41) foi de 0,526, isto é, o MRMC foi cerca de duas vezes mais lento que Peregrine, que usa história condensada classe II para elétrons. Svatos (17) em sua tese de doutorado pondera que o MRMC deve chegar a ser 5 vezes mais rápido que os códigos que usam história condensada de elétrons quando, em sua base de dados, forem utilizados kugel de raios maiores. 


\section{Conclusões}

Implementamos o MRMC usando a biblioteca ROOT como base para o transporte dos kugels, armazenagem e amostragem dos histogramas de função distribuição de probabilidade. Essas funções foram obtidas por meio da simulação dos kugels pelo Geant4 em um cluster de micros. Simulamos três tipos de materiais de interesse na radioterapia para compor a base de dados de kugels: água, tecido mole e osso compacto.

Os espectros de elétrons apresentados pela primeira vez pelo MRMC mostram boa concordância com os gerados pelo Geant4, para as energias entre 25 e $5 \mathrm{MeV}$. Os espectros de $1 \mathrm{MeV}$ ficaram comprometidos por algumas incertezas relacionadas ao transporte local e a aproximação usada para o transporte dos elétrons através das interfaces.

Os espectros obtidos pelo MRMC são mais fontes de informação para a compreensão dos desvios observados nas distribuições de dose absorvida, presentes na literatura.

O MRMC apresentou um bom desempenho, em termos de tempo de simulação, sendo até 15 vezes mais rápido que o Geant 4 em objetos simuladores homogêneos e cerca de 4 a 5 vezes em objetos simuladores heterogêneos, confirmando as previsões de velocidade para este tipo de modelo.

Neste trabalho mostramos, por meio do MRMC, que os algoritmos do tipo LGMC podem ser interessantes para calcular espectros de elétrons em meios materiais, o que sugere que os mesmos podem ser aplicados em outras áreas, além da radioterapia. 


\section{Referências}

1 INTERNATIONAL COMMISSION ON RADIATION UNITS AND MEASUREMENTS. ICRU Report 33. Radiation Quantities and Units. Washington, DC, 1980.

2 WEBB, S. The Physics of Three-Dimensional Radiation Therapy. [S.1.]: IOP Publishing Ltd, 1993. (Medical Science Series).

3 BOYER, A.; MOK, E. A photon dose distribution model employing convolution calculations. Med. Phys., v. 12, n. 2, p. 169-177, 1985.

4 ZHU, Y.; BOYER, A. X-ray dose computations in heterogeneous media using 3-dimensional FFT convolution. Phys. Med. Biol., v. 35, n. 3, p. 351-368, 1990.

5 PERLES, L. A.; CHINELlATO, C. D.; ROCHA, J. R. O. Otimização de um algoritmo para o cálculo 3D da distribuição da dose de radiação em meios heterogêneos para uso no planejamento em radioterapia. In: Anais do VI Congresso Brasileiro de Física Médica. [S.1.: s.n.]. Rio de Janeiro, 04-06 de outubro.

6 HOGSTROM, K. R.; MILLS, M. D.; ALMOND, P. R. Electron beam dose calculations. Phys. Med. and Biol., v. 26, n. 3, p. 445-459, 1981. Disponível em: $<$ http://stacks.iop.org/0031-9155/26/445>.

7 NELSON, W. R.; HIRAYAMA, H.; ROGERS, D. W. O. The EGS4 Code System. Stanford University, Stanford, California 94305, December 1985. SLAC-265.

8 FORSTER, R. A.; GODFREY, T. N. K. MCNP- A General Monte-Carlo Code for Neutrons and Photon Transport. LNP Vol. 240: Monte-Carlo Methods and Applications in Neutronics, Photonics, and Statistical Physics, v. 240, p. 33, 1985.

9 SALVAT, J. M. F.-V. F.; ACOSTA, E.; SEMPAU, J. PENELOPE - A code system for Monte Carlo simulation of electron and photon transport. [S.l.], 2001.

10 AGOSTINELLI, S. et al. Geant4-a simulation toolkit. Nucl. Instrum. Meth. A, v. 506, p. 250-303, 2003.

11 KAWRAKOW, I.; ROGERS, D. W. O. The EGSnrc code system: Monte Carlo simulation of electron and photon transport. 4. ed. [S.1.], 11 nov. 2003.

12 KAWRAKOW, I.; FIPPEL, M. Investigation of variance reduction technics for Monte Carlo photon dose calculation using XVMC. Phys. Med. Biol., n. 45, p. 2163-2183, 2000.

13 KAWRAKOW, I.; FIPPEL, M.; FRIEDRICH, K. 3D electron beam dose calculation using a Voxel based Monte Carlo algorithm (VMC). Med. Phys., n. 23, p. 445-457, 1996. 
14 NEUENSCHWANDER, H.; BORN, E. J. A macro Monte Carlo method for electron beam dose calculations. Phys. Med. Biol., v. 37, n. 1, p. 107-125, 1992.

15 NEUENSCHWANDER, H.; MACKIE, T.; RECKWERDT, P. MMC-a high-performance Monte Carlo code for electron beam treatment planning. Phys. Med. Biol., v. 40, p. 543-574, 1995.

16 BALlinger, C. T. The Response History Monte Carlo method for electron transport. Tese (Doutorado), 1991.

17 SVATOS, M. M. The Macro Response Monte Carlo method for electron transport. Tese (Doutorado) — Lawrence Livermore National Laboratory, 1998.

18 KARLIN, S.; TAYLOR, H. A first course in stochastic processeses. 2nd. ed. San Diego, California, USA: Academic Press, 1975.

19 ATTIX, F. H. Introduction to Radiological Physics and Radiation Dosimetry. New York, New York, USA: John Wiley and Sons, 1986.

20 JOHNS, H. E.; CUNNINGHAM, J. R. The Physics of Radiology. 4th. ed. Springfield, Illiniois, USA: Charles C. Thomas, 1984.

21 ANDREO, P. Monte Carlo techniques in medical radiation physics. Phys. Med. Biol., v. 36, n. 7, p. 861-920, 1991.

22 BERGER, M. Monte Carlo calculation of the penetration and diffusion of fast charged particles. Methods Comput. Phys., v. 1, p. 135-215, 1963.

23 MOLIÈRE, G. Theorie der Streuung schneller geladener Teilchen. II. Mehrfach-und Vielfachstreuung. Z. Naturforsch, n. 3a, 1948.

24 Bethe, H. A. Molière's theory of multiple scattering. Phys. Rev., American Physical Society, v. 89, n. 6, p. 1256-1266, Mar 1953.

25 BERGER, M.; WANG, R. Multiple-scattering angular deflections and energy-loss straggling. In: JENKINS, T.; NELSON, W.; RINDI, A. (Ed.). Monte Carlo Transport of Electrons and Photons. New York and London: Plenun Press, 1988. p. 21-55.

26 LEWIS, H. W. Multiple scattering in an infinite medium. Phys. Rev., American Physical Society, v. 78, n. 5, p. 526-529, Jun 1950.

27 URBAN, L. Multiple scattering model in GEANT4. In: CERN-OPEN-2002. [S.l.: s.n.], 2002 .

28 CERN. GEANT4 - Physics Reference Manual. [S.1.], 22 dez. 2000.

29 MACKIE, T.; BATTISTA, J. A macroscopic Monte Carlo method for electron beam dose calculations: A proposal. In: 8th Intern. Conf. on Use of Computers in Radiation Therapy. Toronto: [s.n.], 1984. p. 123-127.

30 SCORA, D.; FADDEGON, B. A. Monte carlo based phase-space evolution for electron dose calculation. Med. Phys., AAPM, v. 24, n. 2, p. 177-187, 1997. Disponível em:

$<$ http://link.aip.org/link/?MPH/24/177/1>. 
31 SVATOS, M. M. Single scatter electron Monte Carlo. [S.1.], mar. 1997.

32 CERN. GEANT4 User's Guide - For Applications Developer. [S.1.], jun. 2001.

33 BALLINGER, C.; RATHKOPF, J.; MARTIN, W. The Response History Monte Carlo method for electron transport. Nucl. Sci. Eng., v. 112, p. 283-95, 1992.

34 BRUN, R. et al. ROOT User's Guide. 5.08. ed. [S.1.], dez. 2005.

35 MATSUMOTO, M.; NISHIMURA, T. Mersenne Twister: a 623-dimensionally equidistributed uniform pseudo-random number generator. ACM Trans. Model. Comput. Simul., ACM Press, New York, NY, USA, v. 8, n. 1, p. 3-30, 1998. ISSN 1049-3301.

36 National Institut of Standards and Technology - NIST. Material Composition Data. Disponível em: <http://physics.nist.gov/cgi-bin/Star/compos.pl >.

37 CIRRONE, G. et al. Precision validation of Geant4 electromagnetic physics. In: IEEE. IEEE Nuclear Science Symp. [S.1.], 2003. Vol. 1, p. 482-485.

38 AMAKO, K. et al. Validation of Geant4 electromagnetic physics versus protocol data. In: IEEE - Nuclear Science Symp. [S.1.: s.n.], 2004. Vol. 4, p. 2115- 2119.

39 MORHAC, M. et al. Identification of peaks in multidimensional coincidence gamma spectra. Nucl. Instrum. Meth. A, v. 443, n. 1, p. 108-125, 2000.

40 INTERNATIONAL COMMISSION ON RADIATION UNITS AND MEASUREMENTS. ICRU Report 37 - Stopping powers for electrons and positrons. Washington, DC, 1984.

41 SIANTAR, C. H. et al. Description and dosimetric verification of the PEREGRINE Monte Carlo dose calculation system for photon beams incident on a water phantom. Med. Phys., v. 28, n. 7, p. 1322-37.

42 BROKEN, F. B. C++ Annotations. [S.1.]: University of Groningen, 2001. Version 5.1.0b.

43 GROOM, D. Atomic and Nuclear Properties of Materials for 292 substances. 24 jun. 2004. Disponível em: <http://pdg.lbl.gov/2005/AtomicNuclearProperties/>. 


\section{APÊEDICE A - Exemplo de funções de distribuição de probabilidade de um kugel}

Neste apêndice são apresentados os histogramas para as funções de distribuição de probabilidade de um kugel de água com energia incidente de $1,33 \mathrm{MeV}$ e raio de $0,25 \mathrm{~mm}$. O número de histórias foi de $5 \times 10^{5}$. Todos os histogramas são normalizados pelo número de histórias. 


\section{Banda 1 - Cosseno de Posição}

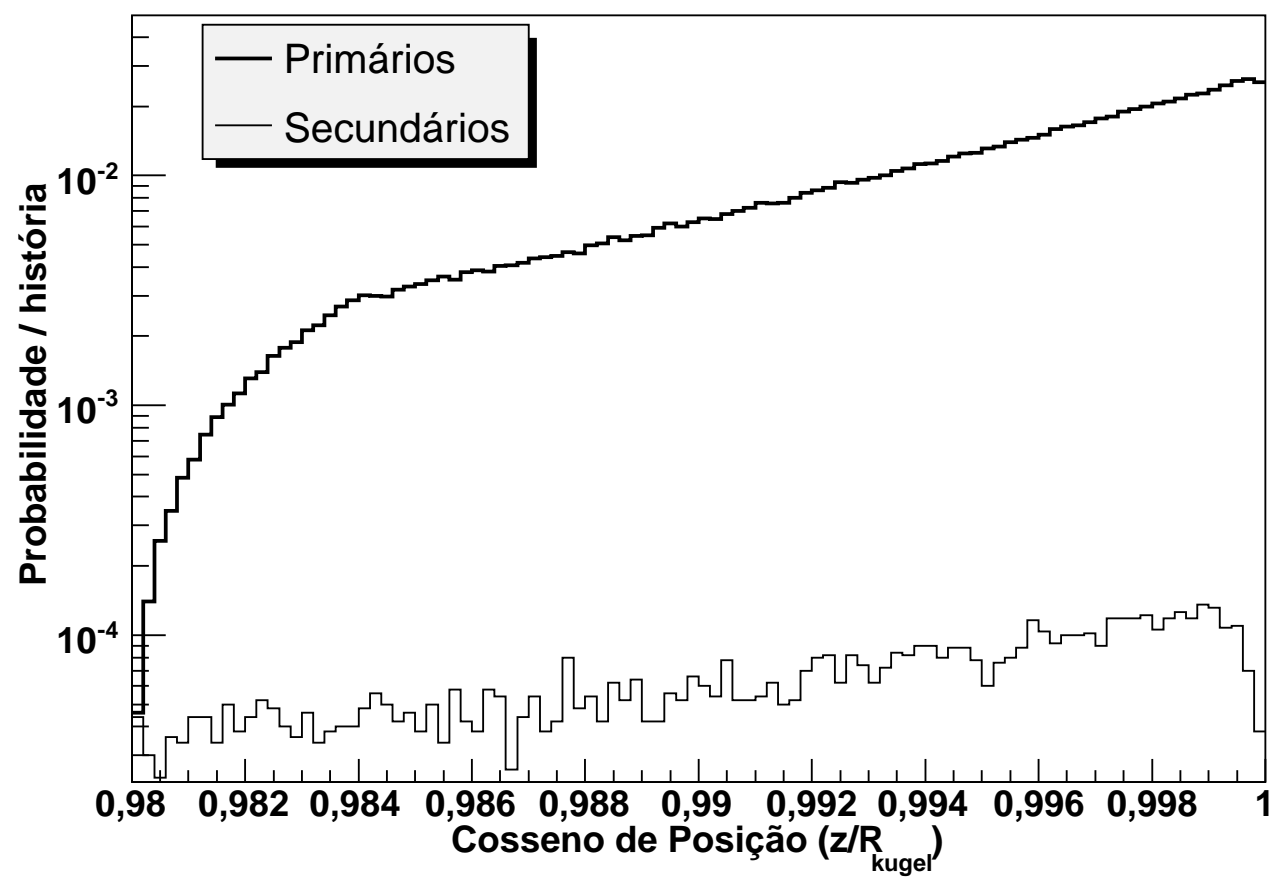

Figura 66: Cosseno da posição de saída para os elétrons primários e secundários da Banda 1.

\section{Banda 2 - Cosseno de Posição}

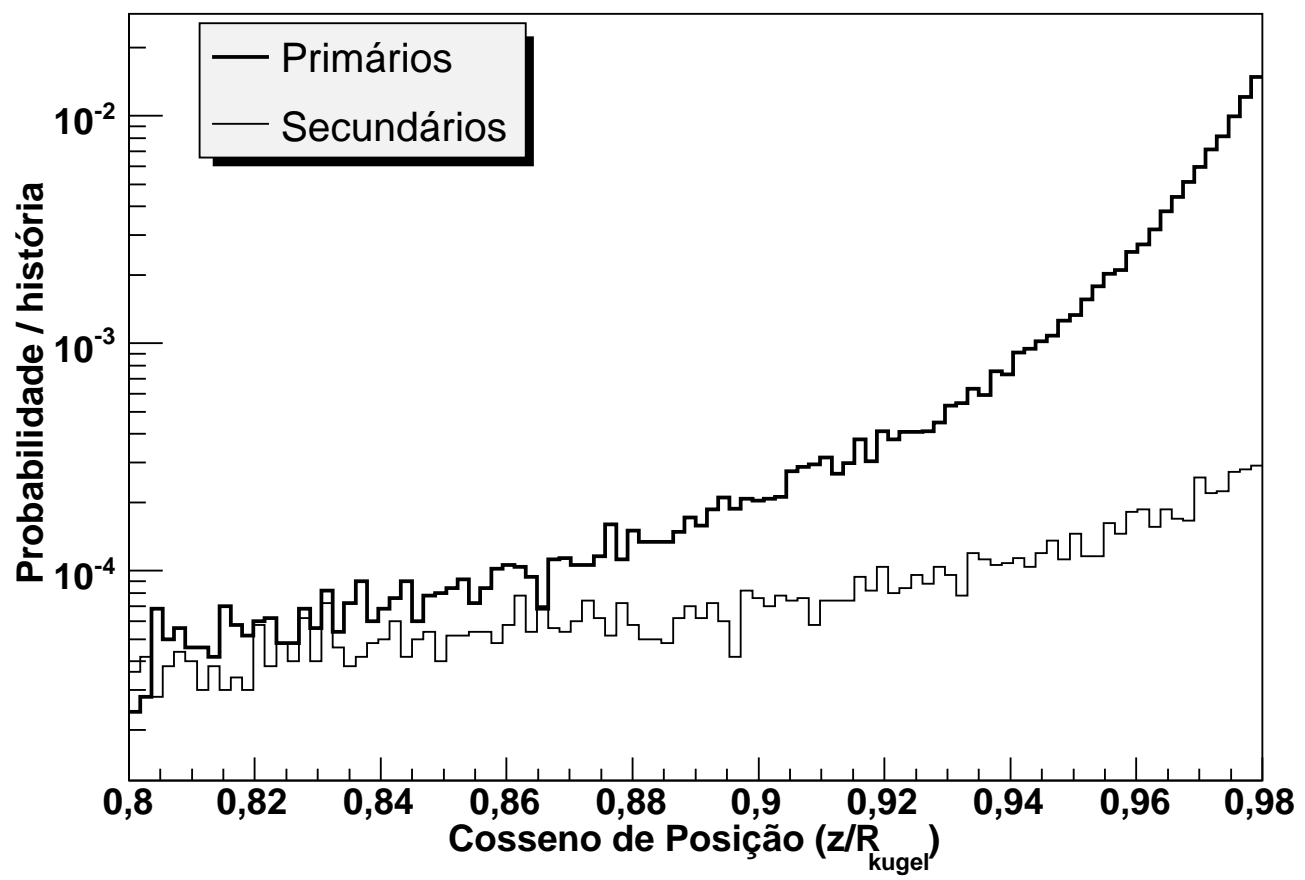

Figura 67: Cosseno da posição de saída para os elétrons primários e secundários da Banda 2. 


\section{Banda 3 - Cosseno de Posição}

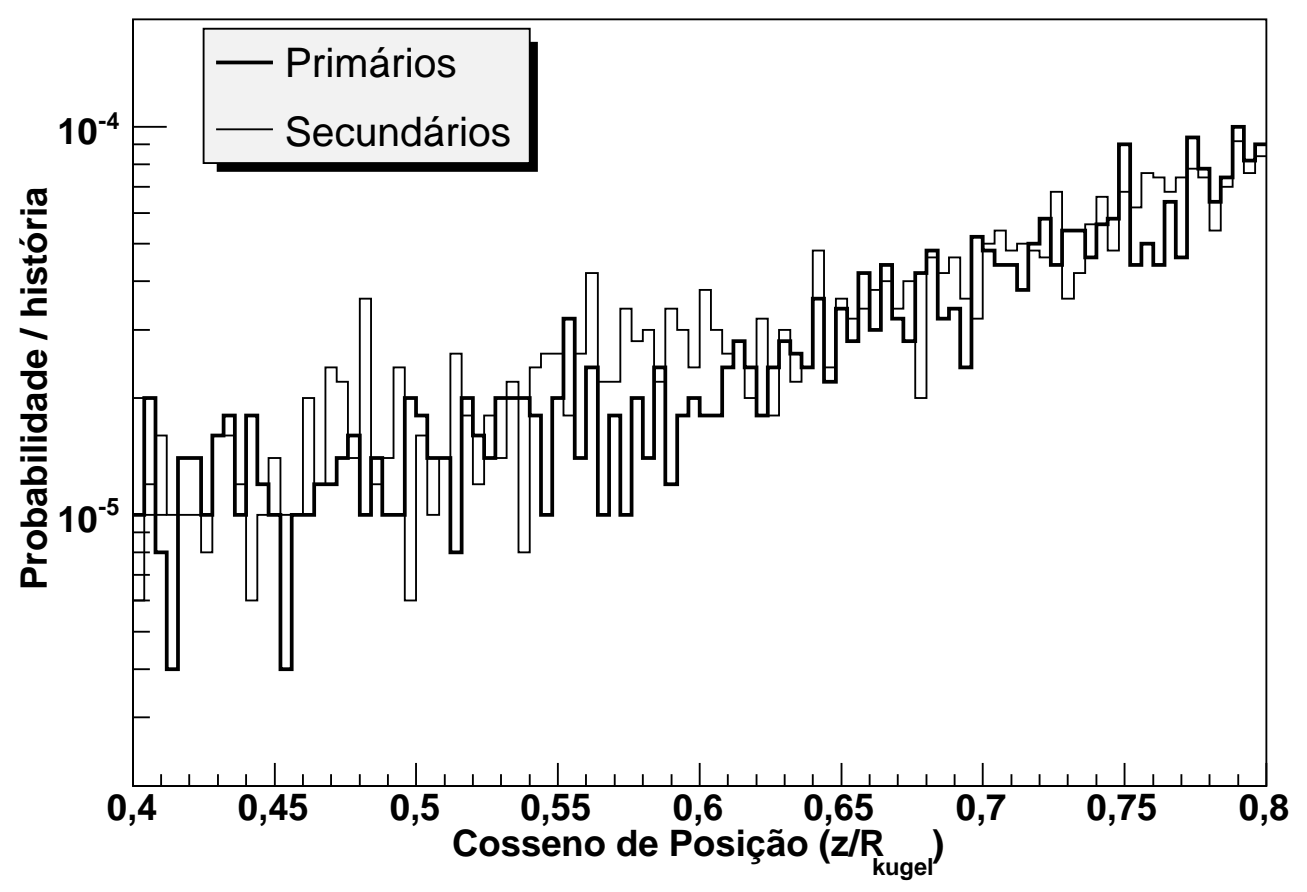

Figura 68: Cosseno da posição de saída para os elétrons primários e secundários da Banda 3.

\section{Banda 4 - Cosseno de Posição}

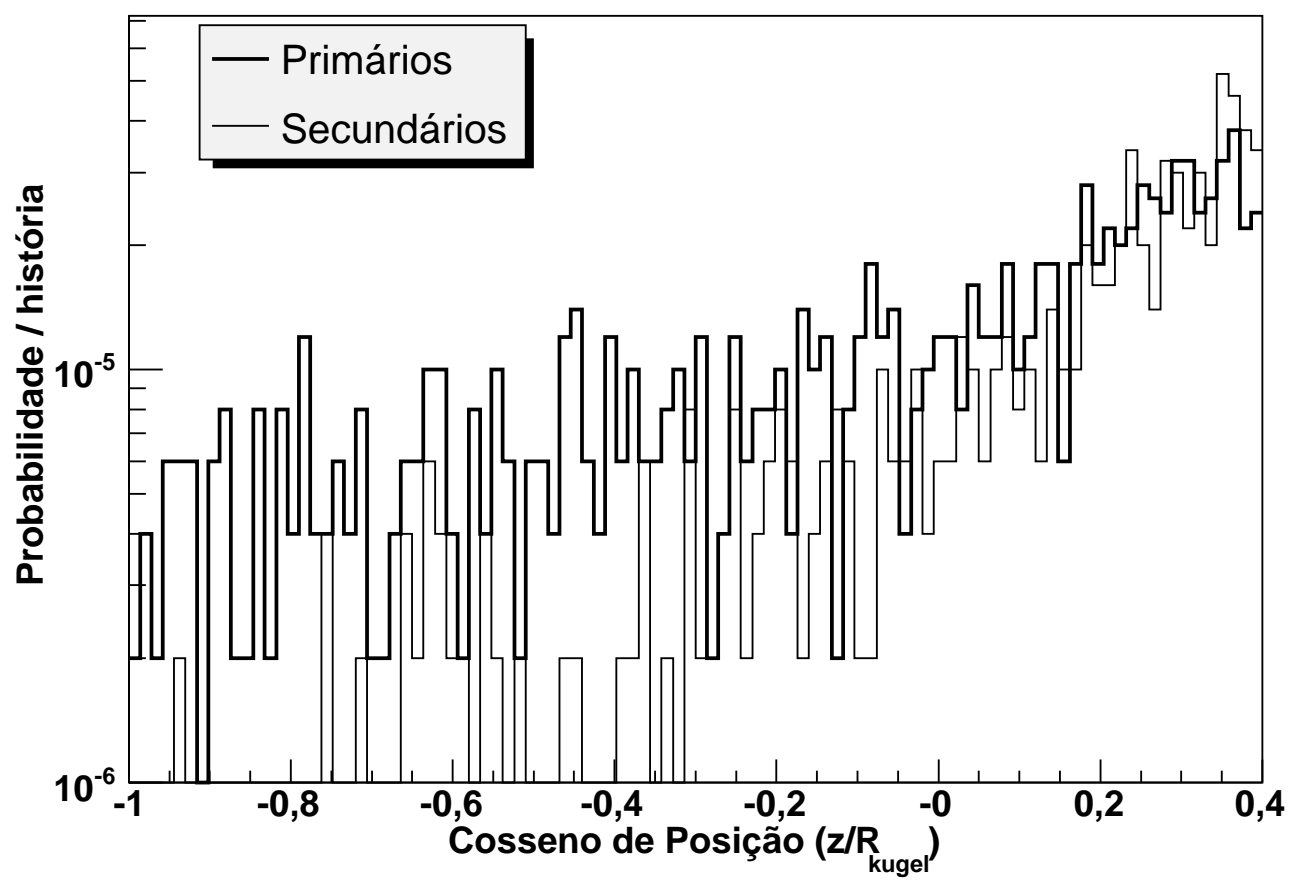

Figura 69: Cosseno da posição de saída para os elétrons primários e secundários da Banda 4. 


\section{Banda 1 - Energia de saída}

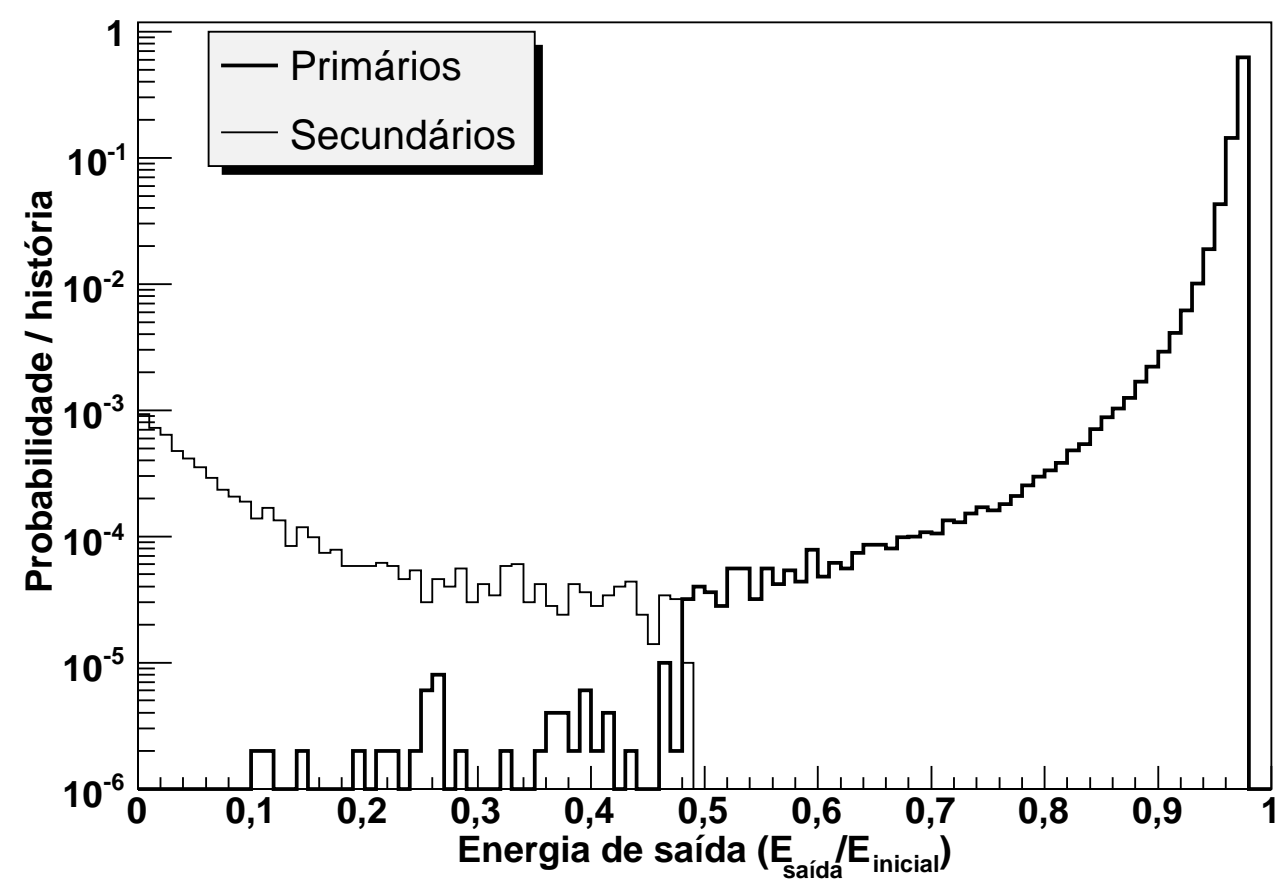

Figura 70: Energia de saída normalizada pela energia inicial dos elétrons primários e secundários da Banda 1.

\section{Banda 2 - Energia de saída}

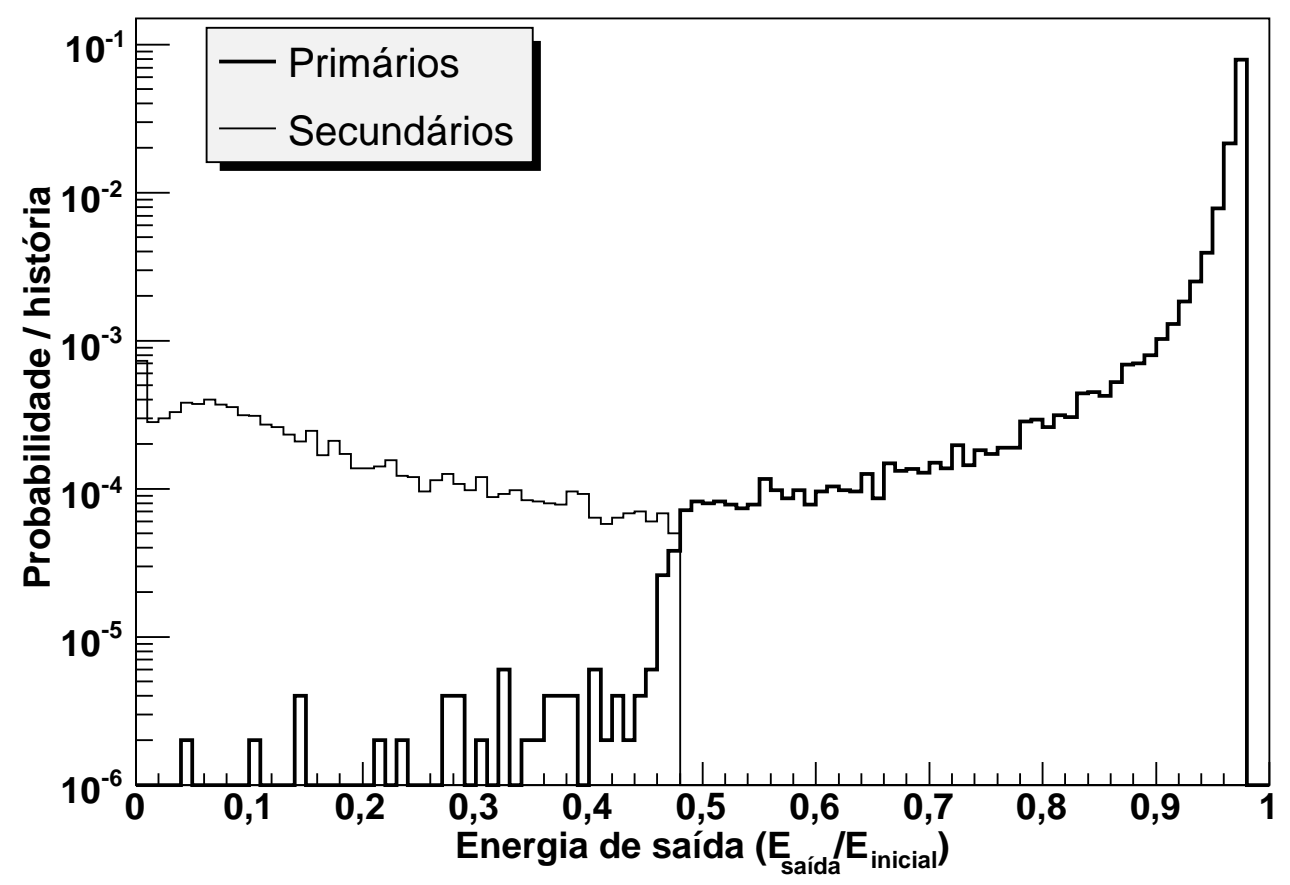

Figura 71: Energia de saída normalizada pela energia inicial dos elétrons primários e secundários da Banda 2. 


\section{Banda 3 - Energia de saída}

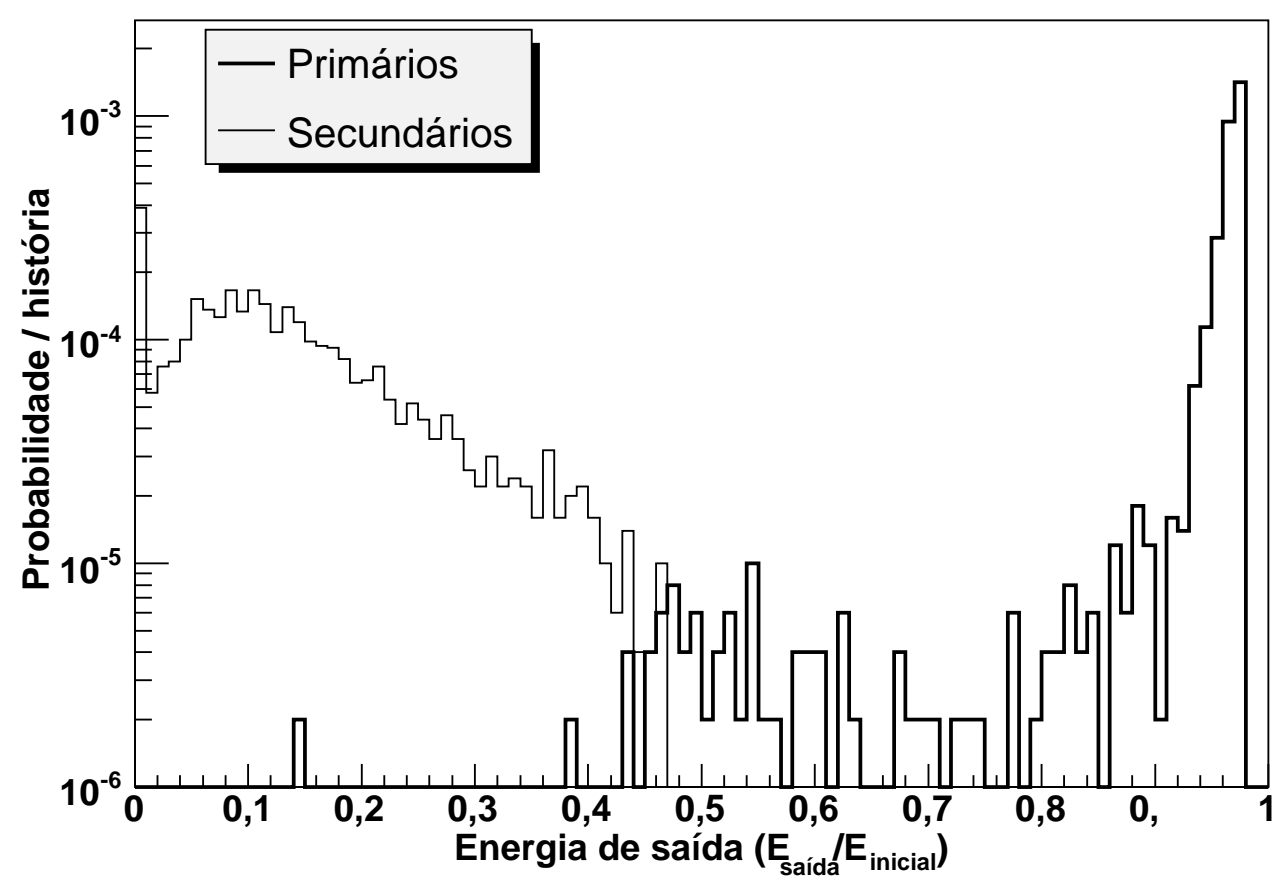

Figura 72: Energia de saída normalizada pela energia inicial dos elétrons primários e secundários da Banda 3.

\section{Banda 4 - Energia de saída}

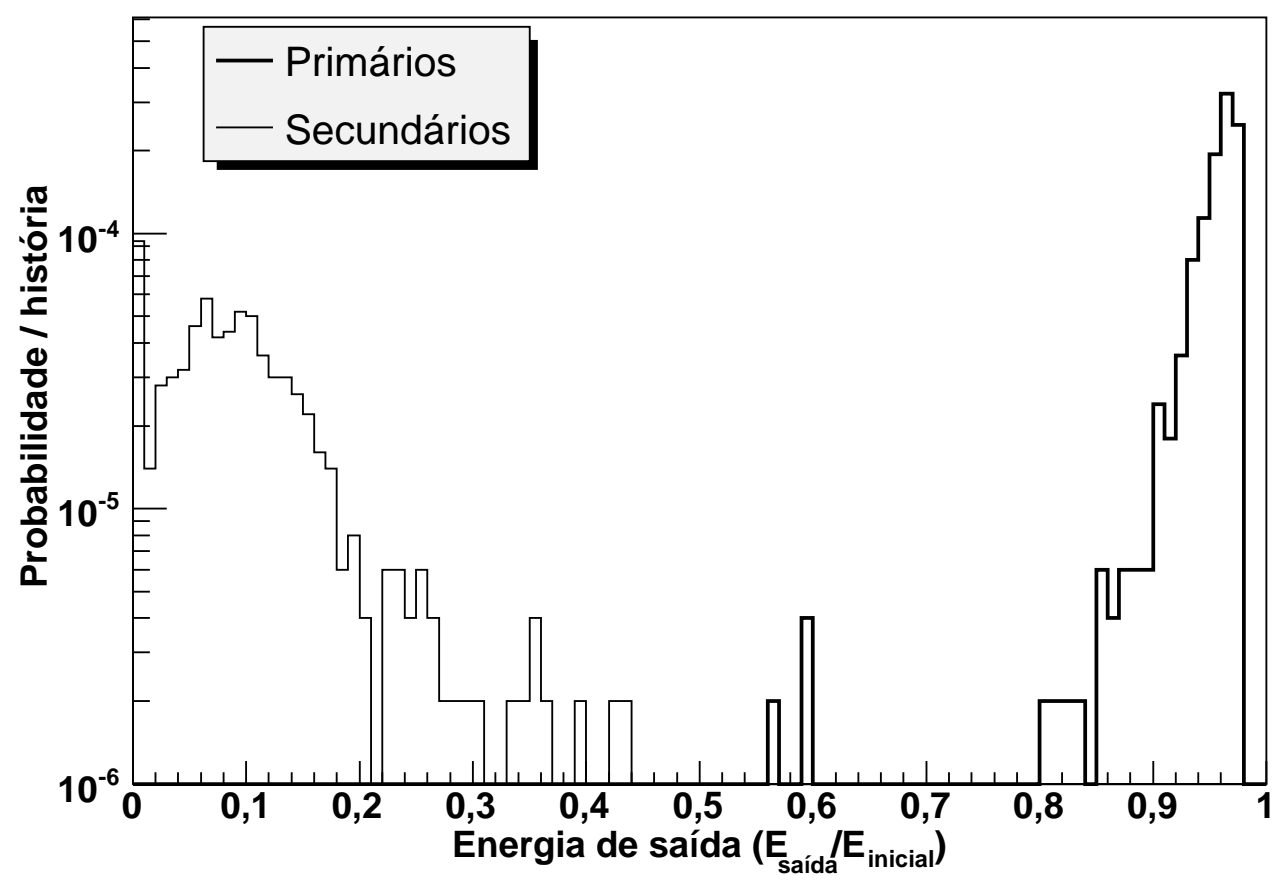

Figura 73: Energia de saída normalizada pela energia inicial dos elétrons primários e secundários da Banda 4. 


\section{Banda 1 - Trajetória de saída dcp}

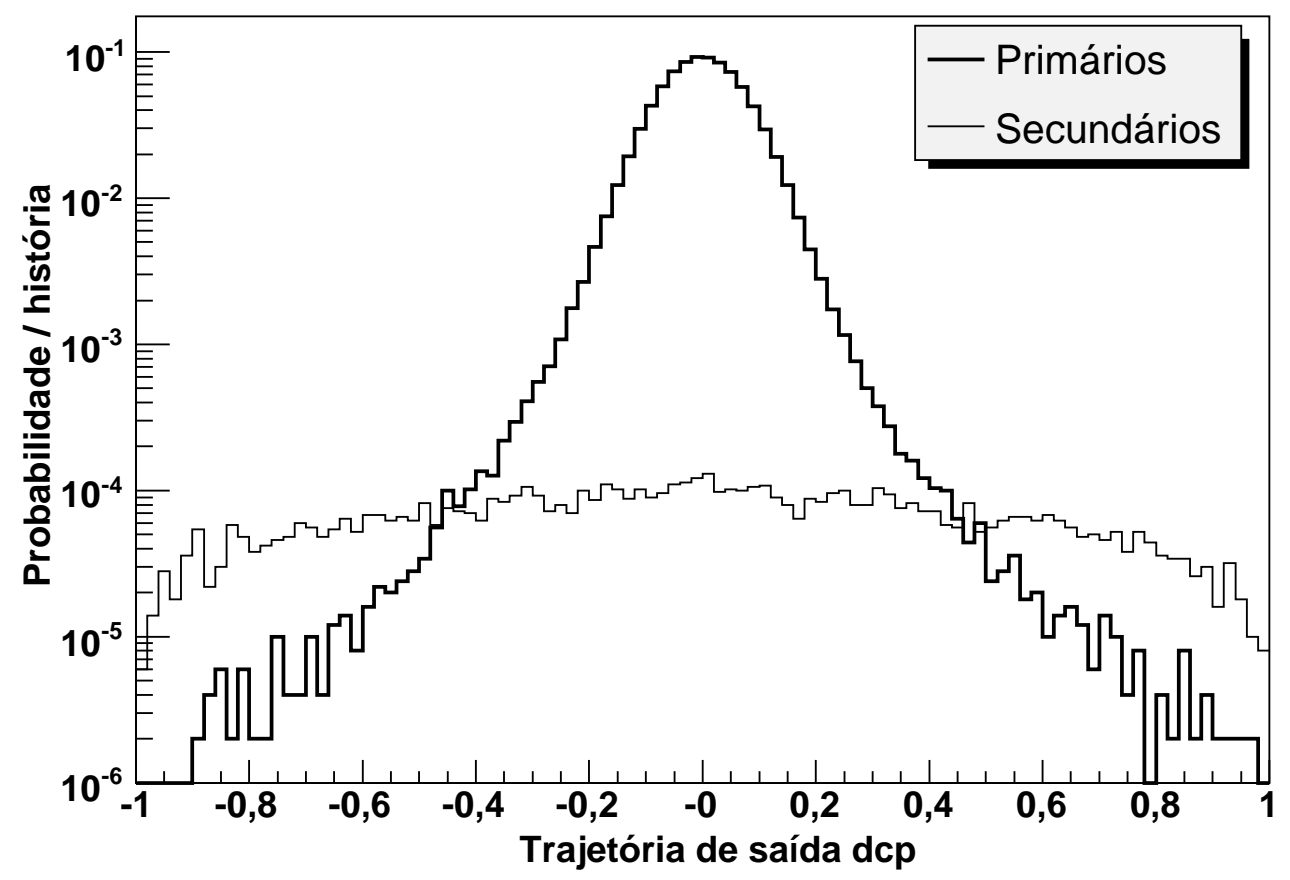

Figura 74: Trajetória de saída dcp dos elétrons primários e secundários da Banda 1.

\section{Banda 2 - Trajetória de saída dcp}

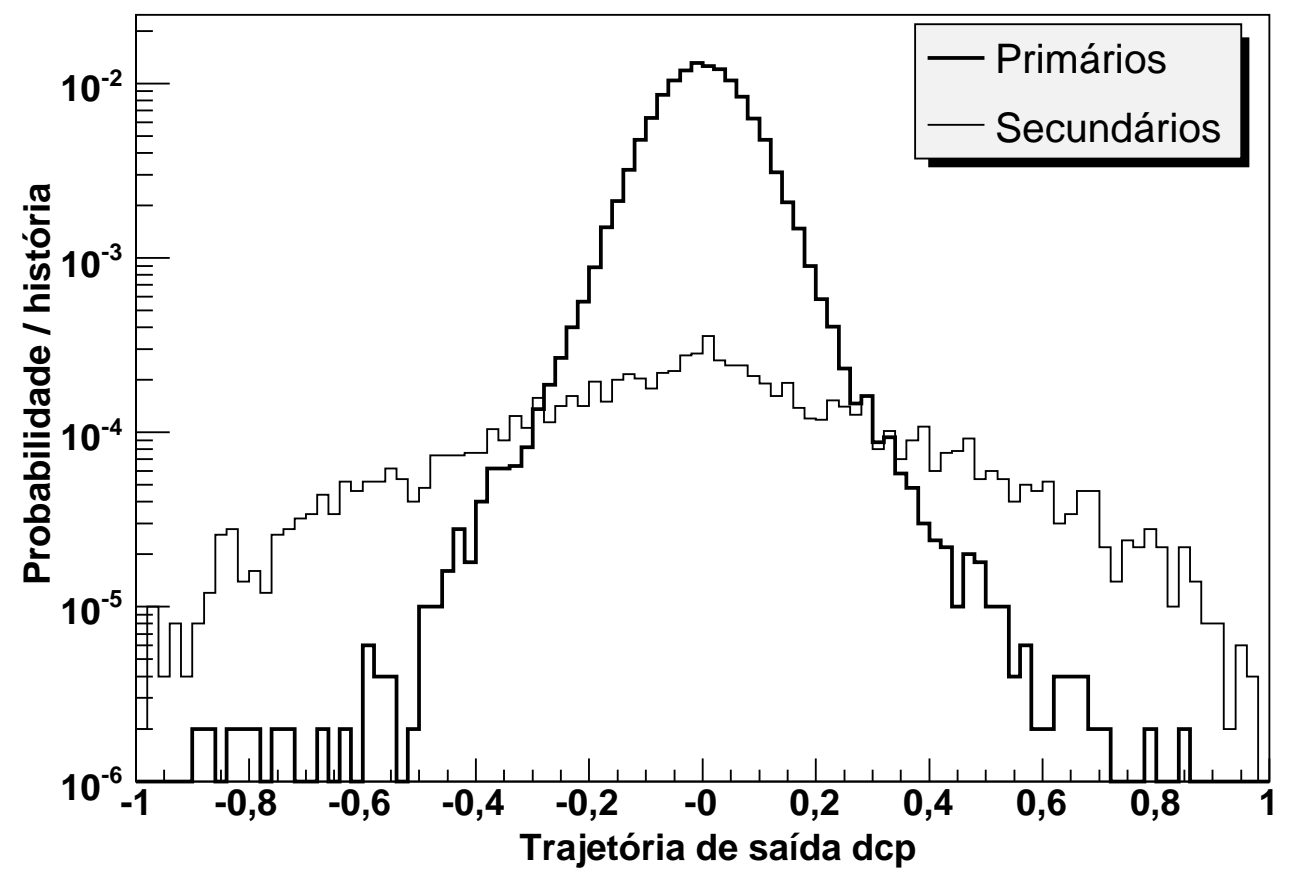

Figura 75: Trajetória de saída dcp dos elétrons primários e secundários da Banda 2. 


\section{Banda 3 - Trajetória de saída dcp}

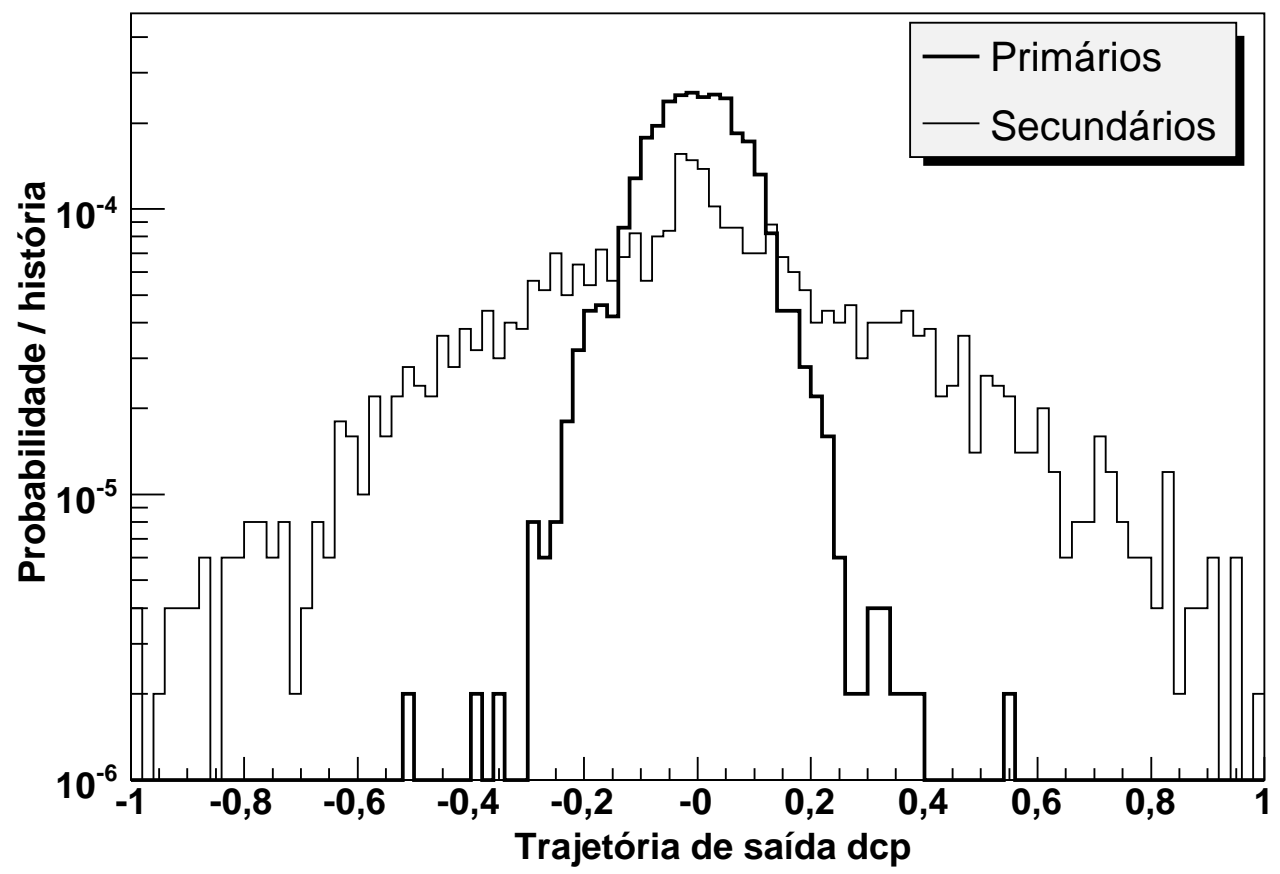

Figura 76: Trajetória de saída dep dos elétrons primários e secundários da Banda 3.

\section{Banda 4 - Trajetória de saída dcp}

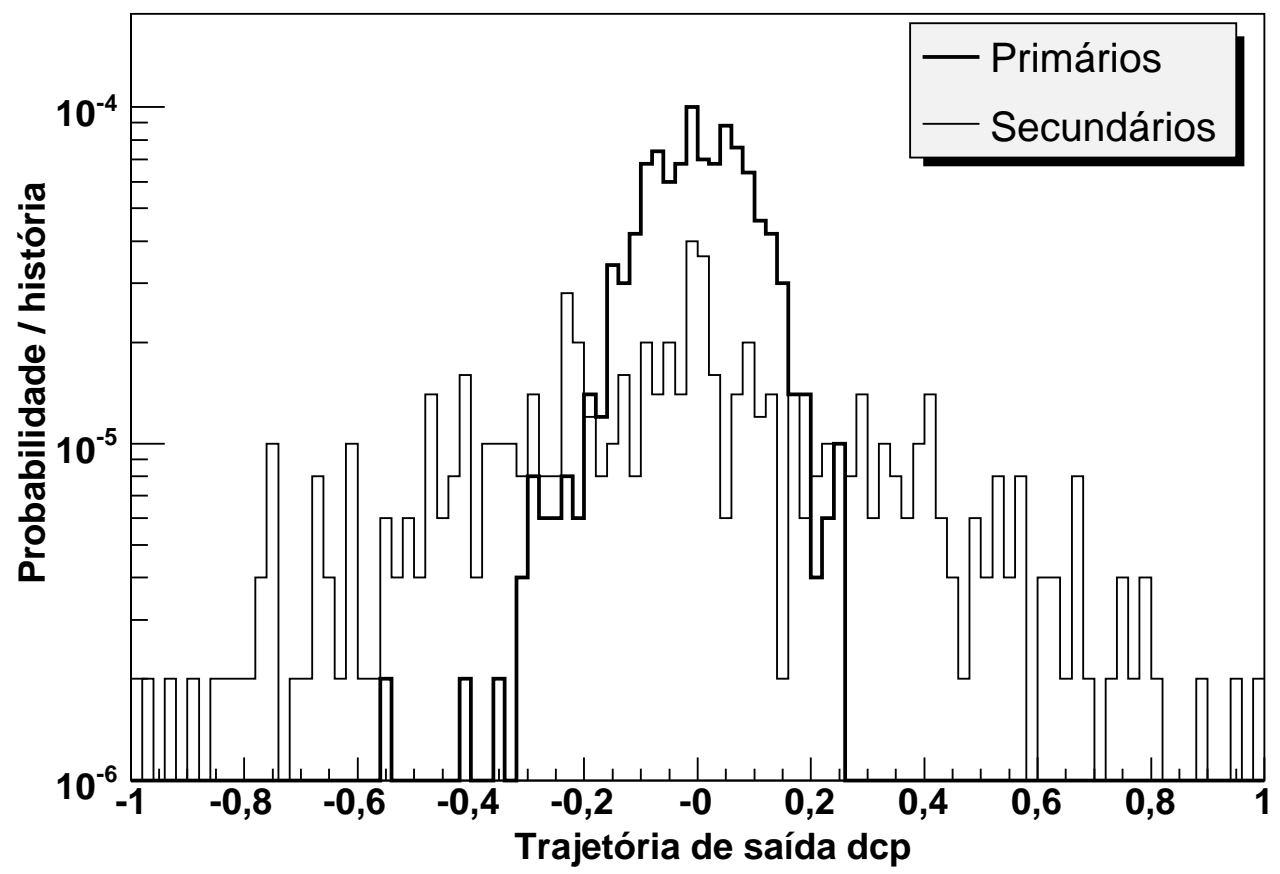

Figura 77: Trajetória de saída dep dos elétrons primários e secundários da Banda 4. 


\section{Banda 1 - Trajetória de saída $\cos (\mu)$}

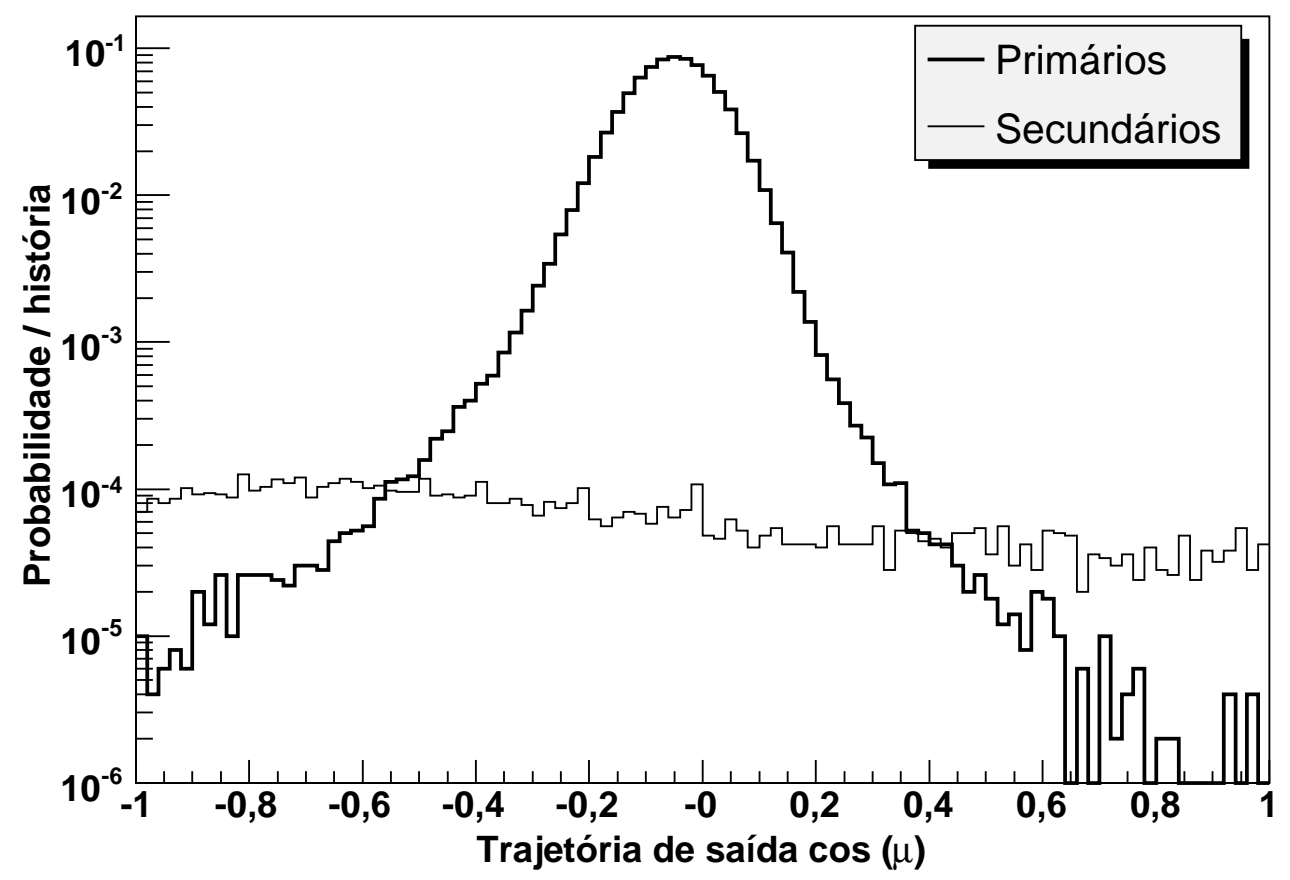

Figura 78: Trajetória de saída, $\cos (\mu)$, dos elétrons primários e secundários da Banda 1.

\section{Banda 2 - Trajetória de saída $\cos (\mu)$}

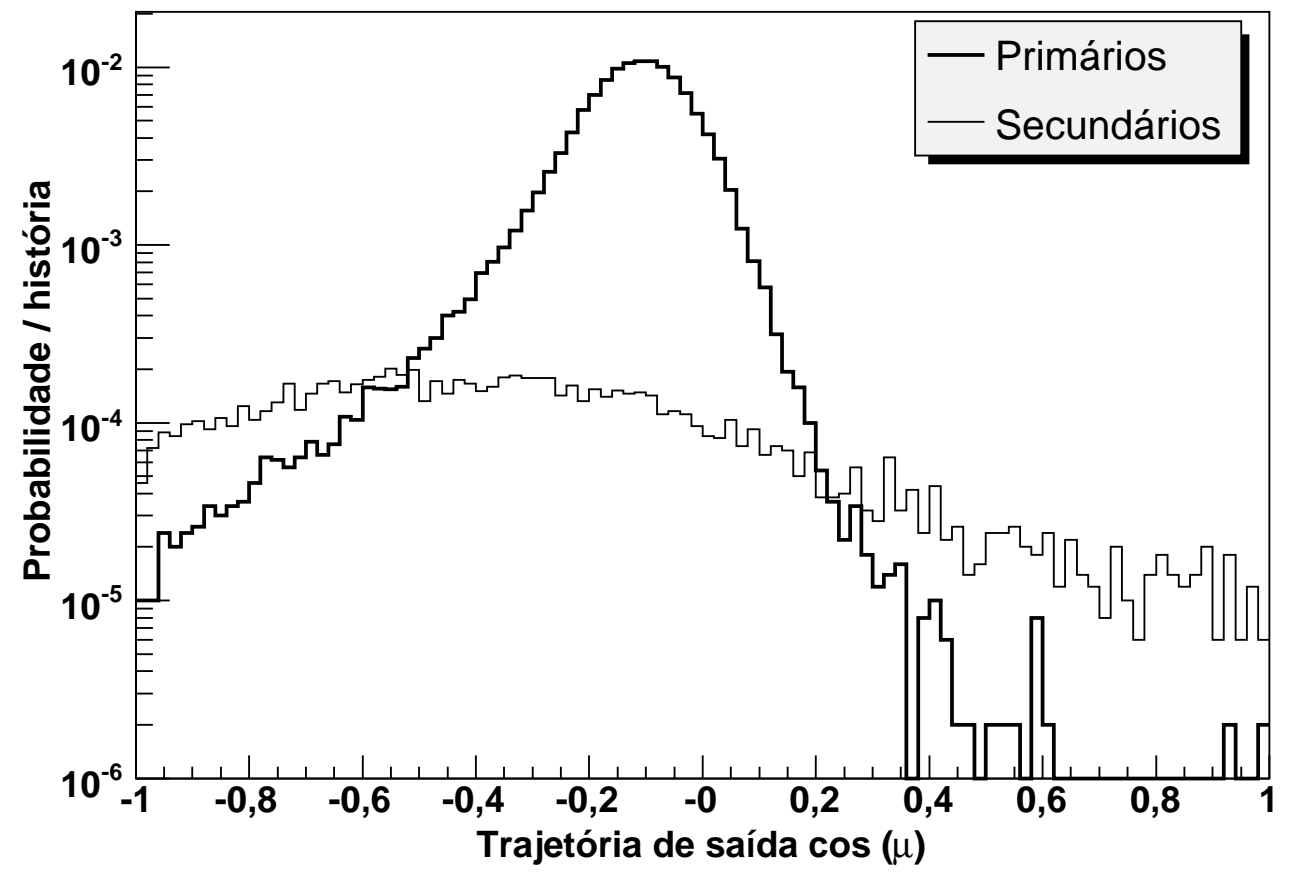

Figura 79: Trajetória de saída, $\cos (\mu)$, dos elétrons primários e secundários da Banda 2. 


\section{Banda 3 - Trajetória de saída $\cos (\mu)$}

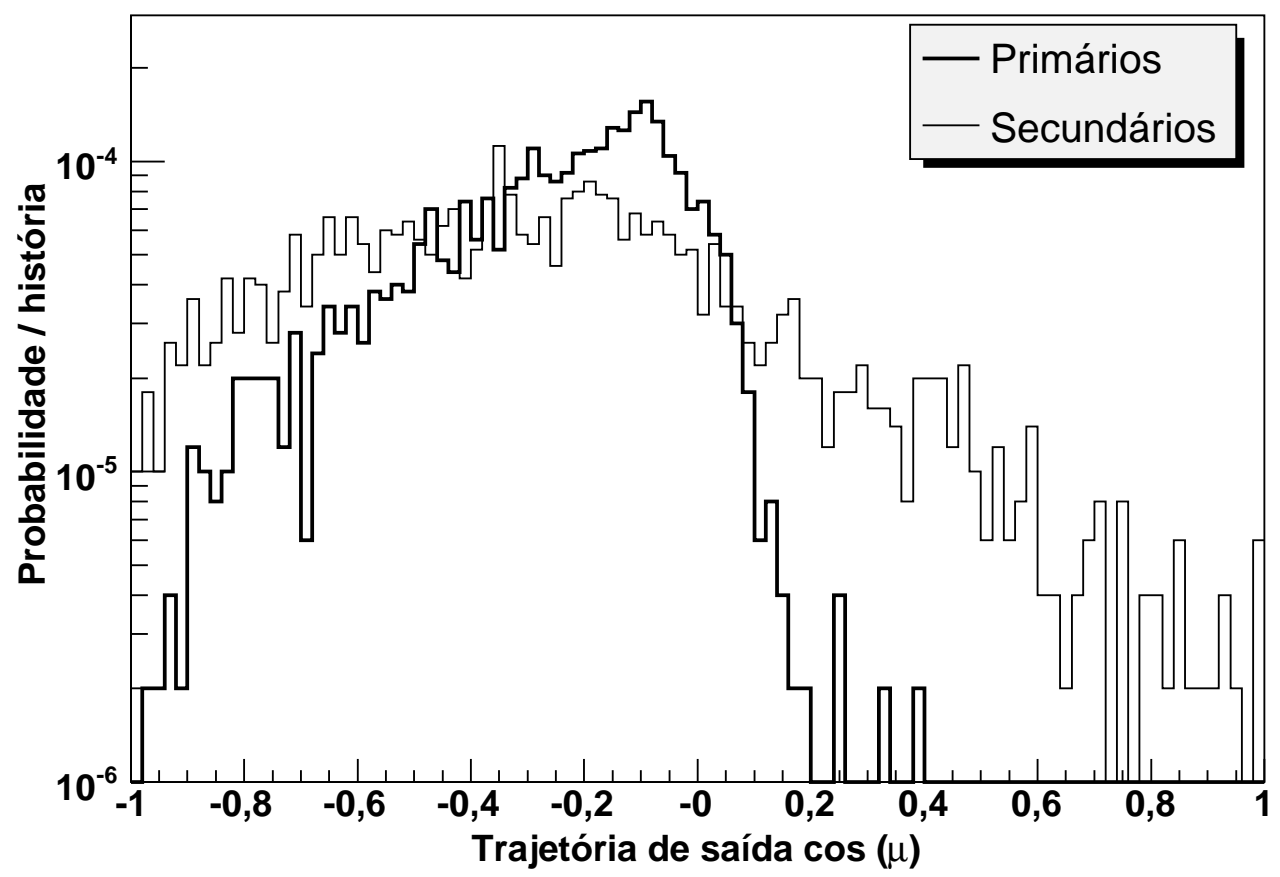

Figura 80: Trajetória de saída, $\cos (\mu)$, dos elétrons primários e secundários da Banda 3.

\section{Banda 4 - Trajetória de saída $\cos (\mu)$}

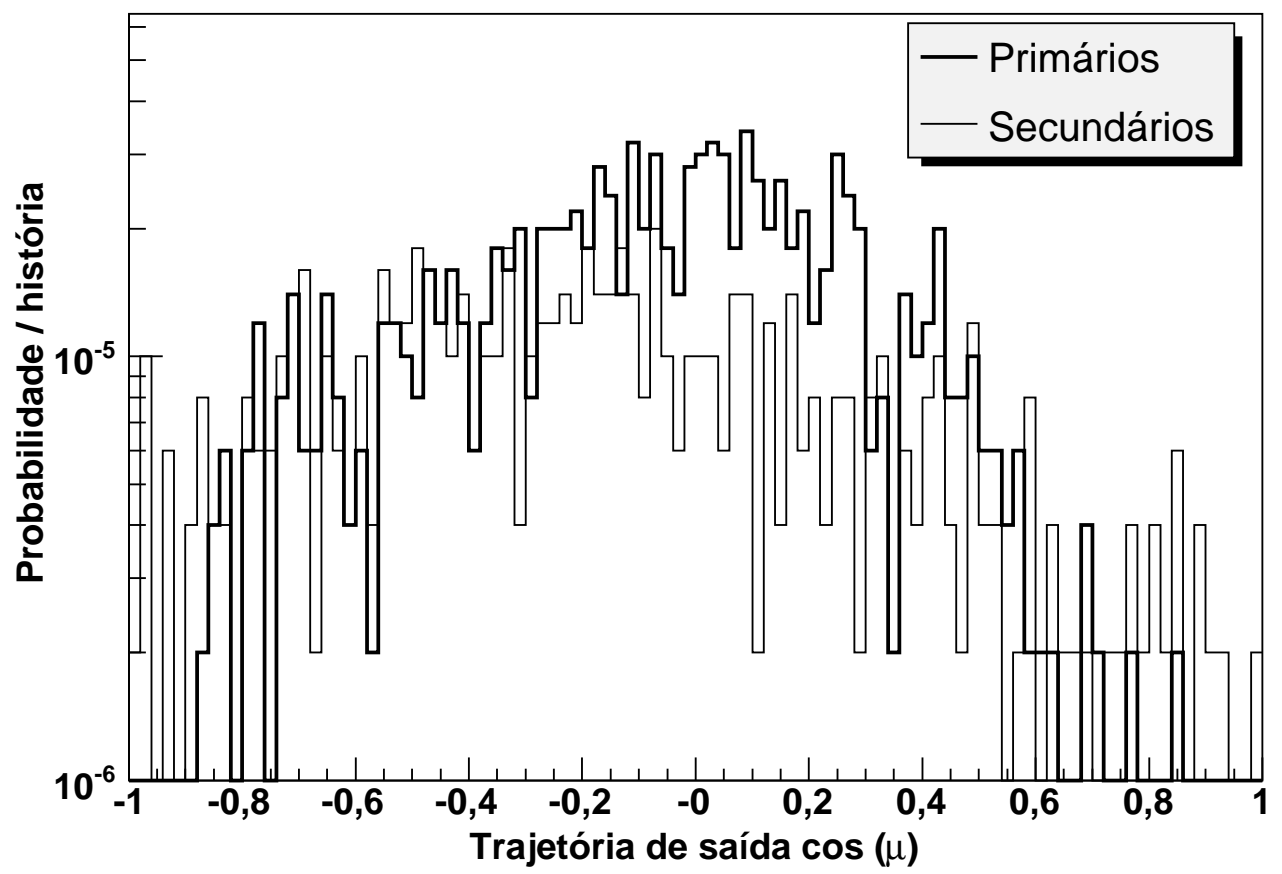

Figura 81: Trajetória de saída, $\cos (\mu)$, dos elétrons primários e secundários da Banda 4. 


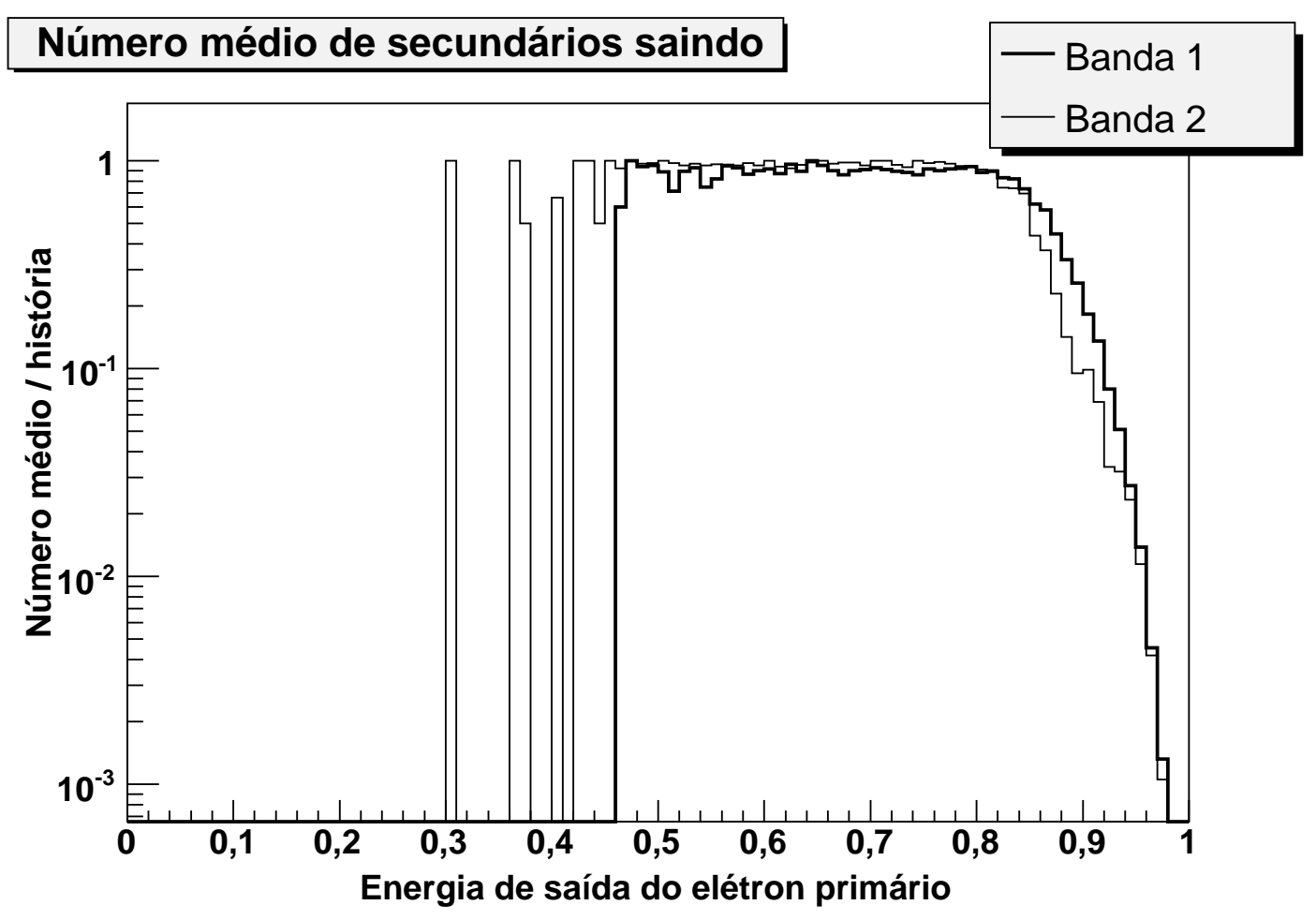

Figura 82: Número médio de elétrons secundários das Bandas 1 e 2.

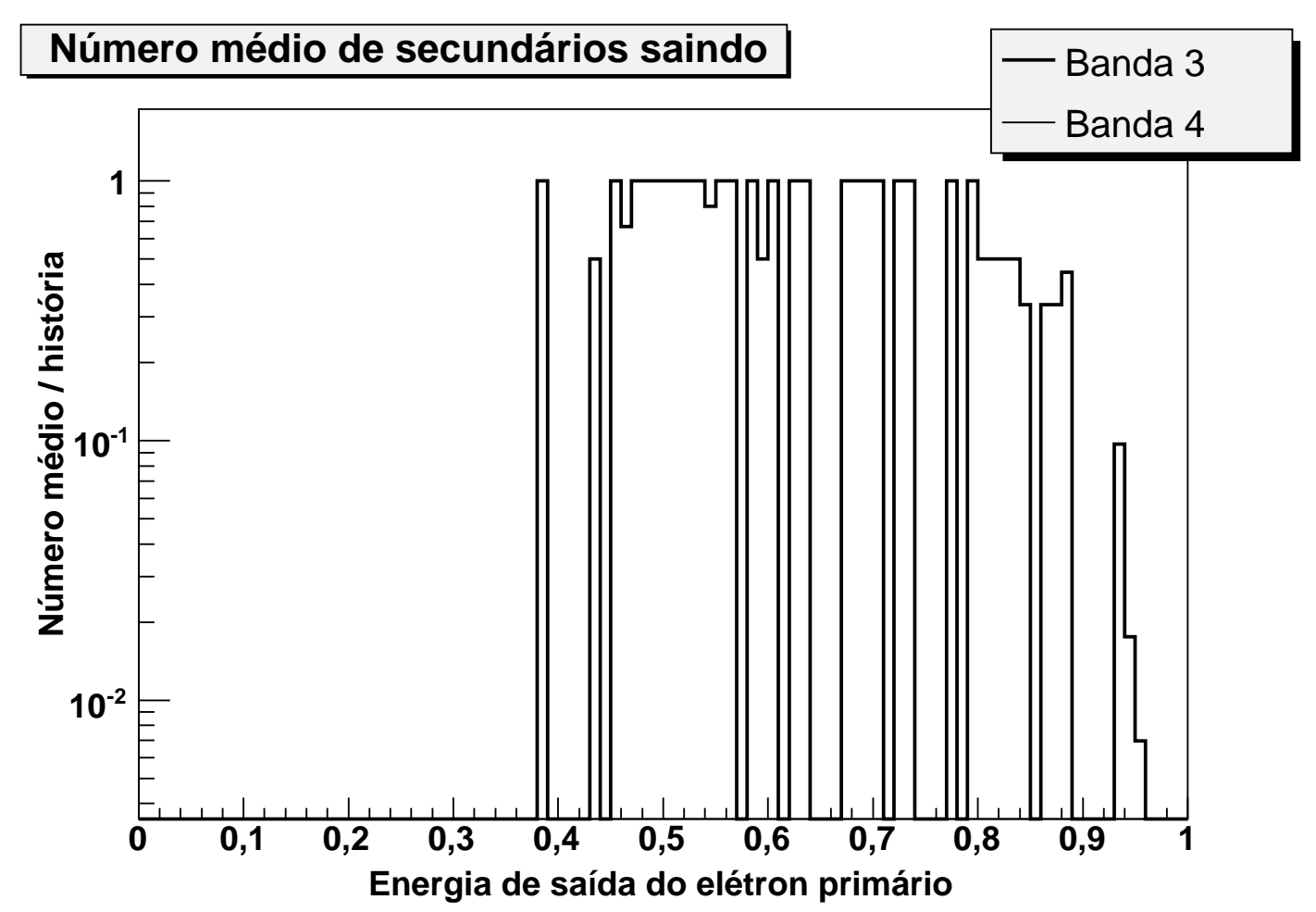

Figura 83: Número médio de elétrons secundários das Bandas 3 e 4. 


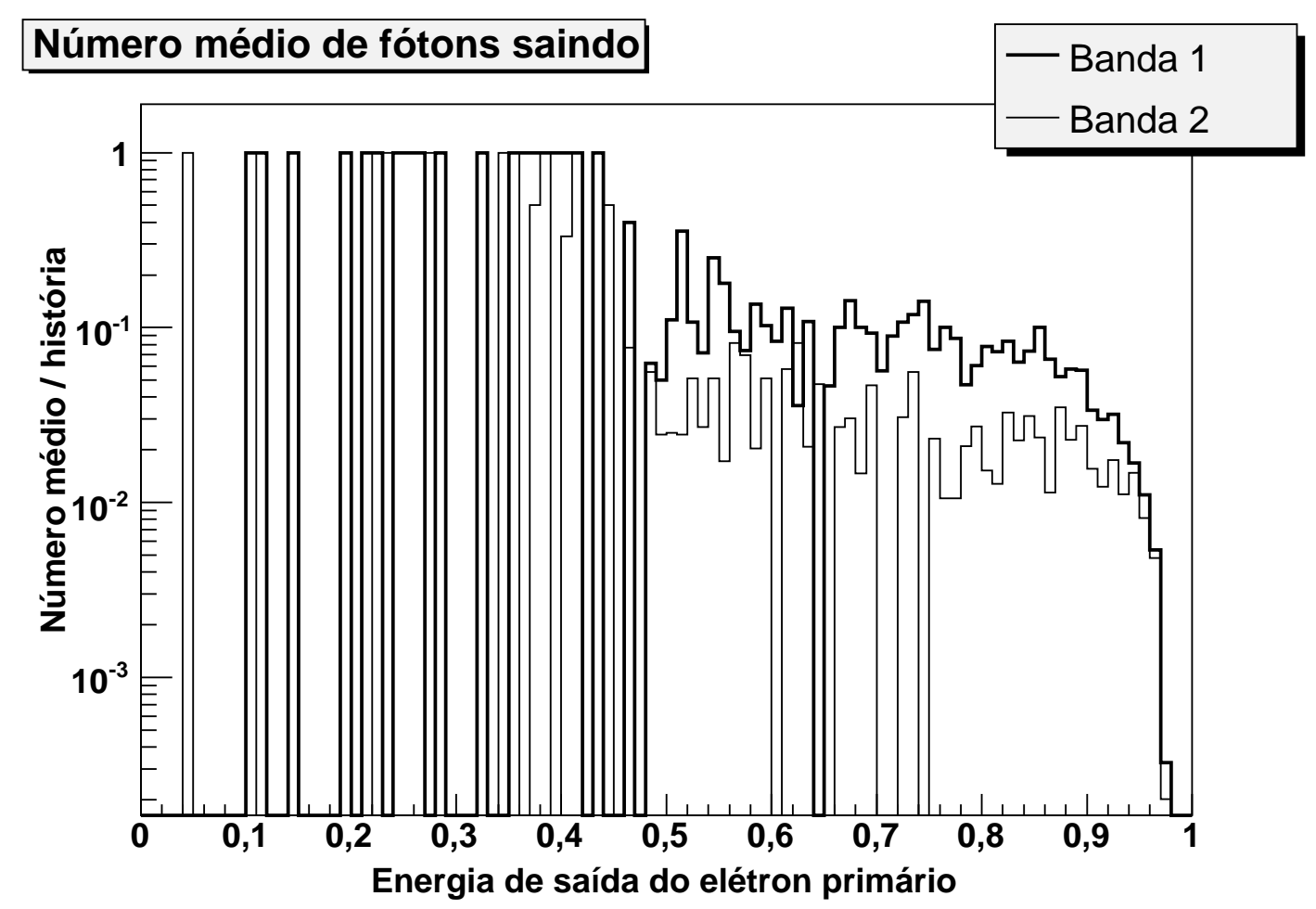

Figura 84: Número médio de fótons das Bandas 1 e 2.

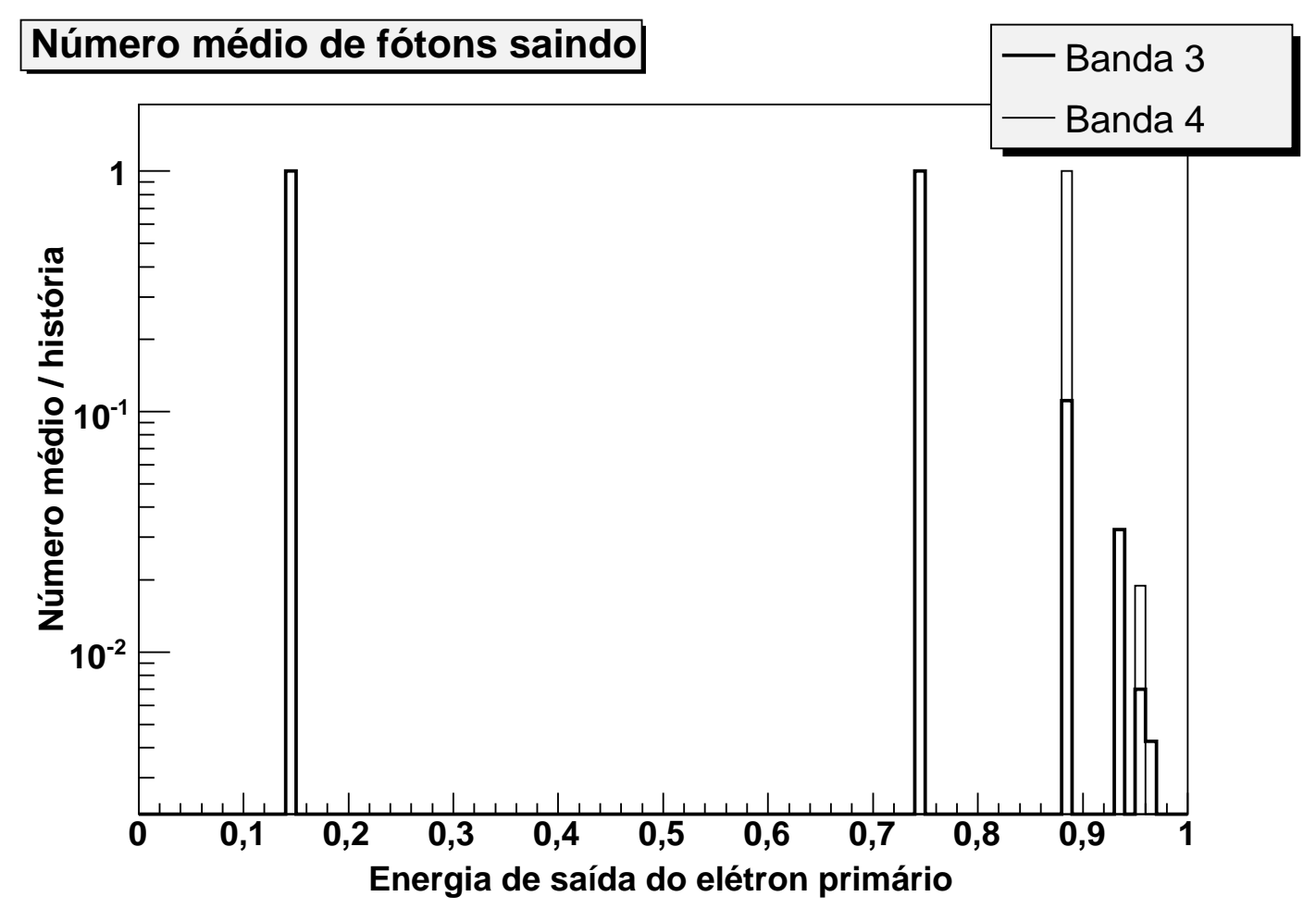

Figura 85: Número médio de fótons das Bandas 3 e 4. 


\section{APÊENICE B - Terminologia usada pelo Geant4}

Neste apêndice são apresentados alguns dos termos usados pelo Geant4 como parâmetros das simulações.

\section{B.1 Limites inferior de energia no transporte de partículas (Cutoffs)}

Tipicamente é comum falarmos em cutoffs de energia em programas de simulação de transporte e interação de partículas tais como EGS4, EGSnrc, PENELOPE e MCNP (7-9, 11). Este é sempre um parâmetro importante porque está associado à precisão dos resultados das simulações em termos de energia, influenciando a energia depositada, os espectros das partículas, ou mesmo a produção de secundários. O comportamento padrão do Geant4 é transportar as partículas até que sua energia seja nula. Porém, este comportamento do Geant4 leva a uma redução no desempenho das simulações. A fim de preservar a precisão sem, no entanto, comprometer o desempenho, inserimos um cutoff de energia baixo, de $990 \mathrm{eV}$, nas simulações da base de dados kugel. Em outras simulações apresentadas neste trabalho foram testados outros valores para esse cutoff, devidamente citados no texto.

\section{B.2 Limiar de produção de secundários (RangeCut)}

Um dos parâmetros mais importantes do Geant4 é o limiar de produção de secundários chamado de RangeCut. Este parâmetro é definido em termos do alcance da partícula e, por meio da equação B.1, o Geant4 calcula os cutoffs de energia para cada combinação de material e 
partícula incidente. Desta forma, podemos especificar a precisão em termos de resolução espacial para todos os materiais de uma única forma. Por exemplo, ao definirmos um RangeCut de $1 \mathrm{~mm}$, o Geant4 irá produzir partículas secundárias com alcance a partir de $1 \mathrm{~mm}$, e transportálas até alcançar o cutoff de energia, caso definido previamente, ou até sua energia ser nula. Se o mesmo sistema de limiar de produção fosse definido em energia ao invés de alcance, teríamos um mesmo limiar de produção para todos os materiais, o que levaria a produção de secundários com diferentes alcances.

$$
R(T)=\int_{0}^{T} \frac{1}{(d E / d x)} d E
$$

Sendo $R(T)$ o alcance da partícula, $T$ a energia de cutoff e $d E / d x$ o Stopping Power total do meio material.

O Geant4 também possui um sistema sofisticado de redução do limiar de produção de secundários. Por exemplo, uma partícula pode ser criada abaixo do limiar de produção caso o sistema de transporte verifique que exista a possibilidade dessa partícula secundária alcançar uma região atribuída pelo usuário como sensível (SensitiveDetector).

\section{B.2.1 A região sensível do detetor (SensitiveDetector)}

O usuário deve sempre registrar a região de seu detetor em que serão contabilizadas as partículas que o atravessarem. A este ítem chamamos de SensitiveDetector, isto é, uma região de seu detetor que é sensível à contagem de partículas. Caso o usuário não registre devidamente essa região de interesse na contagem de partículas, a simulação pode resultar em informações erradas (contagem inferior de partículas). 


\section{APÊENICE C - Parâmetros das simulações dos kugels}

Tipicamente, o espaço exigido para o armazenamento dos dados aumenta com o aumento da resolução. O tempo de simulação também aumenta com o aumento da resolução. Na simulação da base de dados de kugels foram usados parâmetros diferentes para cada tipo de tecido/material, sempre mantendo um compromisso entre o tempo de simulação, espaço em disco e resolução dos resultados. A explicação para os termos usados na tabela 15 encontram-se no apêndice B.

Tabela 15: Parâmetros das simulações

\begin{tabular}{|c|c|c|}
\hline material/tecido & RangeCut & Cutoff \\
\hline \hline água & $10 \mu \mathrm{m}$ & $990 \mathrm{eV}$ \\
\hline tecido mole & $10 \mu \mathrm{m}$ & $990 \mathrm{eV}$ \\
\hline osso compacto & $20 \mu \mathrm{m}$ & $990 \mathrm{eV}$ \\
\hline
\end{tabular}




\section{APÊNDICE D - Diagramas de classes do código MRMC}

A seguir estão os principais diagramas de classes do código MRMC em formato Unified Modeling Language (UML). Os diagramas de classes mostram como é a dependência entre as classes. Nesses diagramas aparecem apenas ítens como agregação, composição e herança (ou generalização).

A agregação é representada por uma linha com um losango aberto $(\diamond)$, onde a classe mais próxima do losango é a classe agregadora. A agregação acontece quando a instância da classe agregada continua existindo após a instância da classe agregadora deixar de existir. A composição é representada por um losango fechado $(\downarrow)$, aqui a classe mais próxima ao losango é a classe principal. Ao contrário da agregação, a composição destrói as instâncias das classes que fazem parte dela quando a mesma deixa de existir. A herança ocorre quando alguma classe herda de outra suas propriedades (métodos e dados). A herança é representada por um triângulo aberto $(\triangle)$ próximo à classe base.

Nos diagramas mostrados aqui, apresentamos uma versão simplificada do diagrama das classes do MRMC, com apenas as principais classes e seus métodos. Por uma questão de clareza não são apresentados seus atributos e atributos dos métodos.

Na figura 86 temos a relação entre as classes responsáveis pela construção geométrica do meio em que serão transportadas as partículas (DetectorConstruction) e a classe responsável pelo gerenciamento das geometrias de transporte (DetectorManager). 


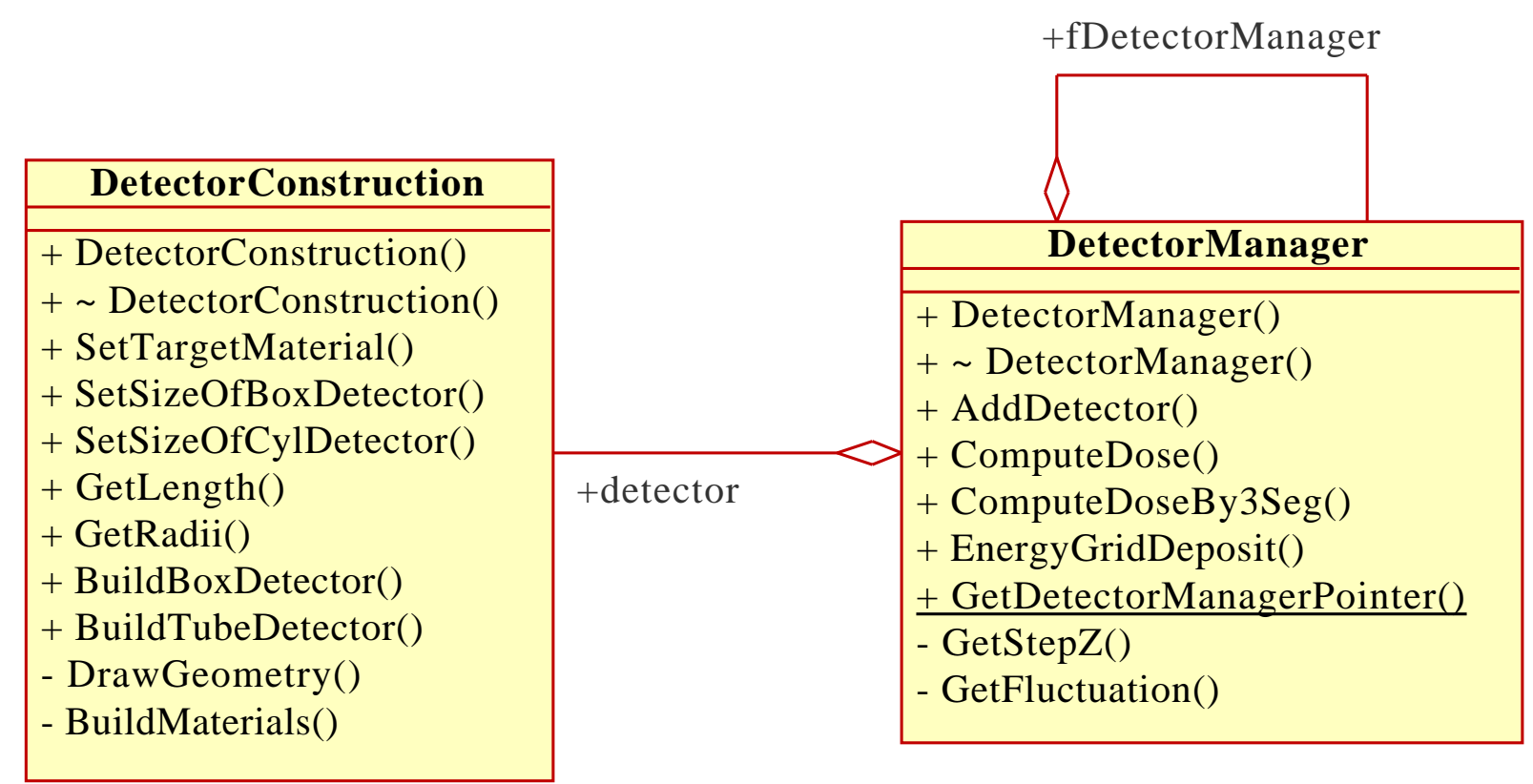

Figura 86: Diagrama UML das classes relacionadas à geometria do MRMC.

A figura 87 apresenta o diagrama das classes relacionadas ao transporte das partículas. As classes TObject, TNamed e TParticle são classes bases do ROOT, que são para a construção do sistema de transporte do MRMC. A classe TClones Array é uma classe do ROOT que funciona como pilha de partículas e posicionamento na memória (place holder) dos eventos usando a técnica de Placement New do C++ (42). Esta técnica permite que os eventos e as partículas geradas sejam criadas e destruídas sem usar muito tempo de sistema. A classe responsável pelo gerenciamento da pilha de partículas e eventos é a EventManager.

O sistema que busca os kugels como função do raio e da energia inicial é mostrado na figura 88. A instância da classe KugelManager contém as instâncias da classe de materiais (KugelMaterial). Este por sua vez contém as instâncias da classe Kugel. Cada instância da classe Kugel contém um raio e uma energia. 


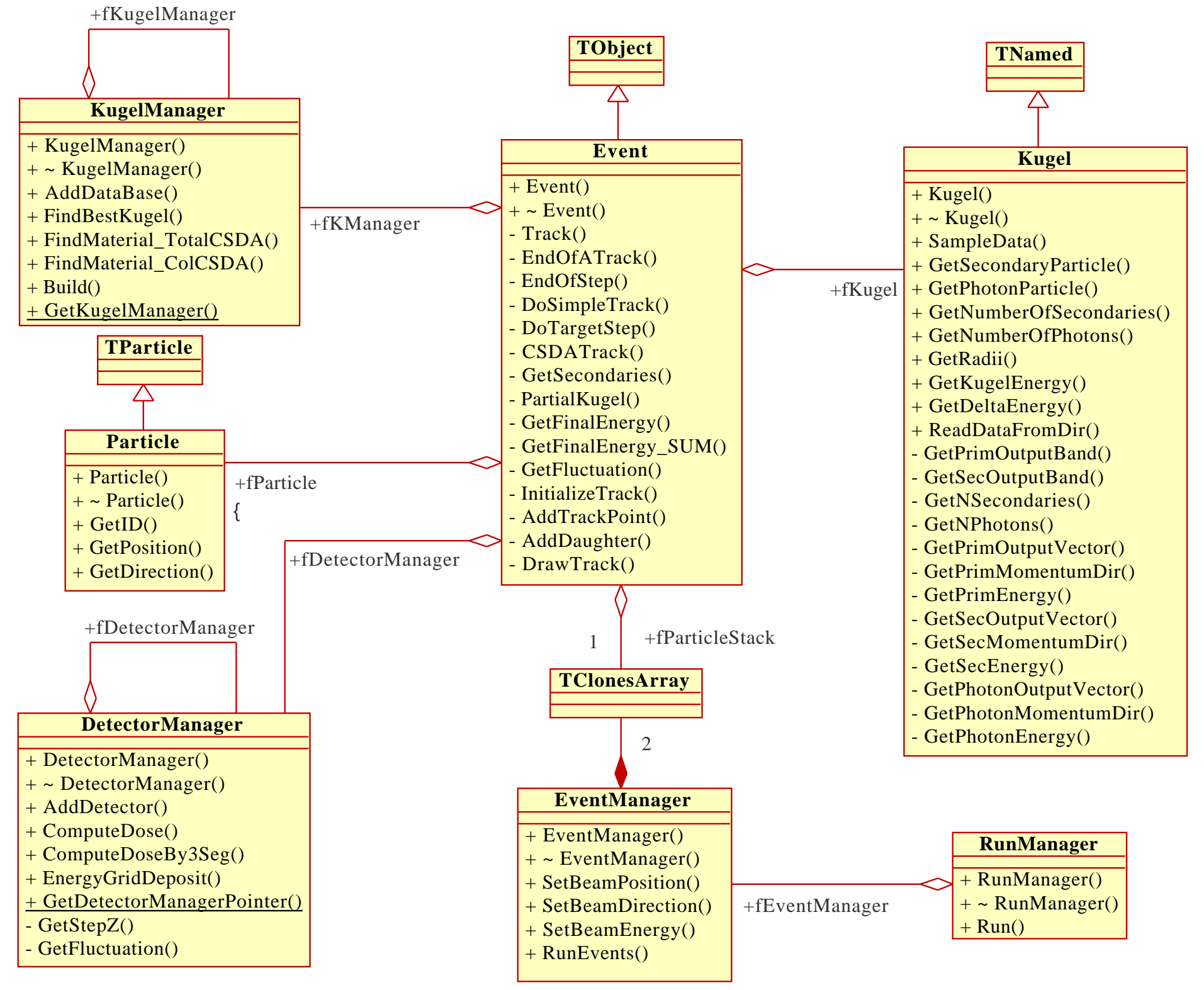

Figura 87: Diagrama UML do código de transporte do MRMC. 


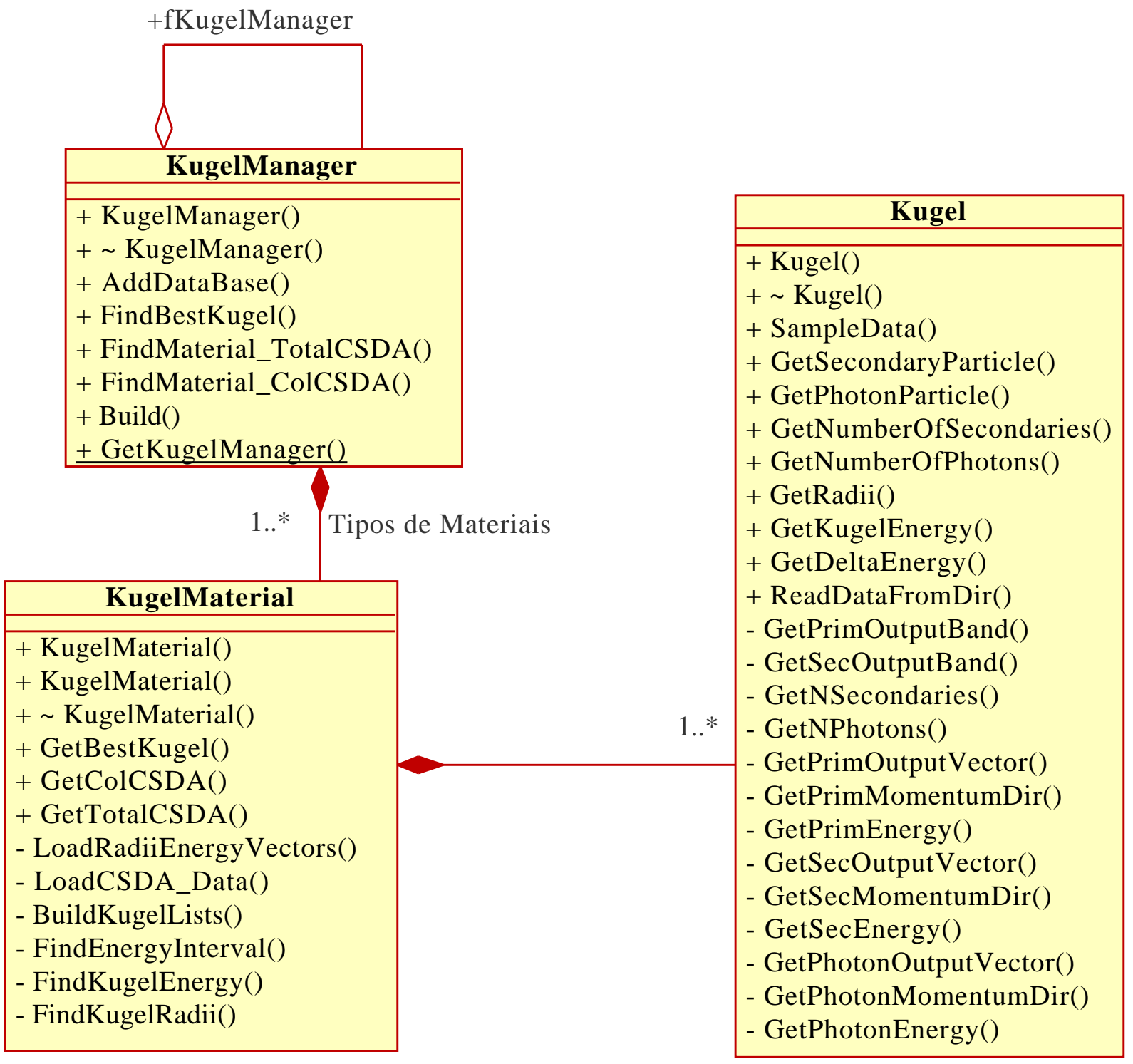

Figura 88: Diagrama da classe de gerenciamento dos kugels e classes correlatas. 


\section{ANEXO A - Dados dos Materiais e Tecidos}

Nas tabelas 17, 18 e 19 temos as composições atômicas da água, tecido mole e osso compacto. Na tabela 16 temos as densidades e comprimentos de radiação desses materiais. Os dados da composição atômica e densidade são do National Institute of Standards and Technology (NIST) (36), e os dados do comprimento de radiação são do Particle Data Group (PDG) (43).

Tabela 16: Densidade e comprimento de radiação dos materiais/tecidos usados neste trabalho

\begin{tabular}{|c|c|c|}
\hline Material/Tecido & Densidade $\left(\mathrm{g} / \mathrm{cm}^{3}\right)$ & Comprimento de Radiação $(\mathrm{cm})$ \\
\hline \hline água & 1,000 & 36,08 \\
\hline tecido mole (ICRP) & 1,000 & 37,63 \\
\hline osso compacto & 1,850 & 16,48 \\
\hline
\end{tabular}

Tabela 17: Composição atômica da água

\begin{tabular}{|c|c|}
\hline Número Atômico & Fração pelo peso \\
\hline \hline 1 & 0,111894 \\
\hline 8 & 0,888106 \\
\hline
\end{tabular}


Tabela 18: Composição atômica do tecido mole

\begin{tabular}{|c|c|}
\hline Número Atômico & Fração pelo peso \\
\hline \hline 1 & 0,104472 \\
\hline 6 & 0,232190 \\
\hline 7 & 0,024880 \\
\hline 8 & 0,630238 \\
\hline 11 & 0,001130 \\
\hline 12 & 0,000130 \\
\hline 15 & 0,001330 \\
\hline 16 & 0,001990 \\
\hline 17 & 0,001340 \\
\hline 19 & 0,001990 \\
\hline 20 & 0,000230 \\
\hline 26 & 0,000050 \\
\hline 30 & 0,000030 \\
\hline
\end{tabular}

Tabela 19: Composição atômica do osso compacto

\begin{tabular}{|c|c|}
\hline Número Atômico & Fração pelo peso \\
\hline \hline 1 & 0,063984 \\
\hline 6 & 0,278000 \\
\hline 7 & 0,027000 \\
\hline 8 & 0,410016 \\
\hline 12 & 0,002000 \\
\hline 15 & 0,070000 \\
\hline 16 & 0,002000 \\
\hline 20 & 0,147000 \\
\hline
\end{tabular}


Este documento foi produzido com o auxílio do processador de textos $\mathrm{LT}_{\mathrm{E}} \mathrm{X}$ através de sua interface gráfica $\mathrm{L}_{Y} X$. 